FY2006

\title{
WIDE-BANDGAP SEMICONDUCTORS
}

Prepared by:

Oak Ridge National Laboratory

Mitch Olszewski, Program Manager

Submitted to:

Energy Efficiency and Renewable Energy

FreedomCAR and Vehicle Technologies

Vehicle Systems Team

Susan A. Rogers, Technology Development Manager

November 2005 
NATIONAL LABORATORY

MANAGED BY UT-BATTELLE

FOR THE DEPARTMENT OF ENERGY

\section{Engineering Science and Technology Division}

\section{WIDE-BANDGAP SEMICONDUCTORS}

\author{
M. S. Chinthavali ${ }^{2}$ \\ B. Ozpineci ${ }^{1}$ \\ L. M. Tolbert ${ }^{1}$ \\ A. S. Kashyap ${ }^{2}$ \\ ${ }^{1}$ Oak Ridge National Laboratory \\ ${ }^{2}$ Oak Ridge Institute for Science and Technology
}

Publication Date: November 2006

Prepared by the

OAK RIDGE NATIONAL LABORATORY

Oak Ridge, Tennessee 37831

managed by

UT-BATTELLE, LLC

for the

U.S. DEPARTMENT OF ENERGY

Under contract DE-AC05-00OR22725 
This report was prepared as an account of work sponsored by an agency of the United States Government. Neither the United States Government nor any agency thereof, nor any of their employees, makes any warranty, express or implied, or assumes any legal liability or responsibility for the accuracy, completeness, or usefulness of any information, apparatus, product, or process disclosed, or represents that its use would not infringe privately owned rights. Reference herein to any specific commercial product, process, or service by trade name, trademark, manufacturer, or otherwise, does not necessarily constitute or imply its endorsement, recommendation, or favoring by the United States Government or any agency thereof. The views and opinions of authors expressed herein do not necessarily state or reflect those of the United States Government or any agency thereof. 


\section{TABLE OF CONTENTS}

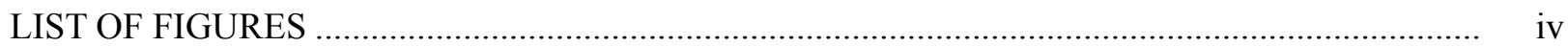

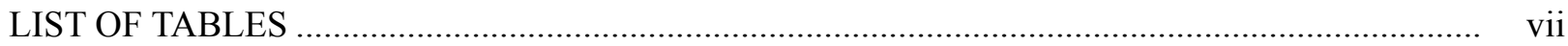

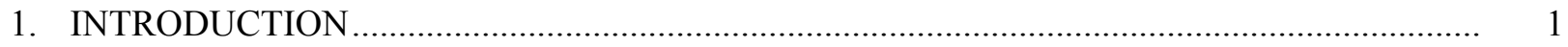

2. SiC DEVICES

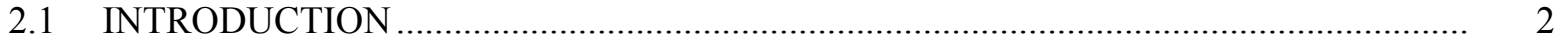

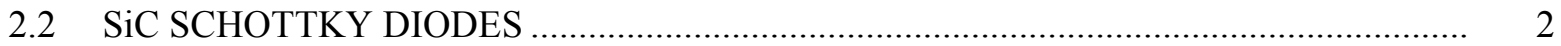

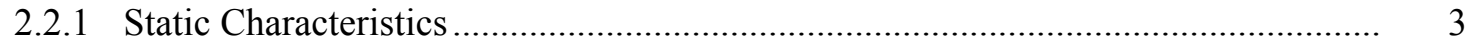

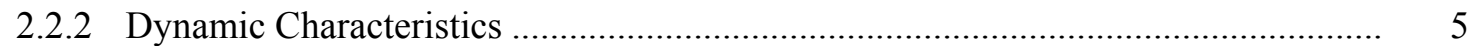

2.3 SiC FIELD EFFECT TRANSISTOR (FET) DEVICES …............................................. 9

2.3.1 Static Characteristics

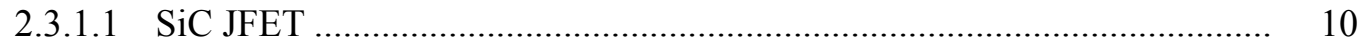

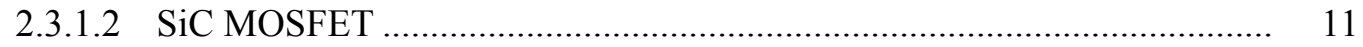

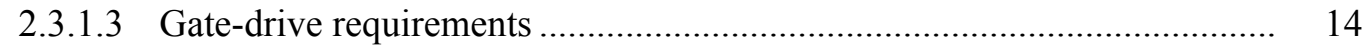

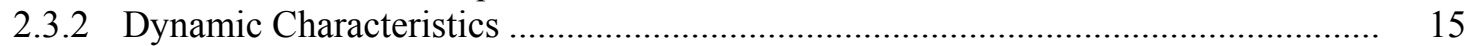

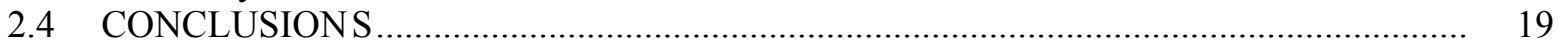

3. HYBRID Si-SiC INVERTER

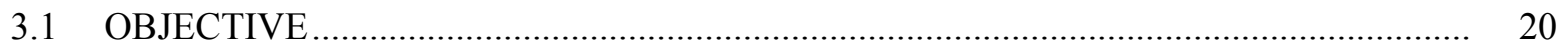

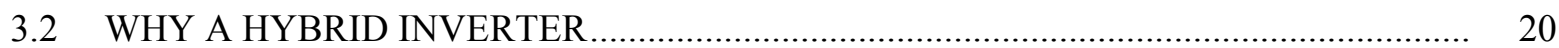

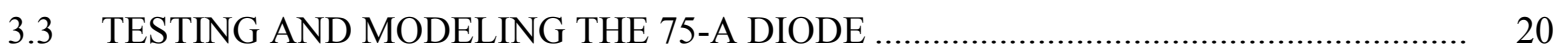

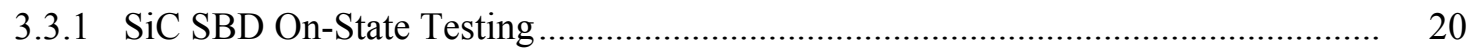

3.3.2 SiC Diode Modeling .......................................................................................... 21

3.3.3 Parameter Extraction and Model Validation Using the Characterized Data

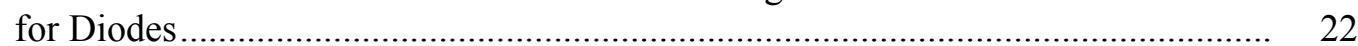

3.4 SCHOTTKY DIODE AT DIFFERENT TEMPERATURES …........................................ 23

3.5 SIMULATION OF Si IGBT-SiC SCHOTTKY DIODE HYBRID INVERTER ............... 25

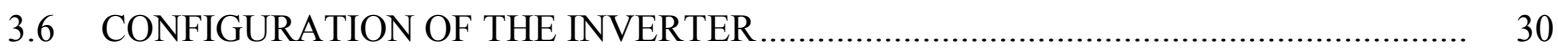

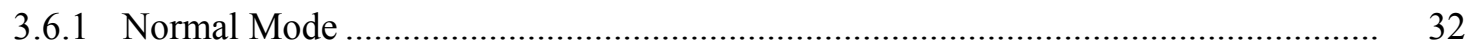

3.6.2 Debug Mode............................................................................ 32

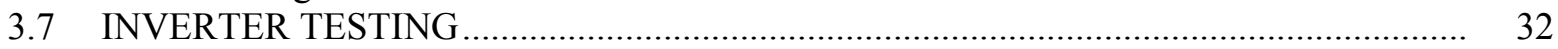

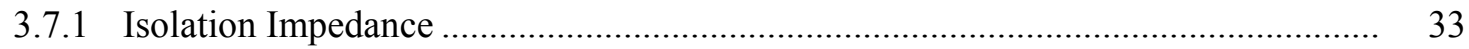

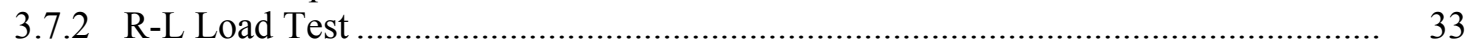

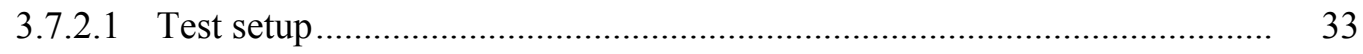

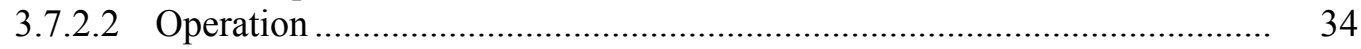

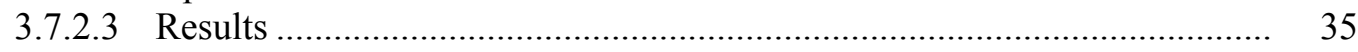

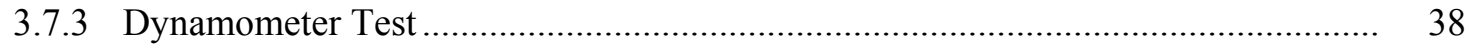

3.7.3.1 Test setup .................................................................................. 38

3.7.3.2 Motoring mode ....................................................................... $\quad 39$

3.7.3.3 Regeneration mode ........................................................................... 43

3.8 EXPLANATION FOR THE POWER LOSS DIFFERENCE BETWEEN

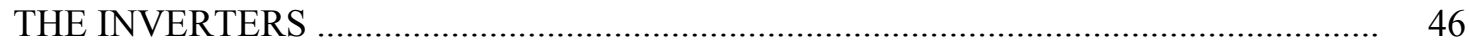

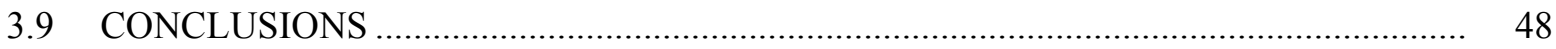


4. ALL-SiC INVERTER

4.1 INTRODUCTION 50

4.2 JFET CHARACTERIZATION AND MODELING

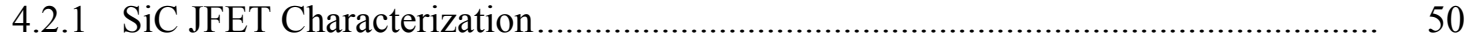

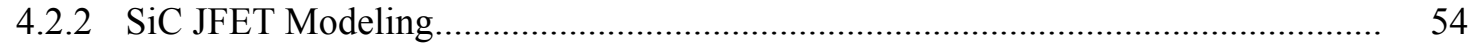

4.2.3 Parameter Extraction and Model Validation of the Rockwell SiC JFET ................ 56

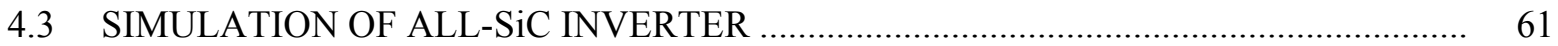

4.4 CONFIGURATION OF THE INVERTERS ..................................................................... 64

4.5 INVERTER TESTING

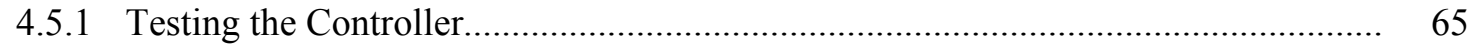

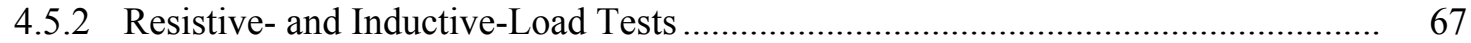

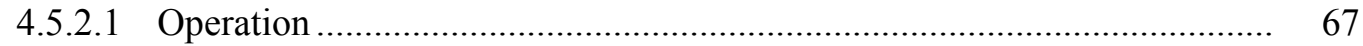

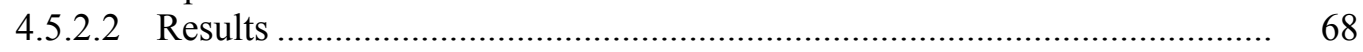

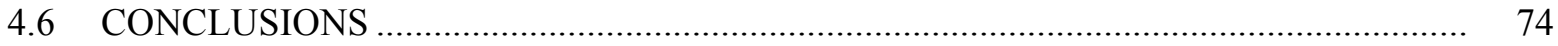

5. DURATION TESTS

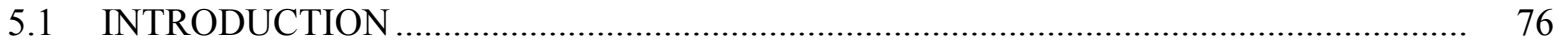

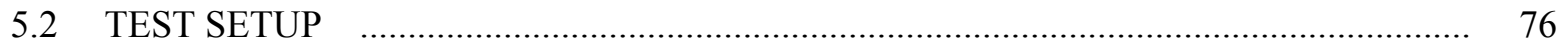

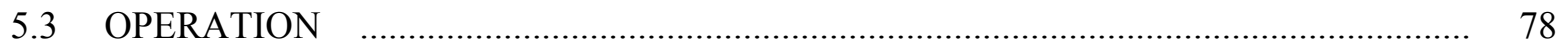

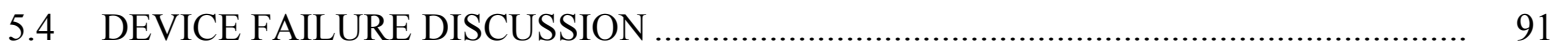

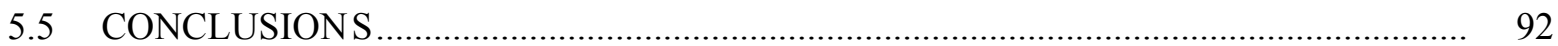

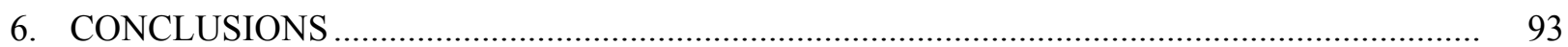

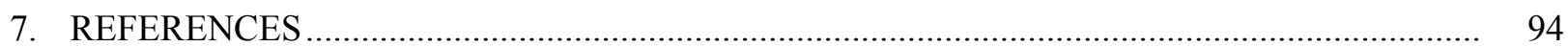

APPENDIX A. o-v CHARACTERISTICS OF SiC AND Si DIODES ............................................ 96

APPENDIX B: MOVING AVERAGE FILTER EXPLANATION …............................................... 98

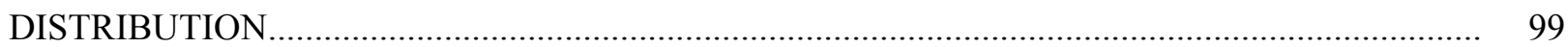




\section{LIST OF FIGURES}

Figure

Page

2.1 Cross-section of a SBD.....

$2.2 \mathrm{i}-\mathrm{v}$ characteristics of Si pn and SiC Schottky diodes at $27^{\circ} \mathrm{C}$ and $\mathrm{SiC}$ diodes

at different operating temperatures

$2.3 \mathrm{i}-\mathrm{v}$ characteristics of $\mathrm{S} 3(600 \mathrm{~V}, 10 \mathrm{~A})$ at different operating temperatures

$2.4 V_{d}$ for $\mathrm{Si}$ and $\mathrm{SiC}$ diodes at different operating temperatures ......

2.5 $R_{d}$ for $\mathrm{Si}$ and $\mathrm{SiC}$ diodes at different operating temperatures .......

2.6 Reverse-recovery test circuit.

2.7 Reverse-recovery test setup

2.8 Reverse-recovery waveforms showing the diode current (top) and voltage (bottom) for the diode S3.

2.9 Reverse-recovery waveforms showing the diode current (top) and voltage (bottom) for the diode $\mathrm{S} 2$.

2.10 Reverse-recovery waveforms showing the diode current (top) and voltage (bottom) for the diode $\mathrm{S} 4$.

2.11 Reverse-recovery waveforms showing the diode current (top) and voltage (bottom) for the diode $\mathrm{S} 1$

2.12 Reverse-recovery waveforms showing the diode current (top) and voltage (bottom) for the Si pn diode.

2.13 Turn-off energy losses with respect to forward current at different operating temperatures.

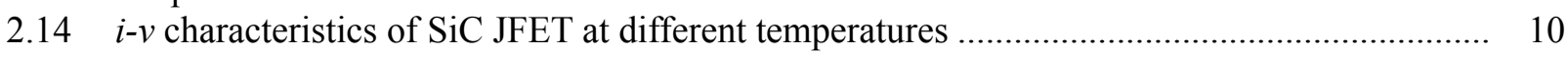

2.15 On-resistance of SiC JFET at different temperatures........................................................ 11

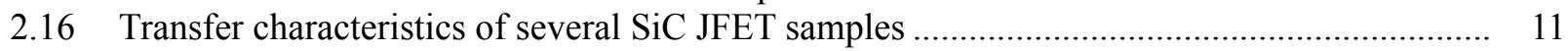

2.17 Forward characteristics of SiC MOSFET at room temperature ........................................... 12

2.18 Forward characteristics of SiC MOSFET at different temperatures .................................... 12

2.19 On-resistance of SiC MOSFET at different temperatures .................................................. 13

2.20 Transfer characteristics of SiC MOSFET at different temperatures .................................... 13

2.21 Gate threshold voltage of SiC MOSFET at different temperatures .................................... 14

2.22 The peak-gate currents and gate-voltage waveforms

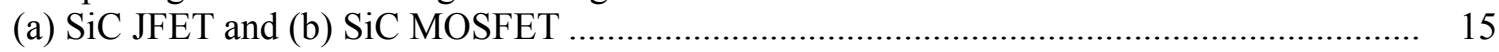

2.23 The gate and switching waveforms of the SiC JFET .................................................... 16

2.24 The gate and switching waveforms of the SiC MOSFET ................................................... 17

2.25 Energy loss plots: (a) SiC JFET, (b) SiC MOSFET ..................................................... 18

$3.1 \quad \mathrm{i}-\mathrm{v}$ characteristics of the 75-A SiC diode from Cree ............................................................. 21

3.2 Model topology of the power diode ........................................................................... 21

3.3 Measured (solid) and simulated (dotted) on-state waveforms of SiC Schottky diode at different temperatures

3.4 Measured (solid) and simulated (dotted) reverse-recovery waveforms of the $\mathrm{SiC}$

Schottky diode from Cree

3.5 Simulation showing the reverse-recovery current in a SiC diode for different

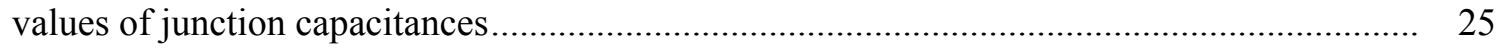

3.6 Schematic representation of the hybrid inverter in Saber ................................................. 26

3.7 Simulated three-phase load currents in the hybrid inverter ............................................... 27

3.8 Simulated phase voltage (phase 1) in the hybrid inverter .................................................. 27

3.9 Total instantaneous output power from the three phases of the hybrid inverter.................... 28

3.10 Comparison of peak-power output vs. efficiencies for hybrid and all-Si inverter.................. 29

3.11 Comparison of efficiencies (from simulation) of hybrid and all-Si inverter ........................ 29 


\section{LIST OF FIGURES}

Figure $\quad$ Page

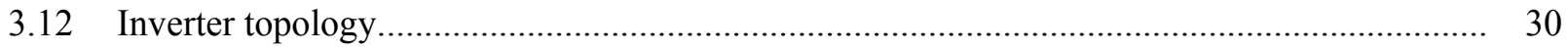

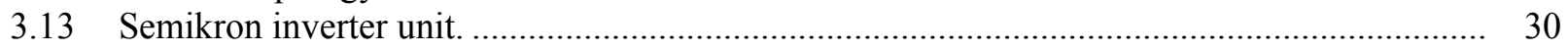

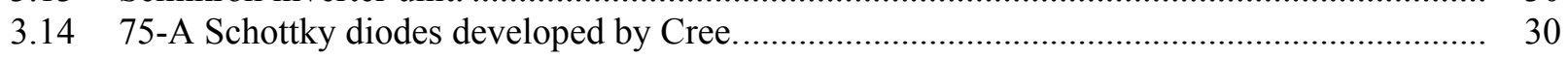

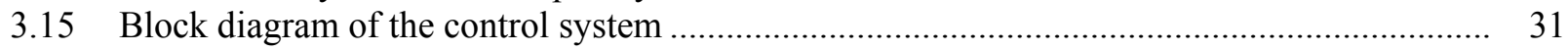

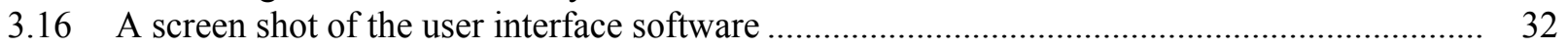

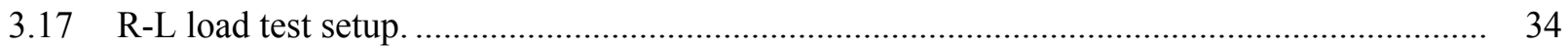

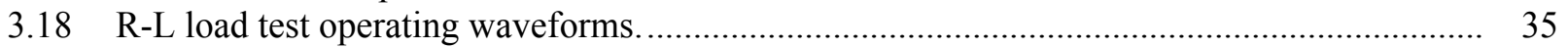

3.19 R-L load test efficiency curves for various load conditions. ............................................... 36

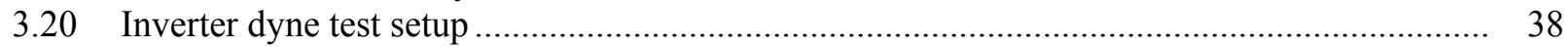

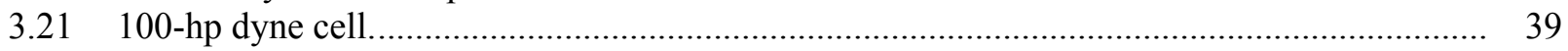

3.22 Dynamometer test-motoring mode operating waveforms............................................ 40

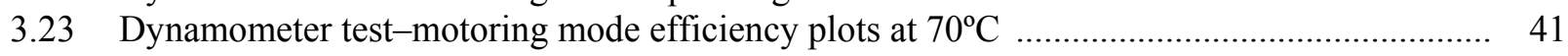

3.24 Dynamometer test-motoring mode data obtained from the power meter............................. 42

3.25 Dynamometer test-regeneration mode operating waveforms......................................... 44

3.26 Dynamometer test-regeneration mode efficiency plots at $70^{\circ} \mathrm{C}$....................................... 45

3.27 Comparison of static characteristics of Si pn diode and SiC Schottky diodes....................... 47

3.28 Comparison of reverse-recovery characteristics of Si pn diode and SiC Schottky diode......... 48

3.29 Instantaneous output power during regeneration. ............................................................. 48

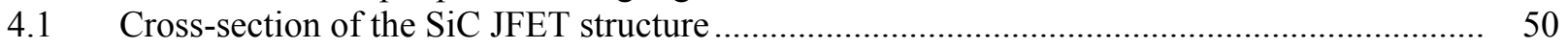

4.2 Unipolar operation of the Rockwell SiC JFET. ....................................................... 51

$4.3 \quad$ Bipolar operation of the Rockwell SiC JFET. .............................................................. 51

$4.4 \quad$ Test for obtaining the pinch-off voltage. .................................................................. 52

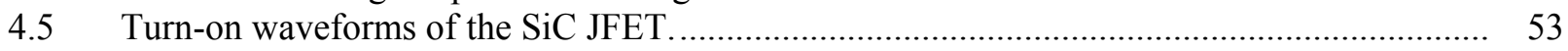

4.6 Turn-off waveforms of the SiC JFET. ...................................................................... 53

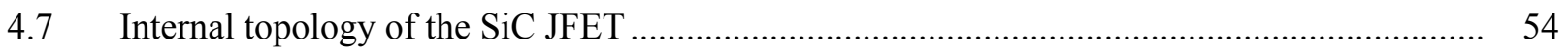

4.8 Transfer characteristic of the Rockwell JFET ............................................................. 57

4.9 Extraction of channel modulation factor LAMBDA. ...................................................... 57

4.10 Rockwell SiC JFET measured (solid) and simulated (dotted) on-state waveforms

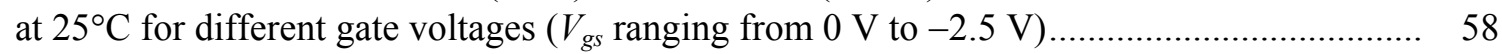

4.11 Extraction of channel modulation factor LAMBDA .......................................... 59

4.12 SiC JFET simulated (dashed) and measured (solid) turn-on waveforms at $25^{\circ} \mathrm{C}$ : (a) gate voltage, (b) drain voltage, and (c) drain current.......................................... 59

4.13 SiC JFET simulated (dashed) and measured (solid) turn-off waveforms at $25^{\circ} \mathrm{C}$ :

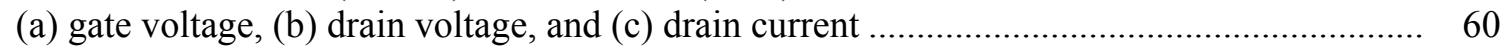

4.14 Schematic representation of the all-SiC inverter. ...................................................... 62

4.15 On-state validation of $\mathrm{SiC}$ diode at $25^{\circ} \mathrm{C}$ - measured (solid) and simulated (dashed)........... 62

4.16 Reverse-recovery validation of $\mathrm{SiC}$ diode at $25^{\circ} \mathrm{C}$ - measured (solid) and

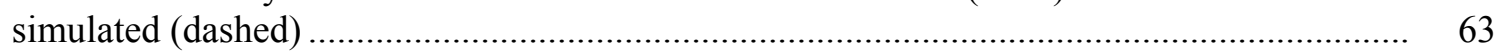

4.17 Simulated output voltage in phase 1 of the all-SiC inverter with resistive load .................... 63

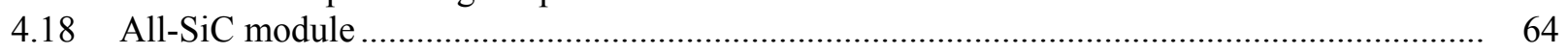

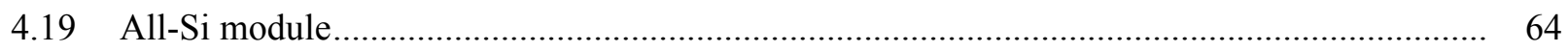




\section{LIST OF FIGURES}

Figure $\quad$ Page

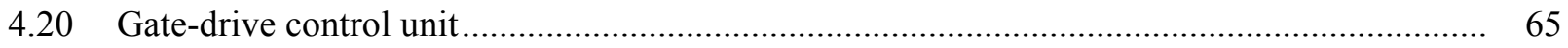

4.21 Controller output voltage with 30-V swing for SiC module ........................................... 66

4.22 Controller output voltage with $20-\mathrm{V}$ swing for Si module ............................................ 66

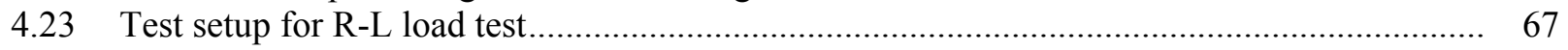

4.24 Operating waveforms of SiC module for R-L load test ............................................... 68

4.25 Efficiencies comparison plot at 30-Hz operation for R-L load test ................................... 69

4.26 Efficiencies comparison plot at $40-\mathrm{Hz}$ operation for R-L load test .................................... 69

4.27 Efficiencies comparison plot at $40-\mathrm{Hz}$ operation for resistive-load test ................................ 70

4.28 Efficiencies comparison plot at 50-Hz operation for resistive-load test ............................. 70

4.29 Efficiencies comparison plot at 50-Hz operation for resistive-load test .............................. 71

4.30 Forward characteristics of IGBT and JFET in the Si and SiC modules............................... 71

4.31 Forward characteristics of diodes in the $\mathrm{Si}$ and $\mathrm{SiC}$ modules ............................................ 72

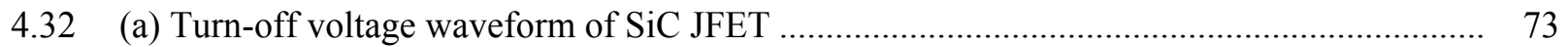

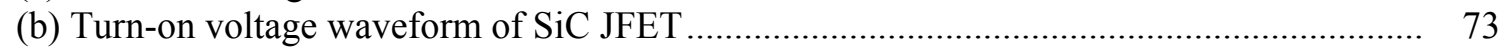

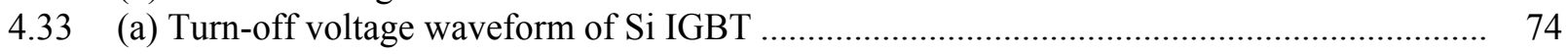

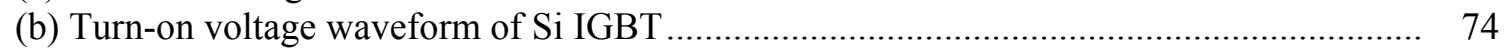

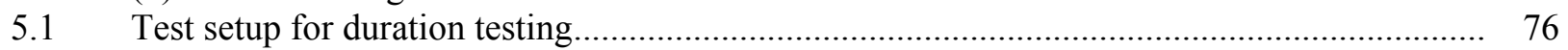

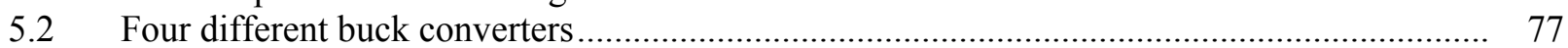

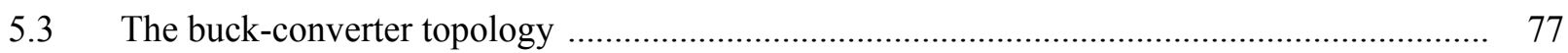

$5.4 \quad$ Plot of temperature data for diodes without the filter ................................................... 78

5.5 Plot of temperature data for switches without the filter ................................................... 79

5.6 Temperature profile for power switches at $250-\mathrm{V}, 10-\mathrm{kHz}$ operation................................ 80

5.7 Turn-on current waveforms of Si IGBTs with $\mathrm{SiC}$ and Si diodes ...................................... 81

5.8 Temperature profile for 10-kHz operation: (a) Switches; (b) Diodes .................................. 82

5.9 Comparison of static charactersitics for Si IGBT and SiC JFET ...................................... 82

5.10 Temperature profile for diodes at $100-\mathrm{kHz}$ operation. .................................................

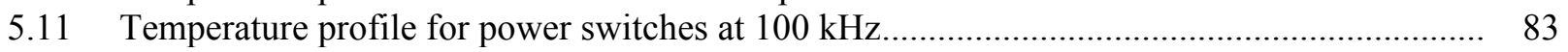

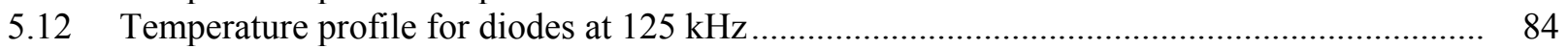

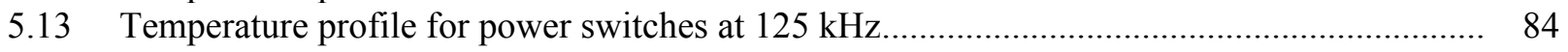

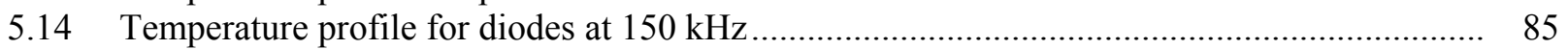

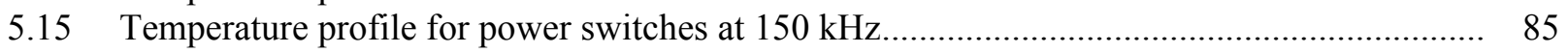

5.16 Temperature profile for diodes at different operating frequencies ................................... 86

5.17 Temperature profile for power switches at different operating frequencies .......................... 86

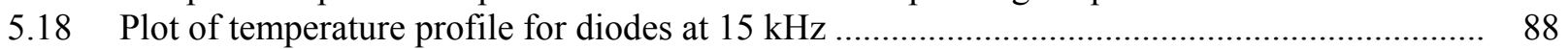

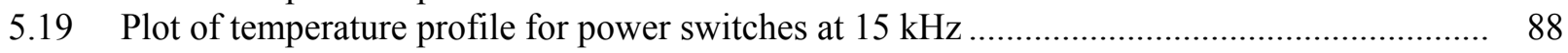

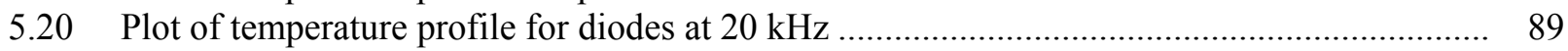

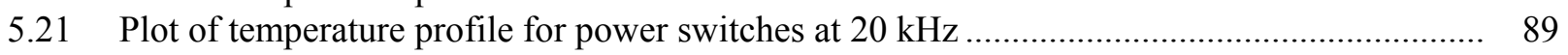

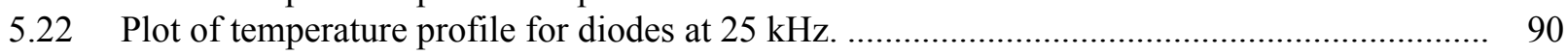

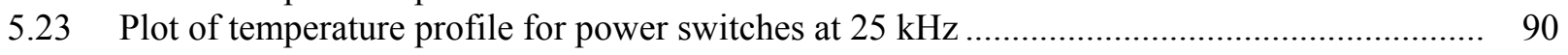

5.24 Plot of temperature profile for power switches at different frequencies............................ 91

A.1 $i-v$ characteristics of S1 $(1200 \mathrm{~V}, 7.5 \mathrm{~A})$ at different operating temperatures ........................ 96

A.2 $i-v$ characteristics of S4 $(300 \mathrm{~V}, 10 \mathrm{~A})$ at different operating temperatures ........................... 96

A.3 $i-v$ characteristics of S2 $(600 \mathrm{~V}, 4 \mathrm{~A})$ at different operating temperatures ........................... 97

A.4 $i-v$ characteristics of Si pn diode $(600 \mathrm{~V}, 10 \mathrm{~A})$ at different operating temperatures ............. 97 


\section{LIST OF TABLES}

Table

Page

3.1 $\mathrm{SiC}$ power diode model parameters and extraction characteristics for the Cree

75-A diode.

26

3.2 Efficiencies of the hybrid inverter during testing and simulation....................................... 28

3.3 Efficiencies of the all-Si inverter during testing and simulation......................................... 28

4.1 SiC power JFET model parameters and extraction characteristics for the

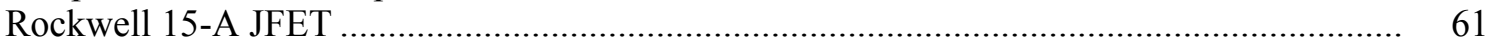

5.1 Specifications of the devices used in the buck converters .............................................. 77

5.2 Temperature data of power devices at $300-\mathrm{V}, 10-\mathrm{kHz}$ operation ....................................... 80 


\section{INTRODUCTION}

With the increase in demand for more efficient, higher-power, and higher-temperature operation of power converters, design engineers face the challenge of increasing the efficiency and power density of converters $[1,2]$. Development in power semiconductors is vital for achieving the design goals set by the industry. Silicon $(\mathrm{Si})$ power devices have reached their theoretical limits in terms of higher-temperature and higher-power operation by virtue of the physical properties of the material. To overcome these limitations, research has focused on wide-bandgap materials such as silicon carbide ( $\mathrm{SiC}$ ), gallium nitride $(\mathrm{GaN})$, and diamond because of their superior material advantages such as large bandgap, high thermal conductivity, and high critical breakdown field strength.

Diamond is the ultimate material for power devices because of its greater than tenfold improvement in electrical properties compared with silicon; however, it is more suited for higher-voltage (grid level) higher-power applications based on the intrinsic properties of the material [3]. GaN and SiC power devices have similar performance improvements over Si power devices. GaN performs only slightly better than $\mathrm{SiC}$. Both $\mathrm{SiC}$ and $\mathrm{GaN}$ have processing issues that need to be resolved before they can seriously challenge $\mathrm{Si}$ power devices; however, $\mathrm{SiC}$ is at a more technically advanced stage than $\mathrm{GaN}$. $\mathrm{SiC}$ is considered to be the best transition material for future power devices before high-power diamond device technology matures.

Since $\mathrm{SiC}$ power devices have lower losses than Si devices, SiC-based power converters are more efficient. With the high-temperature operation capability of $\mathrm{SiC}$, thermal management requirements are reduced; therefore, a smaller heat sink would be sufficient. In addition, since SiC power devices can be switched at higher frequencies, smaller passive components are required in power converters. Smaller heat sinks and passive components result in higher-power-density power converters. With the advent of the use of $\mathrm{SiC}$ devices it is imperative that models of these be made available in commercial simulators. This enables power electronic designers to simulate their designs for various test conditions prior to fabrication.

To build an accurate transistor-level model of a power electronic system such as an inverter, the first step is to characterize the semiconductor devices that are present in the system. Suitable test beds need to be built for each device to precisely test the devices and obtain relevant data that can be used for modeling. This includes careful characterization of the parasitic elements so as to emulate the test setup as closely as possible in simulations.

This report is arranged as follows:

Chapter 2: The testing and characterization of several diodes and power switches is presented.

Chapter 3: A 55-kW hybrid inverter ( $\mathrm{Si}$ insulated gate bipolar transistor-SiC Schottky diodes) device models and test results are presented. A detailed description of the various test setups followed by the parameter extraction, modeling, and simulation study of the inverter performance is presented.

Chapter 4: A 7.5-kW all-SiC inverter ( $\mathrm{SiC}$ junction field effect transistors (JFET)-SiC Schottky diodes) was built and tested. The models built in Saber were validated using the test data and the models were used in system applications in the Saber simulator. The simulation results and a comparison of the data from the prototype tests are discussed in this chapter.

Chapter 5: The duration test results of devices utilized in buck converters undergoing reliability testing are presented. 


\section{SiC DEVICES}

\subsection{INTRODUCTION}

SiC unipolar devices such as Schottky diodes, JFETs, and metal oxide semiconductor field-effect transistors (MOSFETs) have much higher breakdown voltages than their Si counterparts, which makes them suitable for use in medium-voltage applications. At present, SiC Schottky diodes are the only commercially available $\mathrm{SiC}$ devices. The maximum ratings of these commercial devices are $1200 \mathrm{~V}$ and $20 \mathrm{~A}$. Some other $600-\mathrm{V}$ prototype Schottky diodes with a 100-A rating are in the experimental stage and are expected to be commercially available in the near future.

SiC Schottky diodes are being used in several applications and have been proven to increase the system efficiency compared with Si device performance [4]. A significant reduction in the weight and size of $\mathrm{SiC}$ power converters with an increase in the efficiency is projected [1,2]. In the literature, the performance of $\mathrm{SiC}$ converters has been compared with that of traditional Si converters and has been found to be superior $[5,6]$.

This chapter presents the characteristics for several $\mathrm{SiC}$ diodes and power switches and compares their performance. Some applications require that devices be able to handle extreme environments that include a wide range of operating temperatures. In the following sections, the static and dynamic performances of some commercially available SiC Schottky diodes and experimental samples of SiC JFETs and MOSFETs tested over a wide temperature range will be presented.

\section{$2.2 \quad$ SiC SCHOTTKY DIODES}

The Schottky barrier diode (SBD) is a majority-carrier device that has minimal reverse-recovery charge and therefore switches extremely fast.

It consists of a metal in direct contact with the semiconductor drift region, which happens to be the voltage blocking layer as shown in Fig. 2.1. The semiconductor region under the metal is lightly doped, making the contact a rectifying one instead of ohmic. The type of metal contact used to fabricate the device determines the knee voltage of the device (the voltage at which the diode starts conducting).

Schottky Contact Ohmic Contact

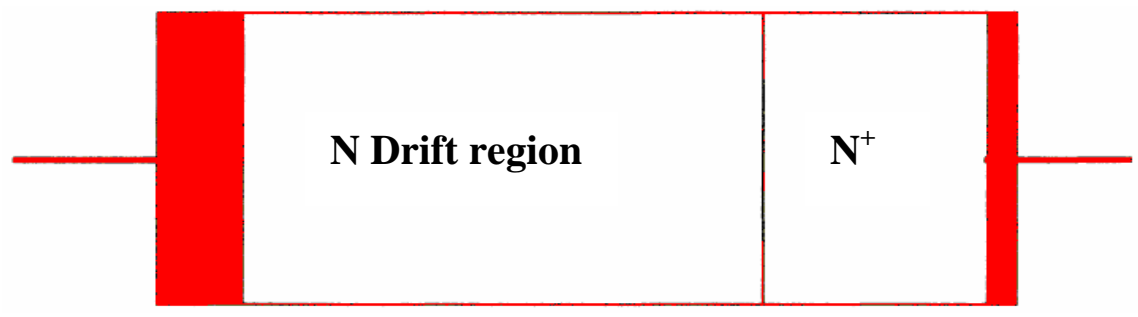

Fig. 2.1. Cross-section of a SBD.

SiC Schottky diodes are majority-carrier devices and are attractive for high-frequency switching because they have lower switching losses than pn diodes. However, they have higher leakage currents, which affect the breakdown voltage ratings of the devices [7]. SiC Schottky diode test results presented in this report are designated as S1 (1200 V, 7.5 A), S2 (600 V, 4A), S3 (600 V, $10 \mathrm{~A})$, and S4 (300 V, $10 \mathrm{~A})$. 


\subsubsection{Static Characteristics}

The static characteristics of different SiC Schottky diodes at room temperature are shown in Fig. 2.2. The threshold voltages (or the knee voltages) and the on-state resistances are different for the diodes because of the differences in device dimensions at different voltage and current ratings. The threshold voltage also varies with the contact metal used in the Schottky diodes because of the variation in the Fermi level for different metal-to-semiconductor contacts [8]. The static characteristics of one of the diodes (S3, $600 \mathrm{~V}$, $10 \mathrm{~A}$ ) over a temperature range of $-50^{\circ} \mathrm{C}$ to $175^{\circ} \mathrm{C}$ are shown in Fig. 2.3. The static characteristics of the remaining diodes can be found in Appendix A.

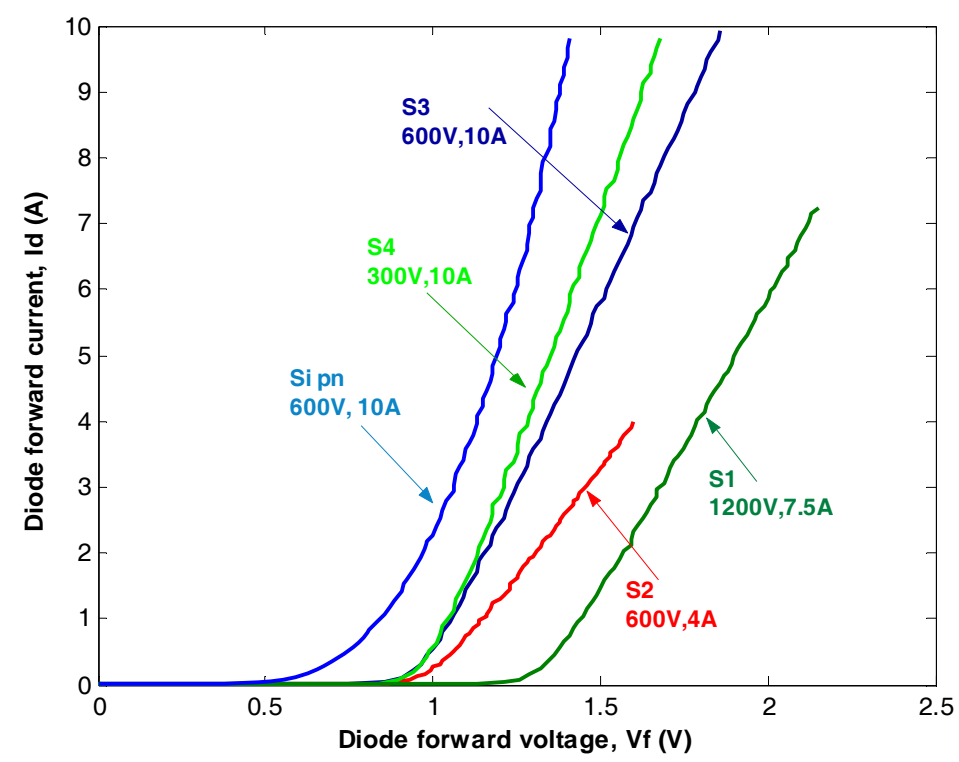

Fig. 2.2. i-v characteristics of $\mathrm{Si}$ pn and $\mathrm{SiC}$ Schottky diodes at $27^{\circ} \mathrm{C}$ and $\mathrm{SiC}$ diodes at different operating temperatures.

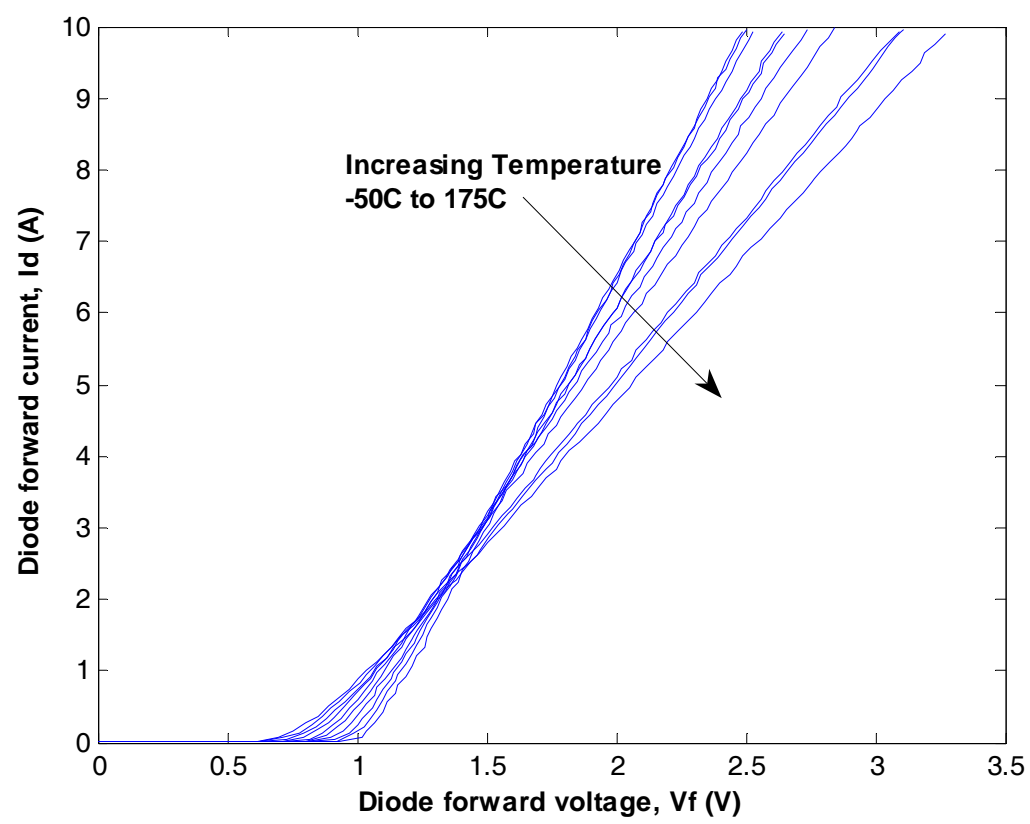

Fig. 2.3. i-v characteristics of $S 3(600 \mathrm{~V}, 10 \mathrm{~A})$ at different operating temperatures. 
The approximate on-state voltage drop equation of a diode is given as

$$
V_{f}=V_{d}+I_{d} \cdot R_{d}
$$

where $V_{d}$ is the forward voltage drop and $R_{d}$ is the series resistance of the diode obtained from the piecewise linear (PWL) model of the diode. The PWL model parameters were extracted from the experimental test data in Fig. 2.3. The variation in $V_{d}$ with temperature is plotted in Fig. 2.4 for all the diodes tested.

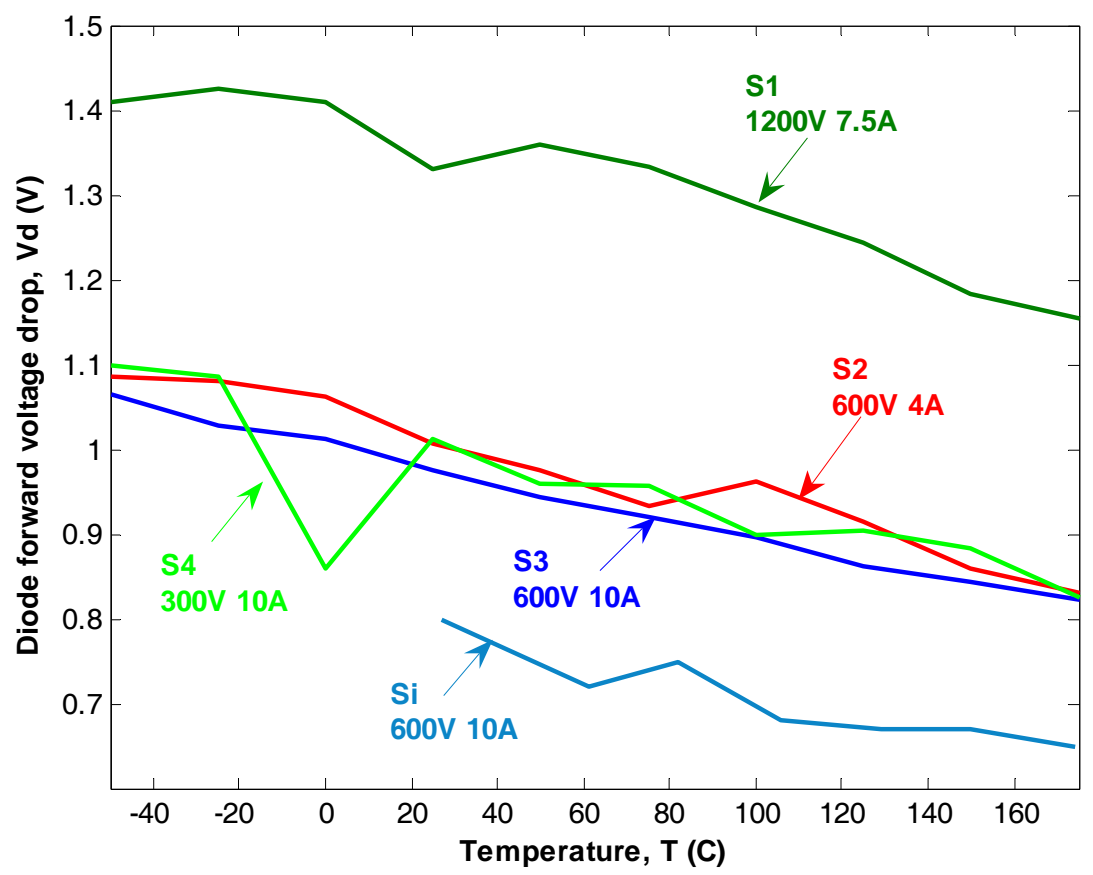

Fig. 2.4. $V_{d}$ for $\mathrm{Si}$ and $\mathrm{SiC}$ diodes at different operating temperatures.

The on-state voltage drop of a Schottky diode depends on the barrier height and the on-state resistance, both of which vary with temperature. At lower current levels, as the temperature increases, the thermal energy of the electrons increase causing the lowering of the barrier height.

A lower barrier height means a lower barrier potential and a lower forward voltage drop [9]. At higher current levels, the on-state voltage drop is mainly because of the series resistance of the diode, which is one of the critical parameters that determine the performance of the device. The dominant component of the diode series resistance is the specific on-resistance, $R_{o n, s p} . R_{o n, s p}$ for majority-carrier devices can be expressed as a function of breakdown voltage and the critical electric field [10];

$$
R_{o n, s p}=\frac{4 V_{B}^{2}}{\varepsilon\left(E_{c}\right)^{3} \mu_{n}},
$$

where $\varepsilon$ is the permittivity $(\mathrm{C} / \mathrm{V} \cdot \mathrm{cm}), V_{B}$ is the breakdown voltage, $E_{c}$ is the breakdown field $(\mathrm{V} / \mathrm{cm})$, and $\mu_{n}$ is the electron mobility $\left(\mathrm{cm}^{2} / \mathrm{V} \cdot \mathrm{s}\right)$.

$R_{o n, s p}$ increases with temperature because the mobility decreases at higher temperatures. Consequently, the diode series resistance increases with the temperature and the device has a positive-temperature 
coefficient, which makes it easier to parallel the devices. The disadvantage, however, is that the diode conduction loss also increases with temperature.

The series resistance, $R_{d}$, for the diodes is calculated from the slope of the $i-v$ characteristics at high currents and is plotted for different temperatures as shown in Fig. 2.5. The series resistance of each diode is unique because of the differences in blocking voltages and in the die area. To withstand high breakdown voltages, the blocking layer thickness must be increased and the doping concentrations must be reduced. This results in an increased series resistance of the diode. Hence, device S1 rated at $1200 \mathrm{~V}$, 7.5 A has a higher series resistance than S3 $(600 \mathrm{~V})$ and S4 $(300 \mathrm{~V})$. The resistance also varies with the area of the device. It is evident from Fig. 2.5 that S2 and S3, with the same voltage but different current ratings, have different series resistances.

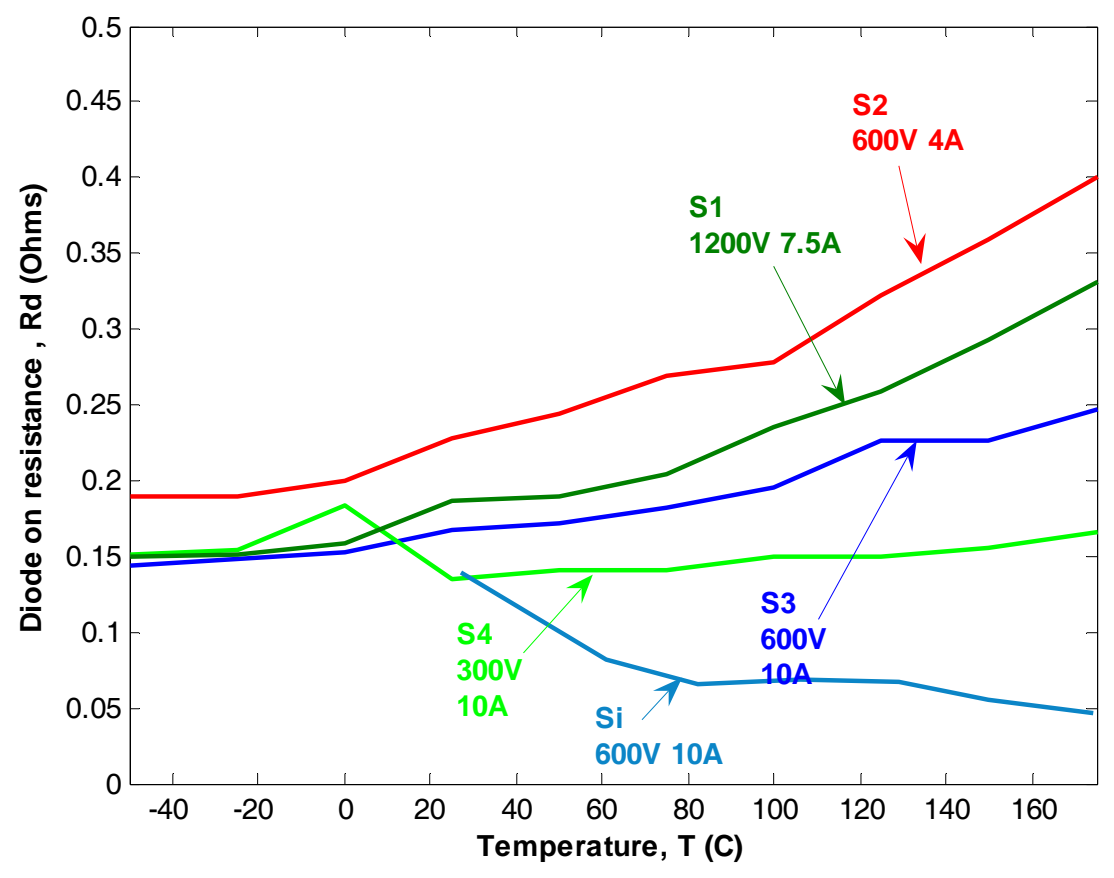

Fig. 2.5. $R_{d}$ for $\mathrm{Si}$ and $\mathrm{SiC}$ diodes at different operating temperatures.

\subsubsection{Dynamic Characteristics}

A buck chopper with an inductive load was built to evaluate the switching characteristics of the diodes. The test circuit shown in Fig. 2.6 was built for the tests.

The test circuit consists of a gate-driver chip that drives the IGBT. The load includes a 24-mH inductor and a $45.5-\Omega$ resistor (with a maximum power dissipation rating of $1200 \mathrm{~W}$ ) in series. The IGBT was switched at $5 \mathrm{kHz}$ with a duty cycle of $50 \%$. The reverse-recovery tests were performed at different direct current $(\mathrm{dc})$ voltages ranging from 50 to $200 \mathrm{~V}$.

The tests were performed for the following diodes: (a) S3 (600 V, 10 A), (b) S2 (600 V, 4 A), (c) S4 (300 V, 10 A), (d) S1 (1200 V, 7.5 A), and (e) a Si pn diode $(600 \mathrm{~V}, 10 \mathrm{~A})$ which was included for comparison purposes. Figure 2.7 shows the reverse-recovery test setup in the lab. Some of the reverserecovery waveforms are shown in Figs. 2.8 and 2.9. 


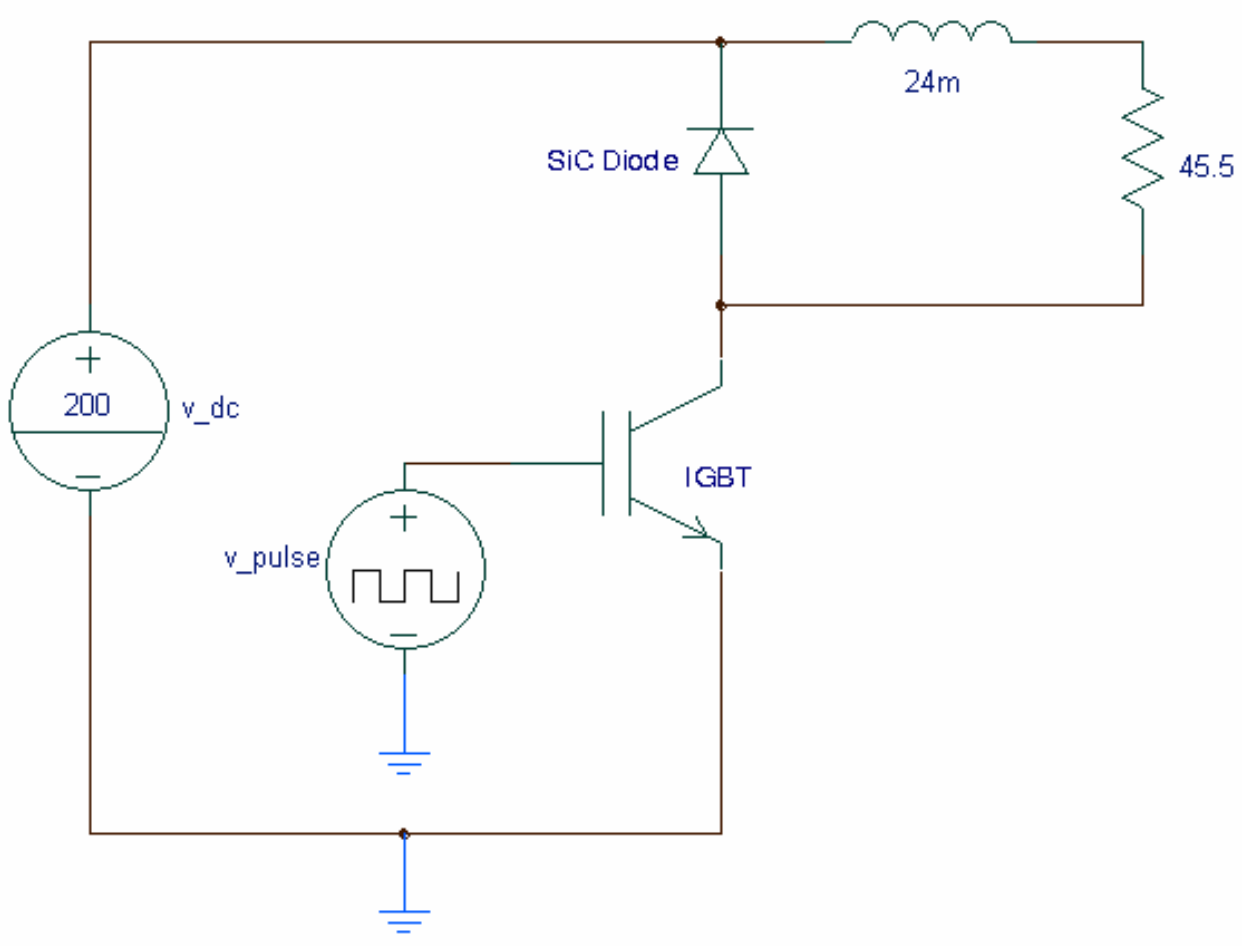

Fig. 2.6. Reverse-recovery test circuit.

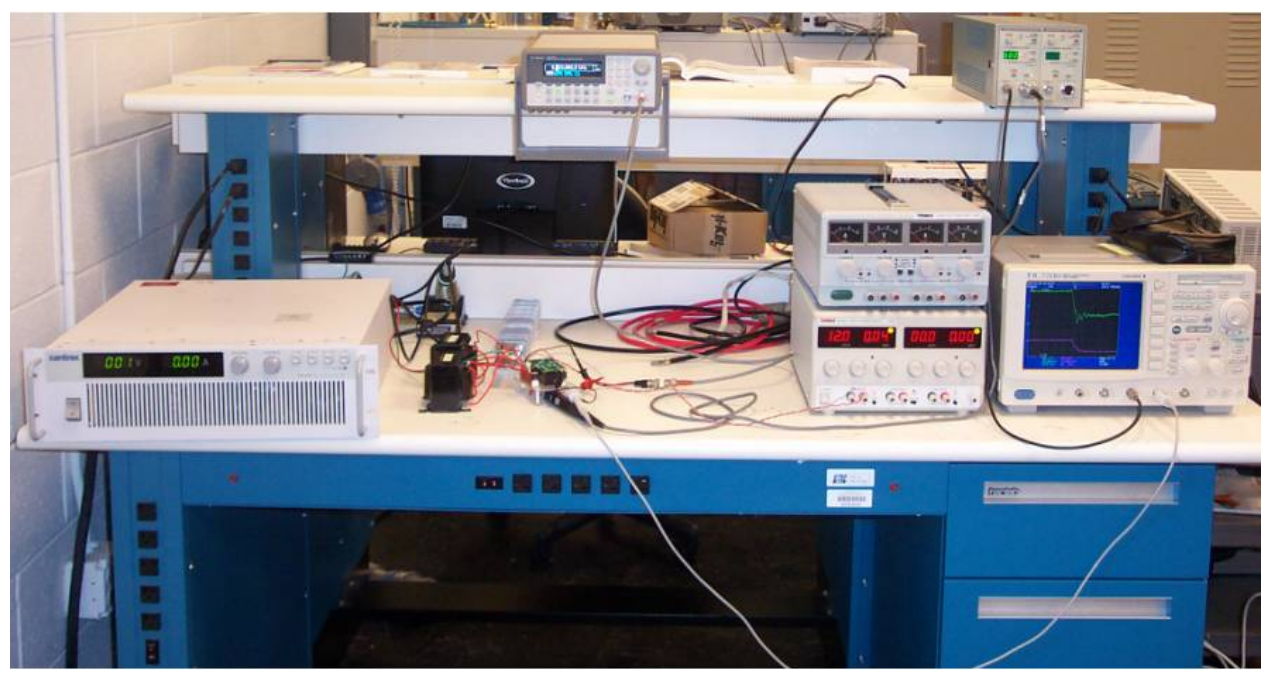

Fig. 2.7. Reverse-recovery test setup. 


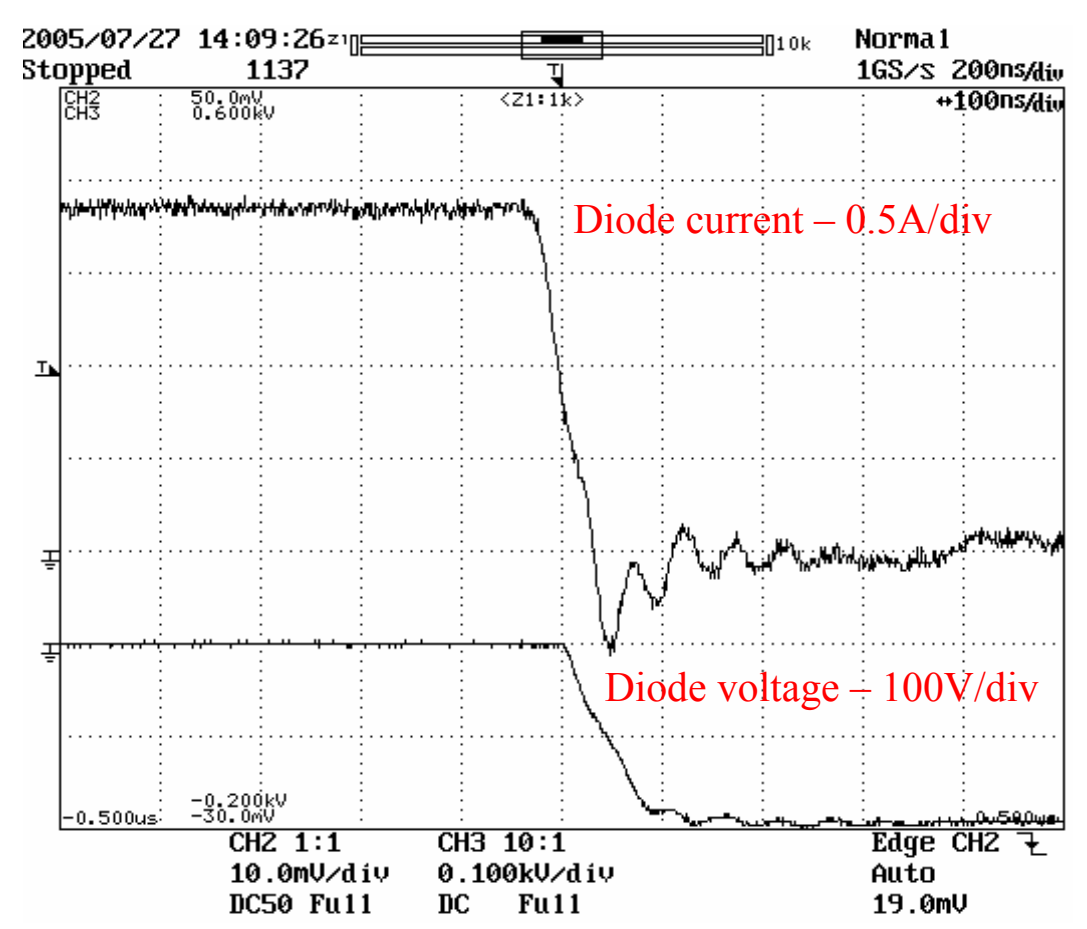

Fig. 2.8. Reverse-recovery waveforms showing the diode current (top) and voltage (bottom) for the diode S3.

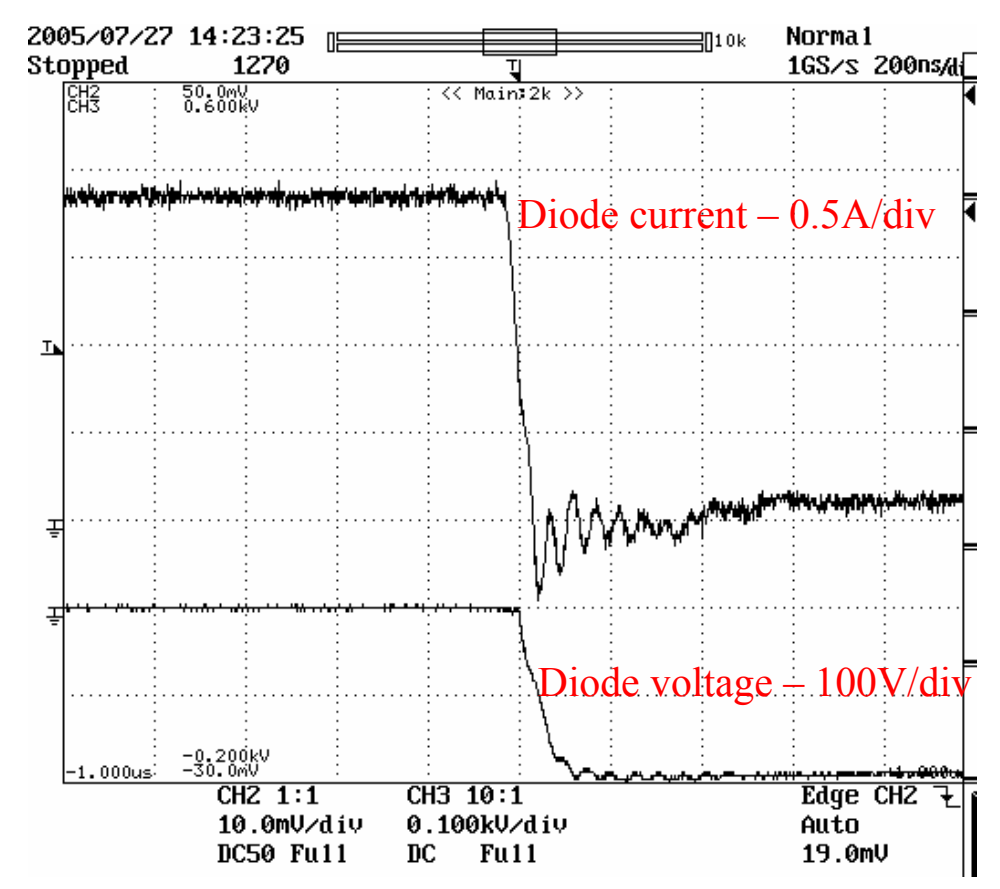

Fig. 2.9. Reverse-recovery waveforms showing the diode current (top) and voltage (bottom) for the diode S2.

The reverse-recovery waveforms for all the diodes tested are shown in Figs. 2.8, 2.10, 2.11, and 2.12. The energy losses for various forward peak currents at different temperatures are shown for the Si diode and 
the SiC diode S4 in Fig. 2.13. The switching loss for the Si diode increases with temperature and forward current, while the switching loss for the $\mathrm{SiC}$ diode $\mathrm{S} 4$ is almost independent of the change in temperature and varies slightly with increasing forward current. The reason is that the reverse-recovery current of a diode depends on the charge stored in the drift region. Schottky diodes have no stored charge because they are majority-carrier devices and thus have no reverse recovery. However, oscillations due to parasitic internal pn diodes and capacitances look like reverse-recovery phenomena. The reduced reverse recovery of Schottky diodes makes it possible to reduce the size of the snubbers. Low reverse-recovery and snubber losses increase the efficiency of the power converters.

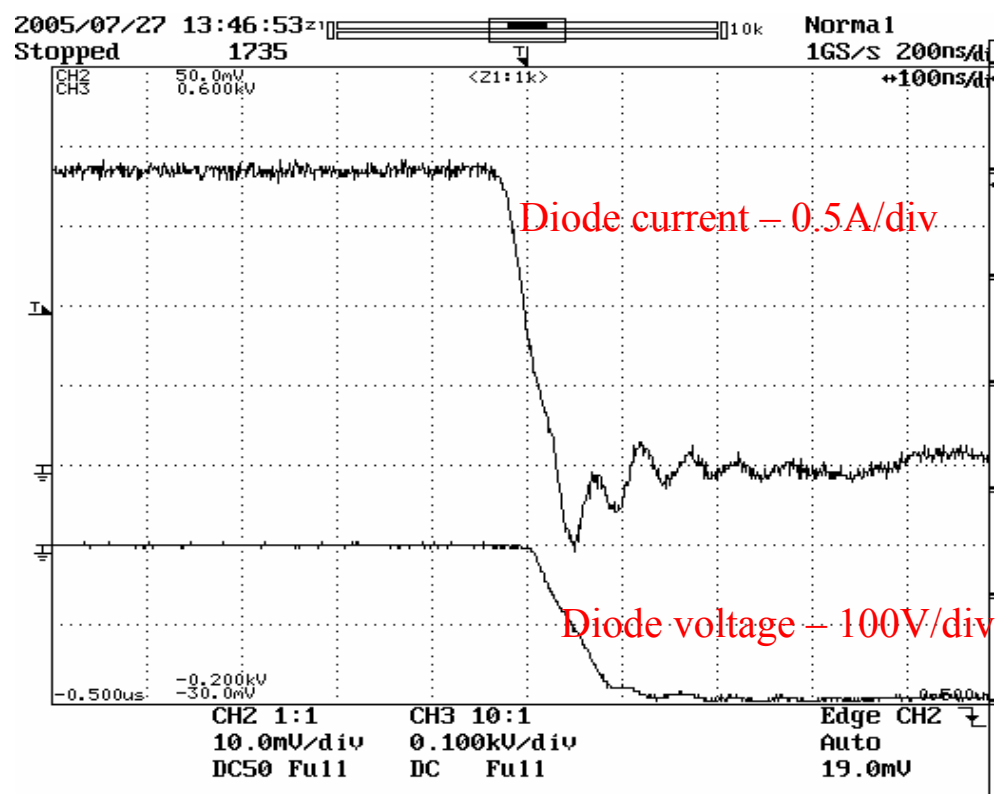

Fig. 2.10. Reverse-recovery waveforms showing the diode current (top) and voltage (bottom) for the diode S4.

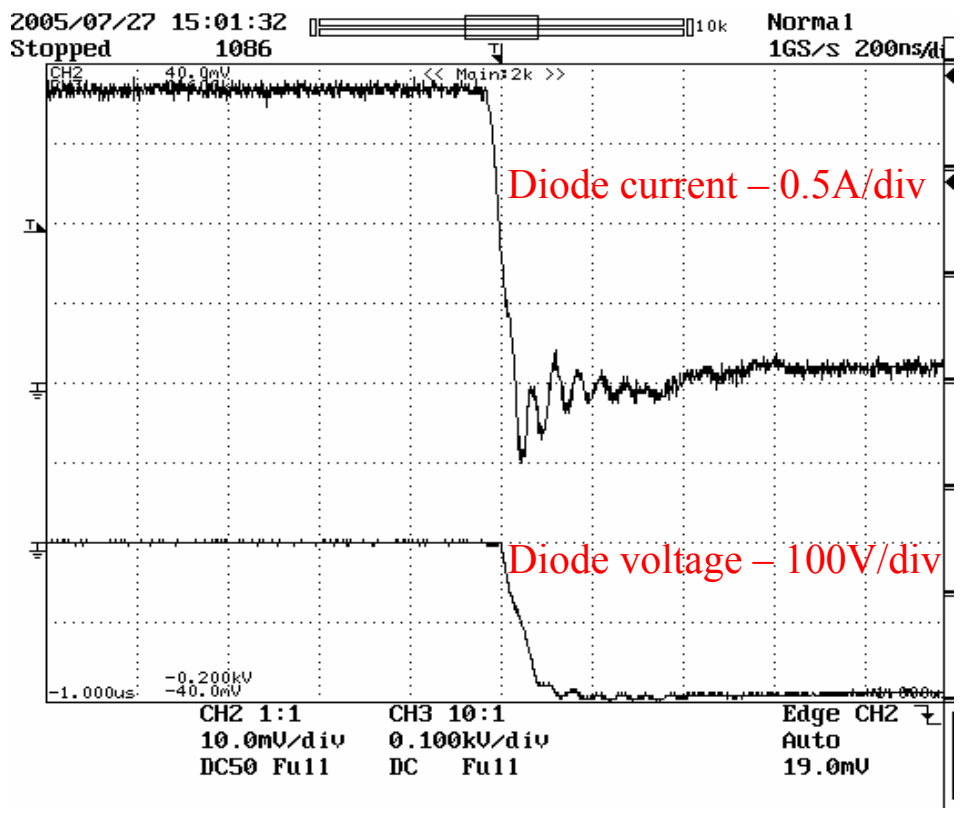

Fig. 2.11. Reverse-recovery waveforms showing the diode current (top) and voltage (bottom) for the diode S1. 


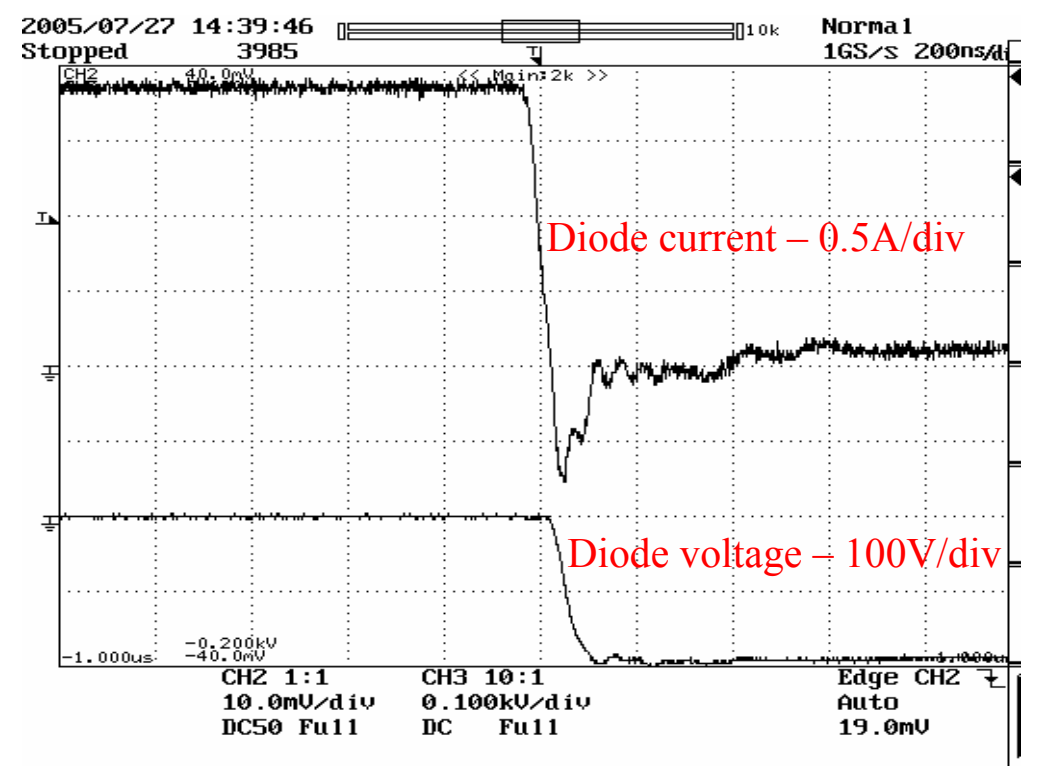

Fig. 2.12. Reverse-recovery waveforms showing the diode current (top) and voltage (bottom) for the Si pn diode.

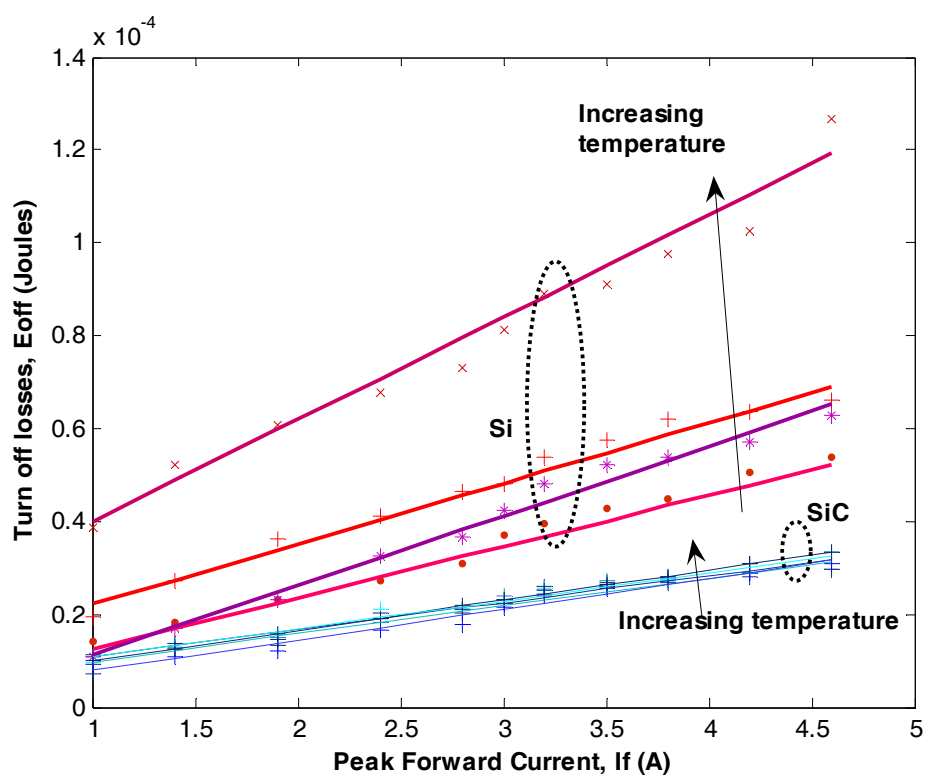

Fig. 2.13. Turn-off energy losses with respect to forward current at different operating temperatures.

\subsection{SiC FIELD-EFFECT TRANSISTOR (FET) DEVICES}

FET devices are majority-carrier devices and are preferred over minority-carrier devices in power converters. However, Si FET devices, like Si Schottky diodes, can only be used in low voltage $(<300-\mathrm{V})$ applications because of their high on-state resistance. Even the first experimental SiC FET devices have blocking voltages of over $1000 \mathrm{~V}$. It is expected that in the near future, SiC FET devices will dominate $\mathrm{Si}$ minority-carrier devices in the medium-voltage $(<3000-\mathrm{V})$ applications. 


\subsubsection{Static Characteristics}

\subsubsection{SiC JFET}

A JFET is a unipolar device and has several advantages compared with MOSFET devices. A JFET has a low voltage drop and a higher-switching speed and is free from gate-oxide interface problems, unlike a MOSFET [11]. A SiC JFET is typically a normally-on device and conducts even though there is no gate voltage applied. A gate voltage must be applied for it to stop conduction. This feature dictates special gate-drivers, increasing the complexity of the design. A normally-on device is not desirable for power electronics since it requires additional protection circuitry to prevent a dc bus short if the gate signals fail.

A Si JFET is not classified as a power electronics device. The SiC JFET, however, can be used in highvoltage, high-power applications, unlike a Si JFET because of its vertical structure and the intrinsic properties of $\mathrm{SiC}$.

A normally-on SiC JFET rated at $1200 \mathrm{~V}$ and $2 \mathrm{~A}$ was tested to study the high-temperature behavior of the device. The forward characteristics of this device at different temperatures are shown in Fig. 2.14. As seen in Figs. 2.14 and 2.15, SiC JFETs have a positive-temperature coefficient, which means that, like $\mathrm{SiC}$ Schottky diodes, their conduction losses will be higher at higher temperatures. A positivetemperature coefficient makes it easier to parallel these devices and reduce the overall on-resistance. The on-resistance of the JFET increases from $0.36 \Omega$ at $-50^{\circ} \mathrm{C}$ to $1.4 \Omega$ at $175^{\circ} \mathrm{C}$, as shown in Fig. 2.16.

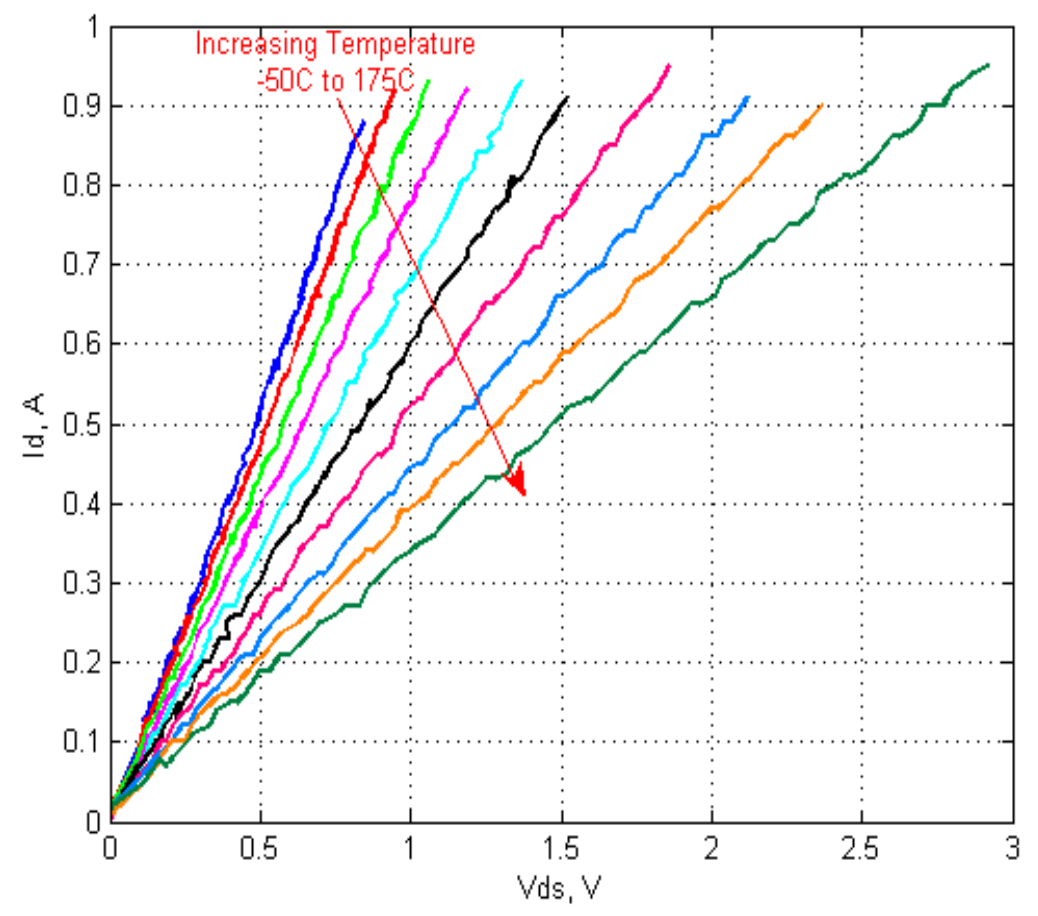

Fig. 2.14. $i-v$ characteristics of SiC JFET at different temperatures. 


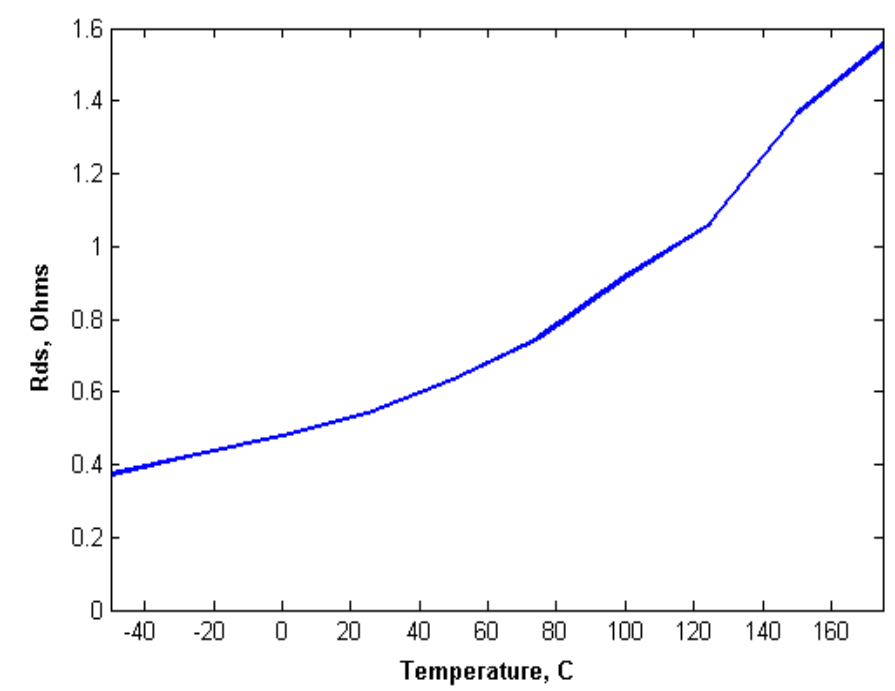

Fig. 2.15. On-resistance of SiC JFET at different temperatures.

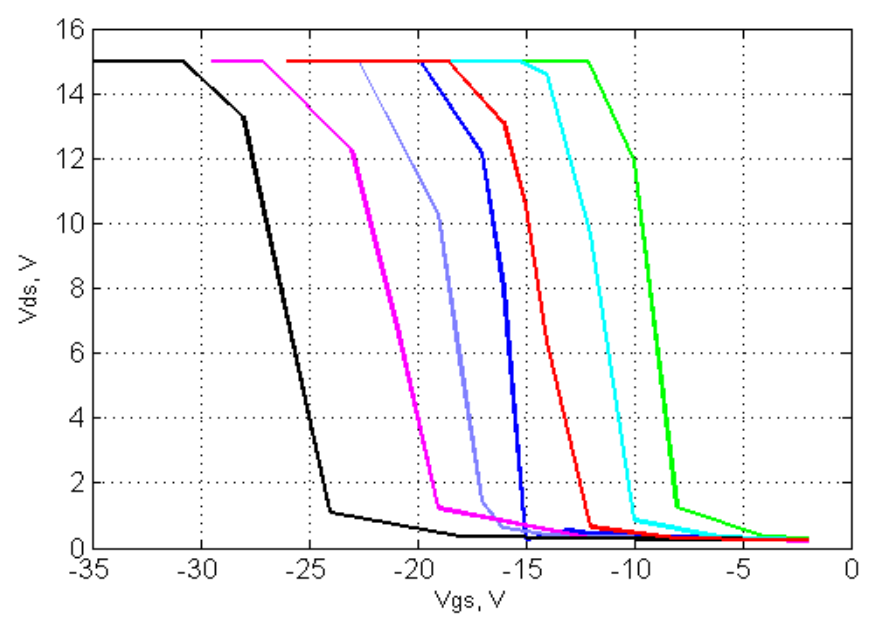

Fig. 2.16. Transfer characteristics of several SiC JFET samples.

The on-resistance is high; however, this device is a low-current-rated device and is an early prototype. It is expected that as the technology matures, lower on-resistances will be possible.

The transfer characteristics of different SiC JFET samples are shown in Fig. 2.16. The negative gate pinch-off voltage required to turn off the device is higher than that required for Si devices and varies from sample to sample. This variation is attributed to the fact that these devices are experimental samples.

\subsubsection{SiC MOSFET}

A MOSFET is a unipolar device and is normally off. The forward characteristics of a $1.2-\mathrm{kV}, 15-\mathrm{A} \mathrm{SiC}$ MOSFET at room temperature are shown in Fig. 2.17. The gate voltage was varied from 0 to $20 \mathrm{~V}$ in increments of $5 \mathrm{~V}$. For $V_{g s}=20 \mathrm{~V}$, there is a $6.7-\mathrm{V}$ drain-to-source voltage drop that corresponds to a 15 -A drain current. Note that it would be more reasonable to operate this device at 5 A with $V_{g s}=20 \mathrm{~V}$ because of a low voltage drop of $1.5 \mathrm{~V}$. The forward characteristics of the same SiC MOSFET for a temperature range of -50 to $175^{\circ} \mathrm{C}$ are shown in Fig. 2.18. Note that the device's response to temperature 
increase changes at $50^{\circ} \mathrm{C}$. To get a better understanding of this phenomenon, the on-state resistances of the device are calculated from the slopes of the different curves and are plotted with respect to temperature in Fig. 2.19. It is interesting to note that this device has a negative temperature coefficient at up to $50^{\circ} \mathrm{C}$ and a positive-temperature coefficient above that. MOSFETs are majority-carrier devices and are expected to have positive-temperature coefficients. The components of the on-resistance of a MOSFET, can be expressed as the sum of several different resistances because of the different regions in the MOSFET structure

$$
R_{\text {on }}=R_{\text {cont }}+R_{\text {sub }}+R_{c h}+R_{a c c}+R_{j f e t}+R_{d},
$$

where $R_{\text {cont }}$ is the contact resistance, $R_{s u b}$ the substrate resistance, $R_{c h}$ the channel resistance, $R_{a c c}$ the accumulation layer resistance, $R_{J F E T}$ the resistance of the JFET like region, and $R_{d}$ is the resistance of the drift region [12].

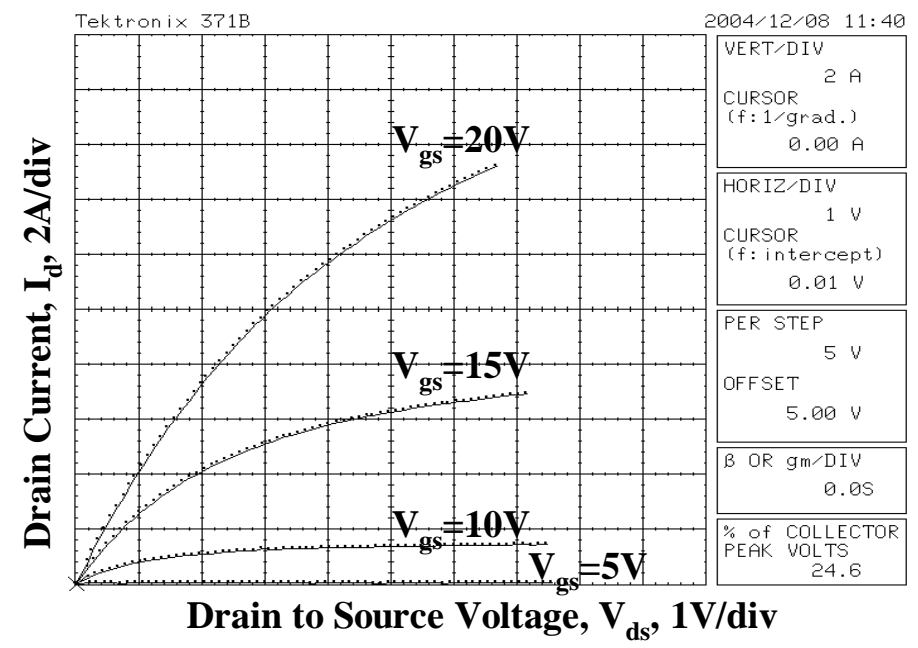

Fig. 2.17. Forward characteristics of SiC MOSFET at room temperature.

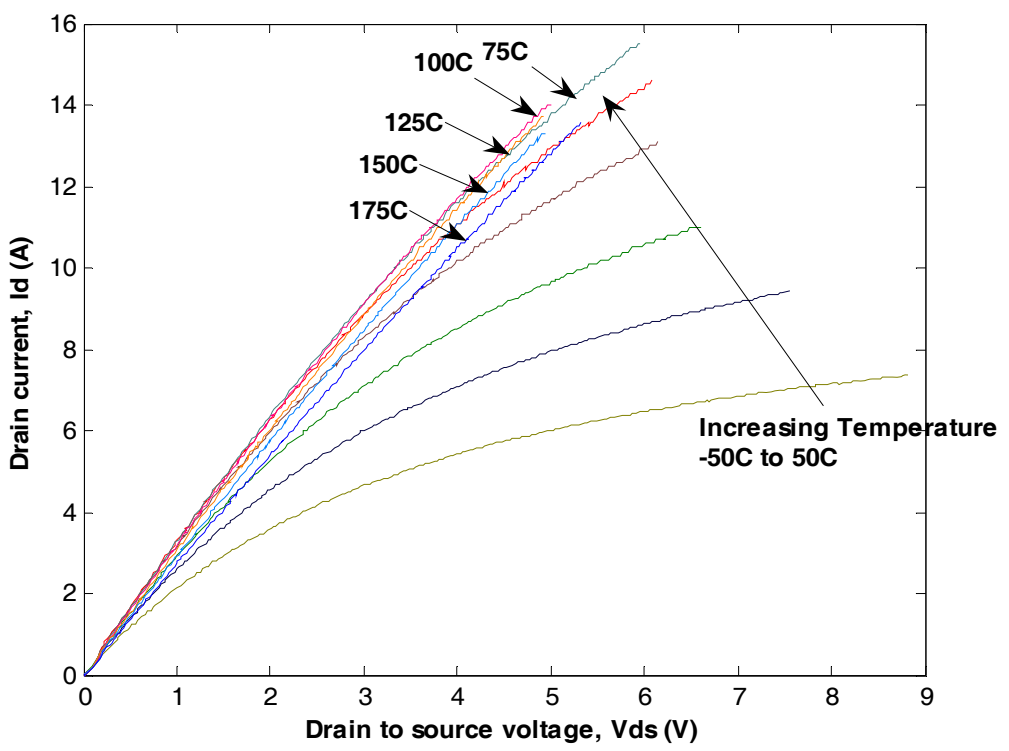

Fig. 2.18. Forward characteristics of SiC MOSFET at different temperatures. 


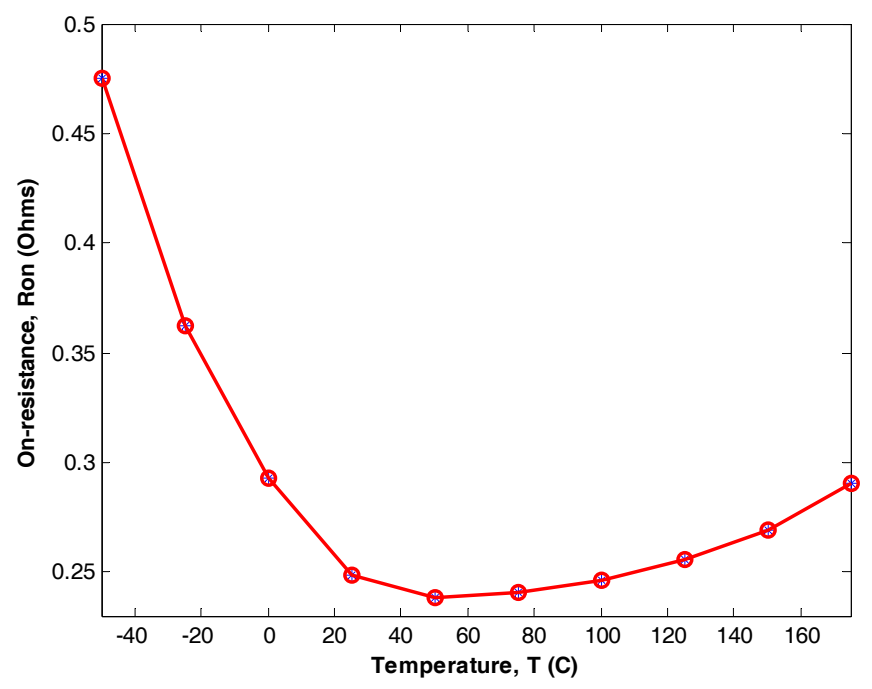

Fig. 2.19. On-resistance of SiC MOSFET at different temperatures.

At lower temperatures, the contribution of the channel resistance to the total on-state resistance is dominant [13]. The channel mobility increases with temperature because the interface traps are closer to the conduction band $[13,14]$; thus the channel resistance decreases with temperature. Consequently, at low temperatures, the MOSFET on-resistance decreases. Above a certain temperature value, the channel resistance is not dominant; and because of the other dominant on-resistance components, the MOSFET overall on-resistance increases.

The SiC MOSFET gate-threshold voltage is measured from the transfer characteristics shown in Fig. 2.20. The gate-threshold voltage decreases with increasing temperature. Figure 2.21 shows the change in threshold voltage from $10.7 \mathrm{~V}$ at $-50^{\circ} \mathrm{C}$ to $2.8 \mathrm{~V}$ at $175^{\circ} \mathrm{C}$. This change is due to the trapped charge in the $\mathrm{SiO}_{2}$, as well as the impurities at the $\mathrm{SiO}_{2}$ interface. These trapped charges become active at high temperatures, which results in a Fermi level shift toward the bandgap, causing the drain current to flow at low threshold voltages. In other words, less gate voltage is required at high temperatures for the same drain current to flow through the device.

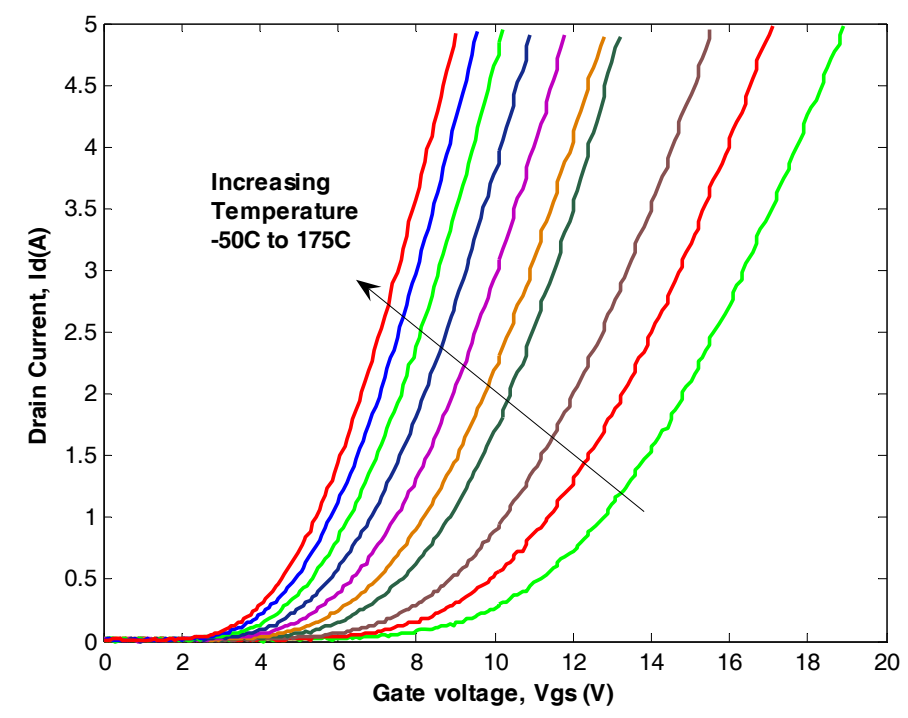

Fig. 2.20. Transfer characteristics of SiC MOSFET at different temperatures. 


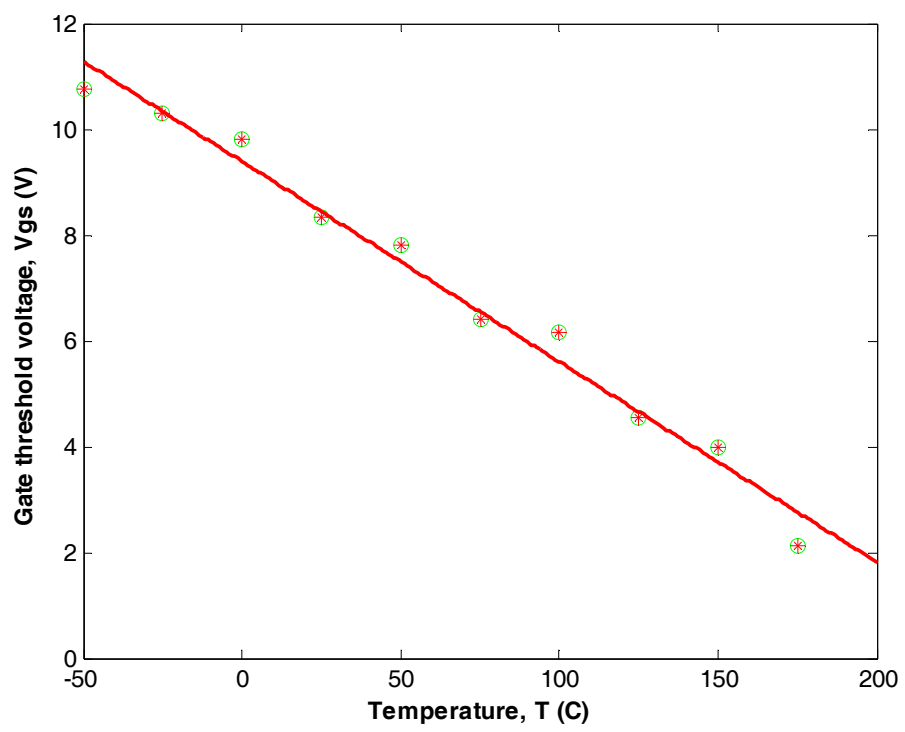

Fig. 2.21. Gate-threshold voltage of SiC MOSFET at different temperatures.

\subsubsection{Gate-drive requirements}

SiC FET switches can be operated at higher switching frequencies and higher temperatures; therefore, they have different gate-drive requirements compared with traditional Si power switches. The switching performance of the FET devices is determined by charging and discharging of the parasitic capacitances across the three terminals, input capacitance, reverse-transfer capacitance, and output capacitance. These capacitances are proportional to the area of the device [6]. Since SiC devices have smaller areas than comparable Si devices, even for high-blocking voltages, the capacitances are reduced. This enables devices to operate at higher switching speeds. A comparison of capacitance values for a SiC MOSFET and for a Si power switch is reported in [15].

One of the important parameters in gate-drive designs is the capacitance between the gate and the other terminals. Total input capacitance of the JFET, $C_{i s s}$, determines the current required by the gate and the rate at which the applied gate voltage is built across the gate and source terminals. Therefore, the gatedrive circuit is required to have the capability of providing peak currents to charge the input capacitance quickly. The peak-gate current is limited by the series resistance between the gate and the gate-driver output. Higher gate-series resistance decreases the ringing effect due to the internal impedance of the device; however, it also results in slower turn-on times.

As mentioned earlier, there are several gate-drive circuit design options for $\mathrm{SiC}$ JFETs using transistors and other discrete devices $[10,16]$. A commercial gate-driver chip IXDD414 was used in this project to drive the SiC FETs under test for a more reliable and quick gate-driver design. Note that this gate-driver chip can be used with most of the SiC JFETs whose transfer characteristics are shown in Fig. 2.16, as well as the SiC MOSFET samples. The gate driver can be redesigned to be used as a SiC MOSFET gate drive by replacing the series-gate resistor and reversing the output-voltage polarity. The peak-gate currents and gate-voltage waveforms driving a SiC JFET and a SiC MOSFET are shown in Fig. 2.22. As seen in this figure, a SiC MOSFET requires a higher current than a SiC JFET to operate at the same switching frequency, i.e. $250 \mathrm{kHz}$ in this case. 


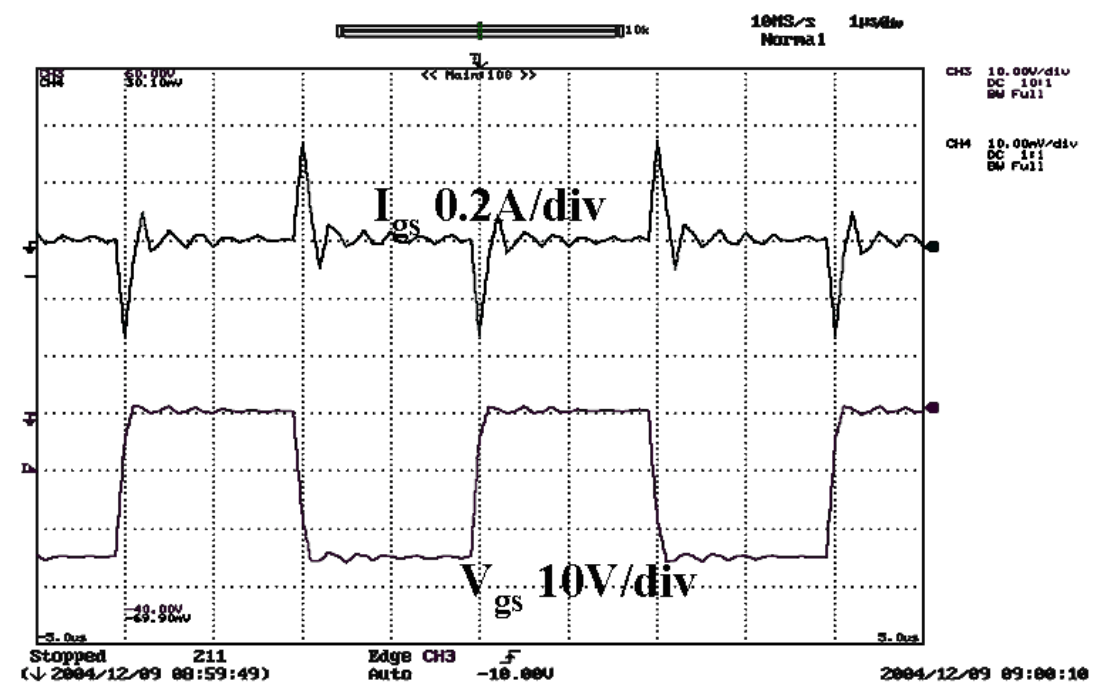

(a) SiC JFET

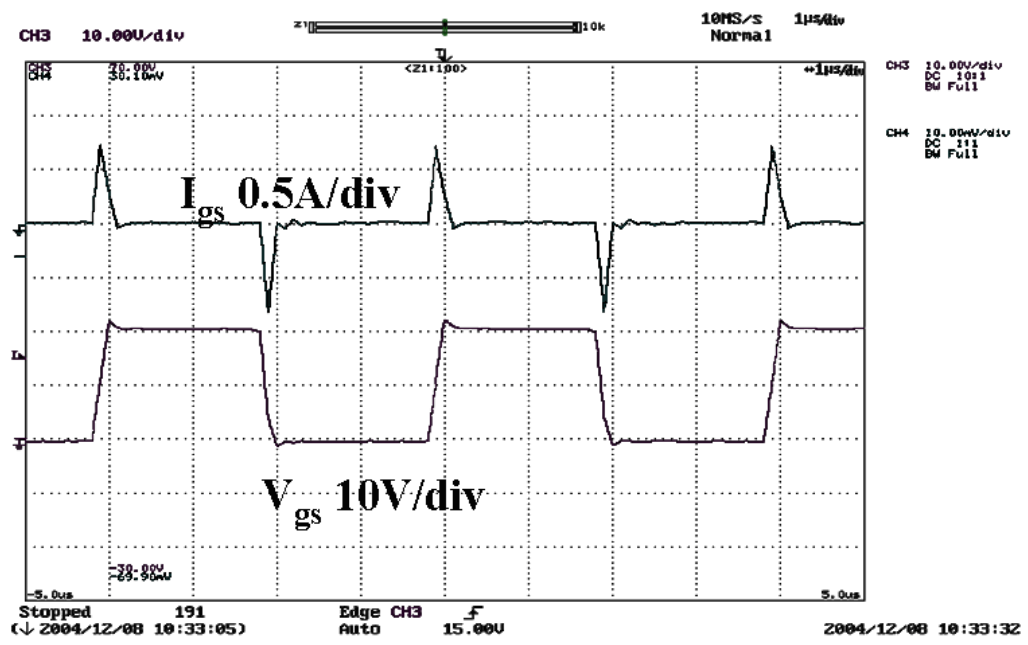

(b) SiC MOSFET

Fig. 2.22. The peak-gate currents and gate-voltage waveforms.

\subsubsection{Dynamic Characteristics}

The gate-drive circuit discussed in the previous section was used to determine the dynamic characteristics of the SiC MOSFET and JFET.

SiC JFETs are normally-on devices and they can be turned off only by applying a negative voltage that is higher than what a typical Si power device requires. Based on the transfer characteristics (Fig. 2.16), the gate drive was designed for a voltage of $-25 \mathrm{~V}$, since that would be enough to turn off most of the samples tested.

When SiC JFETs are operated at high frequencies, they need high peak-gate currents to charge and discharge the gate capacitances faster. For example, $250-\mathrm{kHz}$ switching was achieved with a series-gate resistance of $5.4 \Omega$ and a peak-gate current of $0.38 \mathrm{~A}$. 
The gate voltage and the switching waveforms of the JFET are shown in Fig. 2.23. The device has a turnoff delay $t_{d, \text { off }}$ of $40 \mathrm{~ns}$, fall time $t_{f}$ of $80 \mathrm{~ns}$, turn-on delay $t_{d, o n}$ of $20 \mathrm{~ns}$, and rise time $t_{r}$ of $100 \mathrm{~ns}$.

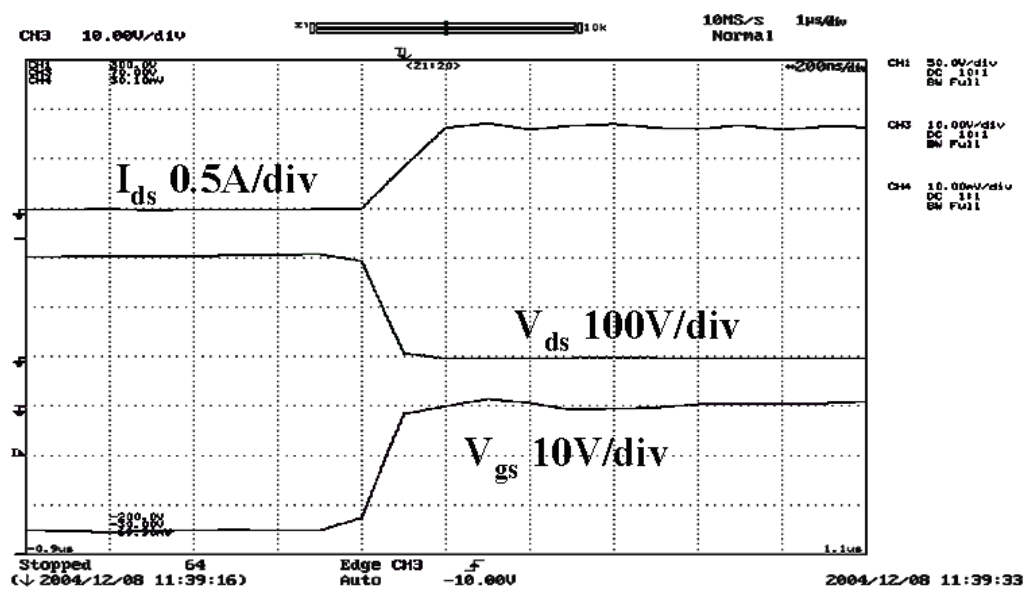

(a)

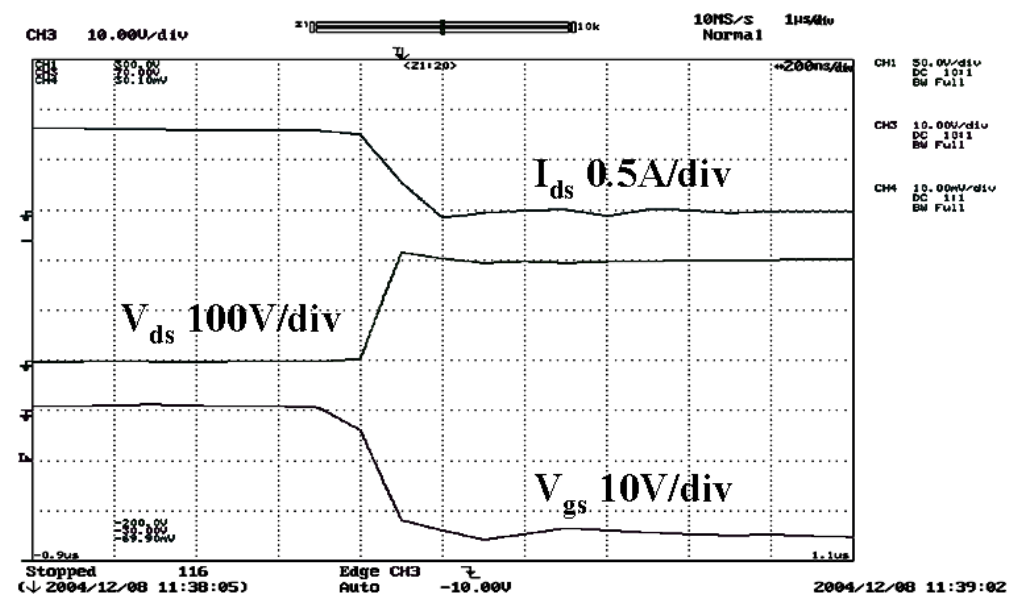

(b)

Fig. 2.23. The gate and switching waveforms of the SiC JFET.

The gate-drive voltage for the MOSFET was selected as $20 \mathrm{~V}$, as determined from the forward characteristics to obtain the optimum performance. The $250-\mathrm{kHz}$ operation was achieved with a seriesgate resistance of $7.2 \Omega$ and a peak-gate current of $0.6 \mathrm{~A}$. The gate and switching waveforms for a $\mathrm{SiC}$ MOSFET are shown in Fig. 2.24. The device has a turn-off delay $t_{d, \text { off }}$ of $40 \mathrm{~ns}$, fall time $t_{f}$ of $100 \mathrm{~ns}$, turnon delay $t_{d, o n}$ of $20 \mathrm{~ns}$, and rise time $t_{r}$ of $100 \mathrm{~ns}$.

Note that both the SiC JFET and the MOSFET show fast dynamic responses, which would be required for high-frequency switching.

The turn-on and turn-off energy losses for both the SiC MOSFET and the JFET were calculated by integrating the instantaneous power over the turn-on $\left(t_{o n}\right)$ and turn-off times $\left(t_{o f f}\right)$. The energy losses calculated for the SiC MOSFET and JFET at different temperatures for a 5-kHz, 50\% duty cycle, $100-\mathrm{V}$, 
0.8-A operation are shown in Fig. 2.25. It is interesting to note that a SiC JFET needs almost no energy to turn on because of its normally-on feature. Another observation from these figures is that the total switching losses do not vary much with temperature.

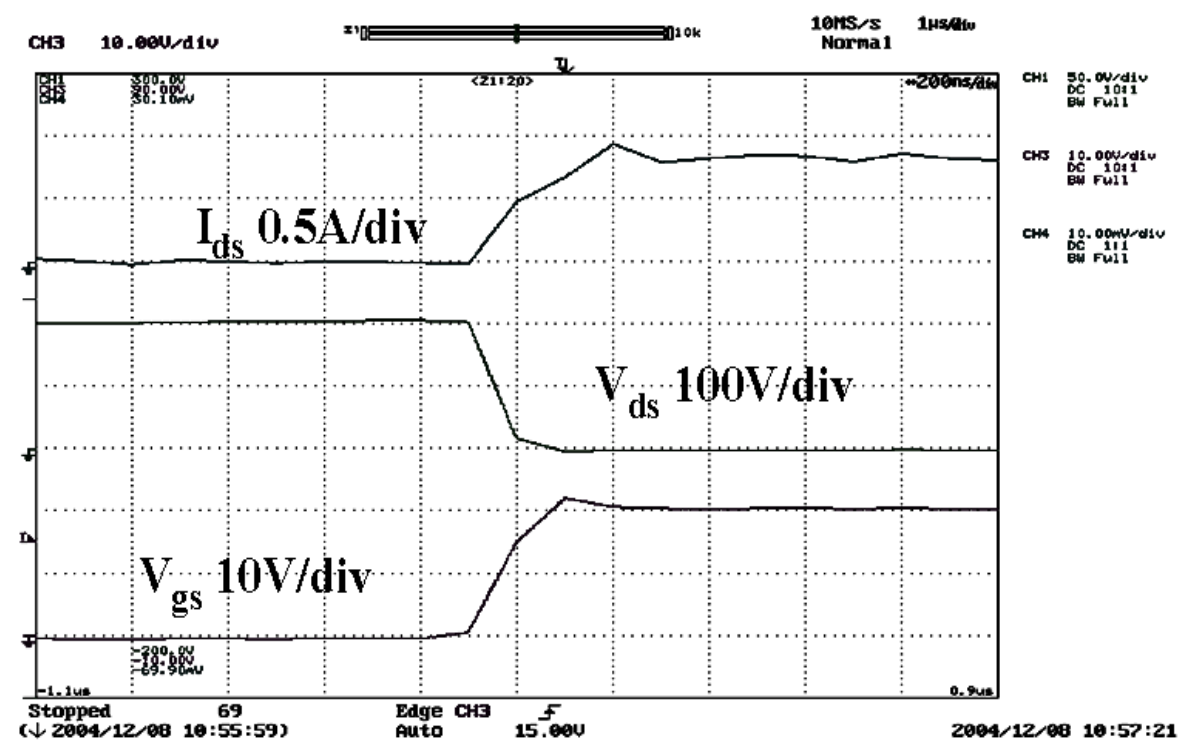

(a)

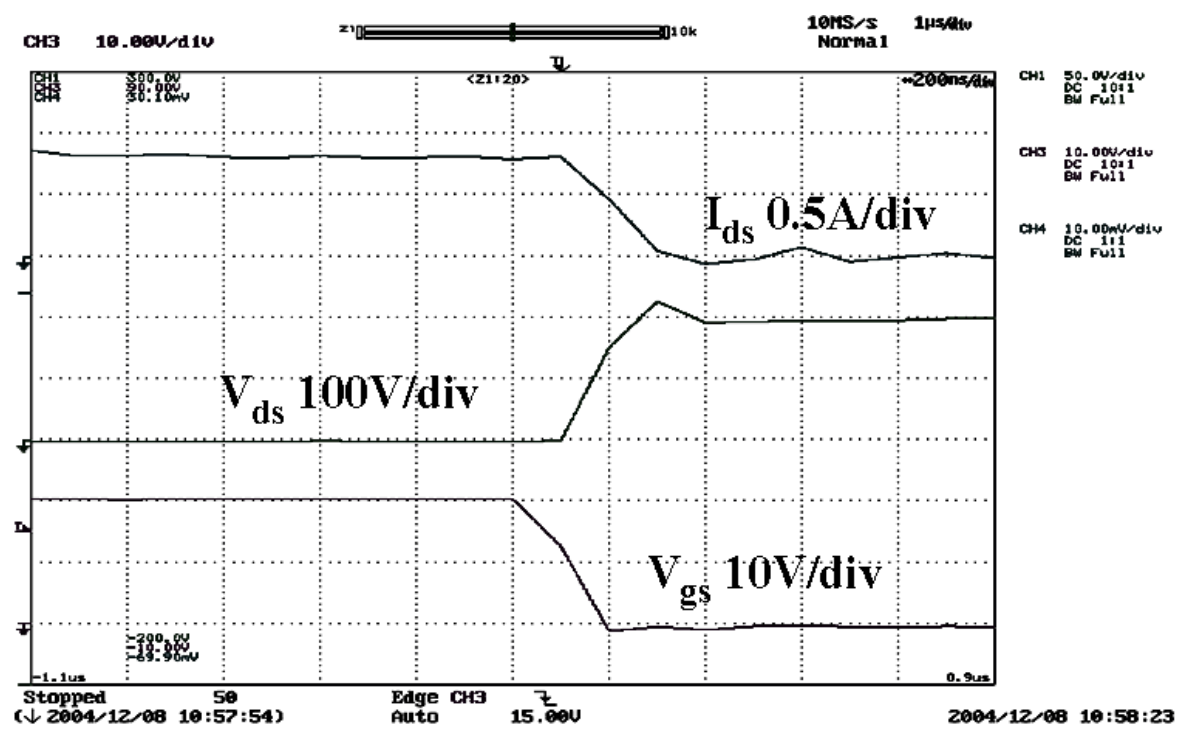

(b)

Fig. 2.24. The gate and switching waveforms of the SiC MOSFET. 


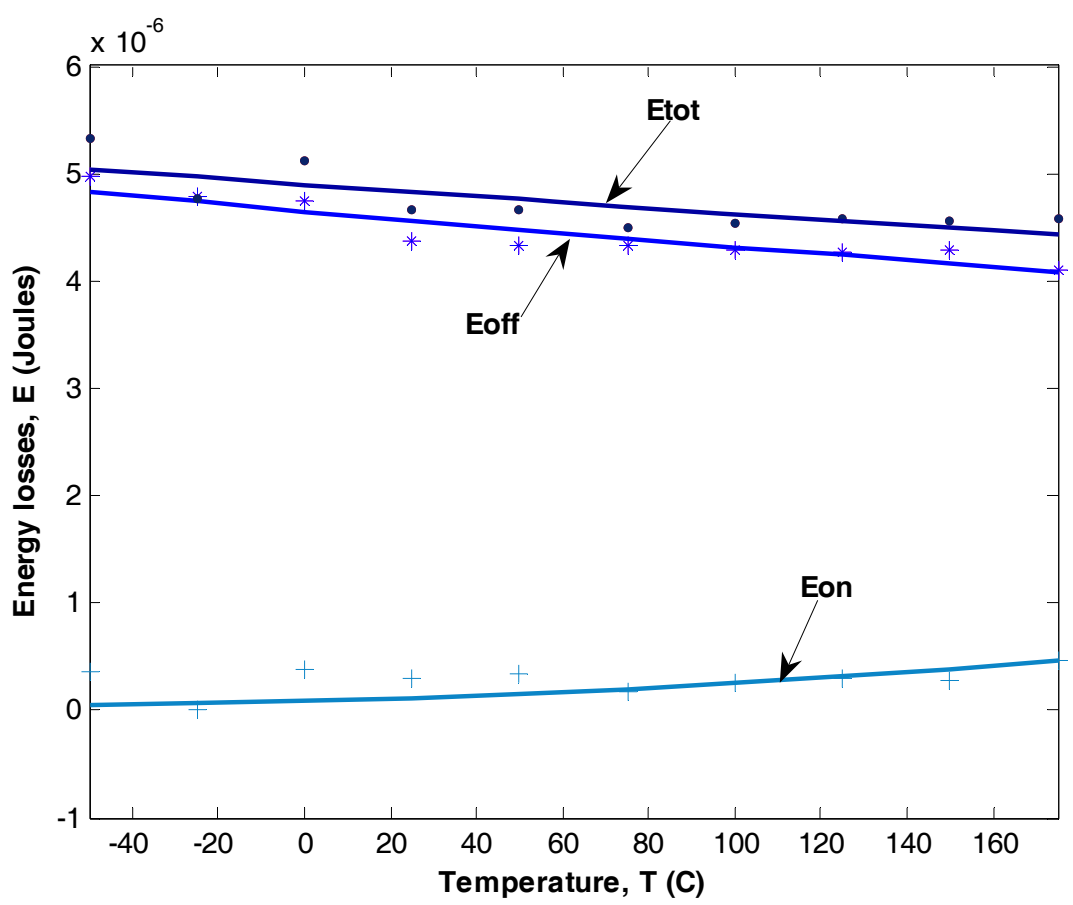

(a) SiC JFET.

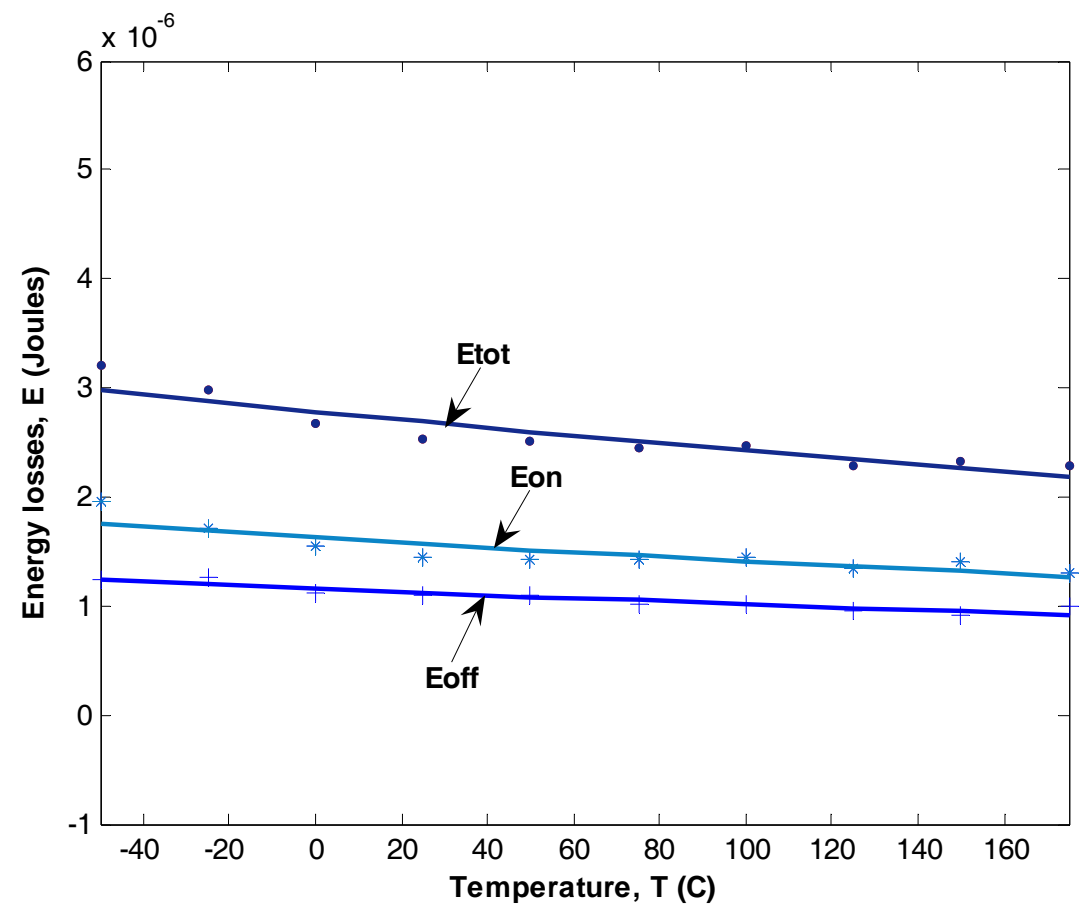

(b) SiC MOSFET.

Fig. 2.25. Energy loss plots. 


\subsection{CONCLUSIONS}

The static and dynamic performances of some SiC Schottky diodes, SiC MOSFETs, and SiC JFETs were analyzed. It was observed that SiC Schottky diodes and JFETs have positive-temperature coefficients. However, SiC MOSFETs display a negative temperature behavior for temperatures below $50^{\circ} \mathrm{C}$ and a positive-temperature coefficient behavior above this value. This is due to the interface-trap defects in the $\mathrm{SiC}$ MOSFET, which will eventually be eliminated with maturing SiC manufacturing technology. SiC Schottky diodes showed excellent reverse-recovery characteristics compared with Si pn diodes. Even though SiC Schottky diodes have higher on-resistances, they exhibit near-perfect switching characteristics, making their performance superior to their Si counterparts. Thus replacing Si devices with comparable SiC Schottky diodes will improve the performance of the power switches in a power converter by reducing the switching stress on the switches and decreasing the overall losses.

The switching losses were almost constant for a wide temperature range for all the SiC unipolar devices presented in this report, showing that $\mathrm{SiC}$ unipolar devices are well suited for high-frequency, hightemperature, and high-power applications. Also, hard-switching circuits at higher power levels and higher frequencies can be realized using $\mathrm{SiC}$ devices because of their excellent switching characteristics. With further improvements in current ratings, SiC MOSFETs can replace Si IGBTs in medium-voltage applications. SiC MOSFETs are preferred over SiC JFETs because of their normally-off feature. However, gate-oxide reliability still remains an issue for SiC MOSFETs. 


\section{HYBRID Si-SiC INVERTER}

\subsection{OBJECTIVE}

The objective is to evaluate the performance of a hybrid Si IGBT-SiC Schottky diode inverter and compare it with the performance of a similar all-Si inverter. The main focus of this project is to study the impact of replacing pn diodes with SiC Schottky diodes in an inverter by performing inductive load and dynamometer tests.

\subsection{WHY A HYBRID INVERTER}

SiC Schottky diodes have been proven to have better performance characteristics than similar Si pn diodes [17], especially with respect to switching characteristics as they have negligible reverse-recovery losses. $\mathrm{SiC}$ devices also can operate at higher temperatures, thereby resulting in reduced heat sink weight and volume. Improved switching performance impacts the main power switches by reducing the stress on them and improving the system performance. SiC Schottky diodes are already commercially available at relatively low current ratings. These diodes are being used in niche applications such as power factor correction circuits. It is expected that the first impact of $\mathrm{SiC}$ devices in inverters will be as a result of $\mathrm{SiC}$ Schottky diodes replacing the Si pn diodes.

Several problems must be addressed to meet the Department of Energy's (DOE's) FreedomCAR and Vehicle Technologies program goals, such as reducing the size and weight of the power electronics and cooling systems and increasing their efficiency. To evaluate the possibility of solving some of these problems using SiC diodes, Oak Ridge National Laboratory (ORNL) collaborated with Cree and Semikron to build a hybrid 55-kW (Si IGBT-SiC Schottky diode) inverter by replacing the Si pn diodes in Semikron's inverter with Cree's SiC Schottky diodes.

\subsection{TESTING AND MODELING THE 75-A DIODE}

For SBDs, the two main tests that need to be performed are testing the static characteristics, consisting of i-v curves, and turn-off testing, from which the reverse recovery of the diode can be evaluated.

\subsubsection{SiC SBD On-State Testing}

SBDs from Cree rated for $75 \mathrm{~A}$ were tested in the TEK 371B curve tracer to obtain the on-state characteristics over a range of temperatures $\left(-55^{\circ} \mathrm{C}\right.$ to $\left.175^{\circ} \mathrm{C}\right)$. The diode was placed in an oven (connected through high-temperature wires) to evaluate the temperature characteristics. Since this is a high-current device, the voltage drops across the connecting wires become significant. The resistance was found to be $0.073 \Omega$, and corresponding voltage drops across the wires were subtracted from the raw data, thereby yielding the true voltage drop across the diode.

As seen in Fig. 3.1, the built-in potential (or the knee voltage) decreases with the increase in temperature because the increasing thermal energy of electrons in the metal overcomes the Schottky barrier height at a lower forward voltage. It can also be seen that there is a decrease in the slope of the on-state characteristics with a temperature increase. This is because of the reduction in mobility, or increase in onresistance, that is typically seen in a majority-carrier device and is a sign of a positive-temperature coefficient. 


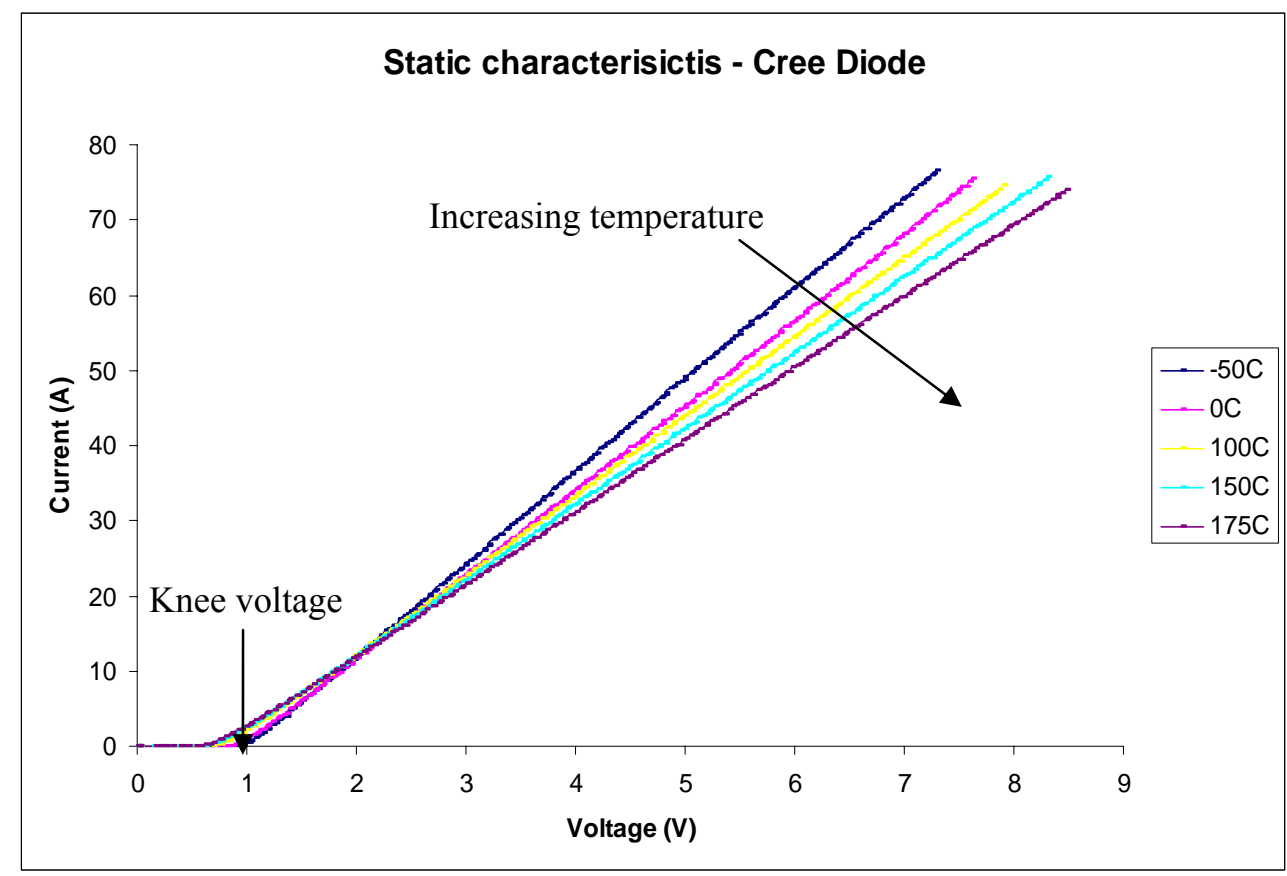

Fig. 3.1. i-v characteristics of the 75-A SiC diode from Cree.

\subsubsection{SiC Diode Modeling}

The SiC diode model used in this project was developed at the University of Arkansas. It is a robust model that can accurately model forward and reverse recovery accurately over temperature. Moreover, many details pertaining to the fabrication of the diode need not be known by the user, making parameter extraction flexible. Figure 3.2 shows the topology of the $\mathrm{SiC}$ power-diode model.

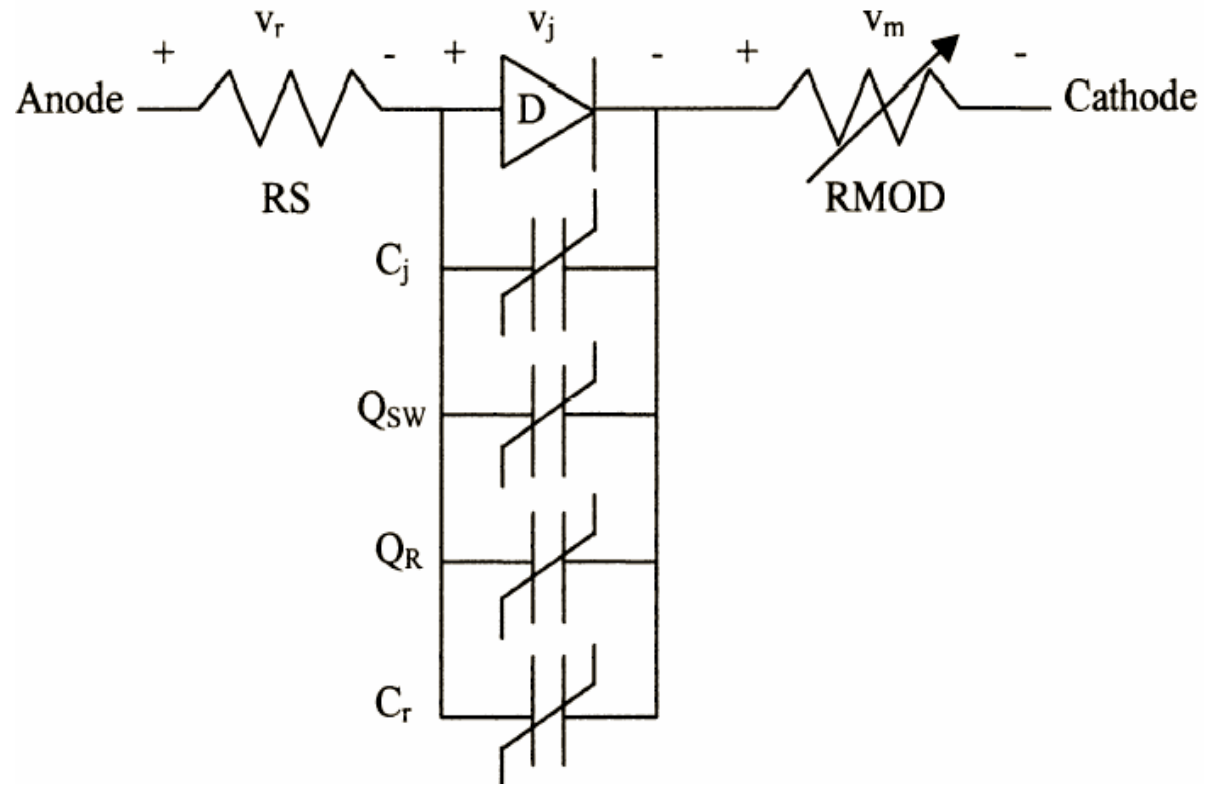

Fig. 3.2. Model topology of the power diode [18]. 
The model described is a "unified" one in that it can model pn, Schottky, and merged pn-Schottky diodes. Therefore, all the features will not be turned on for modeling the Schottky diode for this research effort. Some of the variables seen in Fig. 3.2 do not pertain to Schottky diodes and are therefore not explained.

For modeling the static characteristics, the diode uses several equations of the form

$$
i=\operatorname{IS}\left(e^{\frac{V_{j}}{N \cdot V_{T}}}-1\right)
$$

where $I S$ is the saturation current, $V_{j}$ is the forward diode junction voltage, $N$ is the emission coefficient, and $V_{T}$ is the thermal voltage $(k T / q)$. There are different regions in the diode operation, such as high- and low-level injections and recombination, all of which are modeled with similar equations. Moving boundary conditions are used to model the dynamic characteristics such as turn-on, turn-off, and reverse recovery.

To incorporate temperature effects, Eq. (3.1) is altered as follows

$$
I S(T)=I S(T N O M) \cdot(T / T N O M)^{X T I} \cdot e^{[(T / T N O M)-1] \cdot(E G / N T . V T)},
$$

where $T$ is the user defined temperature, TNOM is room temperature, and $X T I$ is the temperature compensation factor.

Such normalized temperature-based factors are used in all the equations that need to scale with temperature.

\subsubsection{Parameter Extraction and Model Validation Using the Characterized Data for Diodes}

The model was constructed in MAST HDL and simulated in the Saber simulator. The de test-bench consists of a constant dc source connected to the SiC diode model. The physical and structural parameters of the diode are first determined at the nominal temperature. The P-N grading coefficient, $M$, is set to the default value of 0.5 . The parameters $R S$ (series resistance), ISR (low-level recombination saturation current), and $N R$ (low-level recombination emission coefficient) can be extracted from the forward onstate characteristics. For Schottky diodes, $N R$ is typically set to 1 . The forward series resistance, $R S$, can be obtained directly from the inverse of the slope of the on-state current versus the voltage characteristic at high to medium currents. After $R S$ is extracted, the diode current versus internal-junction voltage $\left(V_{j}=\right.$ $\left.V_{D}-I_{D} \cdot R S\right)$ is calculated with the measured data. An $I_{D}$ versus $V_{j \text { semi- }} \log$ plot is then used to extract $N R$ and $I S R$ as follows

$$
2.3 \log I_{D}=2.3 \log I S R+2.3 V_{j} /\left(N R \cdot V_{T}\right)
$$

The y intercept of the semi-log plot gives the value of $I S R$. The temperature-dependent parameters are then extracted. The saturation current, ISR's temperature exponent XTIR, is extracted using the low forward current characteristic over a range of temperatures. The decrease in slope of the on-state characteristics as temperature increases is used to extract the parameters representing the temperature dependency of the series resistance $R S$. In other words, $R S$ is extracted for each on-state curve for all temperatures. The values of the extracted $R S$ for each temperature are then used in Eq. (3.4) to optimize the values of the exponential GAMMA, linear TRS1, and quadratic TRS2 temperature parameters for $R S$.

$$
R S(T)=R S(T N O M) \cdot\left[(T / T N O M)^{\gamma}+T R S 1(T-T N O M)+T R S 2(T-T N O M)^{2}\right]
$$


After the parameters are extracted from the on-state characteristics, the depletion and package capacitance are then extracted from the reverse-recovery waveforms. For Schottky diodes, the absence of stored charge reduces the reverse recovery to just the charging of the depletion and package capacitances. After the diode current crosses zero, the voltage is seen to rise as the depletion and package capacitances are charged. The initial peak in the reverse recovery is due to the junction capacitance, as the depletion region is narrow and is accounted for in the model by $C J 0$ and $F C$ (forward bias-depletion capacitance coefficient); while the further increase in the negative reverse current as the diode voltage rises is due to the package capacitance $(C P)$. At high voltages, the depletion region decreases, and therefore the package capacitance dominates. Therefore, $C P$ is extracted from the high-voltage part of the reverse-recovery waveform. Care should be taken to ensure that the voltage waveforms from which $C J 0$ and $C P$ are extracted are aligned and have the same $d v / d t$.

\subsection{SCHOTTKY DIODE AT DIFFERENT TEMPERATURES}

The on-state validation of the model with the $\mathrm{SiC} 75-\mathrm{A}$ diode from Cree is seen in Fig. 3.3. The percentage error is approximately $0.3-0.4 \%$ in the $100^{\circ} \mathrm{C}$ and $150^{\circ} \mathrm{C}$ curves and approximately $2-3 \%$ in the $25^{\circ} \mathrm{C}$ curve.

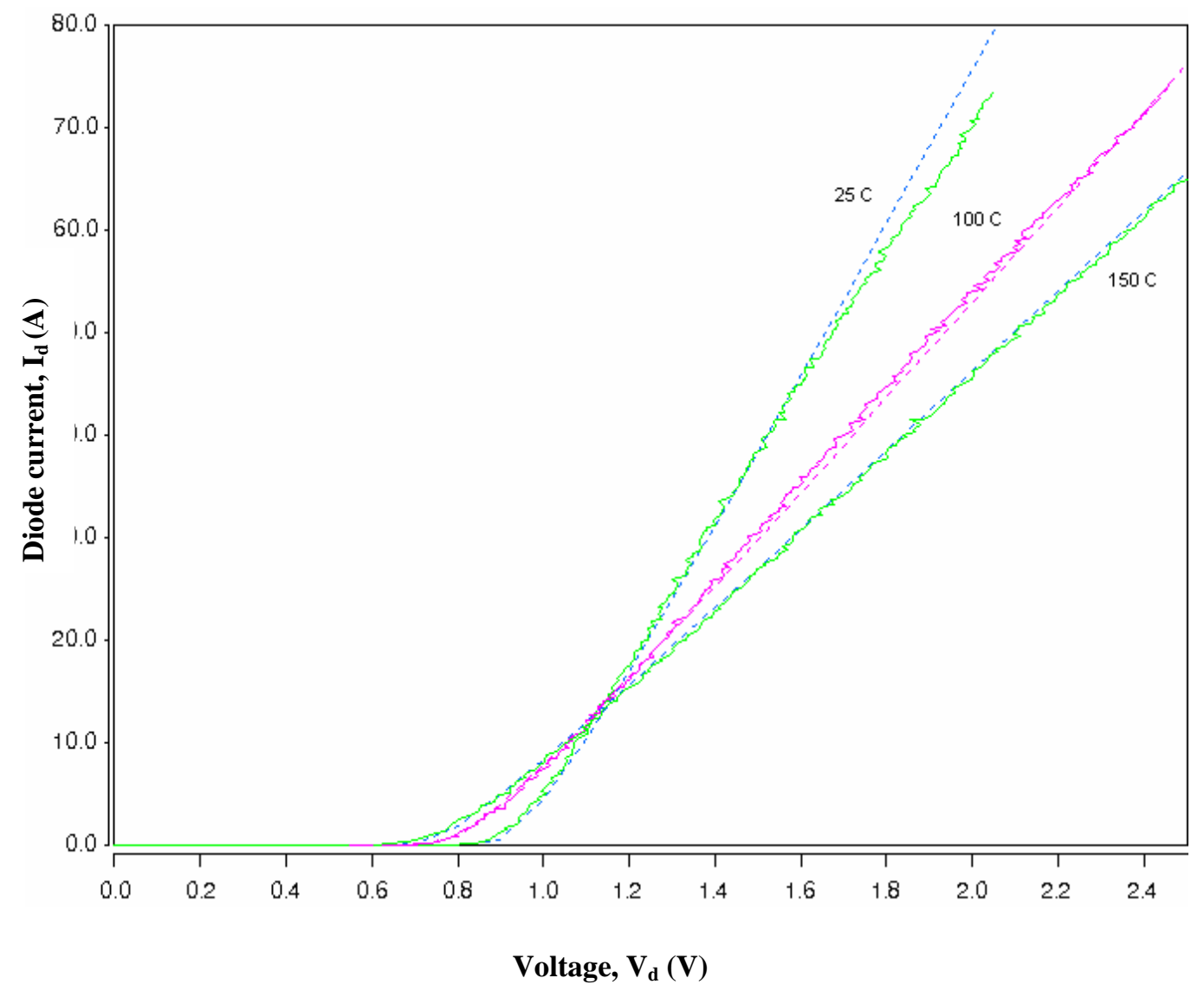

Fig. 3.3. Measured (solid) and simulated (dotted) on-state waveforms of the SiC Schottky diode at different temperatures.

Figure 3.4 shows the reverse recovery of the $\mathrm{SiC}$ diode and the corresponding behavior of the model (in dotted lines) with the extracted $C J 0$ parameter. The model is accurately tracking the test data. 


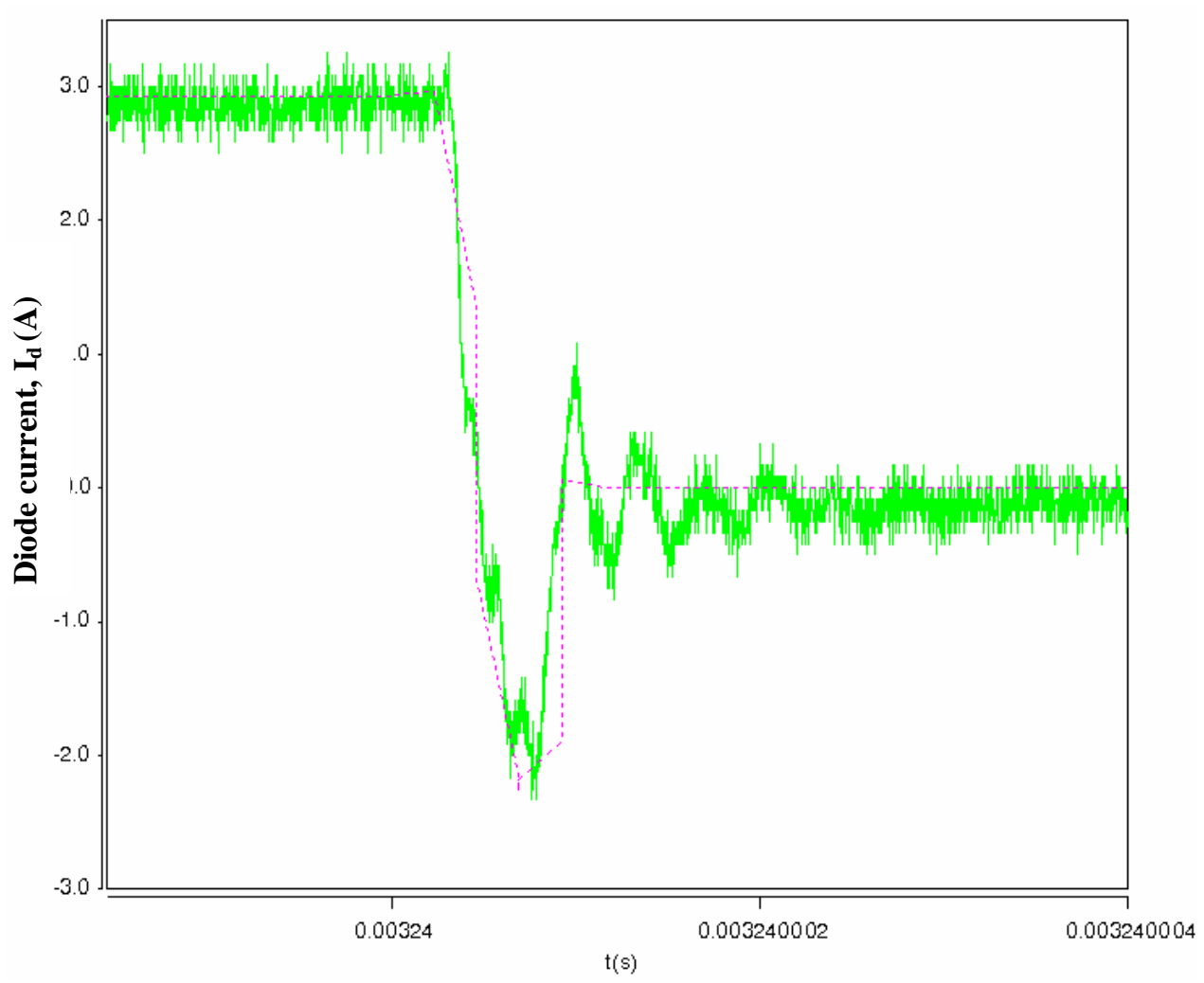

Fig. 3.4. Measured (solid) and simulated (dotted) reverse-recovery waveforms of the SiC Schottky diode from Cree.

The junction capacitance can then be extracted from the reverse-recovery data that essentially determines the switching speed and the peak-reverse-recovery current of the device. In Fig. 3.5, the effect of the junction capacitance can be seen on the reverse-recovery current. It can be easily deduced that the peakreverse-recovery current is directly proportional to the diode-junction capacitance. 


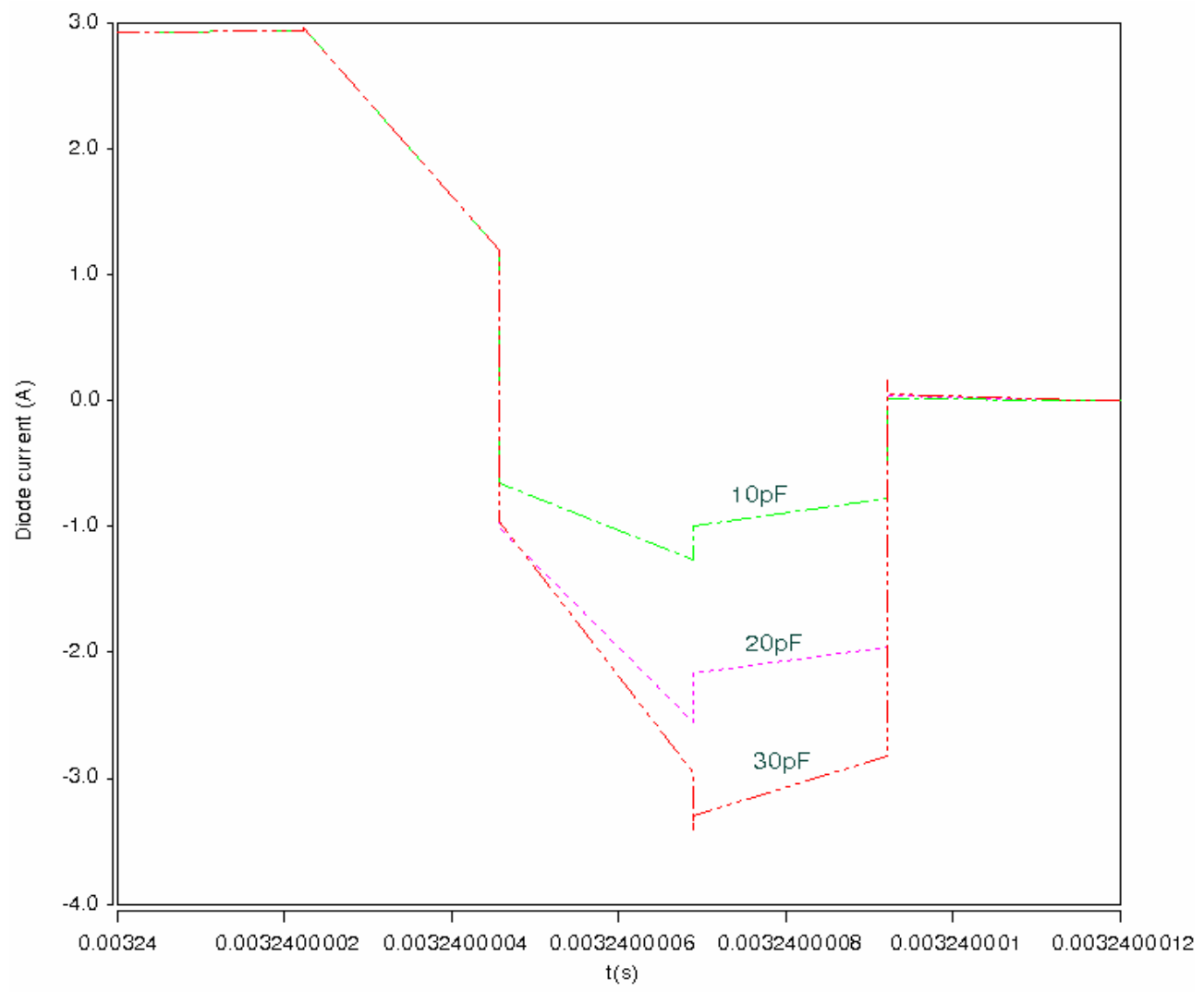

Fig. 3.5. Simulation showing the reverse-recovery current in a SiC diode for different values of junction capacitances.

\subsection{SIMULATION OF Si IGBT-SiC SCHOTTKY DIODE HYBRID INVERTER}

After the modeling and parameter extraction of the devices, the device models were used to construct a three-phase voltage-source inverter in Saber. The Saber Sketch software in the suite was used. The model closely emulated the prototype inverter from Semikron in terms of the inverter topology. The switching frequency was set to $10 \mathrm{kHz}$. Library models were used for the comparators, voltage sources, and passive elements. A graphical representation of the SiC Schottky diode model was created which can be interfaced directly with other library elements instead of manually creating net lists. The modulating sine wave had a frequency of $75 \mathrm{~Hz}$, which was therefore the frequency of the output current. The IGBT that was used for constructing the Semikron inverter was not available in the Saber library. Therefore, another IGBT with similar ratings was used as the transistor switch instead. The load consisted of a 1.24- $\Omega$ resistor and a $1.5-\mathrm{mH}$ inductor. The input dc bus voltage was set at $325 \mathrm{~V}$. The inverter topology is shown in Fig. 3.6. 


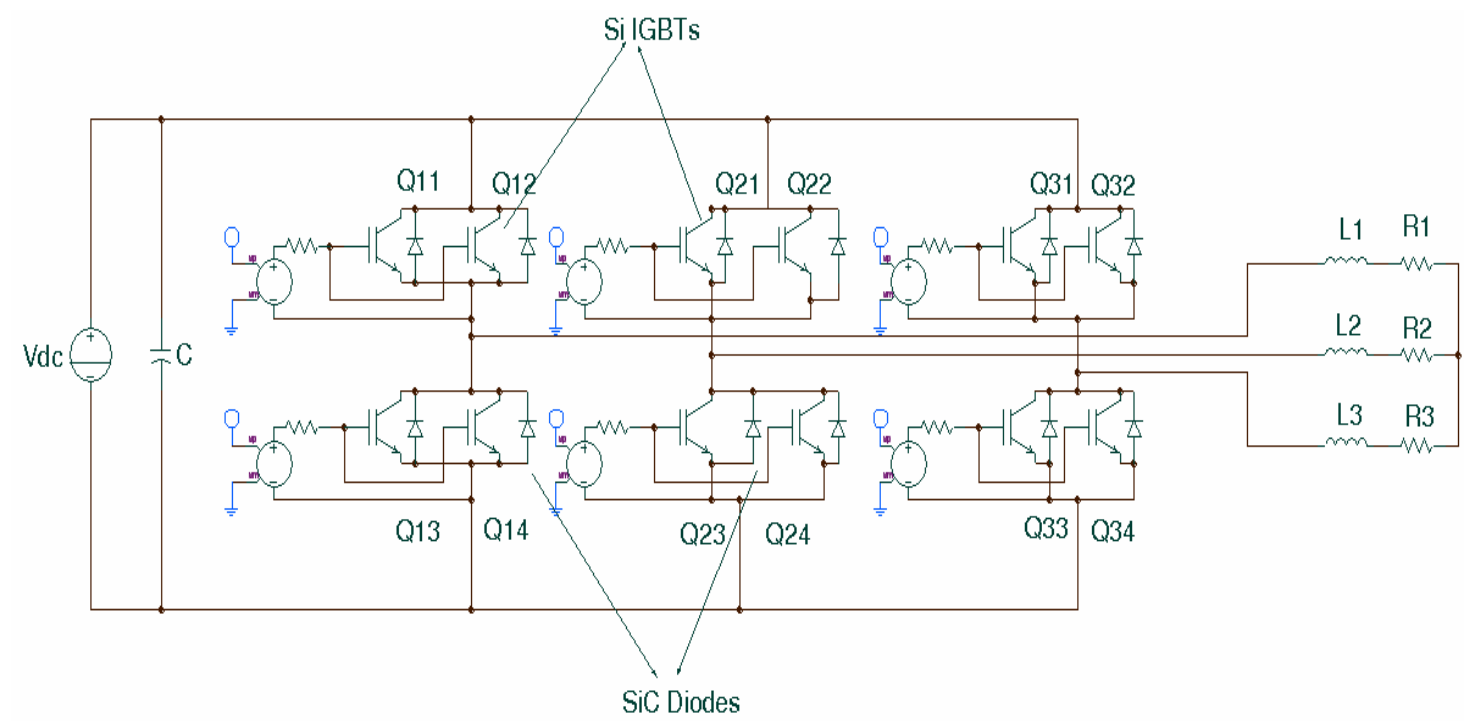

Fig. 3.6. Schematic representation of the hybrid inverter in Saber.

Table. 3.1. SiC power diode model parameters and extraction characteristics for the Cree 75-A diode

\begin{tabular}{|c|l|l|c|}
\hline Parameter & \multicolumn{1}{|c|}{ Parameter name } & \multicolumn{1}{c|}{ Extraction characteristic } & Value \\
\hline$E G$ & Bandgap & Device-specific & 1.6 \\
\hline$V J$ & Built-in junction potential & Device-specific & 1.5 \\
\hline$C J 0$ & Zero-bias junction capacitance & Device-specific & $20 \mathrm{pF}$ \\
\hline$M$ & P-N grading coefficient & Device-specific & 0.5 \\
\hline$F C$ & Forward-bias deletion capacitance coefficient & Device-specific & 0.5 \\
\hline$N B$ & Base doping concentration & Device-specific & $1 \mathrm{e}^{15}$ \\
\hline$R S$ & Forward series contact resistance & $\begin{array}{l}\text { High- to medium-current on- } \\
\text { state slope }\end{array}$ & 0.013 \\
\hline$I S R$ & Low-level recombination saturation current & Low-current on-state region & $5 \mathrm{e}^{-16}$ \\
\hline$N R$ & Low-level recombination emission coefficient & Low-current on-state region & 1 \\
\hline$X T I R$ & $I S R$ temperature exponent & Low-current on-state vs. T & 3 \\
\hline$T N R 1$ & Linear $N R$ temperature coefficient & Low-current on-state vs. T & 0 \\
\hline$T N R 2$ & Quadratic $N R$ temperature coefficient & Low-current on-state vs. T & 0 \\
\hline$T R S 1$ & Linear $R S$ temperature coefficient & $\begin{array}{l}\text { High- to medium-current on- } \\
\text { state slope vs. T }\end{array}$ & $-14 \mathrm{e}^{-3}$ \\
\hline$T R S 2$ & Quadratic $R S$ temperature coefficient & $\begin{array}{l}\text { High- to medium-current on- } \\
\text { state slope vs. T }\end{array}$ & $-16 \mathrm{e}^{-6}$ \\
\hline$G A M M A$ & $R S$ temperature exponent & $\begin{array}{l}\text { High- to medium-current on- } \\
\text { state slope vs. T }\end{array}$ & 2.5 \\
\hline
\end{tabular}

An all-Si inverter with Si IGBTs and diodes was also simulated using the device parameters in Table 3.1. The load currents and a single-phase voltage from the simulations are shown in Figs. 3.7 and 3.8, respectively. The efficiencies of the inverter obtained during simulations are shown in Table 3.2. Table 3.3 shows the modulation index used and the resulting inverter efficiencies of the inverter. Note that the Si IGBT-SiC Schottky diode hybrid has much better efficiencies than the all-Si inverter. 


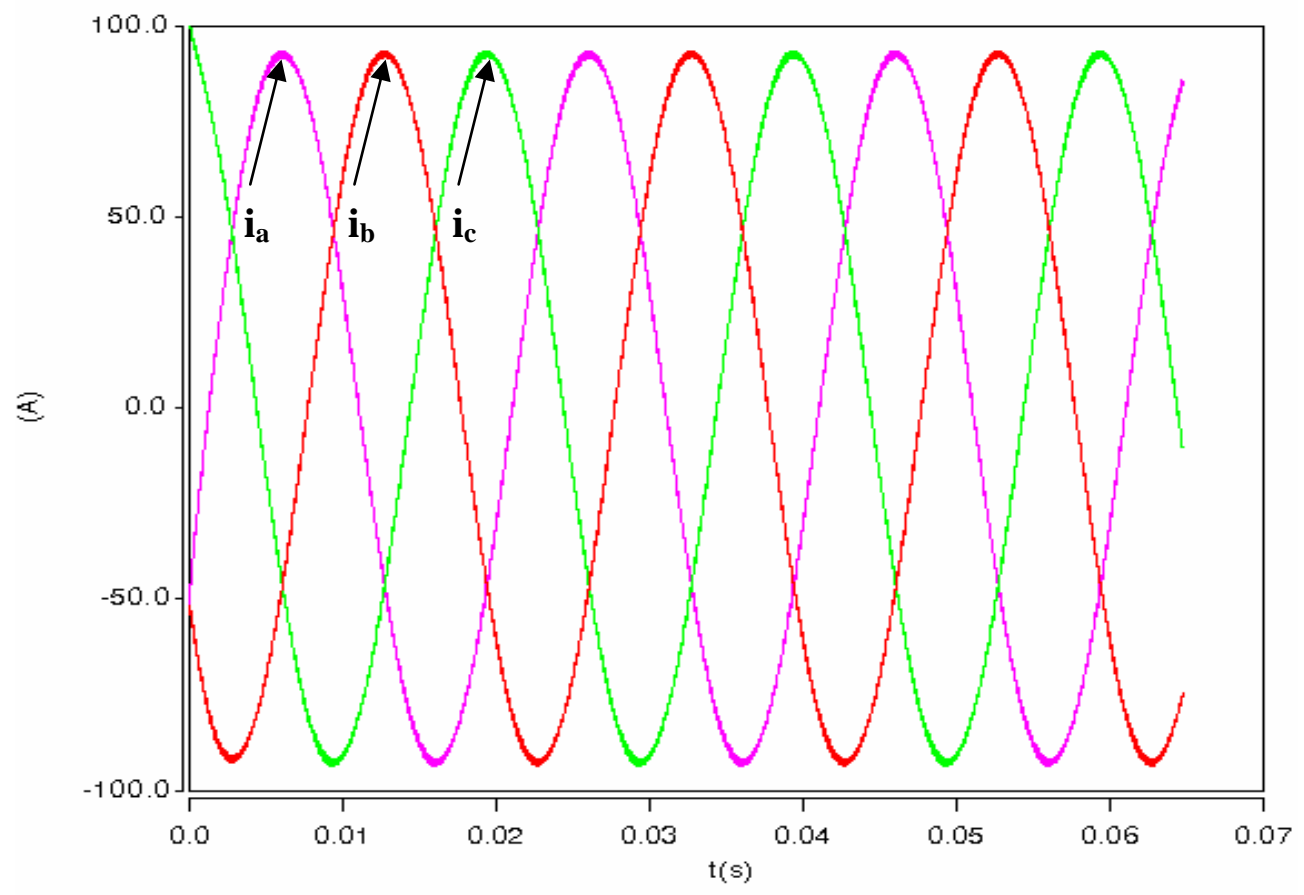

Fig. 3.7. Simulated three-phase load currents in the hybrid inverter.

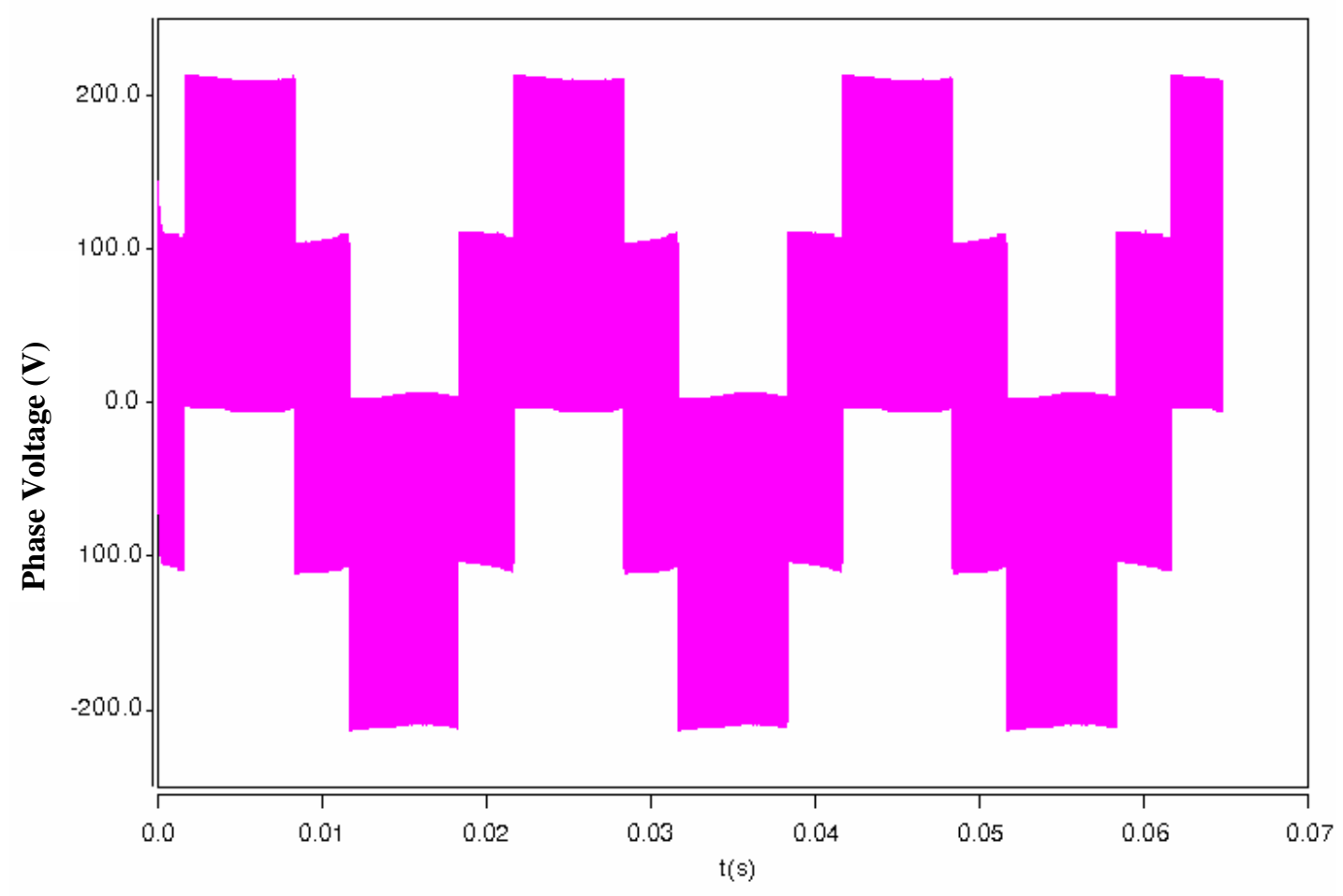

Fig. 3.8. Simulated phase voltage (phase 1) in the hybrid inverter. 
Table 3.2. Efficiencies of the hybrid inverter obtained from simulation

\begin{tabular}{|c|c|c|}
\hline Modulation index & $\begin{array}{c}\text { Peak power output } \\
\text { from simulation } \\
\text { (kW) }\end{array}$ & $\begin{array}{c}\text { Efficiency (simulation) } \\
\text { percent }\end{array}$ \\
\hline 0.572671 & 41.65 & 93.54 \\
\hline 0.700348 & 48.43 & 94.27 \\
\hline 0.801846 & 54.97 & 95.15 \\
\hline 0.899974 & 62.88 & 96.27 \\
\hline 0.985006 & 68.92 & 97.36 \\
\hline
\end{tabular}

Table 3.3. Efficiencies of the all-Si inverter obtained from simulation

\begin{tabular}{|c|c|c|}
\hline Modulation index & $\begin{array}{c}\text { Peak power output } \\
\text { from simulation } \\
\text { (kW) }\end{array}$ & $\begin{array}{c}\text { Efficiency } \\
\text { (simulation) percent }\end{array}$ \\
\hline 0.586299 & 40.33 & 92.07 \\
\hline 0.710617 & 48.17 & 93.48 \\
\hline 0.821163 & 54.43 & 94.41 \\
\hline 0.910835 & 61.77 & 95.14 \\
\hline 1.001043 & 68.09 & 96.53 \\
\hline
\end{tabular}

The simulation and testing was performed for all conditions with a constant dc supply of $325 \mathrm{~V}$. The instantaneous-power output from the inverter is shown in Fig. 3.9. The peak-power output can also be gauged from the output-power plot. The hybrid inverter was found to have a peak-instantaneous-power output ranging from 41-69 kW, depending on the amplitude modulation index. When the amplitude modulation index was set at 0.8 , the peak-power output was found to be $55 \mathrm{~kW}$.

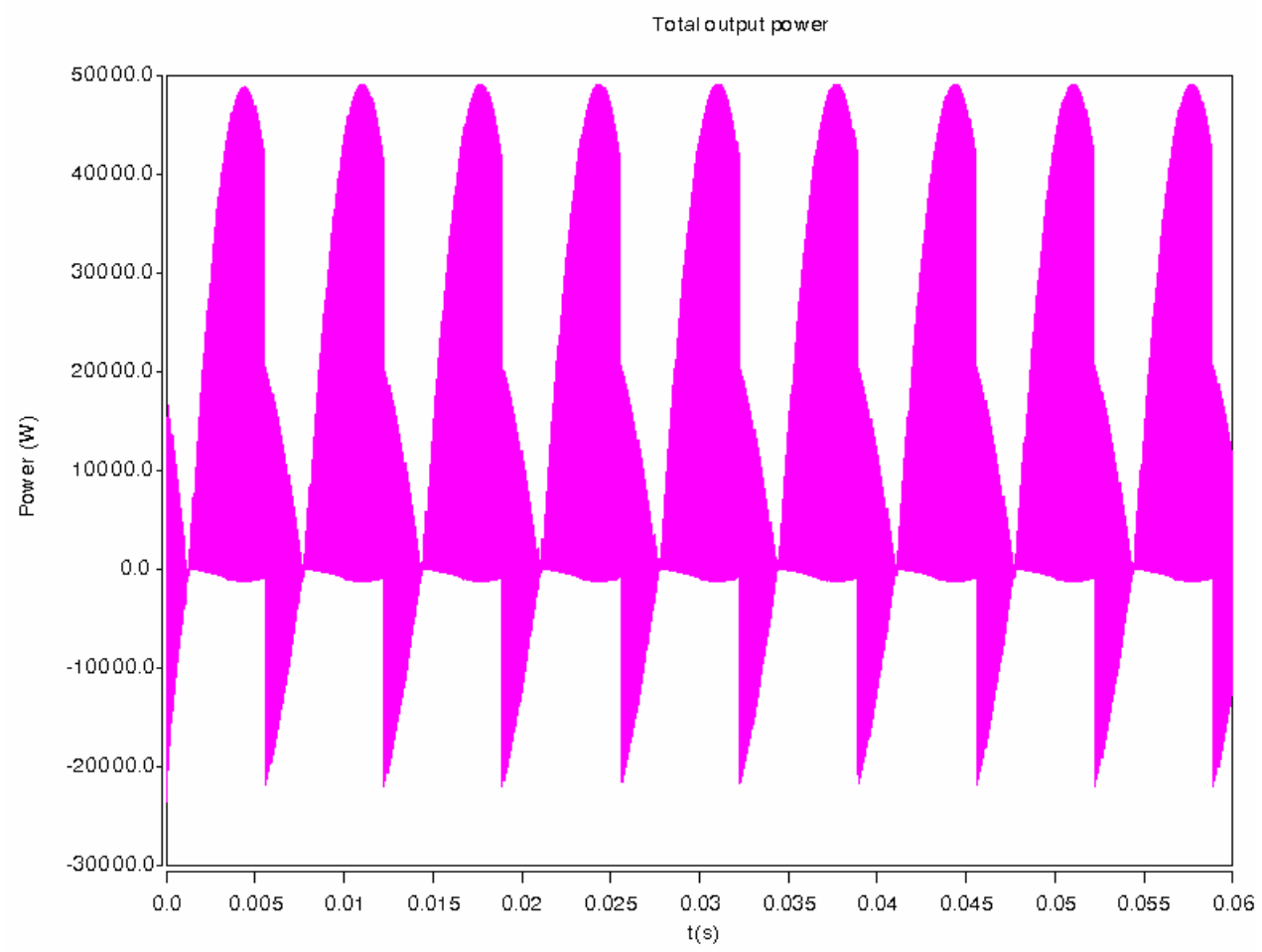

Fig. 3.9. Total instantaneous output power from the three phases of the hybrid inverter. 
The difference in efficiencies between the simulated inverters is clearly visible in Figs. 3.10 and 3.11. When the Si diode in the all-Si inverter was replaced with the SiC Schottky diode, a $1.5-2 \%$ increase in the operational efficiency was observed.

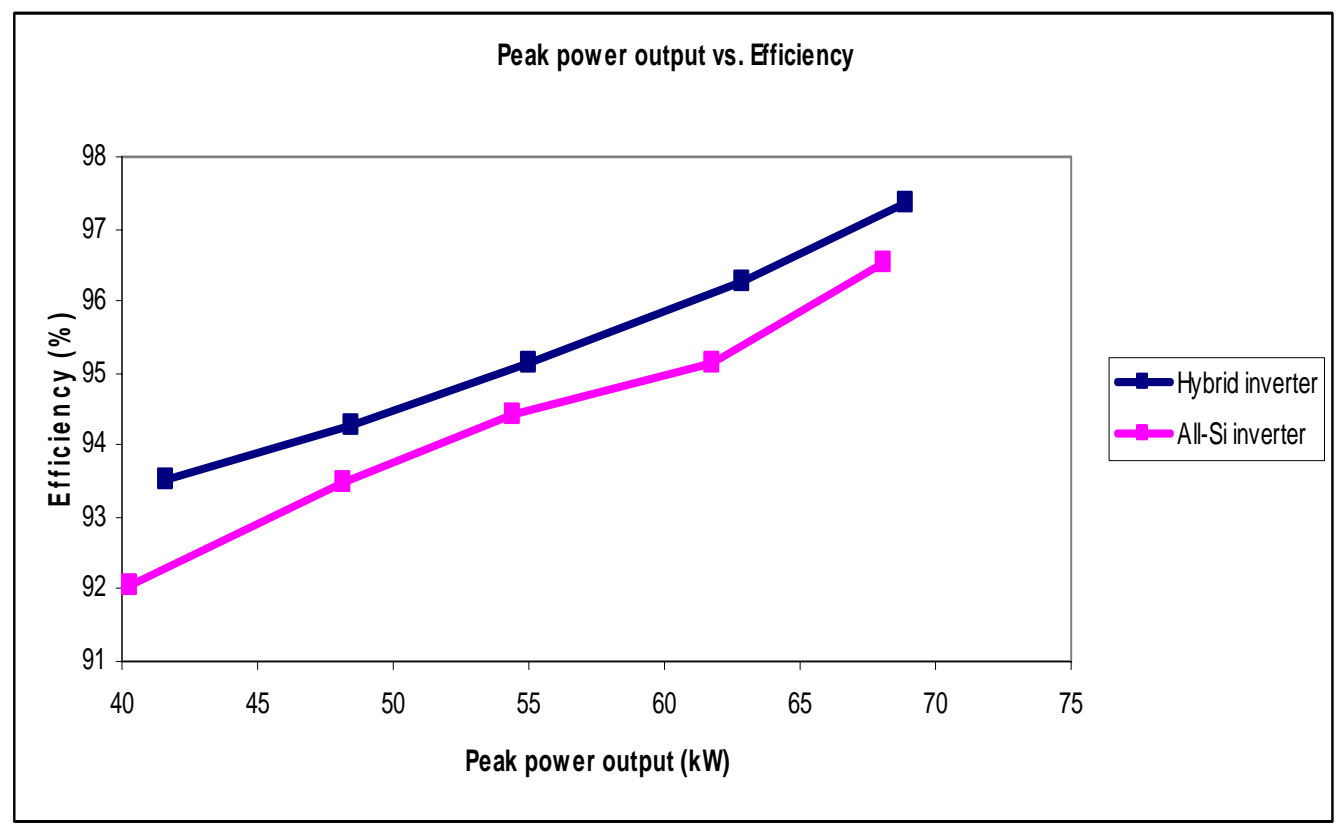

Fig. 3.10. Comparison of peak-power output vs. efficiencies for hybrid and all-Si inverter.

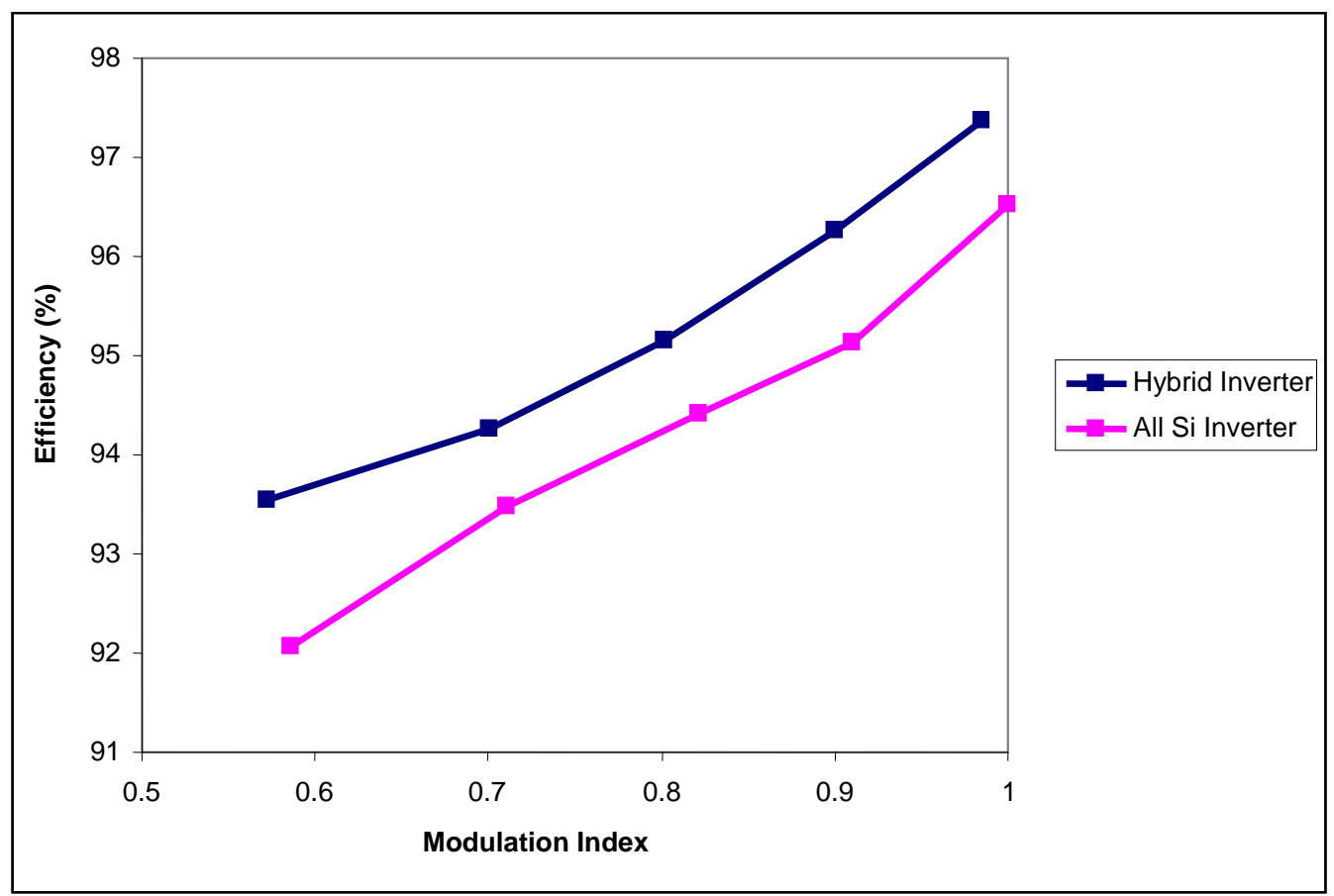

Fig. 3.11. Comparison of efficiencies (from simulation) of hybrid and all-Si inverter. 


\subsection{CONFIGURATION OF THE INVERTER}

The inverter module SKAI (Semikron Advanced Integration) from Semikron was developed for hybrid electric vehicle traction drives. It is a three-phase 55-kW inverter unit (Figs. 3.12 and 3.13) built using $600-\mathrm{V}, 600-\mathrm{A}$ IGBT and 600-V, 450-A pn diode modules. Cree has developed 75-A, 600-V, $4 \times 6.65 \mathrm{~m}$ $\mathrm{SiC}$ Schottky diodes as shown in Fig. 3.14. The 3-in. wafer is also shown in Fig. 3.14. The yield for the wafer was about $46.7 \%$, with 67 good devices from the wafer. Semikron has replaced each Si pn diode $(9 \times 9 \mathrm{~mm})$ in its automotive integrated power module (AIPM) with two 75-A SiC Schottky diodes.

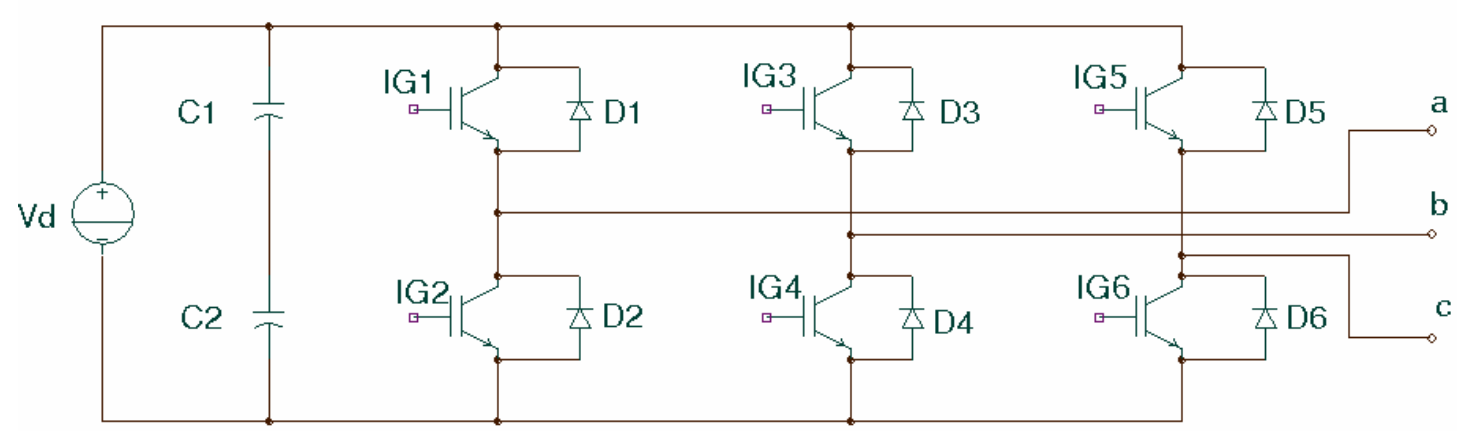

Fig. 3.12. Inverter topology.

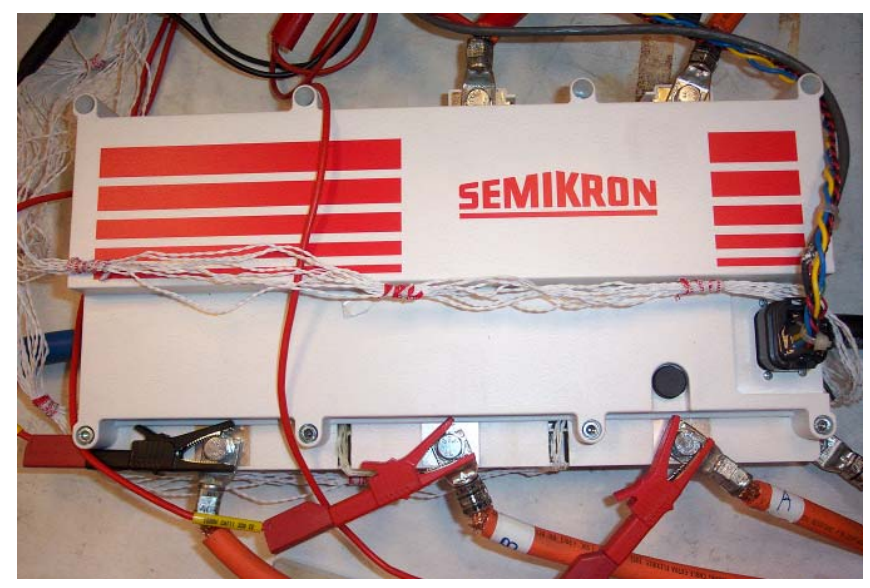

Fig. 3.13. Semikron inverter unit.
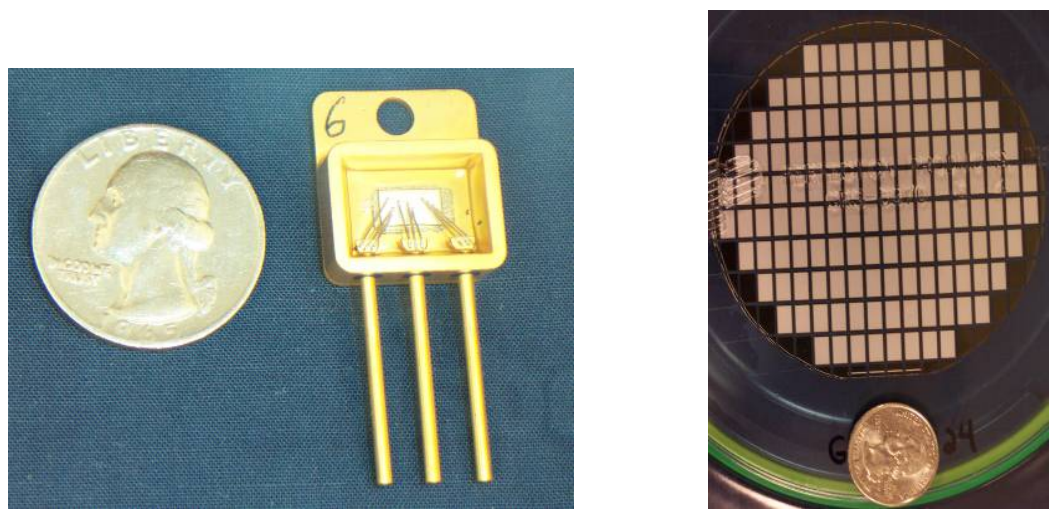

Fig. 3.14. 75-A Schottky diodes developed by Cree. 
The inverter is liquid-cooled with a recommended coolant-flow rate of 2.5 gal per minute (gpm). The Semikron unit shown in Fig. 3.13 is roughly rectangular in shape, but it has irregular dimensions and weighs approximately $17 \mathrm{lb}(7.7 \mathrm{~kg})$. The maximum length, including mounting flanges and hose connections, is 17.6 in. (449 mm). Excluding the mounting flanges and hose connections, the unit measures $16.1 \mathrm{in} .(410 \mathrm{~mm})$. The maximum width of the unit is $8.2 \mathrm{in} .(210 \mathrm{~mm})$ and the minimal width is $7.2 \mathrm{in.}(185 \mathrm{~mm})$. The maximum height of the unit is about 4 in. $(100 \mathrm{~mm})$. The volume of the unit is approximately $6.9 \mathrm{~L}$. The unit has built-in current sensors and dc-link capacitors. It has a CAN bus interface with a built-in digital signal processor (DSP) controller and gate drivers.

The control system implemented uses indirect field-oriented control techniques with a closed-current loop feedback. The speed and torque controls are achieved by a space vector pulse-width modulation (SVPWM) control scheme with current and speed as feedback parameters. A control-system block diagram is shown in Fig. 3.15 [19]. The control firmware module was provided by Semikron with user interface software as shown in Fig. 3.16. Different modes of operation are possible with the controller.

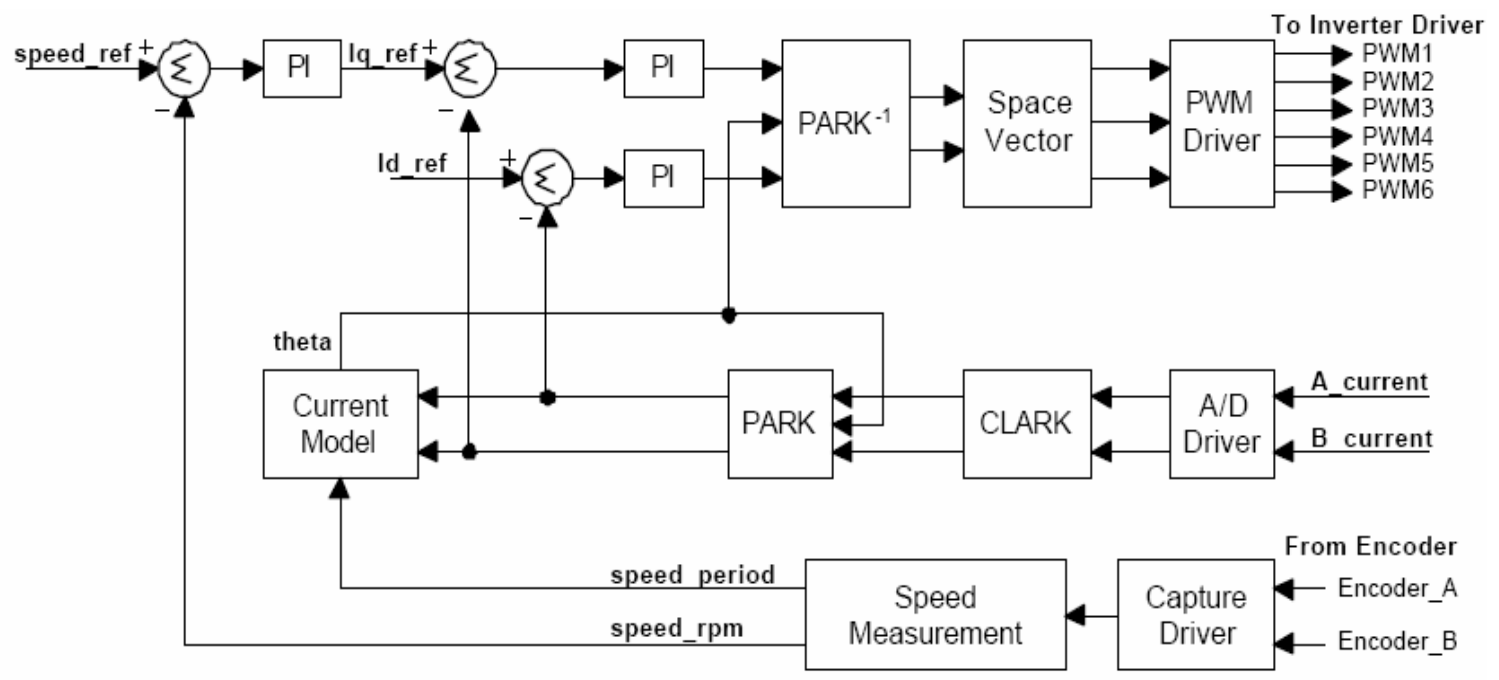

Fig. 3.15. Block diagram of the control system. 


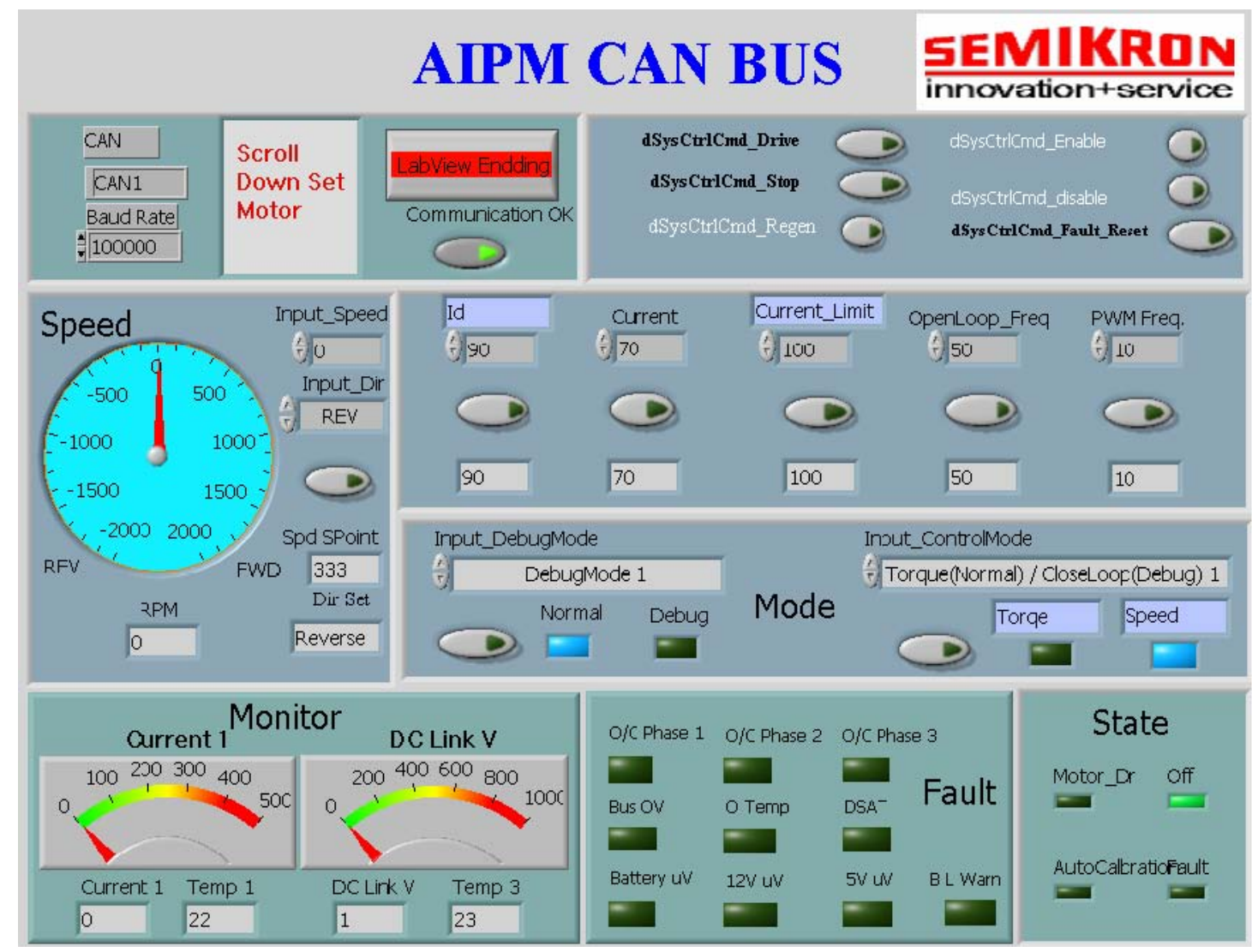

Fig. 3.16. A screen shot of the user interface software.

\subsubsection{Normal Mode}

The controller operates as a closed-loop system and has two control modes

- Speed mode

- Torque mode

\subsubsection{Debug Mode}

The controller operates as an open-loop system, and the pulse-width modulation (PWM) frequency and the open-loop frequency can be adjusted. There are several user control parameters that can be accessed through the software interface to set the values for different operating conditions. A fault monitoring system provides protection to the system from faults such as over-current, bus over-voltage, overtemperature, and desaturation.

\subsection{INVERTER TESTING}

There are two major tests to be performed, an R-L load test to evaluate the inverter's power handling capability and the dynamometer test for dynamic performance. Both the hybrid inverter and the all-Si inverter were tested with the same procedure. As discussed in the previous section, the modes of operation were controlled using the manufacturer-supplied user interface software. The inverter efficiency curves were obtained using the speed mode of operation, and the power handling capability was tested 
using the debug mode of operation. The coolant temperature of the inverter was varied $\left(20-70^{\circ} \mathrm{C}\right)$ to stress the wire bonds and bond joints in the inverter and to test for strength.

\subsubsection{Isolation Impedance}

As a safety measure, prior to the start of electrical testing, the unit was checked for a fault condition that could have occurred as a result of shipping or handling damage. The isolation impedance between the inverter terminals and case was measured with a multi-meter to verify proper isolation. The isolation impedance between the terminals and case of the inverter was measured as being greater than $1 \mathrm{M} \Omega$.

\subsubsection{R-L Load Test}

\subsubsection{Test setup}

The output leads of the inverter are connected to a three-phase star-connected variable resistor bank with a three-phase inductor in series. The dc inputs are connected to a voltage source capable of supplying the maximum rated operating voltage and current levels for the inverter. The test setup uses the following equipment, as shown in Fig. 3.17.

- Yokogawa PZ4000 power analyzer for power measurement.

- Variable resistor load with a capacity of $24 \mathrm{~kW}$.

- Inductor with 400-A capacity.

- Coolant pump with a temperature controller.

- A de power supply with four-quadrant operation (not seen in the figure).

\subsubsection{Operation}

During this test, the inverter unit was operated in the debug mode instead of the normal mode. In this mode, the open-loop frequency and the PWM frequency can be adjusted and the power capability of the inverter can be tested. 


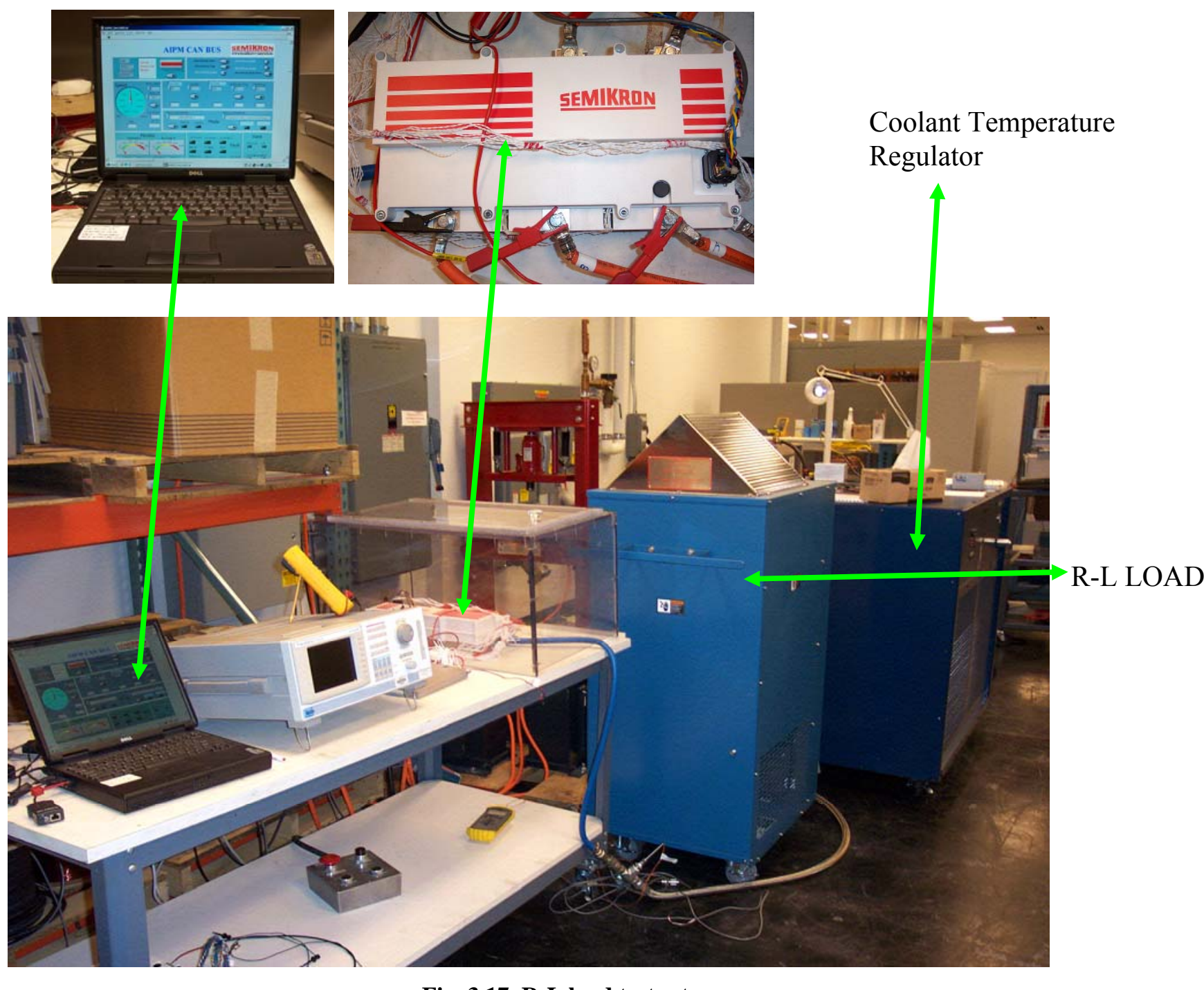

Fig. 3.17. R-L load test setup.

For this test, the dc-link voltage was varied from the minimum operating voltage $(200 \mathrm{~V})$ to the maximum bus voltage $(450 \mathrm{~V})$. The bus voltage trip fault occurs for voltages beyond $450 \mathrm{~V}$. The load resistance was set to the minimum value, and the current was controlled using the current controller. The coolant was set at $20^{\circ} \mathrm{C}$ and at a flow rate of $2.5 \mathrm{gpm}$. The open-loop frequency of operation and the PWM frequency were fixed, and the current command was varied for a particular dc-link voltage. For each value of the current command and open-loop frequency, the dc-link voltage, dc-link current, input power, output power, efficiency, and output-line currents and voltages were recorded. The three-phase power was measured using the two-wattmeter method. The command current was increased in steps of $10 \mathrm{~A}$ without exceeding the power rating of the inverter or the power rating of the load.

The procedure was repeated by increasing the open-loop frequency in steps of $25 \mathrm{~Hz}$. The coolant temperature was changed to $70^{\circ} \mathrm{C}$, and the data were recorded for a wide range of current and open-loop frequencies. 


\subsubsection{Results}

The operating waveforms for two specific operating conditions of one phase of the hybrid inverter are shown in Fig. 3.18. The data obtained for both the inverters were analyzed and the corresponding efficiencies were calculated. The efficiency versus output-power plots for several operating conditions comparing the inverters are shown in Fig. 3.19 (a) and (b). The hybrid inverter efficiencies are higher than the all-Si inverter efficiencies for all operating conditions. The results show a reduction of up to $33.6 \%$ in the losses when everything is kept the same and SiC Schottky diodes are used instead of Si pn diodes. The percentage of loss reduction was calculated by comparing the power losses between the hybrid inverter and the all-Si inverter as follows:

Percentage loss reduction $=\left(d_{\text {ploss }(\mathrm{Si})}-\mathrm{d}_{\text {ploss }(\mathrm{SiC})}\right) /\left(\mathrm{d}_{\text {ploss }(\mathrm{Si})}\right) \times 100$
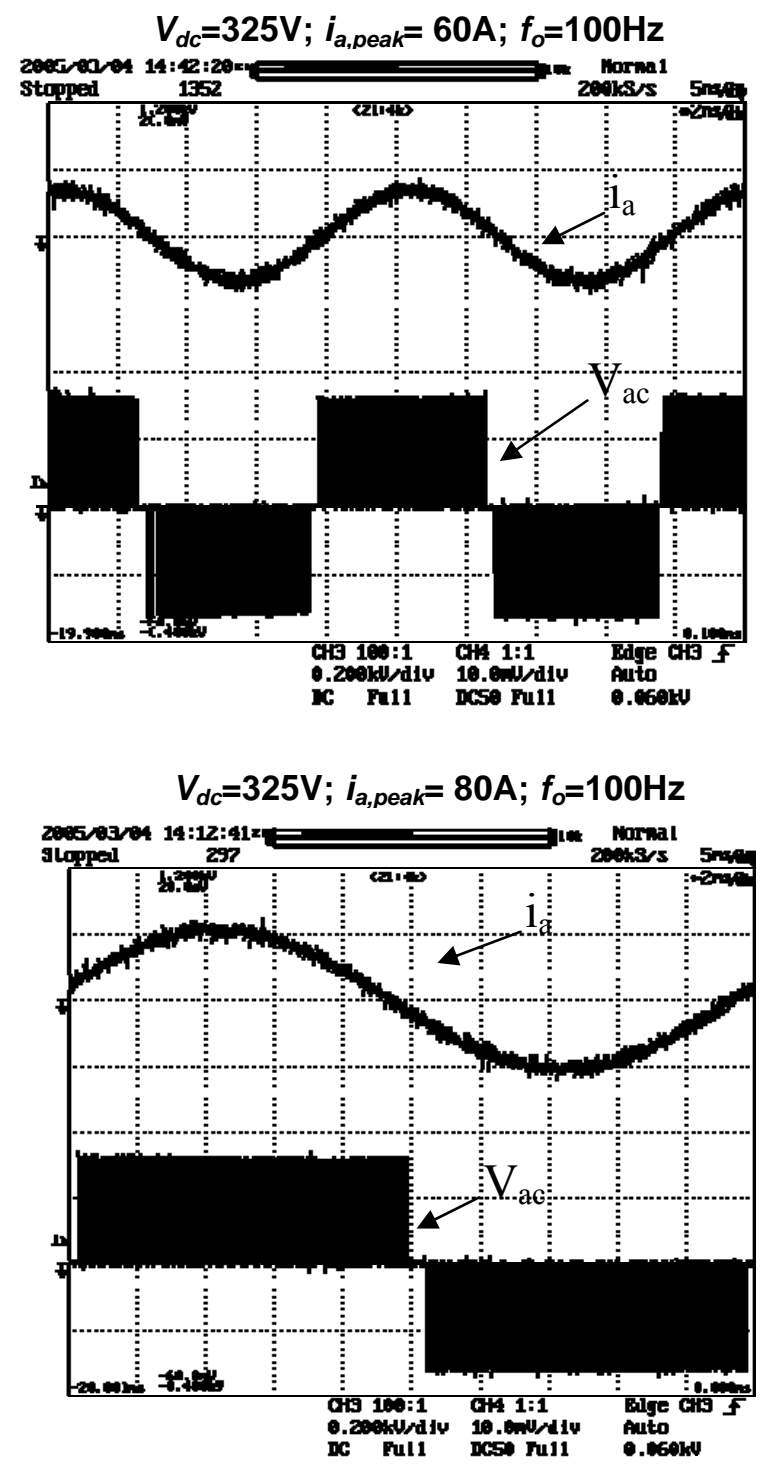

Fig. 3.18. R-L load test operating waveforms. 

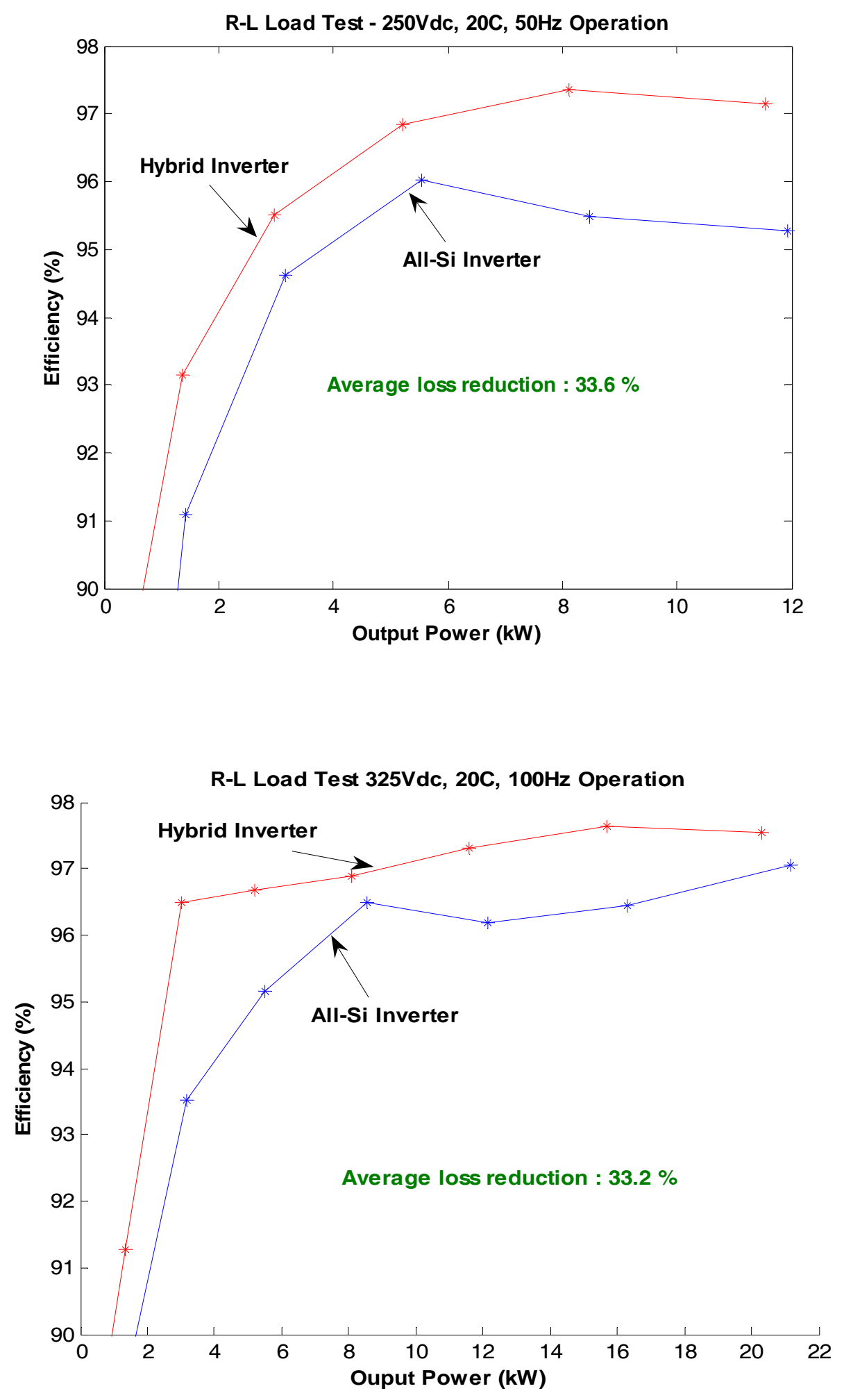

Fig. 3.19. R-L load test efficiency curves for various load conditions. 

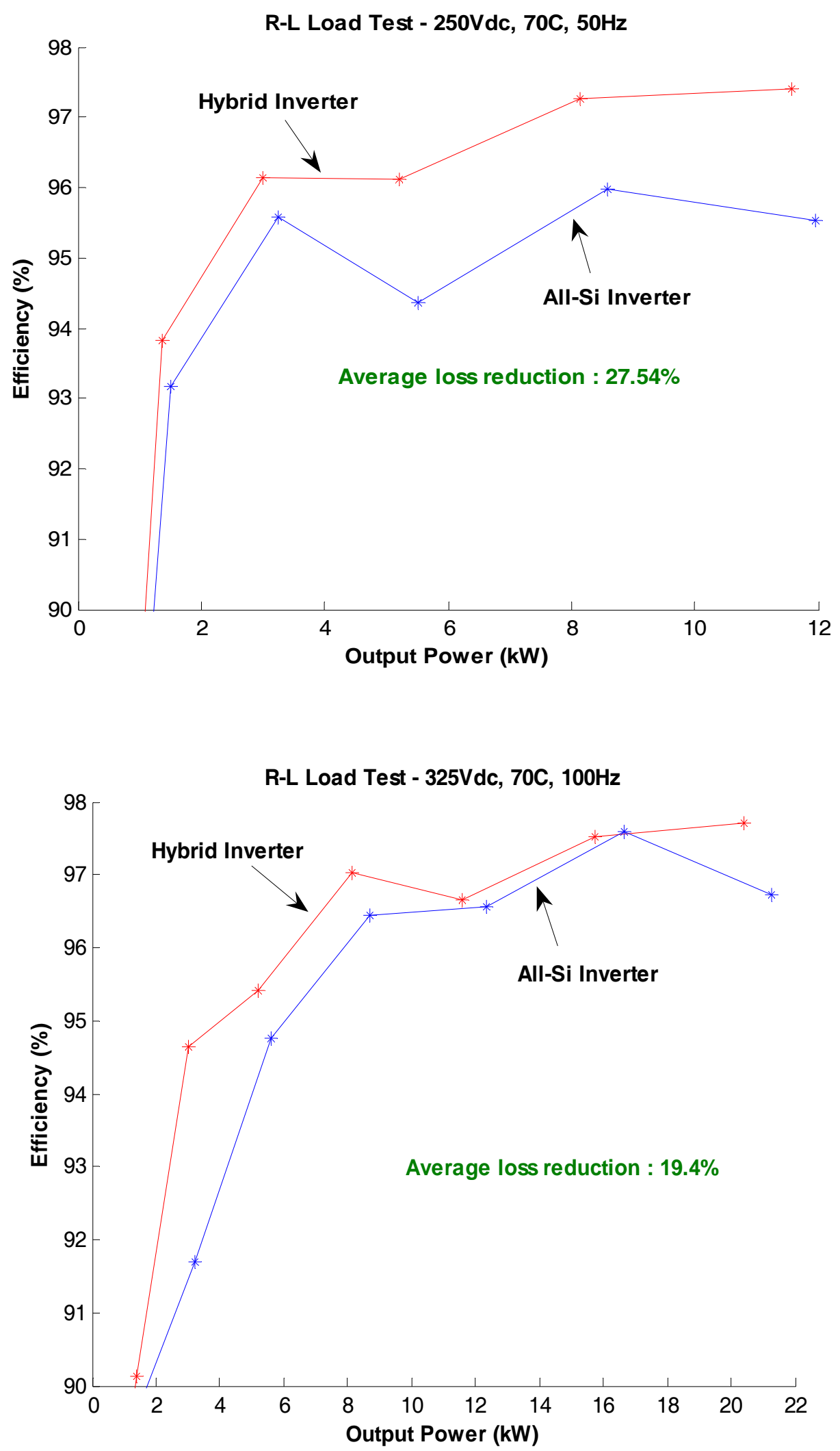

Fig. 3.19. R-L load test efficiency curves for various load conditions (cont'd). 


\subsubsection{Dynamometer Test}

\subsubsection{Test setup}

The inverter was connected to a Solectria motor and setup in a dynamometer test cell to test the dynamic performance of the inverter in the motoring and regeneration modes. The Solectria motor is a four-pole induction motor with a base speed of $2500 \mathrm{rpm}$, and the dynamometer has 100-hp capacity. The setup is shown in Figs. 3.20 and 3.21. The tests were performed with the inverters supplied with $70^{\circ} \mathrm{C}$ coolant at a flow rate of $2.5 \mathrm{gpm}$.

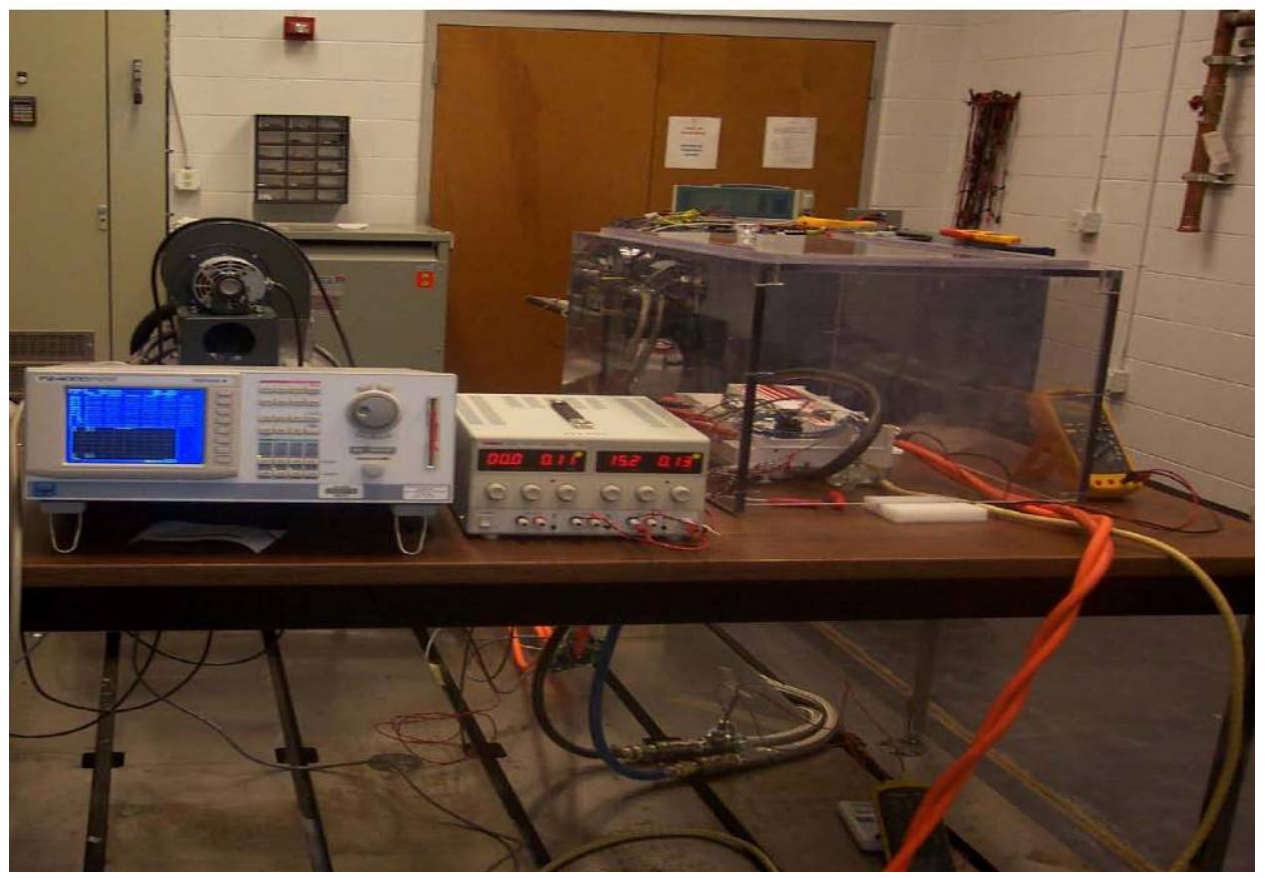

Fig. 3.20. Inverter dyne test setup. 


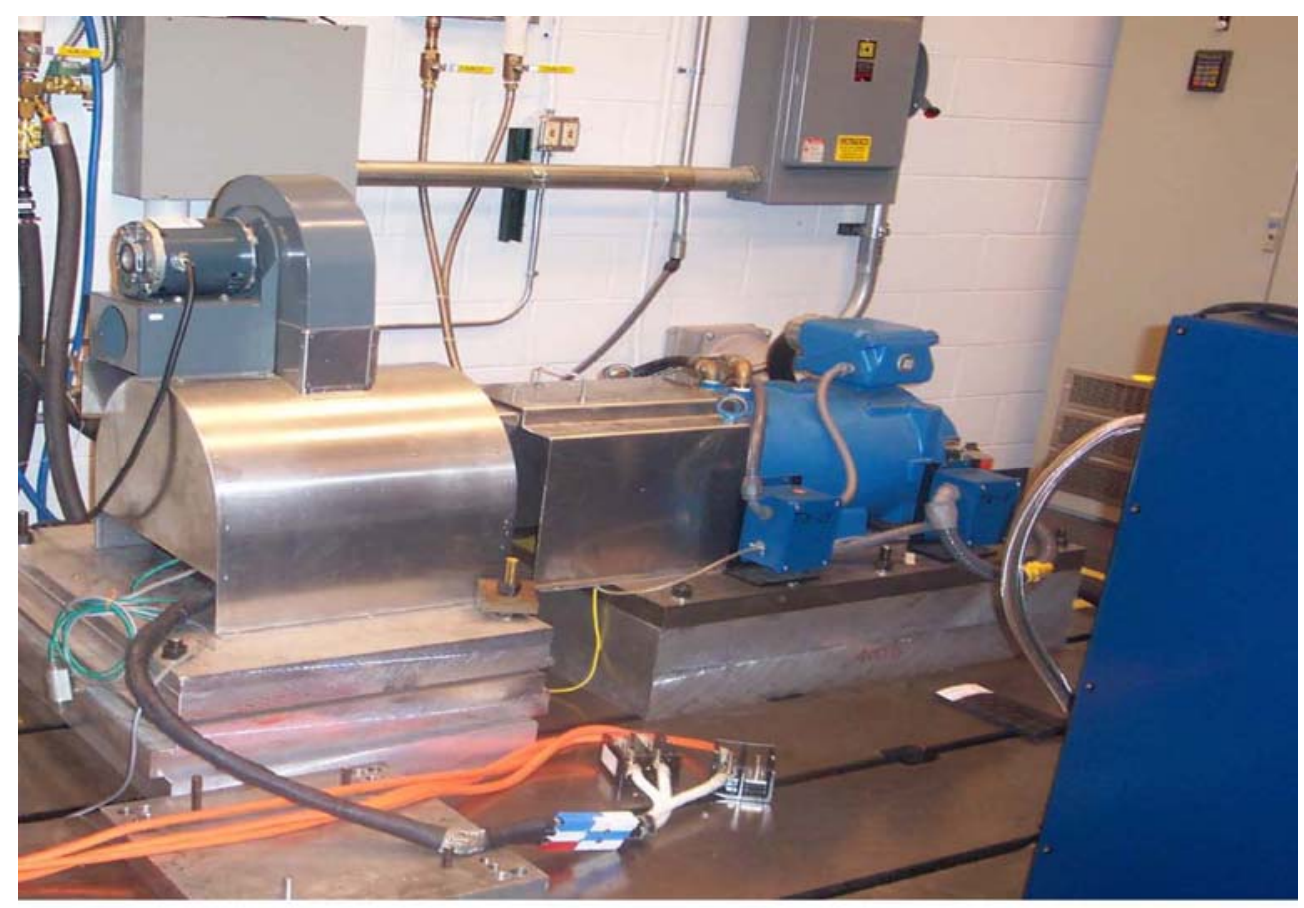

Fig. 3.21. 100-hp dyne cell.

\subsubsection{Motoring mode}

The test setup connections were verified in the test cell. During this test, the inverter unit was operated in the normal mode instead of the debug mode, and the control mode was set to speed instead of torque. In this mode, the speed set point, the magnetizing current, the direction of rotation, and the current limit were adjustable parameters. The dc-voltage input to the inverter was set at the nominal battery operating voltage (325 $\mathrm{Vdc})$.

The closed-loop speed controller gains were adjusted for a given magnetizing current value and current limit to achieve stable operation of the system for a wide range of speeds. The direction of rotation was set to forward, and the motor speed was increased from $750 \mathrm{rpm}$ to the rated base speed for a specific continuous-load torque. The data were obtained for a wide range of speed and torque values by changing the load torque (from 100, 150, $200 \mathrm{Nm}$ ) using the dynamometer controller. The following information was recorded at each speed increment: motor shaft speed (rpm and rad/second); motor torque; input voltage and current to the inverter; and output voltages and currents from the inverter. The output voltage and current waveforms for $40 \%$ and $80 \%$ of rated speed and several load-torque values were obtained.

The waveforms for two different loads are shown in Fig. 3.22. The efficiency plots for various speeds and load-torque values are shown in Fig. 3.23. The average loss reduction in motoring mode was up to $10.7 \%$. The difference in the efficiencies of the inverters is higher at low-load torque because the diodes conduct for relatively longer periods. The reduction in losses becomes smaller at higher-load torques as the conduction time of the power switches increases. Note that one of the reasons the average loss reduction is less in the motoring than in the R-L load test is that the power levels achieved are much lower in motoring.

Figure 3.24 shows a screen shot of the test data obtained from the power meter PZ4000 for one of the operating conditions. 


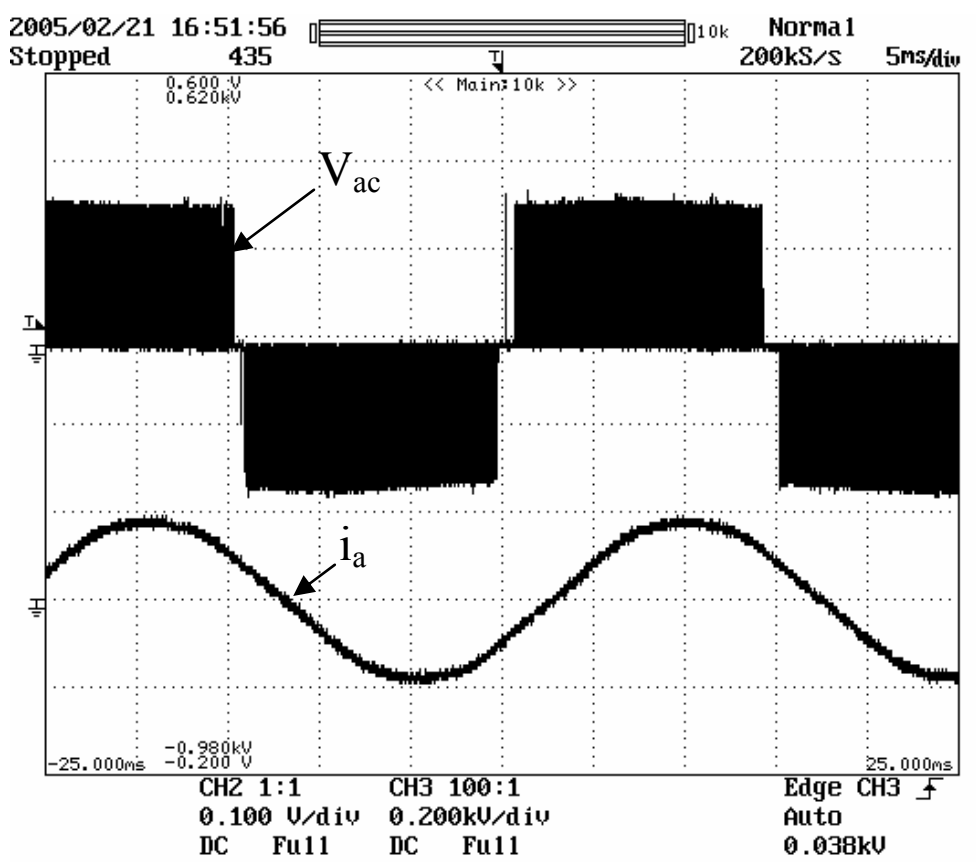

(a) $1000 \mathrm{rpm}$ and $50 \mathrm{Nm}$.

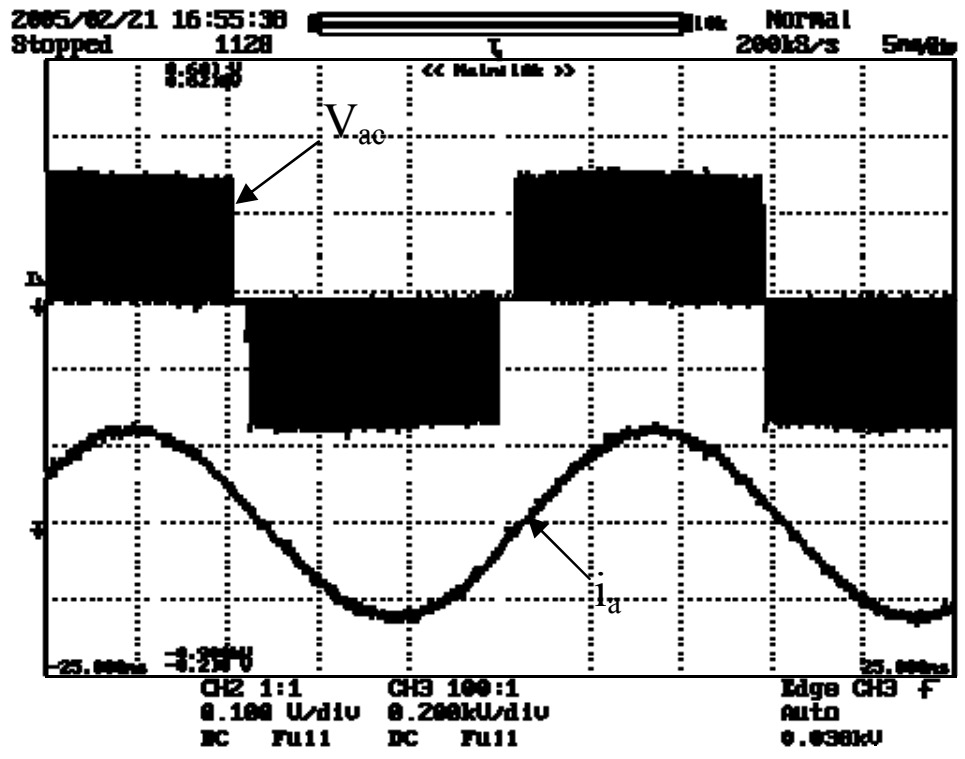

(b) $1000 \mathrm{rpm}$ and $150 \mathrm{Nm}$.

Fig. 3.22. Dynamometer test-motoring mode operating waveforms. 


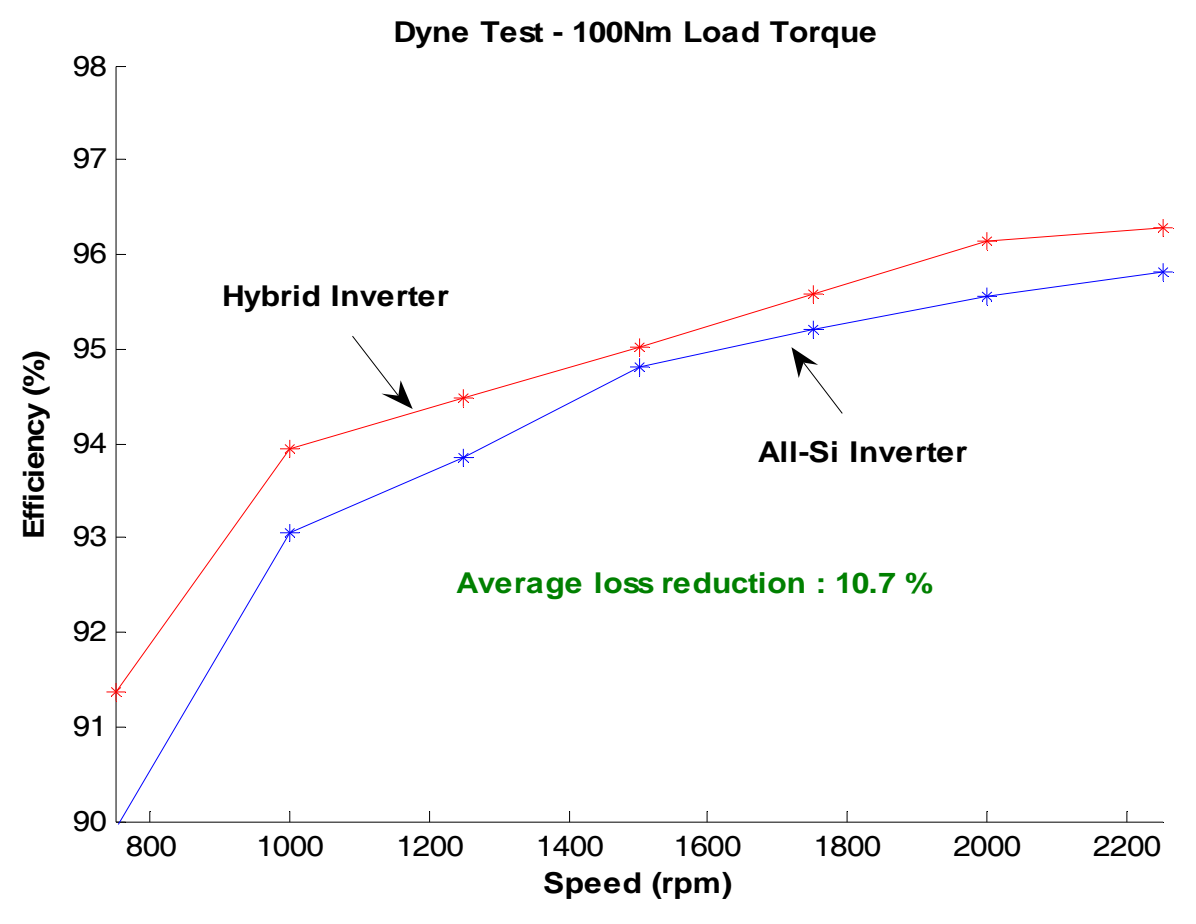

(a) $100 \mathrm{Nm}$ load torque.

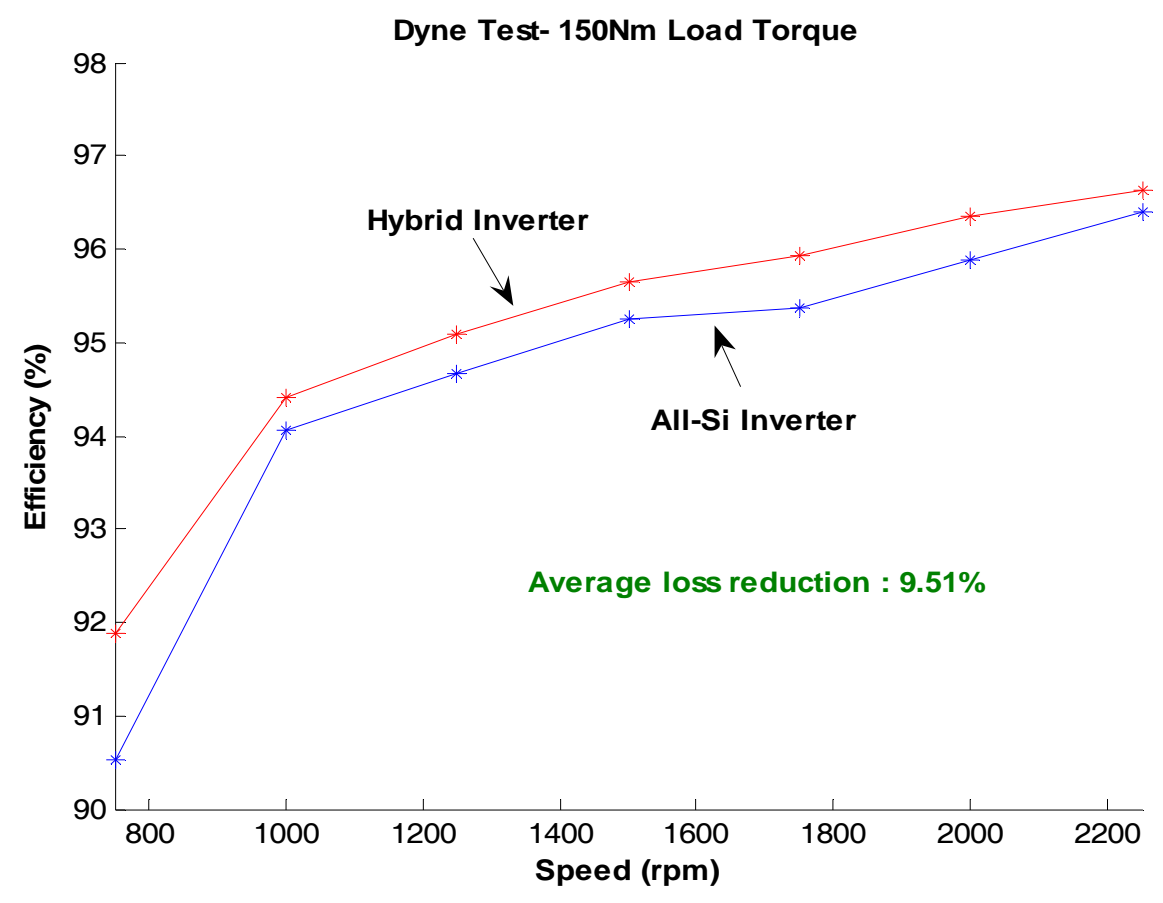

(b) $150 \mathrm{Nm}$ load torque.

Fig. 3.23. Dynamometer test-motoring mode efficiency plots at $70^{\circ} \mathrm{C}$. 


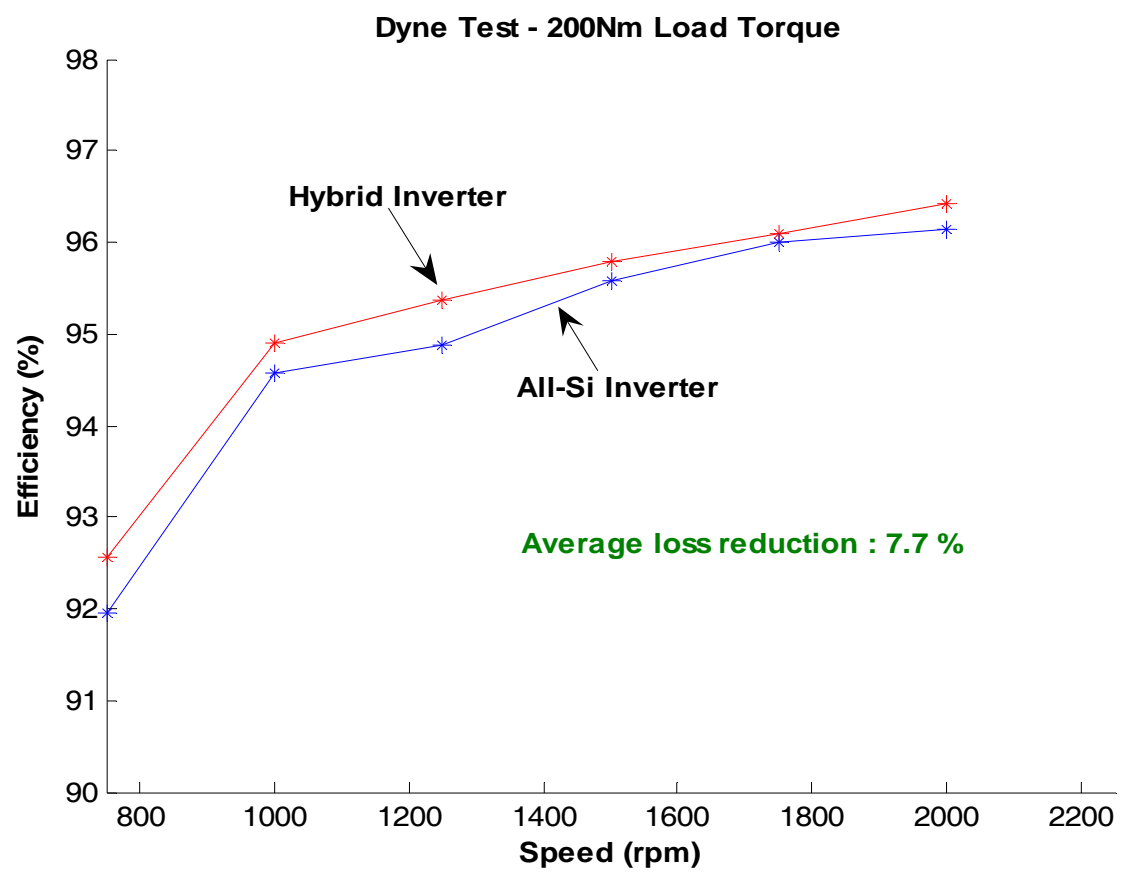

(c) $200 \mathrm{Nm}$ load torque.

Fig. 3.23. Dynamometer test-motoring mode efficiency plots at $\mathbf{7 0}^{\circ} \mathrm{C}$ (cont'd).

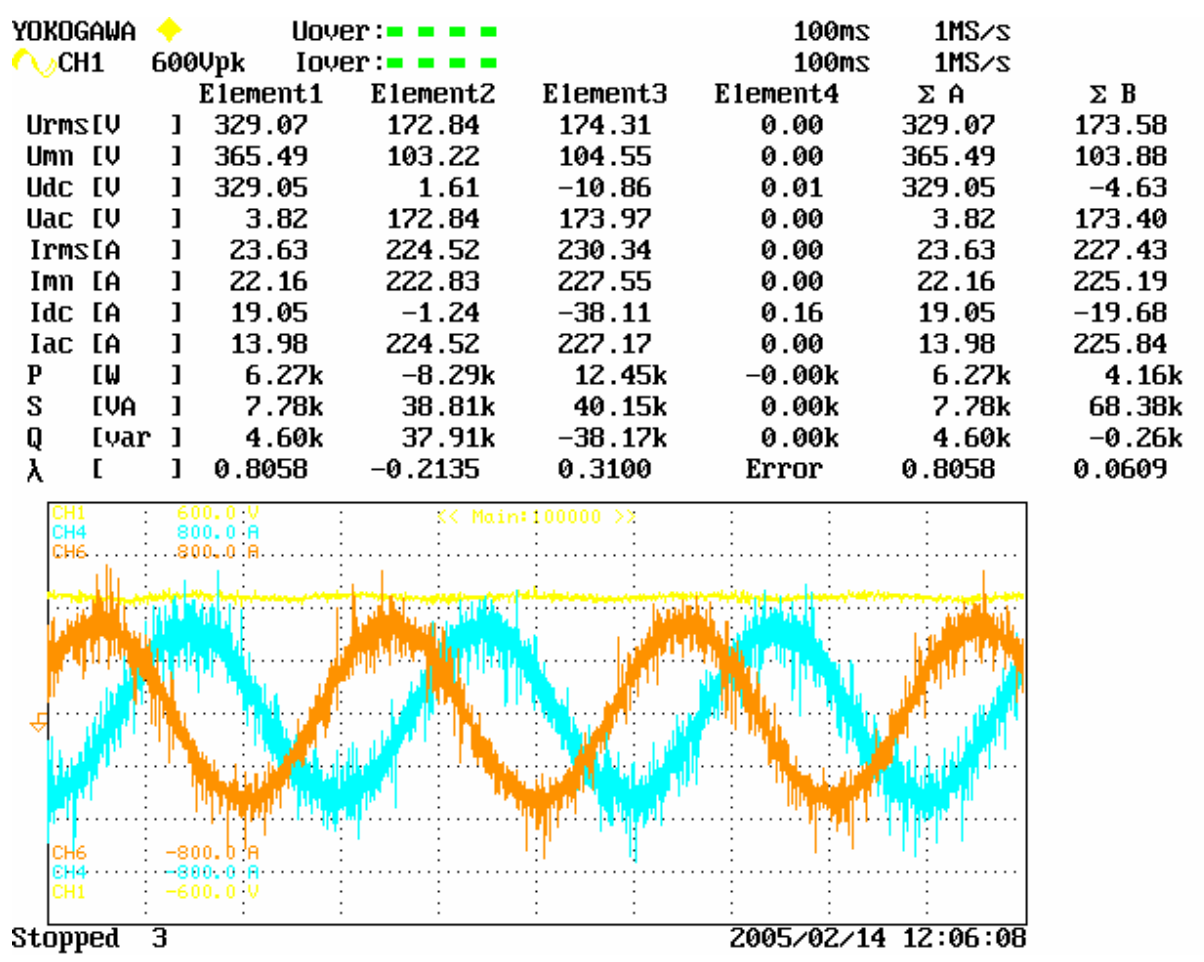

Fig. 3.24. Dynamometer test-motoring mode data obtained from the power meter. 


\subsubsection{Regeneration mode}

During this test, the inverter unit was operated in the normal mode instead of the debug mode, and the control mode was set to torque instead of speed. With these settings, the torque limit and the operating current can be adjusted. The dc-voltage input to the inverter was set at the nominal battery-operating voltage $(325 \mathrm{~V})$. The direction of rotation was set to be forward. The dynamometer controller was adjusted to control the speed. The motor speed was increased from $750 \mathrm{rpm}$ to the rated speed for a specific operating current of the inverter to achieve a specific load torque. The current was varied from zero to the values corresponding to different torque values and then decreased to zero. The procedure was repeated to obtain the data for a wide range of speed and torque values. At each speed increment, motorshaft speed (rpm and $\mathrm{rad} / \mathrm{second})$, motor torque, input voltage and current to the inverter, and output voltages and currents from the inverter were recorded. The output voltage and current waveforms for $40 \%$ and $80 \%$ of rated speed and several load-torque values were obtained. The operating waveforms for the regeneration mode are shown at two different speeds in Fig. 3.25. The curves comparing the efficiency of the inverters at $70^{\circ} \mathrm{C}$ coolant temperature are shown in Fig. $3.26(\mathrm{a}-\mathrm{c})$. The results show a reduction of up to $12.71 \%$ in average losses, similar to the results obtained in the motoring mode.

The IGBTs used in the actual inverter and in the simulation are not the same. Therefore, a direct comparison of the efficiencies of the simulation and the testing would not be accurate. But it is seen that the efficiencies of the simulation and the testing do have the same trend. 


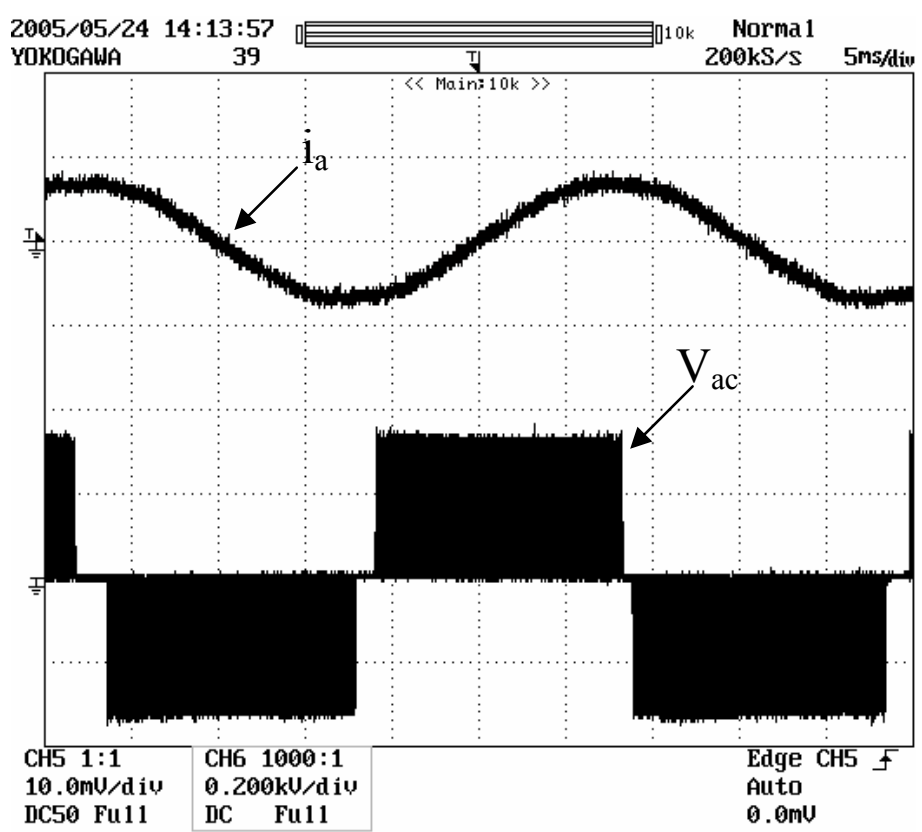

(a) $1000 \mathrm{rpm}$ and $50 \mathrm{Nm}$.

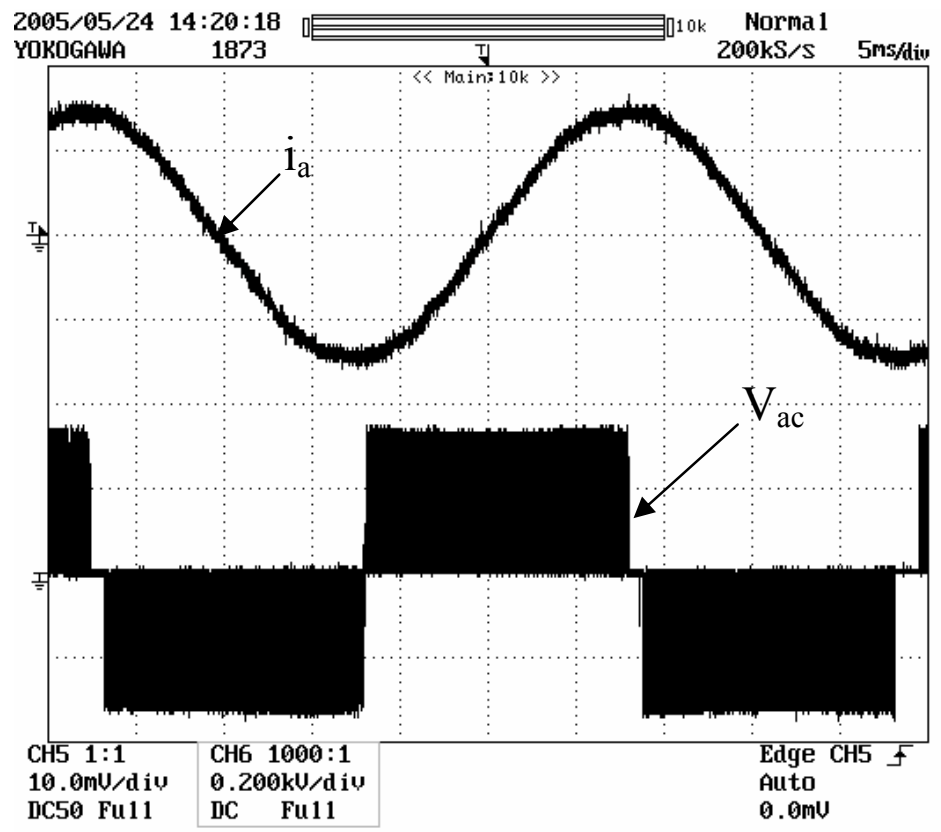

(b) $1000 \mathrm{rpm}$ and $150 \mathrm{Nm}$.

Fig. 3.25. Dynamometer test-regeneration mode operating waveforms. 


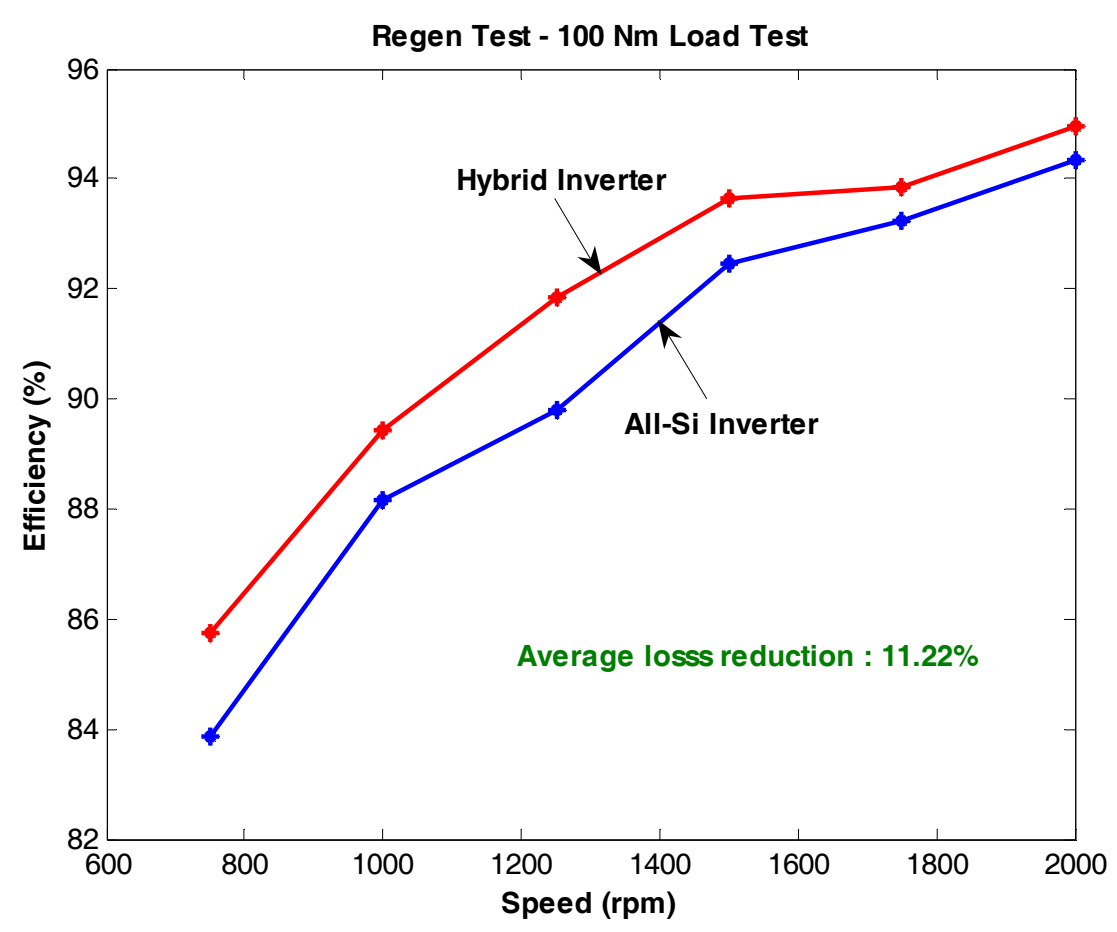

(a) $100 \mathrm{Nm}$ load torque.

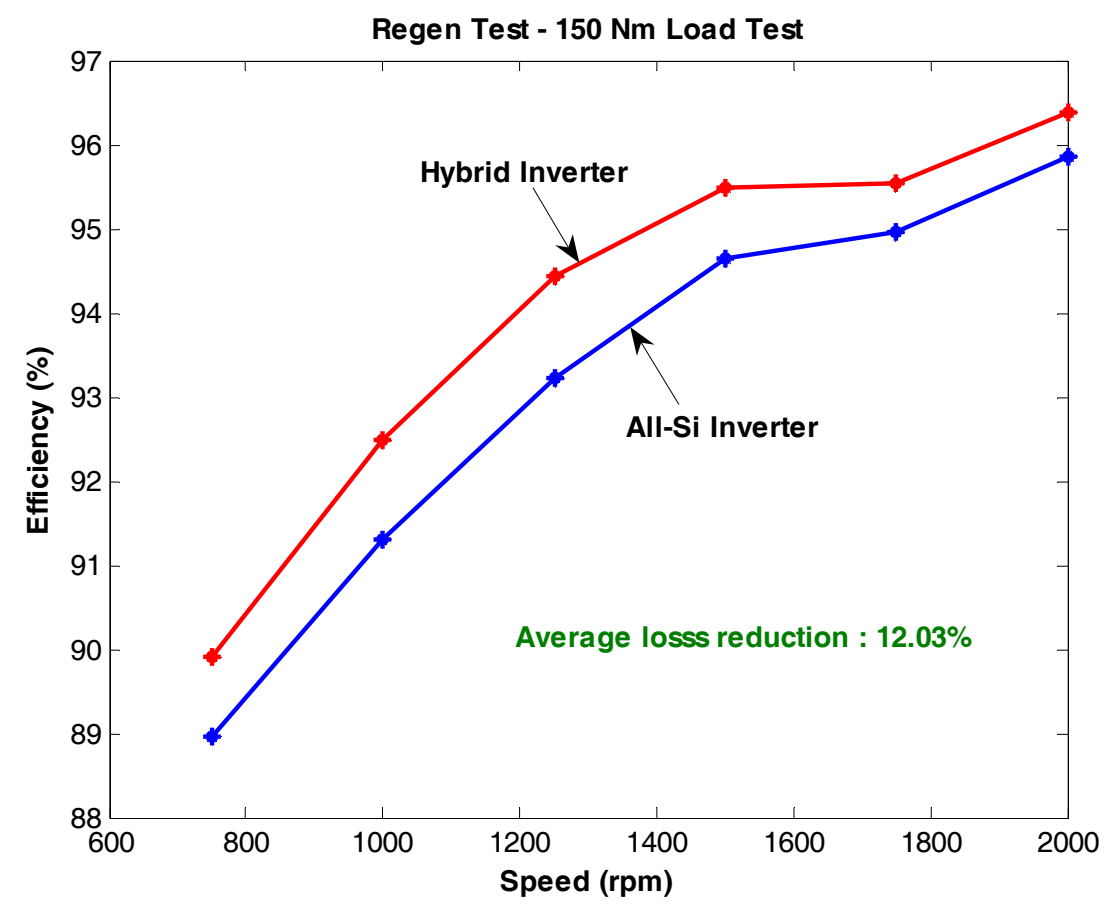

(b) $150 \mathrm{Nm}$ load torque.

Fig. 3.26. Dynamometer test-regeneration mode efficiency plots at $70^{\circ} \mathrm{C}$. 


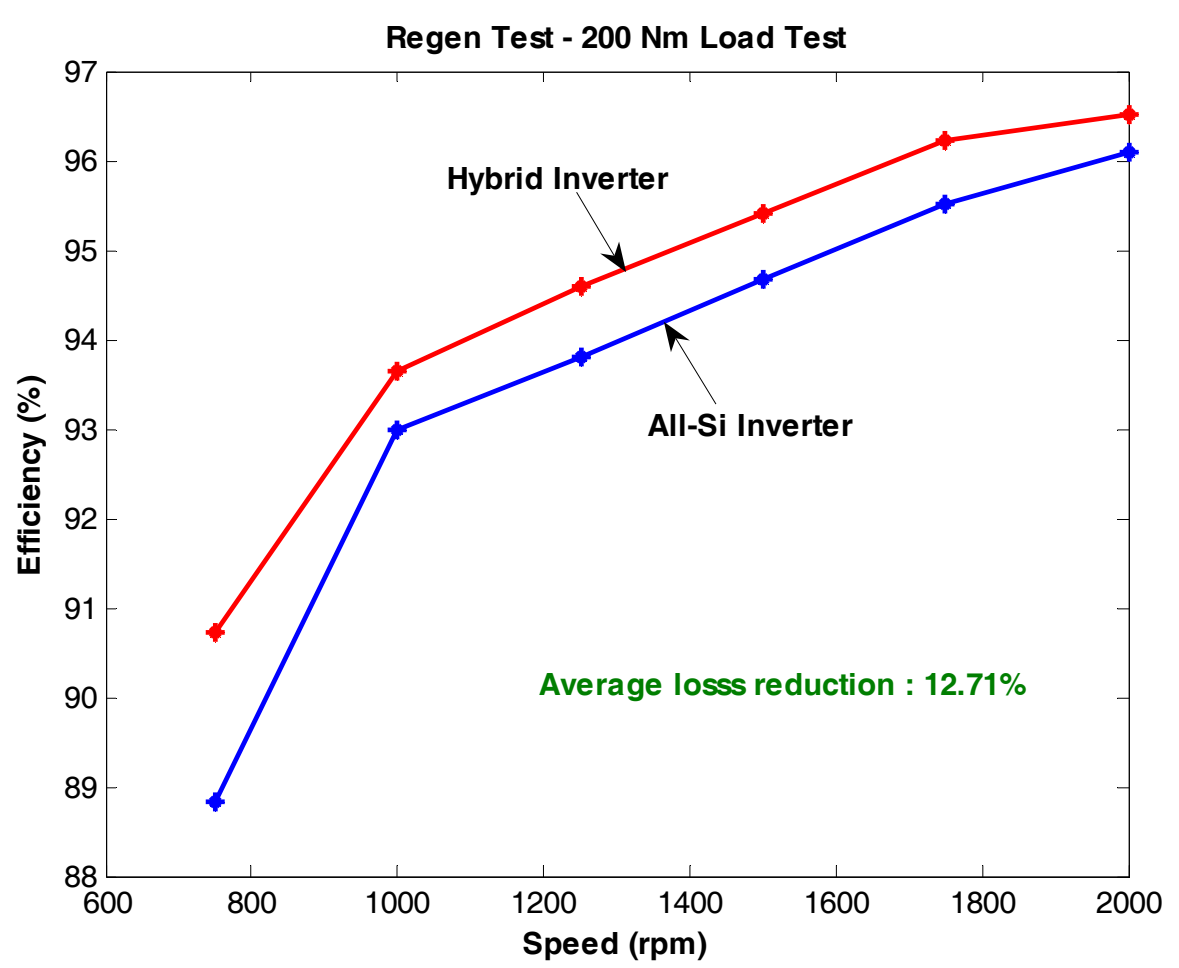

(c) $200 \mathrm{Nm}$ load torque.

Fig. 3.26. Dynamometer test-regeneration mode efficiency plots at $70^{\circ} \mathrm{C}$ (cont'd).

\subsection{EXPLANATION FOR THE POWER LOSS DIFFERENCE BETWEEN THE INVERTERS}

The results for the all-Si and the hybrid inverters for the various tests conducted have proved that the $\mathrm{Si}$ IGBT-SiC Schottky diode hybrid inverter has better performance than the all-Si inverter. The effect of replacing the $\mathrm{Si}$ pn diodes with the $\mathrm{SiC}$ Schottky diodes resulted in improved inverter efficiency.

The difference in efficiencies for the various operating conditions of the two inverters can be explained by the static and dynamic characteristics of the diodes. A comparison of the static characteristics of the Si pn diodes and SiC Schottky diodes obtained from one of the inverter phase legs is shown in Fig. 3.27. The built-in forward voltage drop of the $\mathrm{SiC}$ and $\mathrm{Si}$ diodes is almost the same; however, the on-state resistance of the Si pn diode at higher currents is much higher (slope of the static characteristics much lower) than that of the SiC Schottky diode. Therefore, the conduction losses of the SiC diode will be less compared with the Si pn diode at higher currents.

The $\mathrm{SiC}$ diode has lower reverse-recovery losses than the Si pn diode, as shown in Fig. 3.28. It should be noted that the package for the $\mathrm{SiC}$ diode is not a commercial package; hence the turn-off of the $\mathrm{SiC}$ Schottky diode has more oscillations because of the package capacitance. The superior reverse-recovery characteristics of the $\mathrm{SiC}$ diode also results in reduced losses in the IGBT. This is because when a diode in an inverter is turning off, the diode-reverse-recovery current passes through the other IGBT in the same phase leg causing additional losses. The effect of this difference in diode-switching losses becomes significant as the frequency increases; therefore, for the same operating conditions (same load current, operating voltage, operating frequency, and coolant temperature) the losses in the hybrid inverter will be less than in the all-Si inverter. 
Some other observations and explanations for loss difference between the inverters in different modes are as follows

1. The average loss reduction is much higher in the regeneration mode than the motoring mode because the diodes conduct more in the regeneration mode, which is evident from Fig. 3.29.

2. At higher load torques in the motoring mode, the displacement factor is higher and hence the average loss reduction is less. The reason is that at higher power factors in motoring mode, the main switches conduct more than the diodes.

3. During the regeneration mode at higher torques, the average losses increase as the displacement factor increases and the diodes conduct more.

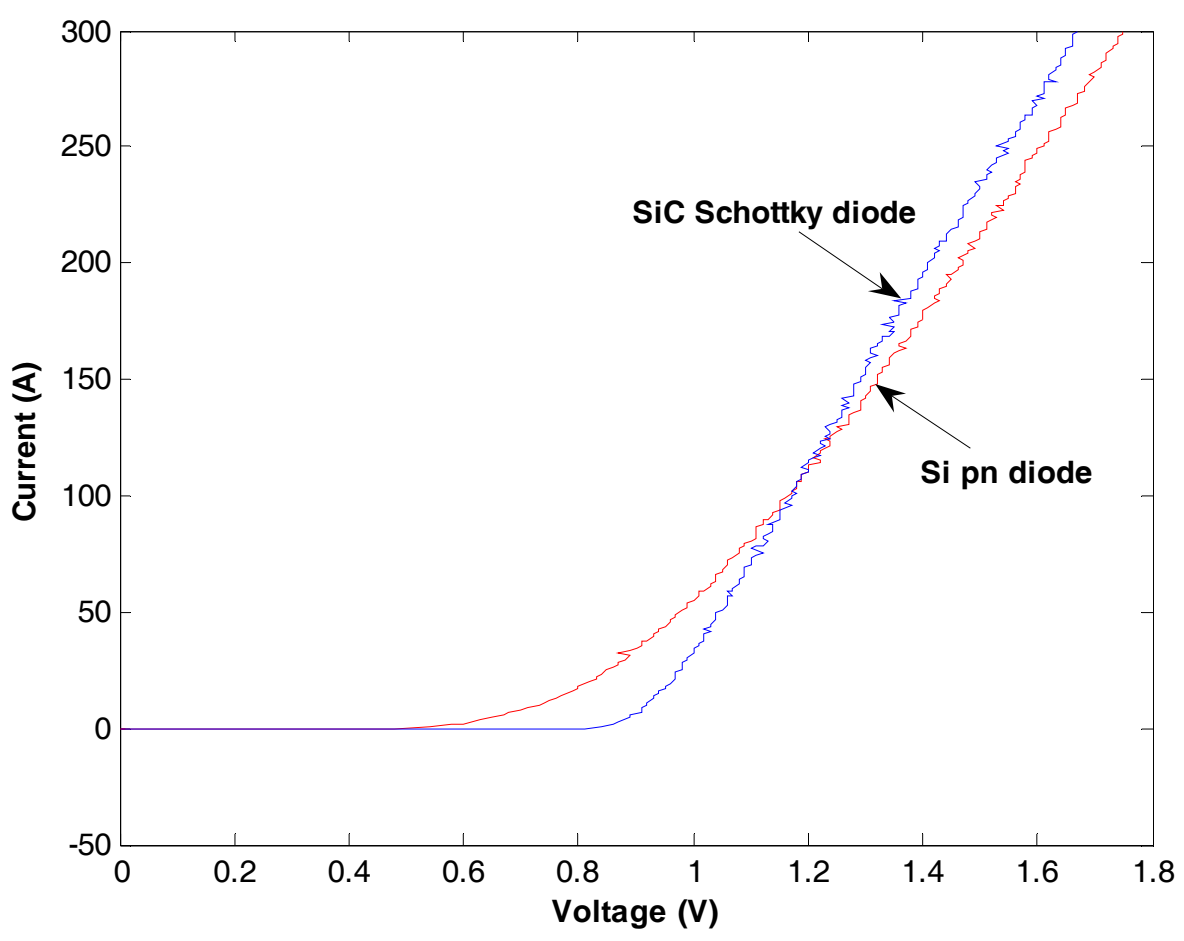

Fig. 3.27. Comparison of static characteristics of Si pn diode and SiC Schottky diodes. 


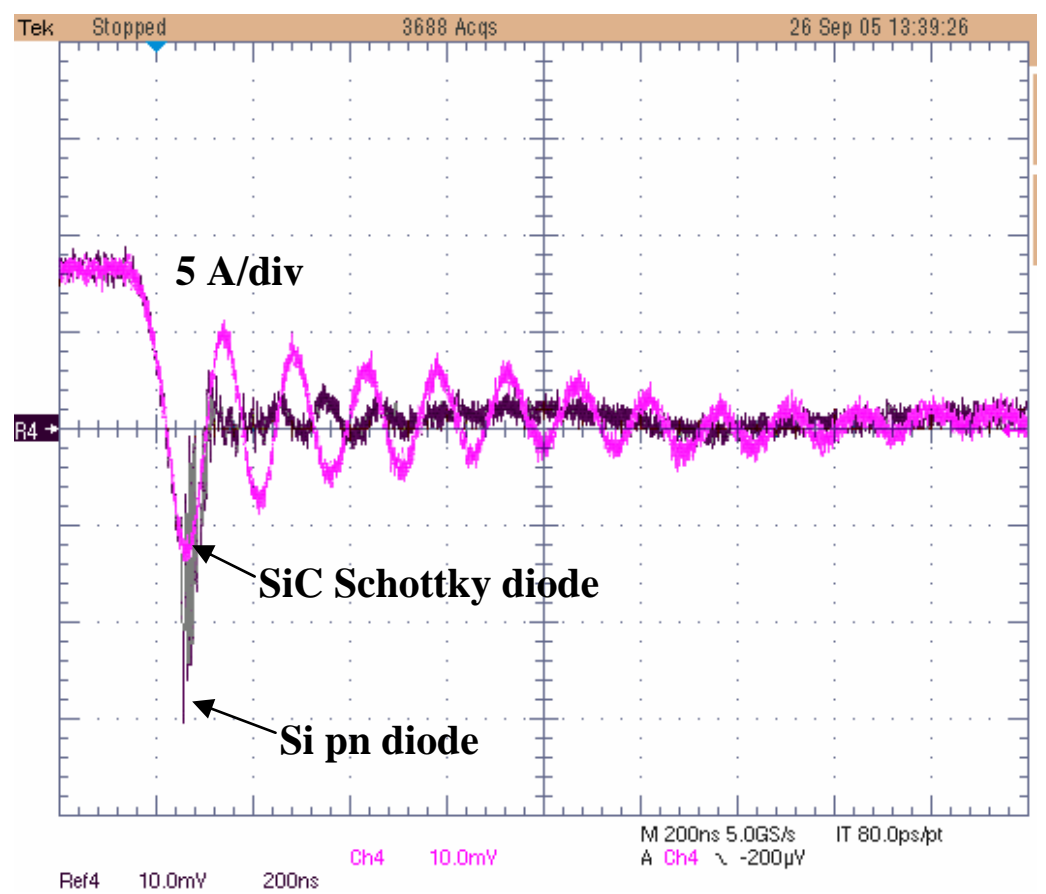

Fig. 3.28. Comparison of reverse-recovery characteristics of Si pn diode and SiC Schottky diode.

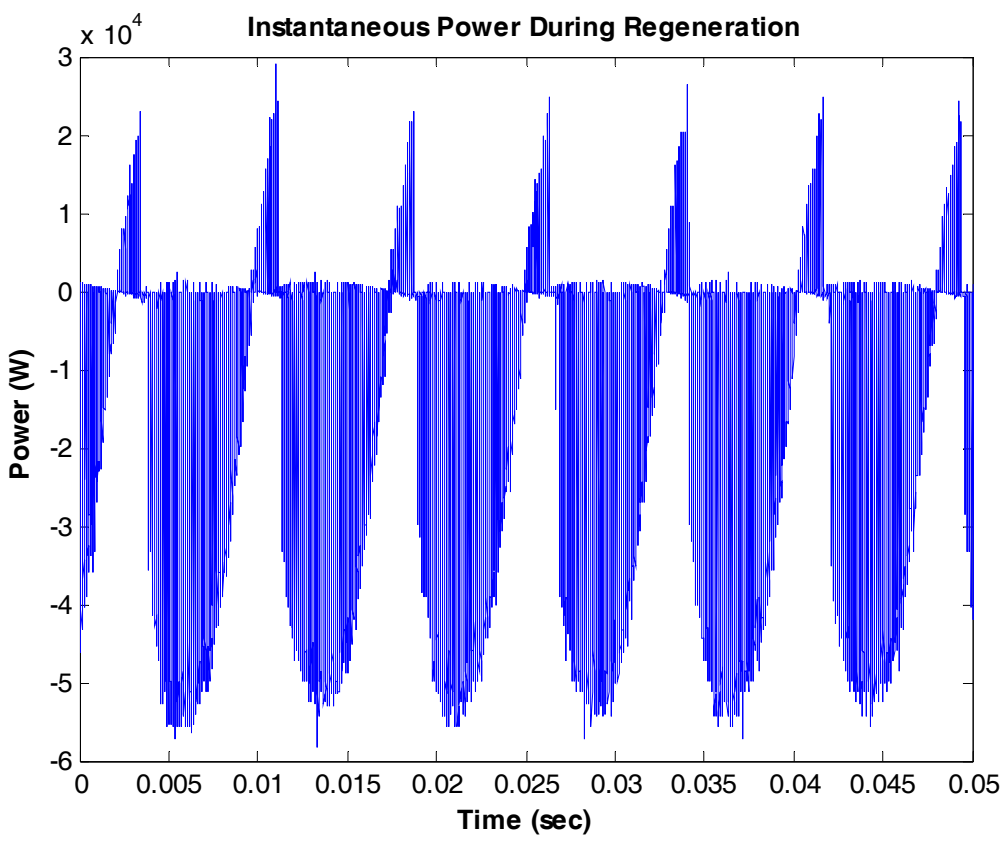

Fig. 3.29. Instantaneous output power during regeneration.

\subsection{CONCLUSIONS}

The 75-A SiC Schottky diodes used in the Si IGBT-SiC Schottky diode hybrid inverter were characterized and the parameter extraction was conducted to build a model using Saber. The model was used in an inverter model with Si IGBTs, and the performance of the inverter was studied with $\mathrm{Si}$ and $\mathrm{SiC}$ 
diodes. The efficiencies of the hybrid inverter were $1.5-2 \%$ higher than in the all-Si inverter, similar to the test data.

The testing of both the hybrid and the all-Si inverters was completed successfully. The inverters were able to operate at peak power levels with efficiencies of greater than $90 \%$. The inverters were tested for a maximum continuous power of $47 \mathrm{~kW}$. The hybrid inverter had an average loss reduction of up to $33.6 \%$ compared with the all-Si inverter for the R-L load test. The motoring and regeneration tests were done at lower power levels and showed a reduction of around $10 \%$ in the average power losses. These test results show a trend similar to the results obtained in the simulation. 


\section{ALL-SiC INVERTER}

\subsection{INTRODUCTION}

$\mathrm{SiC}$ power switches have been demonstrated to have better performance compared with the equivalent $\mathrm{Si}$ power switches. Simulation studies have proved that $\mathrm{SiC}$ devices, when compared with their $\mathrm{Si}$ counterparts, have a better effect on the total system performance. SiC diodes are the only commercialized devices available in the market. The $\mathrm{SiC}$ power switches are only available as some experimental samples.

A 7.5-kW all-SiC inverter was built in collaboration with Rockwell Scientific to study the effect of replacing the Si devices with $\mathrm{SiC}$ devices in the inverters. The module was built using JFETs as the main power switches and SiC Schottky diodes. The performance of the all-SiC inverter was compared with a similarly rated all-Si inverter.

\subsection{JFET CHARACTERIZATION AND MODELING}

\subsubsection{SiC JFET Characterization}

JFETs have reached a high level of maturity in SiC technology beyond that of other transistors, but they still require further improvements for commercialization. Power JFETs are built with vertical topologies, as shown in Fig. 4.1, and can support higher breakdown voltages as a result of their thick drift layer.

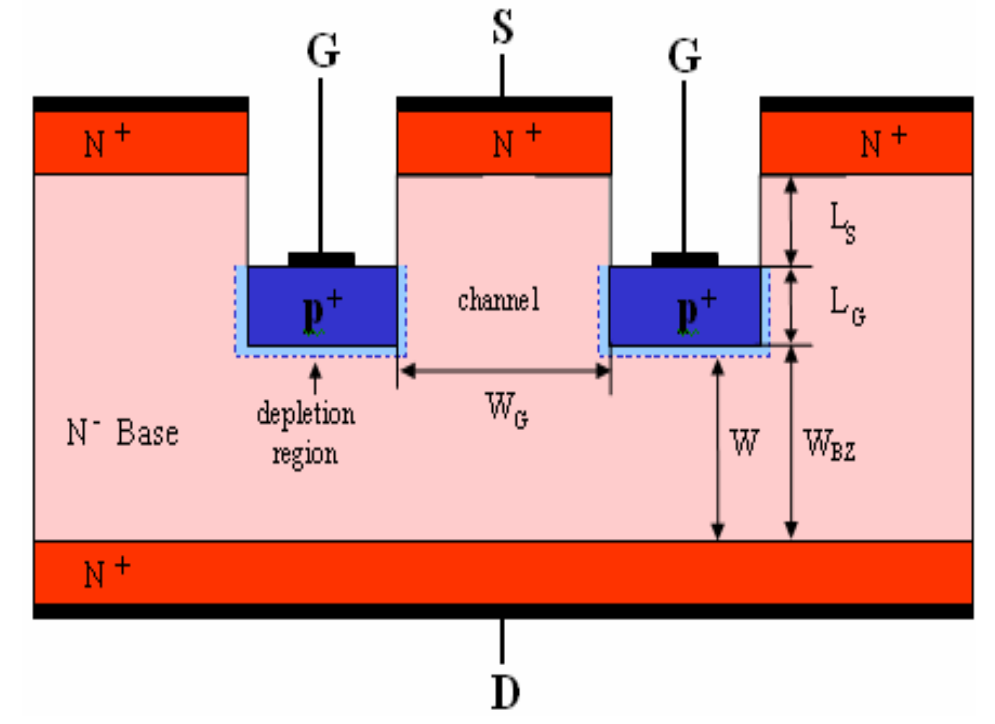

Fig. 4.1. Cross-section of the SiC VJFET structure.

One of the SiC JFETs from Rockwell (rated at $1200 \mathrm{~V}, 15 \mathrm{~A}$ ) was tested for on-state and switching characteristics to obtain data for modeling. The JFET was placed in the Tek371B curve tracer and the onstate characteristics were measured in the unipolar and the bipolar mode.

The SiC JFETs from Rockwell are normally-on devices, meaning a negative-gate voltage is required to turn them off. The gate voltage, $V_{g s}$, at which the JFET actually stops conducting (drain current $I_{d s}=0$ for any value of $V_{d s}$ ) is known as the pinch-off voltage. In the unipolar configuration, the gate is negatively biased with respect to the source. Figure 4.2 shows the measured data of the JFETs in the unipolar region 
of operation. In the unipolar mode, the JFET acts as a majority-carrier device and hence only the electrons are carriers. On the other hand, in the bipolar mode of operation, the gate is positively biased with respect to the source. In this case, both electrons and holes conduct and the total current is higher than in the unipolar mode as a result of the increased conduction. The JFET was also tested in the bipolar mode; the results are shown in Fig. 4.3.

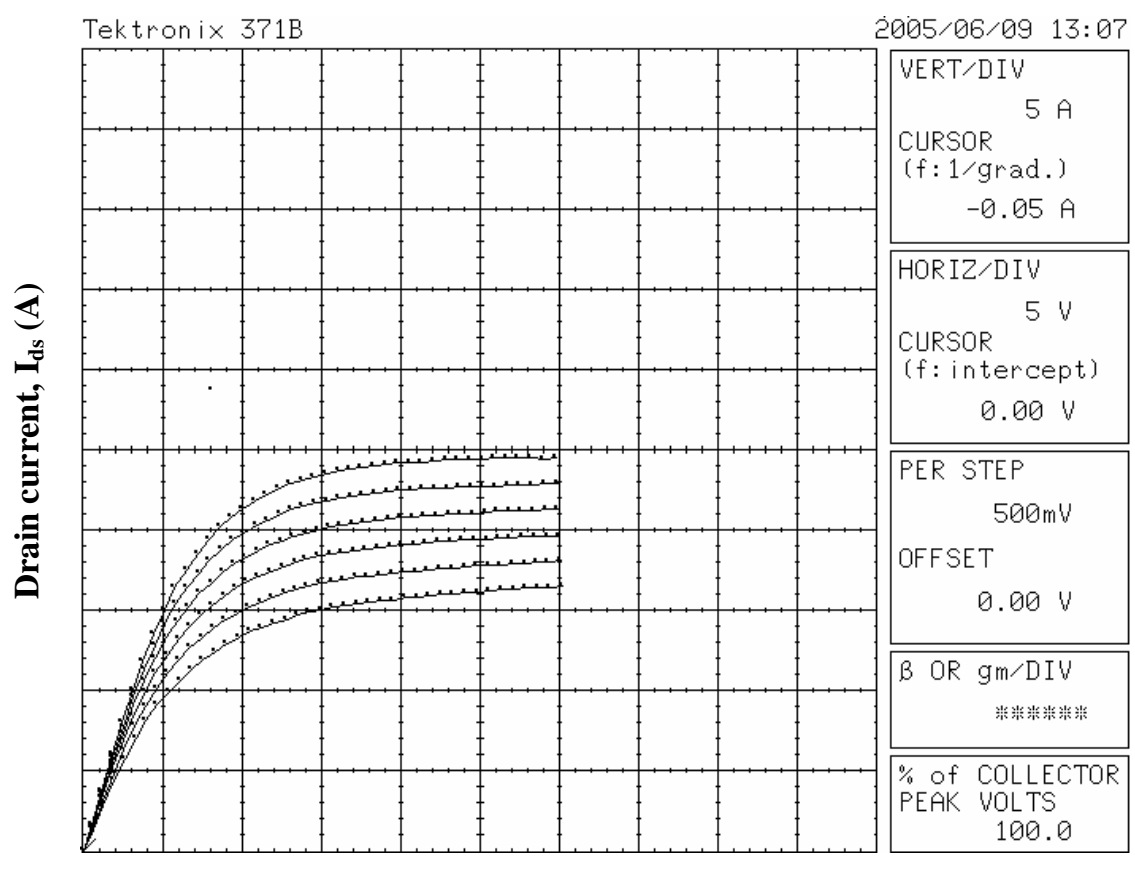

Drain-source voltage, $V_{\mathrm{ds}}(\mathrm{V})$

Fig. 4.2. Unipolar operation of the Rockwell SiC JFET.

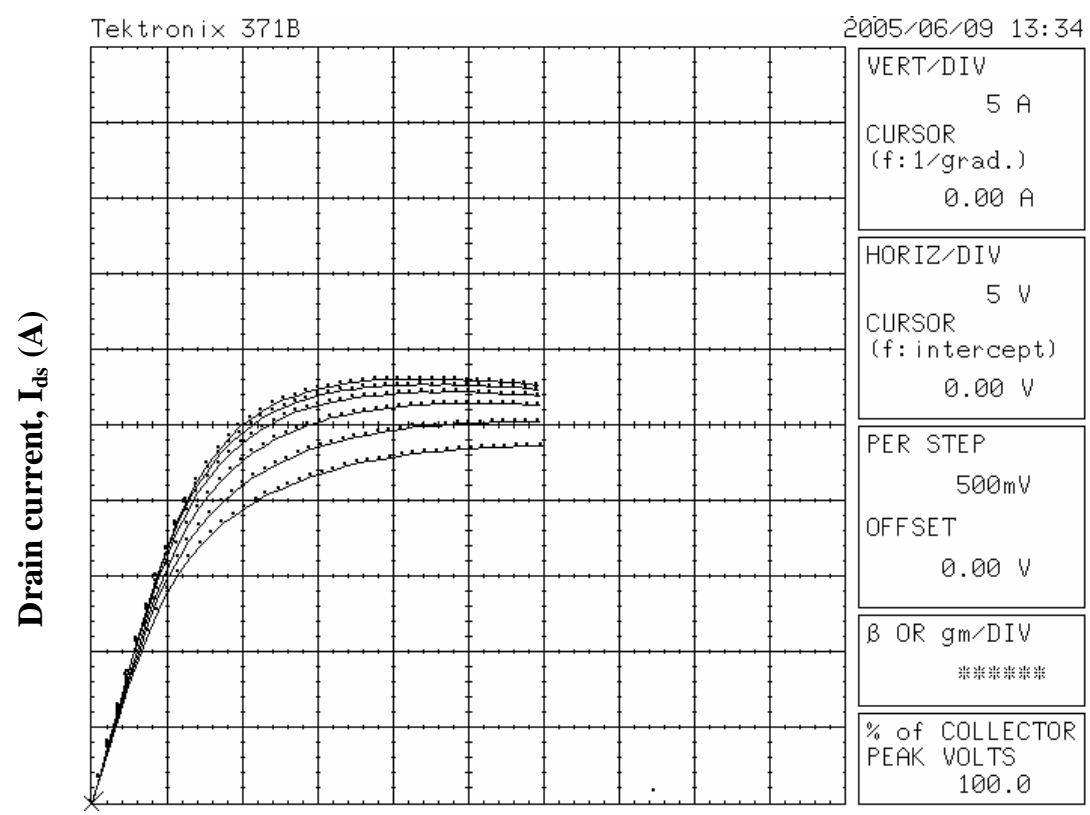

Drain-source voltage, $\mathrm{V}_{\mathrm{ds}}(\mathrm{V})$

Fig. 4.3. Bipolar operation of the Rockwell SiC JFET. 
An interesting observation from Figs. 4.2 and 4.3 is that even though the JFETs are rated only for 15 A, they were able to operate at nearly twice the rated current. This is because the curve tracer uses a pulsedvoltage supply that greatly decreases the self-heating of the device.

The pinch-off voltage is an important parameter in the model, and it must be evaluated by performing a separate test. To find the pinch-off voltage, a constant drain-to-source voltage $\left(V_{d s}\right)$ is imposed on the device and the gate-to-source voltage is swept. This is also known as the transfer characteristic. The $V_{g s}$ at which the JFET just stops conducting is known as the pinch-off voltage, which was found to be approximately $-25 \mathrm{~V}$ for this particular JFET. Figure 4.4 shows the results of the pinch-off voltage test.

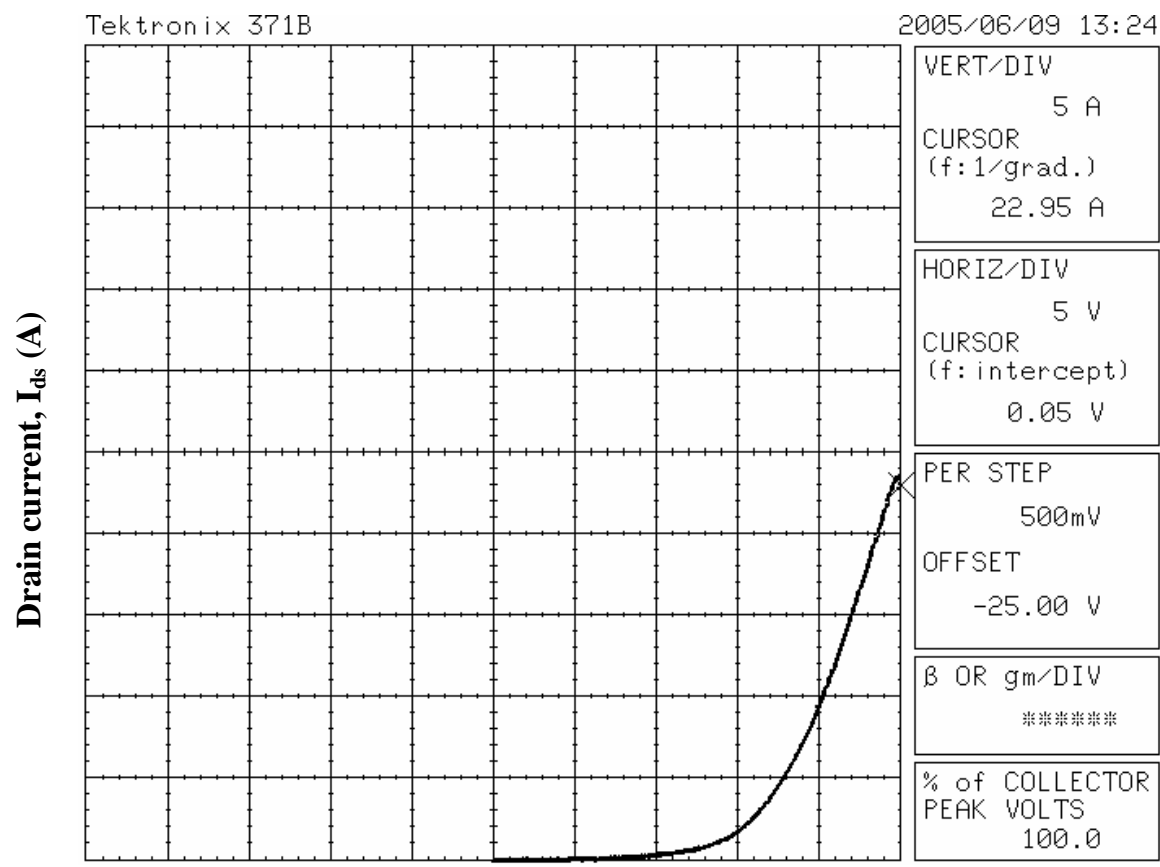

Gate-source voltage, $V_{\mathrm{gs}}(\mathrm{V})$

Fig. 4.4. Test for obtaining the pinch-off voltage.

After the dc characteristics were tested, the transient characteristics were tested. A high-speed gate-driver circuit developed at ORNL was used to drive the JFETs. The turn-on and the turn-off characteristics were tested to accurately model the switching characteristics. The circuit consists of a constant dc supply $(40 \mathrm{~V})$ connected to the drain. The load consists of a $40-\Omega$ resistor and a parasitic inductance of $13 \mu \mathrm{H}$. The gate had a series resistance of $25 \Omega$ and parasitic inductance of $0.5 \mu \mathrm{H}$. To ensure that the JFET was completely turned off, the gate voltage was switched between -25 and $0 \mathrm{~V}$. The turn-on and turn-off waveforms are shown in Figs. 4.5 and 4.6. 


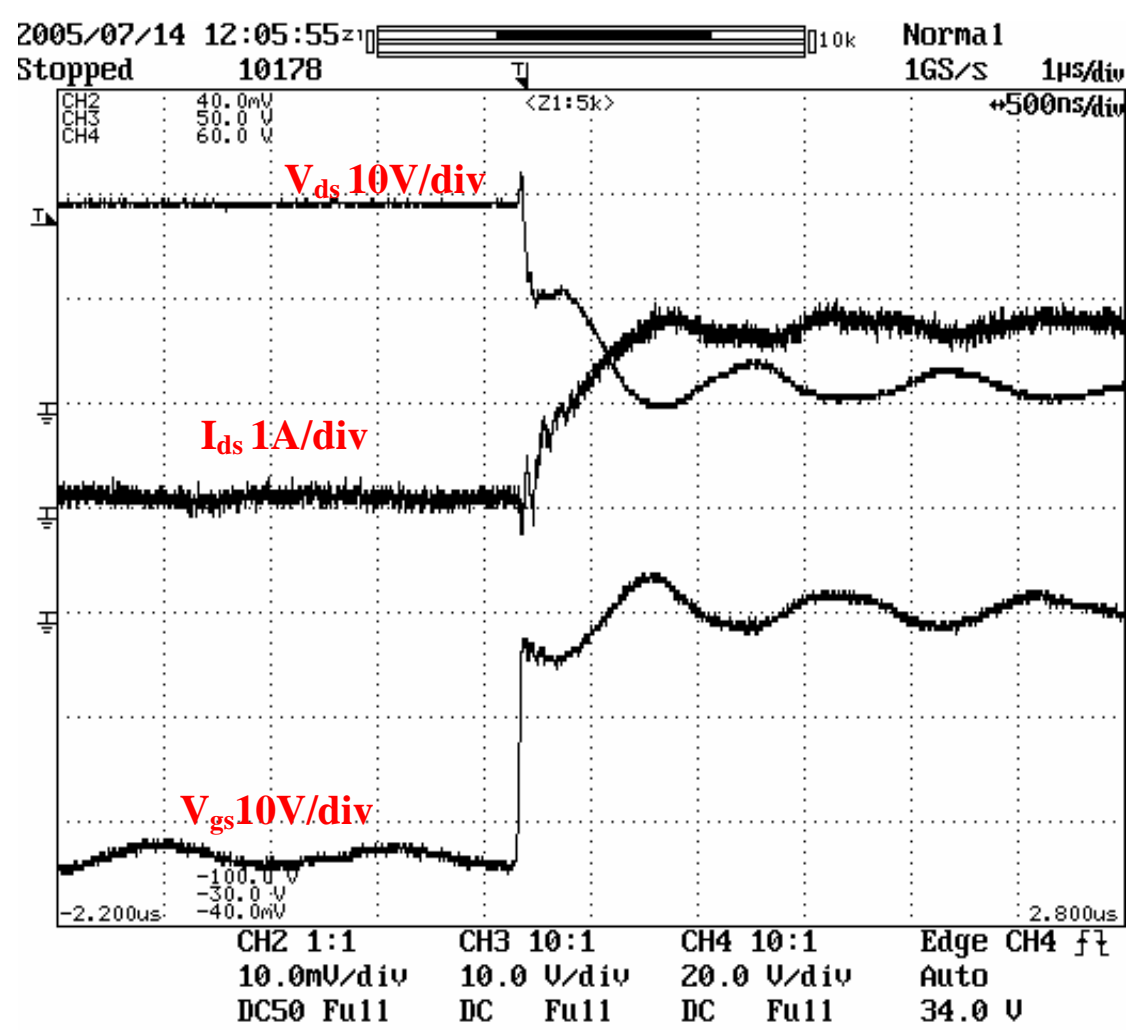

Fig. 4.5. Turn-on waveforms of the SiC JFET.

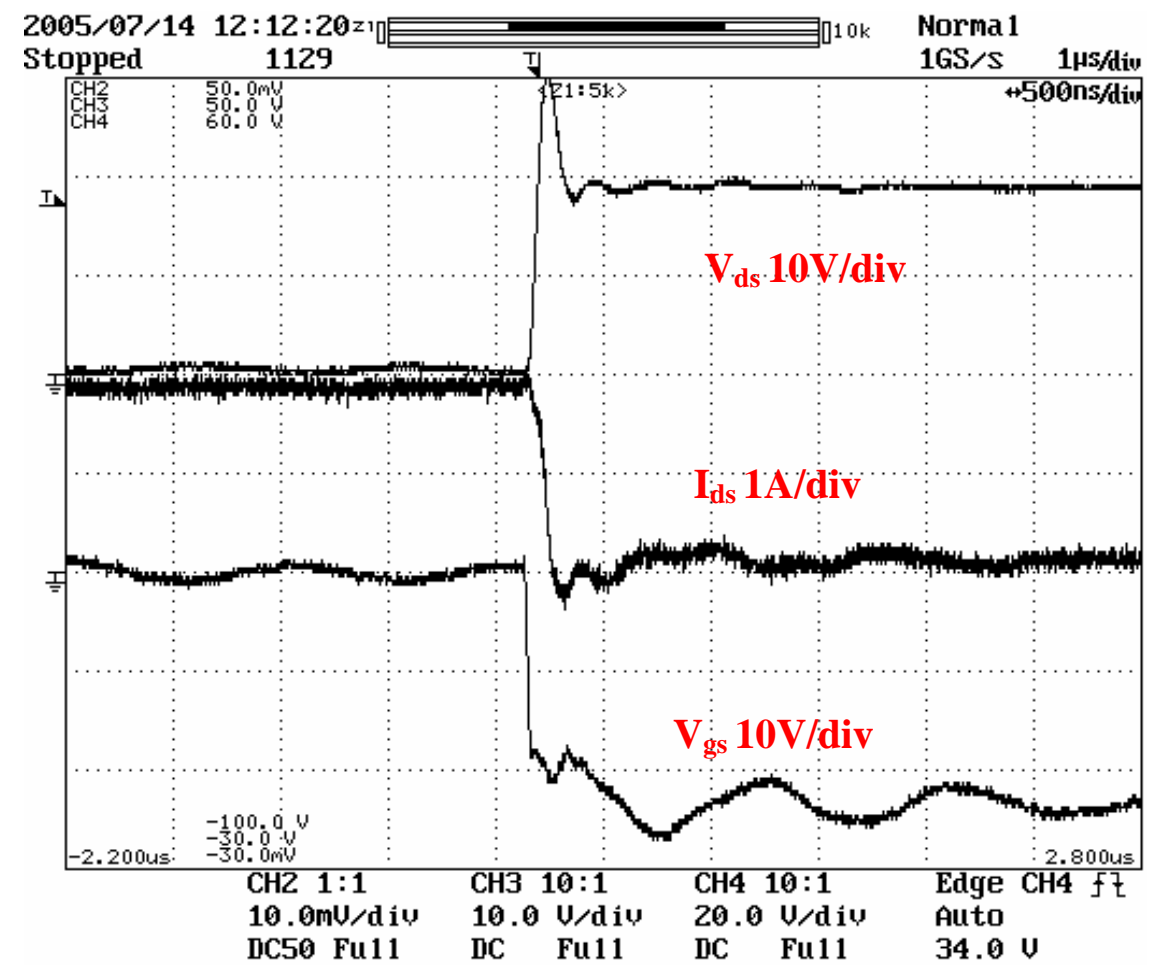

Fig. 4.6. Turn-off waveforms of the SiC JFET. 


\subsubsection{SiC JFET Modeling}

The device physics-based analytical SiC JFET model (Fig. 4.7) used for this project was developed by the University of Arkansas. It is a flexible model that can predict the unipolar and bipolar operation of $\mathrm{SiC}$ JFETs. This circuit representation allows the modeler to visualize and qualitatively assign equations for all the branches and elements. It should be noted that the topology does not represent a sub-circuit of any kind.

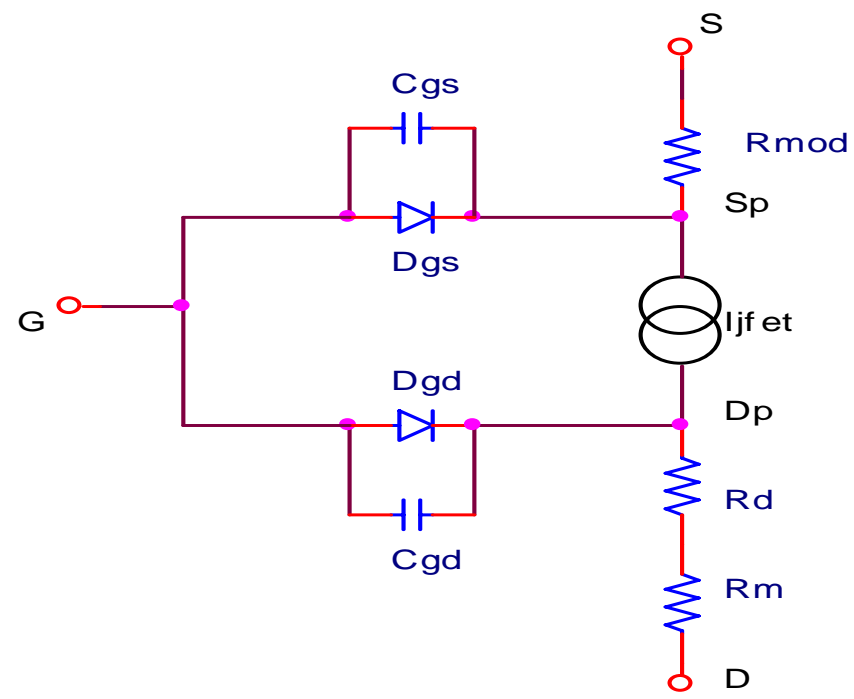

Fig. 4.7. Internal topology of the SiC JFET [20].

The model can be visualized as consisting of a source-region resistance, $R_{m o d}$, that is conductivity modulated by $i_{\text {mod }}$ for positive-gate voltages; an ideal JFET that describes the channel current, $I_{J F E T}$; a bias-dependent series base or drift-region resistance, $R_{d}$; and a series-contact resistance, $R_{m} . D_{g s}$ and $D_{g d}$ are representations of the gate-source and gate-drain pn junctions. $C_{g s}$ and $C_{g d}$ are the corresponding junction capacitances. $D_{p}$ and $S_{p}$, seen in the topology as shown in Fig. 4.7, are the internal nodes in the model.

The major equations used to model the on-state characteristics are as follows

$$
I_{g}+I_{d}=I_{s} .
$$

(i) Pre-turn-on: if $V_{g s}+V_{p}-V_{b i}<=0$,

$$
I d s=0 .
$$

(ii) Linear: if $V_{d s}<\left(V_{g s}+V_{p}-V_{b i}\right)$,

$$
I_{d s}=G_{o}\left\{V_{d s}-\frac{2}{3} \sqrt{\frac{1}{V_{p}}}\left[\sqrt{\left(V_{b i}-V_{g s}+V_{d s}\right)^{3}}-\sqrt{\left(V_{b i}-V_{g s}\right)^{3}}\right]\right\} .
$$

(iii) Saturation: if $V_{d s} \geq\left(V_{g s}+V_{p}-V_{b i}\right)$, 


$$
I_{d s}=\frac{G_{o} V_{p}}{3}\left[1-3 \frac{V_{b i}-V_{g s}}{V_{p}}+2 \sqrt{\left(\frac{V_{b i}-V_{g s}}{V_{p}}\right)^{3}}\right] .
$$

In many cases, parameters involving device geometry and dimensions may not be available to the modeler. Those parameters are lumped together to form an extractable parameter called $G_{o}$, which is defined as the conductance of the device with which the modeler or the circuit designer can adjust the saturation current of the device. The metallurgical base width of the Static induction transistor (SIT) is given by the equation:

$$
W=W_{b z}-W_{g d}
$$

where $W_{b z}$ is the zero-bias value of the depletion width and $W_{g d}$ is the gate-drain junction depletion width. As only the unipolar operating mode is considered, the only carriers are electrons, and their mobility is given by the relation

$$
\mu_{\mathrm{n}}=\frac{947}{\left(1+\left(\frac{\mathrm{N}_{\mathrm{b}}}{1.94 \times 10^{17}}\right)\right)^{0.61}}\left(\frac{\mathrm{T}}{300}\right)^{-2.15} .
$$

For the bipolar mode, the mobility of the holes should also be considered. It is given as

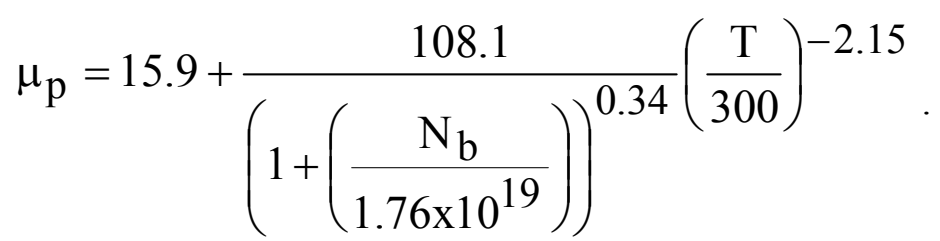

The bias-dependent drift-region resistance is given as

$$
\mathrm{R}_{\mathrm{d}}=\frac{\mathrm{W}}{\mathrm{qN}_{\mathrm{b}} \mu_{\mathrm{n}}\left(\mathrm{A}_{\mathrm{g}}+\mathrm{A}_{\mathrm{s}}\right)}
$$

The conduction charge due to background doping is

$$
q_{m}=\tau \cdot I_{g s},
$$

where $\tau$ is the minority-carrier lifetime and $I_{g s}$ is the gate-source current.

The modulation current in the bipolar mode is 


$$
i_{\text {mod }}=\frac{\left(\mu_{n}+\mu_{p}\right) V_{g s} q_{m}}{W_{g d}^{2}}
$$

The current flow in the gate-drain pn junction:

$$
I_{g d}=I_{s g d}\left(\exp \left(V_{g d} / n g d \cdot V_{t}\right)-1\right)
$$

The current flow in the gate-source pn junction:

$$
I_{g s}=I_{s g s}\left(\exp \left(V_{g s} / n g s \cdot V_{t}\right)-1\right)
$$

While the above equations describe the operation of the model under dc conditions, a separate set of equations must be developed for predicting the transient response. The turn-on and turn-off mechanisms are mainly dominated by the junction capacitances between the gate-source and gate-drain areas. They are mathematically described as follows in Eq. (4.13). The gate-source depletion width is given by the relation

$$
W_{g s}=\sqrt{\frac{2 \varepsilon_{\mathrm{SiC}}\left(\mathrm{V}_{\mathrm{gs}}+\mathrm{V}_{\mathrm{bi}}\right)}{\mathrm{qN}}} .
$$

The associated capacitance is

$$
\mathrm{C}_{\mathrm{gS}}=\frac{\mathrm{f}_{\mathrm{csj}} \mathrm{A}_{\mathrm{S}} \varepsilon_{\mathrm{SiC}}}{\mathrm{W}_{\mathrm{gS}}}
$$

Similarly, the gate-drain depletion area is given by the relation

$$
W_{g d}=\sqrt{\frac{2 \varepsilon_{S i}\left(V_{g d}+V_{b i}\right)}{q N_{D}}} .
$$

And the capacitance of the depletion region is

$$
C_{g d}=\frac{A_{g} \varepsilon_{S i C}}{W_{g d}} .
$$

\subsubsection{Parameter Extraction and Model Validation of the Rockwell SiC JFET}

The first parameter that was evaluated was the pinch-off voltage $(V P)$ that determines the voltage at which the JFET is completely turned off. 
The base doping $\mathrm{Nb}$ was set at the default value of $2 \times 10^{15} / \mathrm{cm}^{3}$, which is the typical doping for the drift layer in $\mathrm{SiC}$ devices.

The conductance Go is found in an empirical way. Its value is set at the highest-current value divided by 2. In the unipolar mode, the highest-current value was found to be 24 A. Therefore, Go was set at 12 .

The constant-series resistance $R S$ is found from the inverse of the slope (taken at the medium- to high-current region) from the transfer characteristic as seen in Fig. 4.8. The ideality factor $N G S$ and $N G D$ for the gate-source and gate-drain pn junctions are set at the default value of 2 .

The channel modulation factor $L A M B D A$ can be extracted as seen in Fig. 4.9.

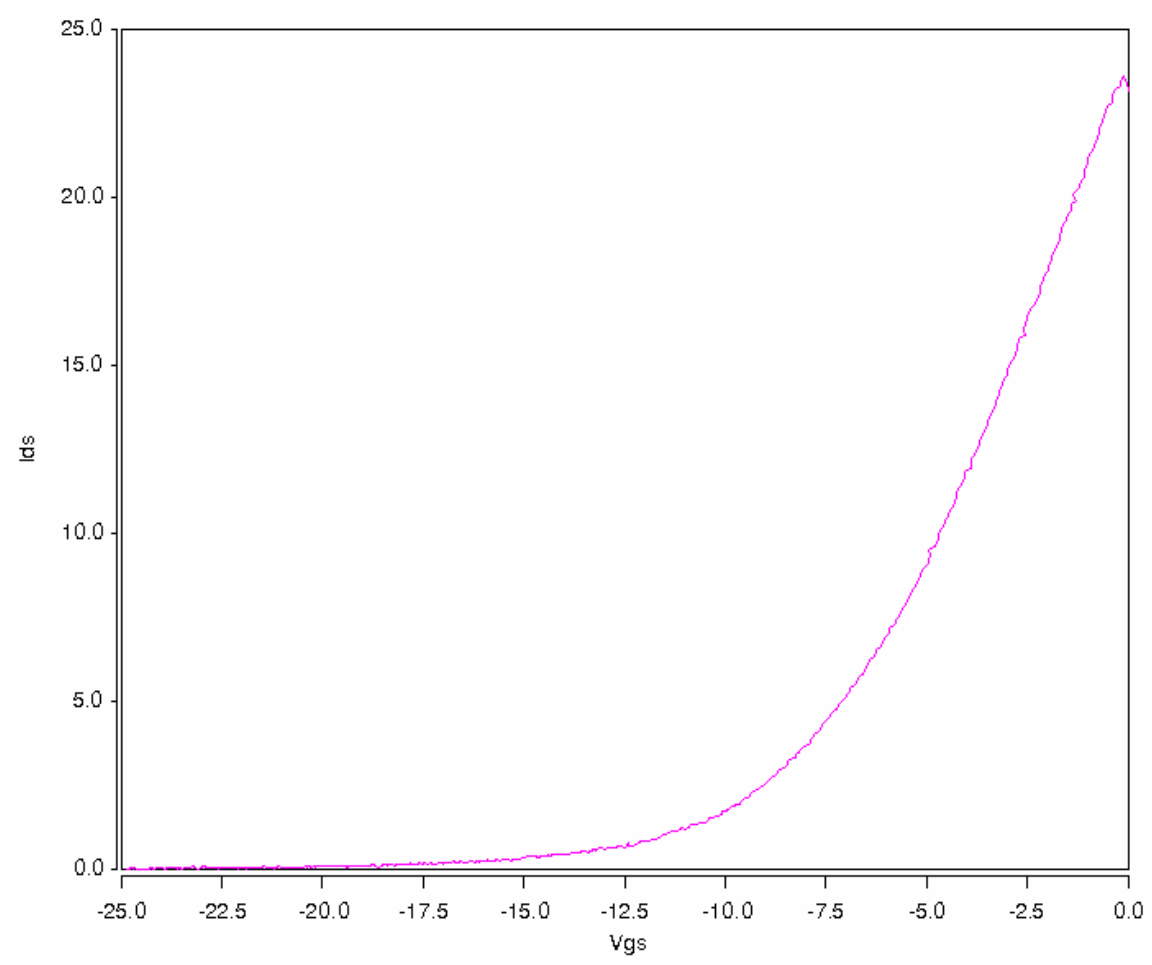

Fig. 4.8. Transfer characteristics of the Rockwell JFET.

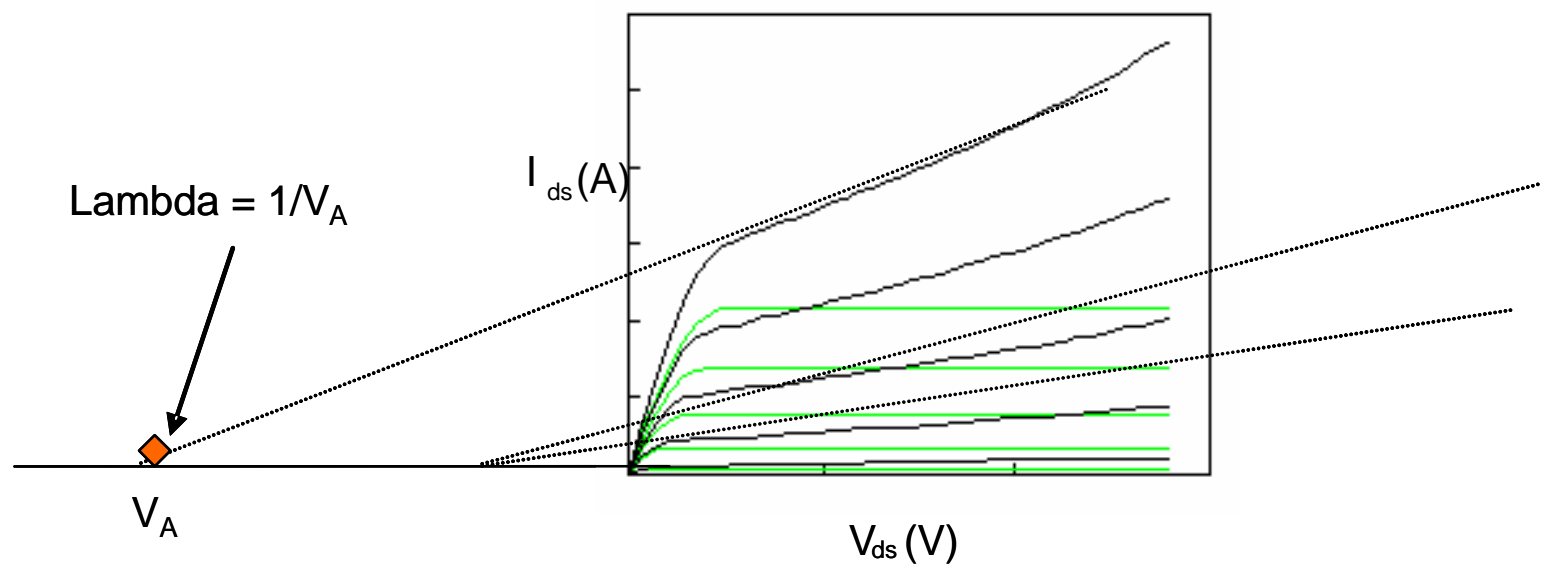

Fig. 4.9. Extraction of channel modulation factor LAMBDA. 
In Fig. 4.9, the green waveforms are the ones where $L A M B D A$ is set to zero (ideal condition). But in most transistors, the drain current never stays the same during saturation; there is a slight increase, as seen in the on-state curves shown in black. When extrapolated, it is seen that the linear waveforms converge at a point in the x-axis denoted as $V_{A}$ (or the "early" voltage in MOSFET parlance). The inverse of $V_{A}$ is taken as the value of $L A M B D A$. The constant gate-source metallization capacitance (CGSM) can be obtained from the switching waveforms.

The on-state validation was done only for the unipolar operation, as the JFET is mainly used in that area, as shown in Fig. 4.10. The simulated values agree with the measured value, the fitting error being approximately $2-3 \%$.

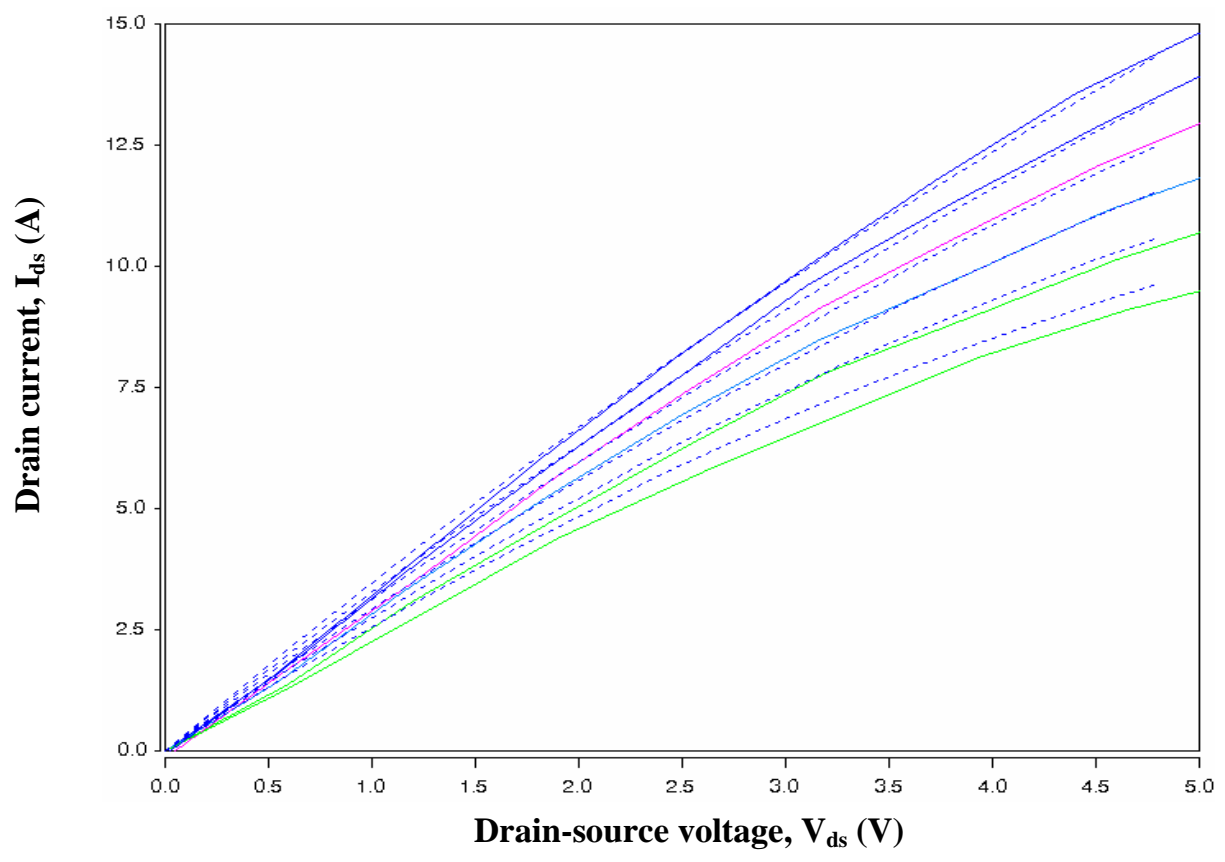

Fig. 4.10. Rockwell SiC JFET measured (solid) and simulated (dotted) on-state waveforms at $25^{\circ} \mathrm{C}$ for different gate voltages $\left(V_{g s}\right.$ ranging from $0 \mathrm{~V}$ to $\left.-2.5 \mathrm{~V}\right)$.

The transient response validation was done in Saber by building a behavioral model of the experimental test-bench as seen in Fig. 4.11. 


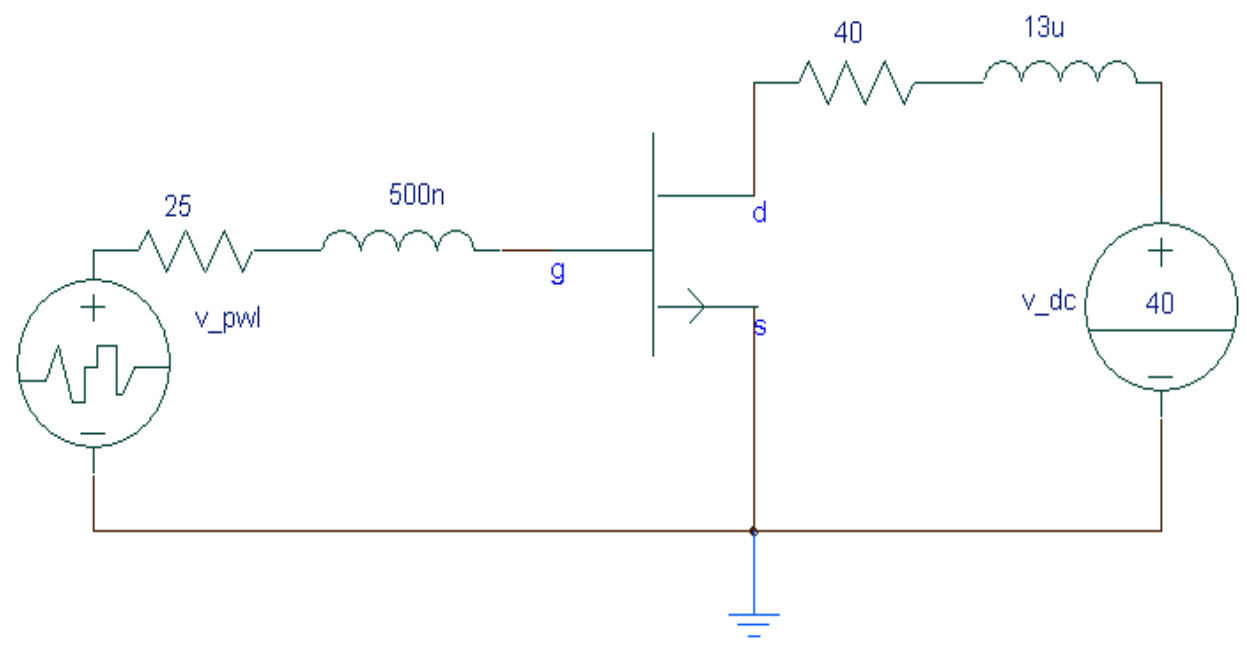

Fig. 4.11. Extraction of channel modulation factor LAMBDA.

The switching characteristics seen in Figs. 4.12 and 4.13 can be explained by the capacitance effects among the various internal model nodes. The gate-source capacitance can be described as a constantmetallization capacitance, $C_{g s m}$, and a voltage-dependent capacitance, $C_{g s j}$, because of the gate junction relative to the source. From the gate to drain, there exists a voltage-dependent gate- $\mathrm{N}^{-}$base junction capacitance $C_{g d j}$. For the case of the turn-on waveforms in Fig. 4.12, the gate-voltage waveform is represented by a two-phase capacitive response. During the initial rise of the gate voltage, the constant $C_{g s m}$ and small junction capacitance, $C_{g s j}$, are charged yielding the initial slope in $V_{g s}$

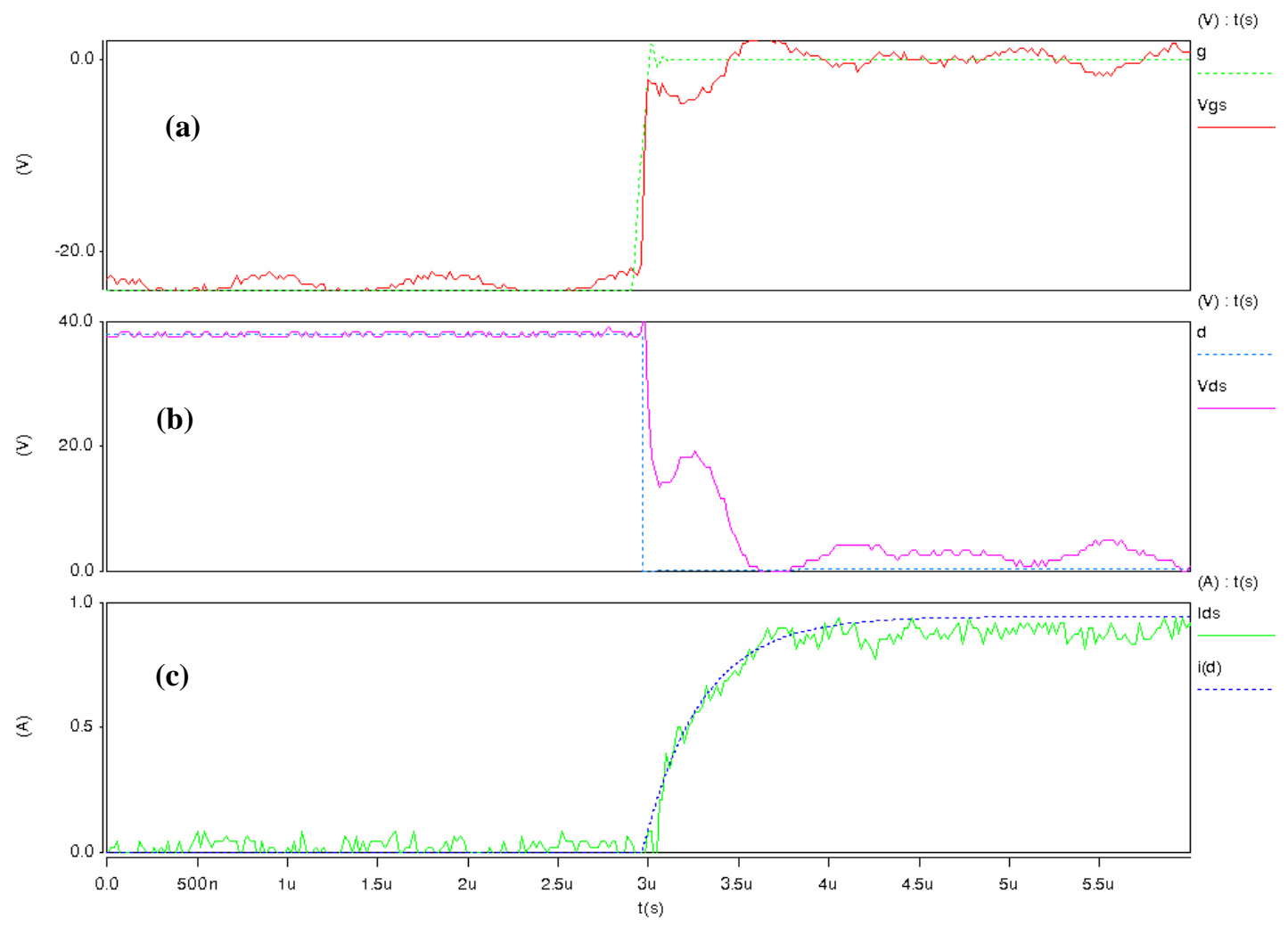

Fig. 4.12. SiC JFET simulated (dashed) and measured (solid) turn-on waveforms at $25^{\circ} \mathrm{C}$ : (a) gate voltage, (b) drain voltage, and (c) drain current. 


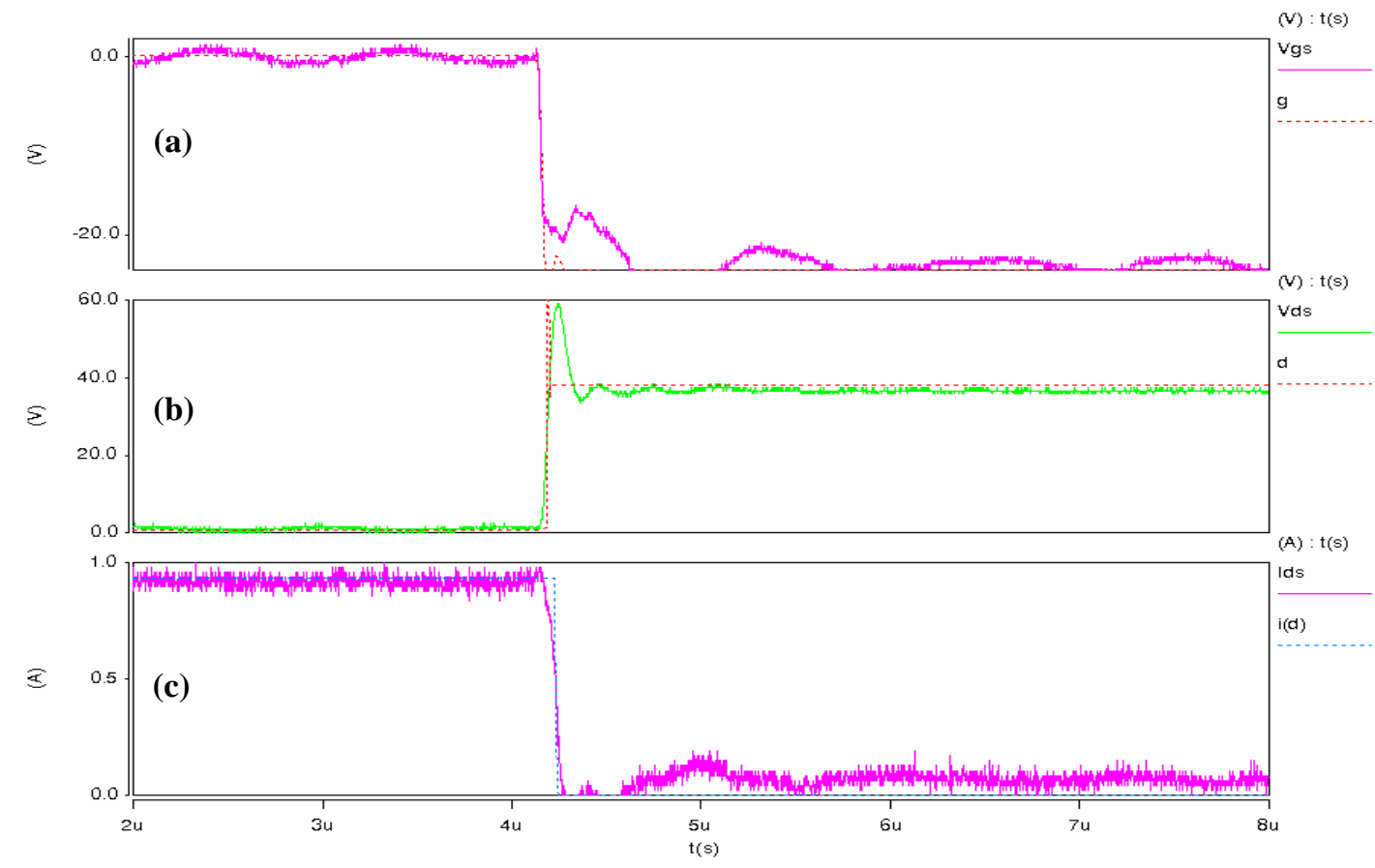

Fig. 4.13. SiC JFET simulated (dashed) and measured (solid) turn-off waveforms at $25^{\circ} \mathrm{C}$ : (a) gate voltage, (b) drain voltage, and (c) drain current.

Once the gate-source capacitance is charged, $V_{g s}$ rises according to the larger gate-drain depletion capacitance $C_{g d j}$. The gate-drain capacitance, $C_{g d j}$, is charged until the threshold voltage $V_{t}\left(V_{t}=V_{p}-V_{b i}\right)$ is reached, at which point the drain current flows as $C_{g d j}$ continues charging. The higher the gate resistance, the more time it takes to charge the capacitances; therefore, the switching response gets slower. As observed in the transient modeling results, the switching time is on the order of $0.1 \mu$ s for a $25-\Omega$ gate resistance. The various depletion capacitances described in the model can accurately predict the switching characteristics of the SiC JFET. The turn-off waveforms are shown in Fig. 4.13. The turn-off waveforms are seen to be much faster than the turn-on as the discharging of the junction and package capacitances happens over a shorter interval of time. Table 4.1 shows the extracted parameters of the $\mathrm{SiC}$ JFET. 
Table. 4.1. SiC power JFET model parameters and extraction characteristics for the Rockwell 15-A JFET

\begin{tabular}{|c|l|l|c|}
\hline Parameter & \multicolumn{1}{|c|}{ Parameter name } & \multicolumn{1}{c|}{ Extraction characteristic } & Value \\
\hline$V P$ & Pinch-off voltage & Measured & $-18 \mathrm{~V}$ \\
\hline$G o$ & Conductance of the JFET & Device-specific & $2 \mathrm{~S}^{15} \mathrm{~cm}^{-3}$ \\
\hline$N B$ & Doping density & Device-specific & $1 \mathrm{e}^{-30} \mathrm{~A}$ \\
\hline$I S G S$ & $\begin{array}{l}\text { Gate-source junction saturation } \\
\text { current }\end{array}$ & $\begin{array}{l}\text { High- to medium current on- } \\
\text { state region }\end{array}$ & $1 \mathrm{e}^{-30} \mathrm{~A}$ \\
\hline$I S G D$ & $\begin{array}{l}\text { Gate-drain junction saturation } \\
\text { current }\end{array}$ & $\begin{array}{l}\text { High- to medium-current on- } \\
\text { state region }\end{array}$ & $2.8 \mathrm{~V}$ \\
\hline$V B I$ & Built-in junction potential & Technology-specific & $0.3 \Omega$ \\
\hline$R S$ & Metallurgical resistance & $\begin{array}{l}\text { Slope of high-current area in } \\
\text { transfer curve }\end{array}$ & $3 \mathrm{e}^{-4}$ \\
\hline$L A M B D A$ & Channel modulation parameter & $\begin{array}{l}\text { Extrapolation of output } \\
\text { characteristics }\end{array}$ & 2 \\
\hline$N G S$ & $\begin{array}{l}\text { Gate-source junction emission } \\
\text { coefficient }\end{array}$ & $\begin{array}{l}\text { High- to medium-current on- } \\
\text { state region }\end{array}$ & 2 \\
\hline$N G D$ & $\begin{array}{l}\text { Gate-drain junction emission } \\
\text { coefficient }\end{array}$ & $\begin{array}{l}\text { High- to medium-current on- } \\
\text { state region }\end{array}$ & $100 \mathrm{pF}$ \\
\hline$C G S M$ & $\begin{array}{l}\text { Gate-source metallization } \\
\text { capacitance }\end{array}$ & Device-specific & 0.5 \\
\hline$F C S J$ & Gate-source area factor & Device-specific & $947 \mathrm{~cm}^{2} / \mathrm{Vs}$ \\
\hline
\end{tabular}

\subsection{SIMULATION OF ALL-SiC INVERTER}

The SiC JFET and diode models were used to simulate an all-SiC inverter. This is a technology demonstrator that shows a full power electronic system in $\mathrm{SiC}$ being successfully simulated. The validated models were used to construct the inverter system as seen in Fig. 4.14. The all-SiC inverter from Rockwell was first tested to ascertain the performance and collect test data for the inverter model validation.

A balanced three-phase 15- $\Omega$ resistive load was used to simulate the operating conditions. The switching frequency was set at $10 \mathrm{kHz}$, and the output frequency was set to $50 \mathrm{~Hz}$. The inverter was simulated for different values of dc voltages and modulation indices. As explained before, the SiC JFETs used in the inverter were modeled and all the parameters were extracted. The 1200-V, 15-A SiC diode in the inverter was also modeled by the procedure explained previously. The results of the diode fitting are seen in Figs. 4.15 and 4.16. Figure 4.17 shows the output voltage of phase 1 of the inverter. The efficiency of the all-SiC inverter ranged from $83.2-87.8 \%$. 


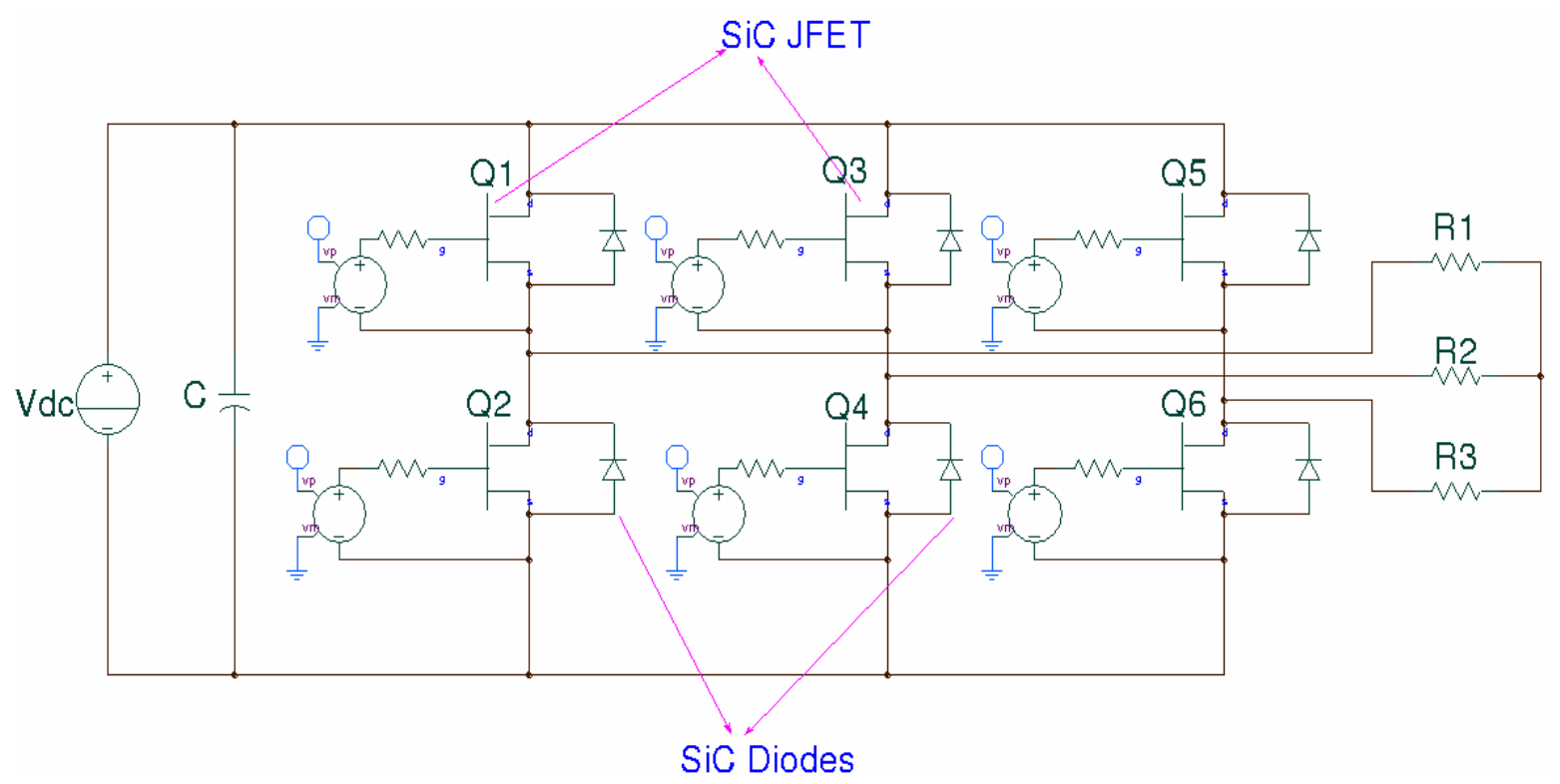

Fig. 4.14. Schematic representation of the all-SiC inverter.

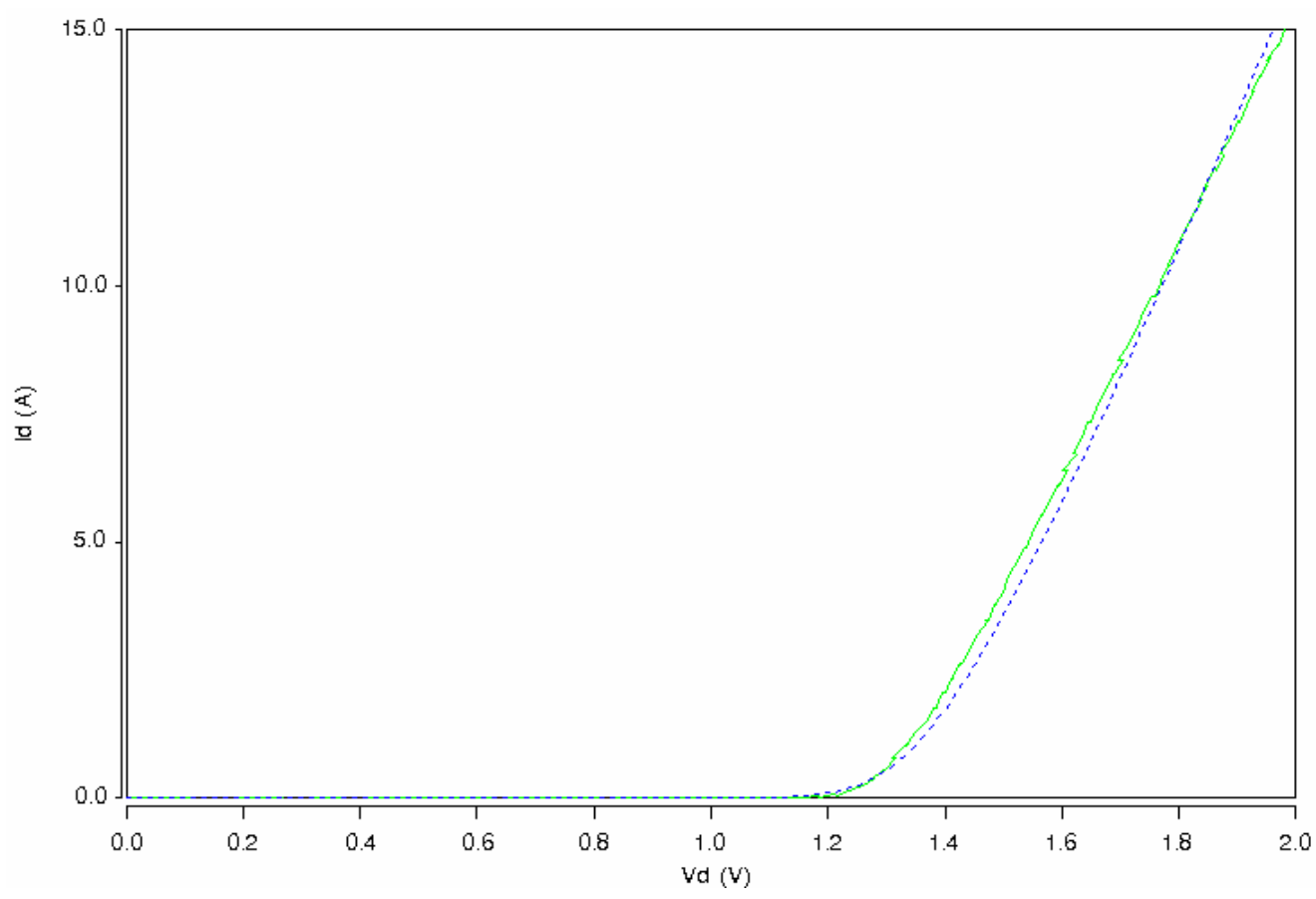

Fig. 4.15. On-state validation of $\mathrm{SiC}$ diode at $25^{\circ} \mathrm{C}$-measured (solid) and simulated (dashed). 


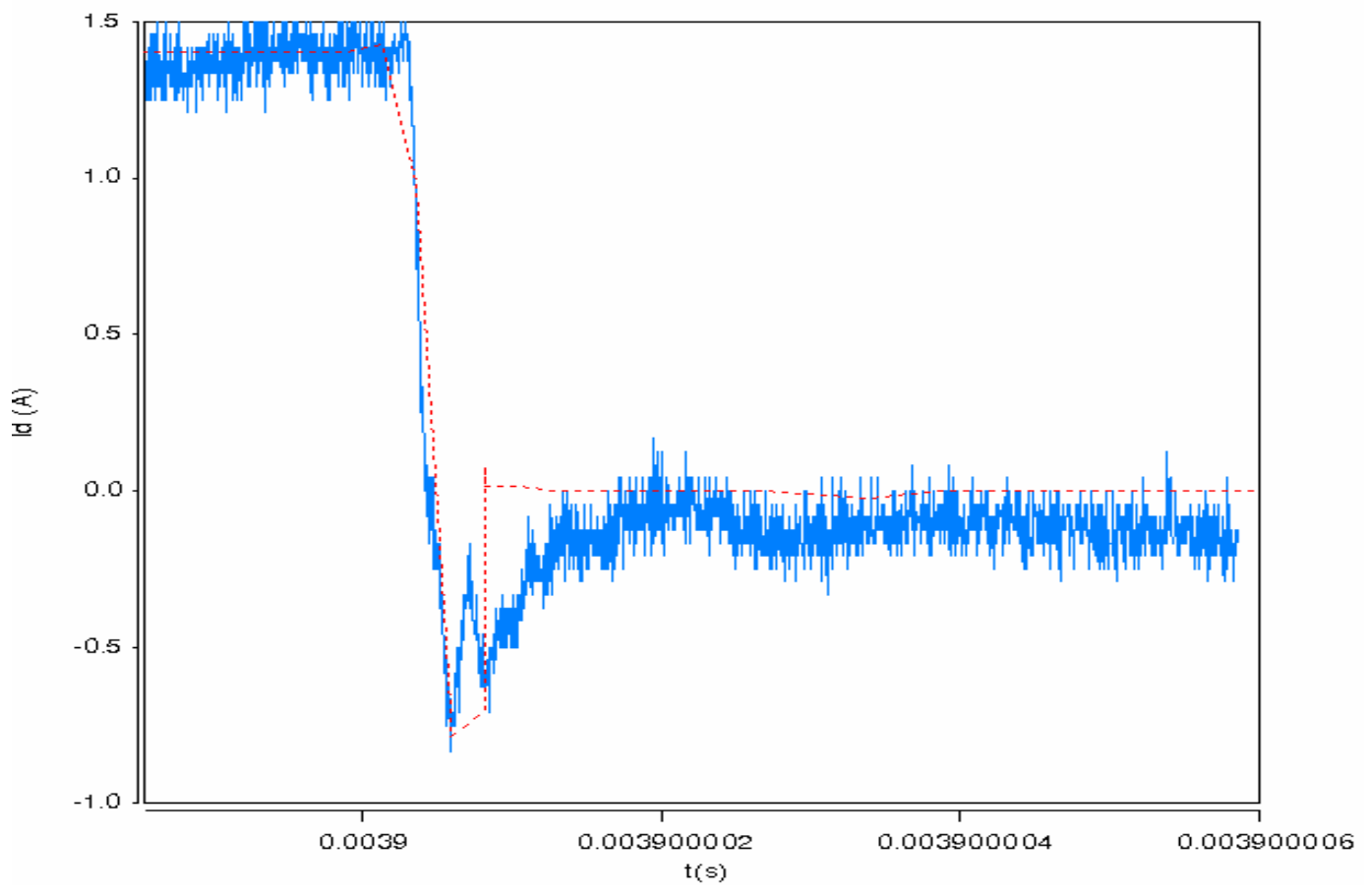

Fig. 4.16. Reverse-recovery validation of $\mathrm{SiC}$ diode at $25^{\circ} \mathrm{C}$-measured (solid) and simulated (dashed).

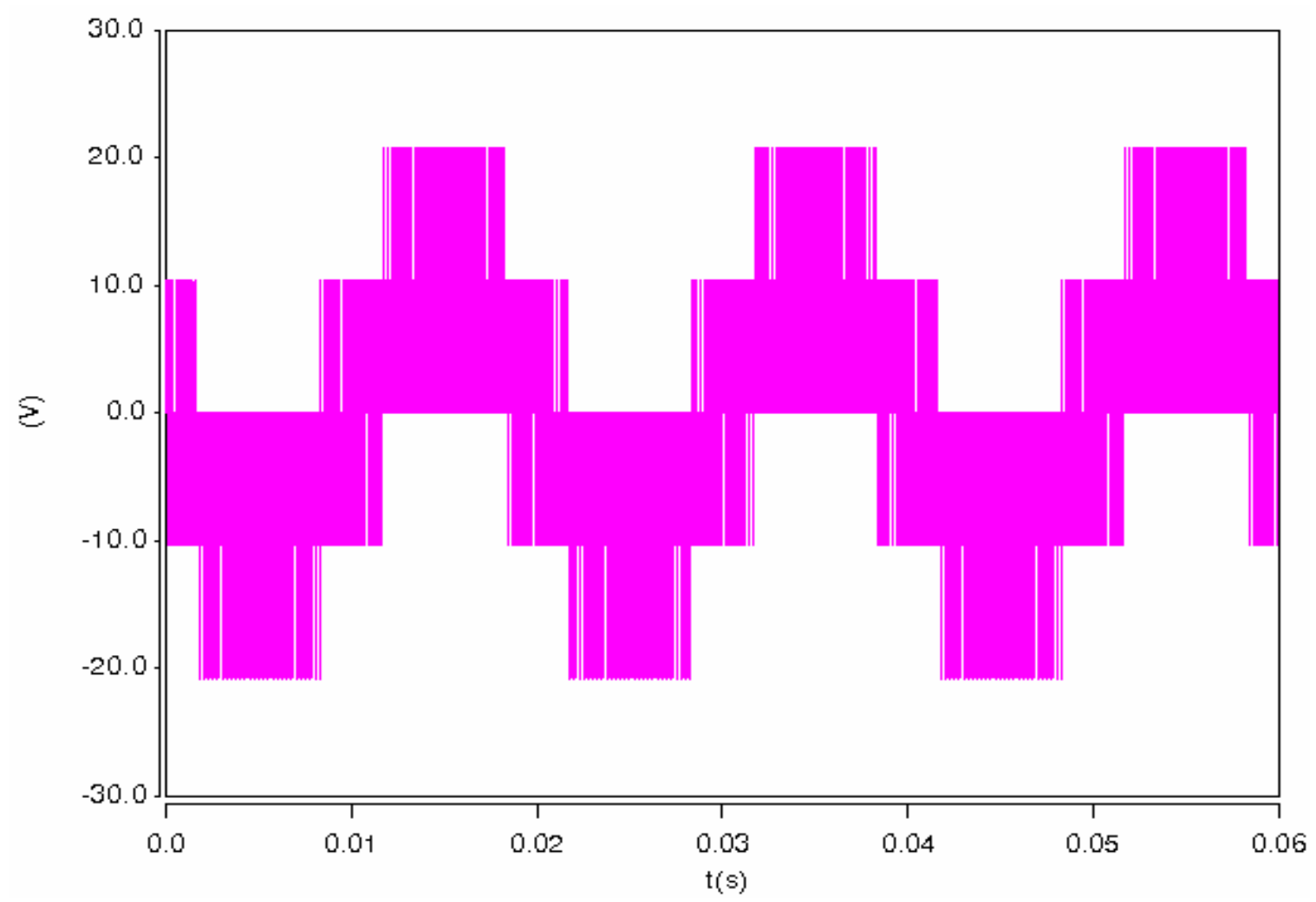

Fig. 4.17. Simulated output voltage in phase 1 of the all-SiC inverter with resistive load. 


\subsection{CONFIGURATION OF THE INVERTERS}

The SiCinverter module was built using 1200-V, 7.5-A JFETs and 1200-V, 15-A SiC Schottky diodes. The main switches in each phase leg consisted of two JFETs with 7.5-A ratings in parallel. Three modules were developed by Rockwell Scientific and delivered to ORNL.

A Si inverter module with similar ratings was selected for a performance comparison with the all-SiC unit. Pictures of the SiC and the Si modules are shown in Figs. 4.18 and 4.19.

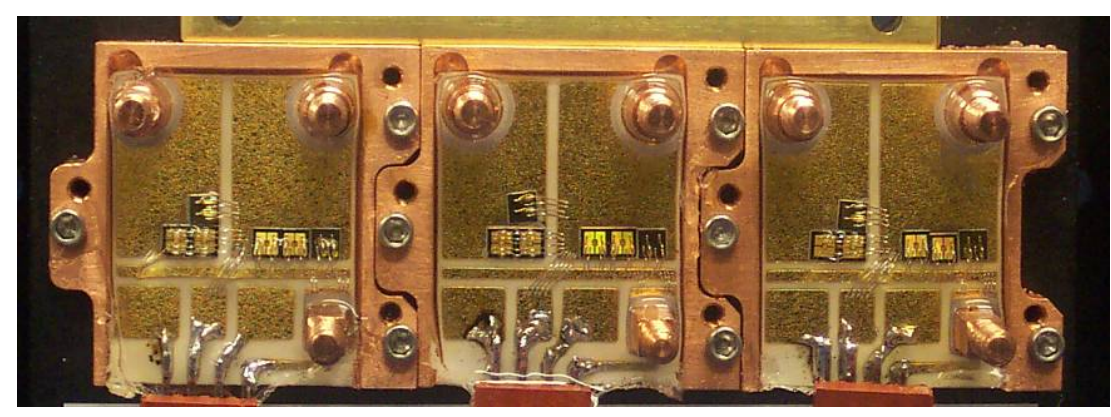

Fig. 4.18. All-SiC module.

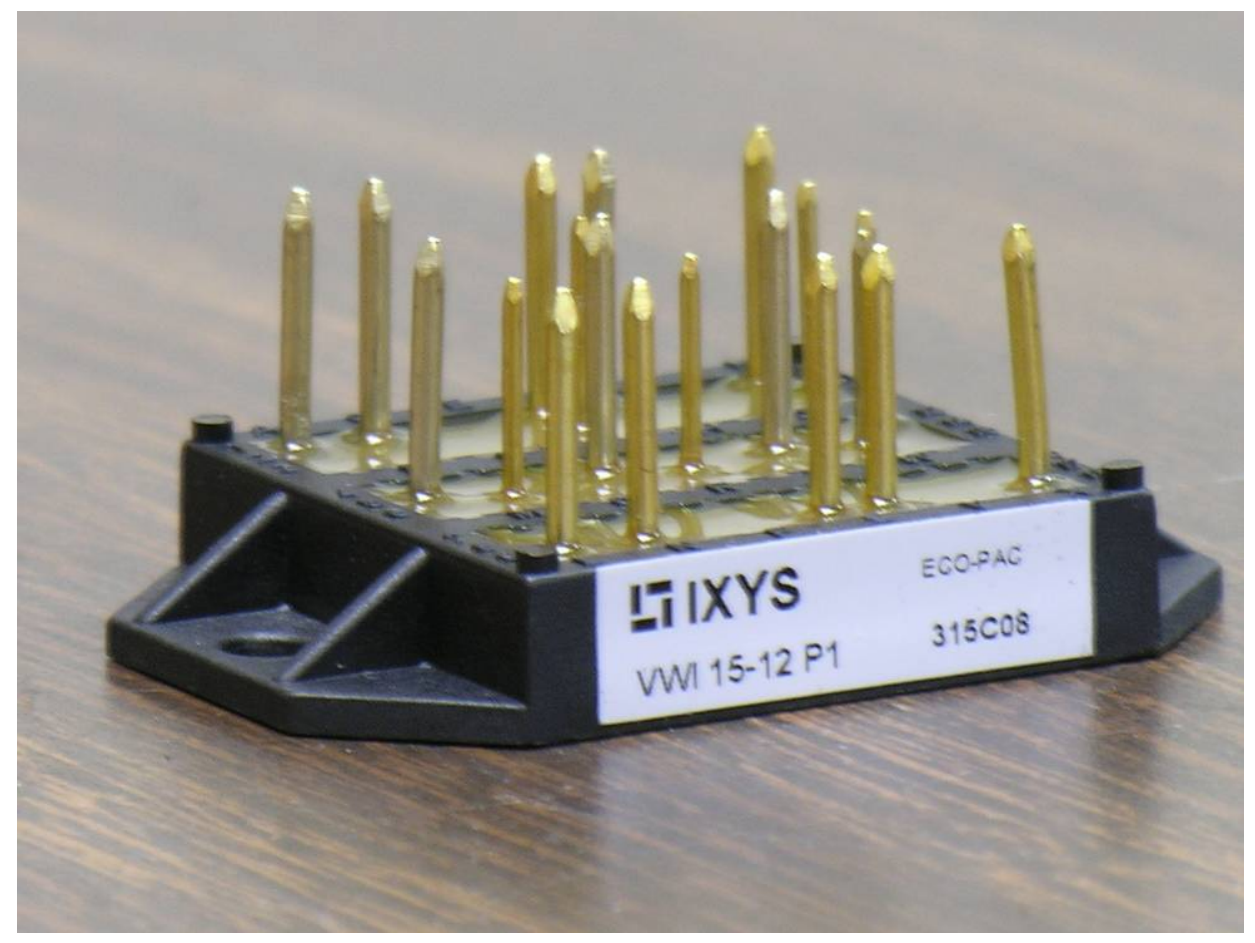

Fig. 4.19. All-Si module. 


\subsection{INVERTER TESTING}

\subsubsection{Testing the Controller}

A modified motor-drive controller shown in Fig. 4.20 was delivered by Rockwell to be used as the inverter controller. This is an open-loop controller that features two different gate-driver outputs, one for driving Si IGBTs (20-V swing) and another for driving SiC JFETs (30-V swing). Figures 4.21 and 4.22 show typical $30-\mathrm{V}$ and $20-\mathrm{V}$ swing output voltages supplied by the controller. The controller has a keypad to adjust the frequency of operation.

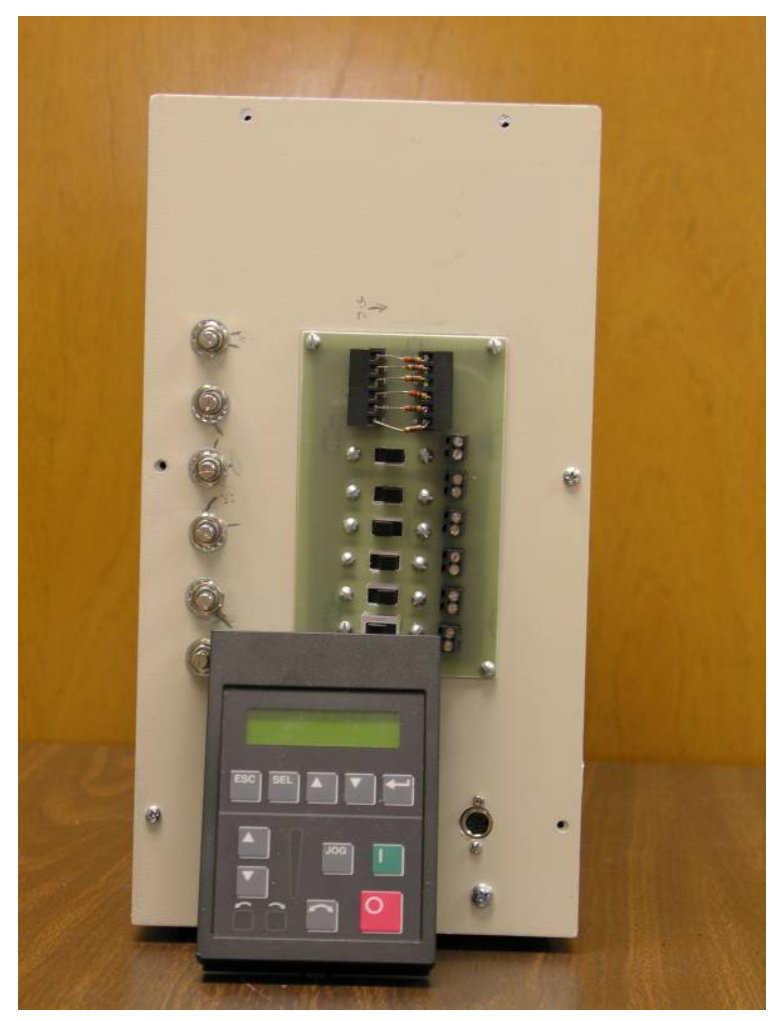

Fig. 4.20. Gate-drive control unit. 


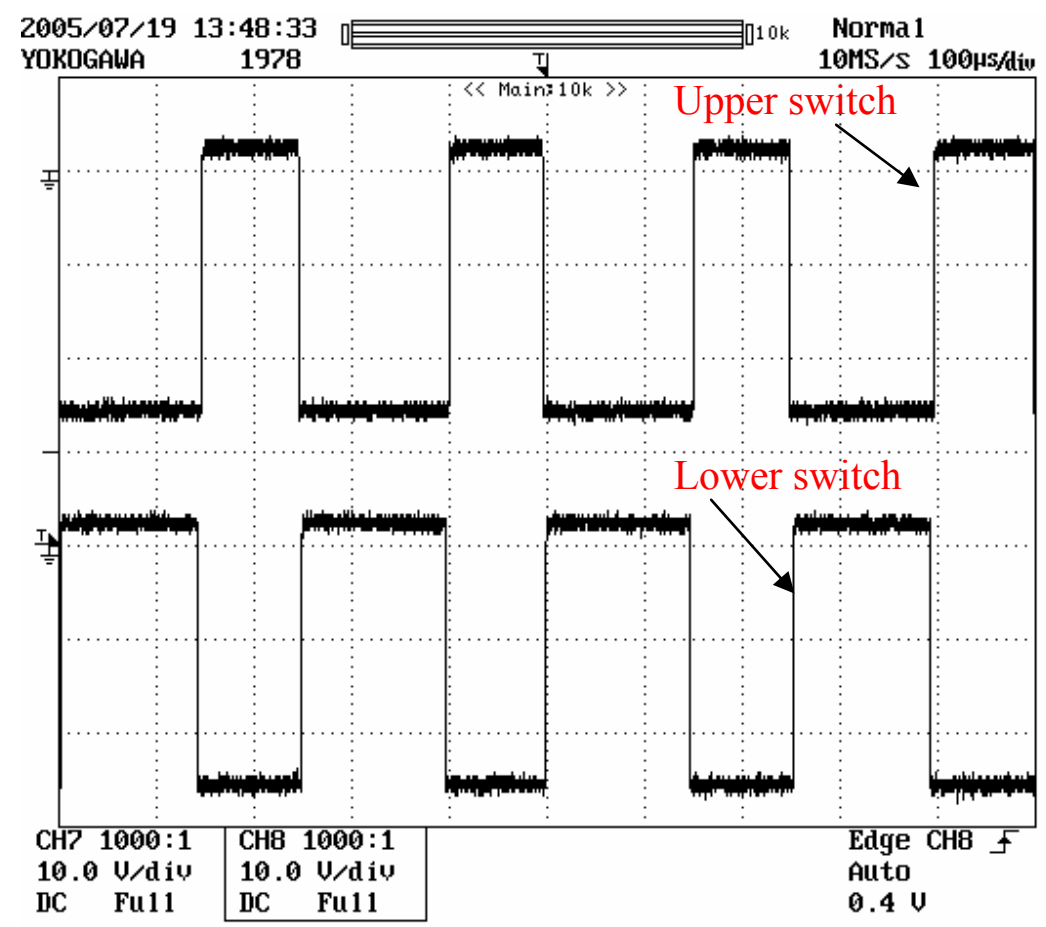

Fig. 4.21. Controller output voltage with $30-\mathrm{V}$ swing for $\mathrm{SiC}$ module.

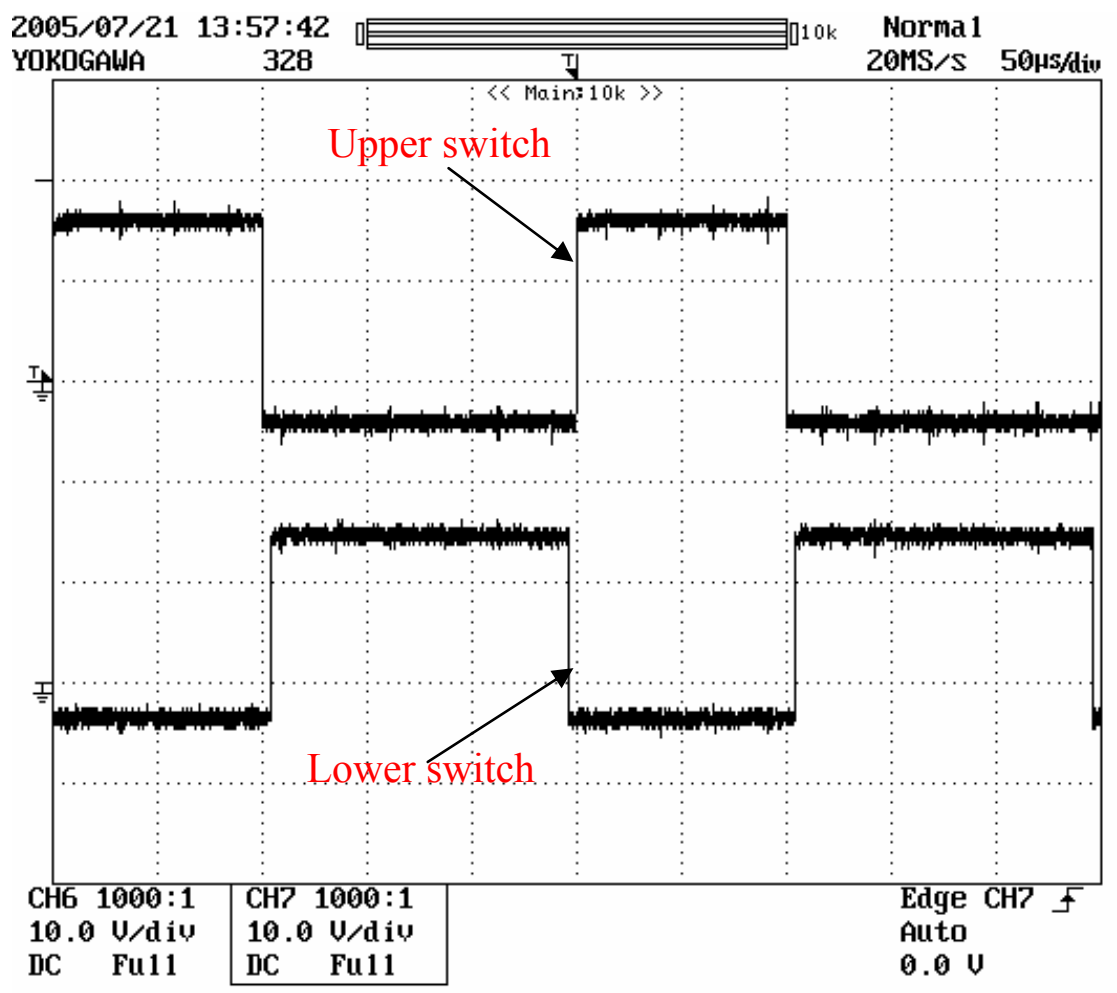

Fig. 4.22. Controller output voltage with $20-\mathrm{V}$ swing for Si module. 


\subsubsection{Resistive- and Inductive-Load Tests}

The test setup used the following equipment, as shown in Fig. 4.23.

- Yokogawa PZ4000 power analyzer for power measurement

- Variable resistor load with a capacity of $24 \mathrm{~kW}$

- Inductor with 400-A capacity

- Coolant pump with a temperature controller

- A de power supply

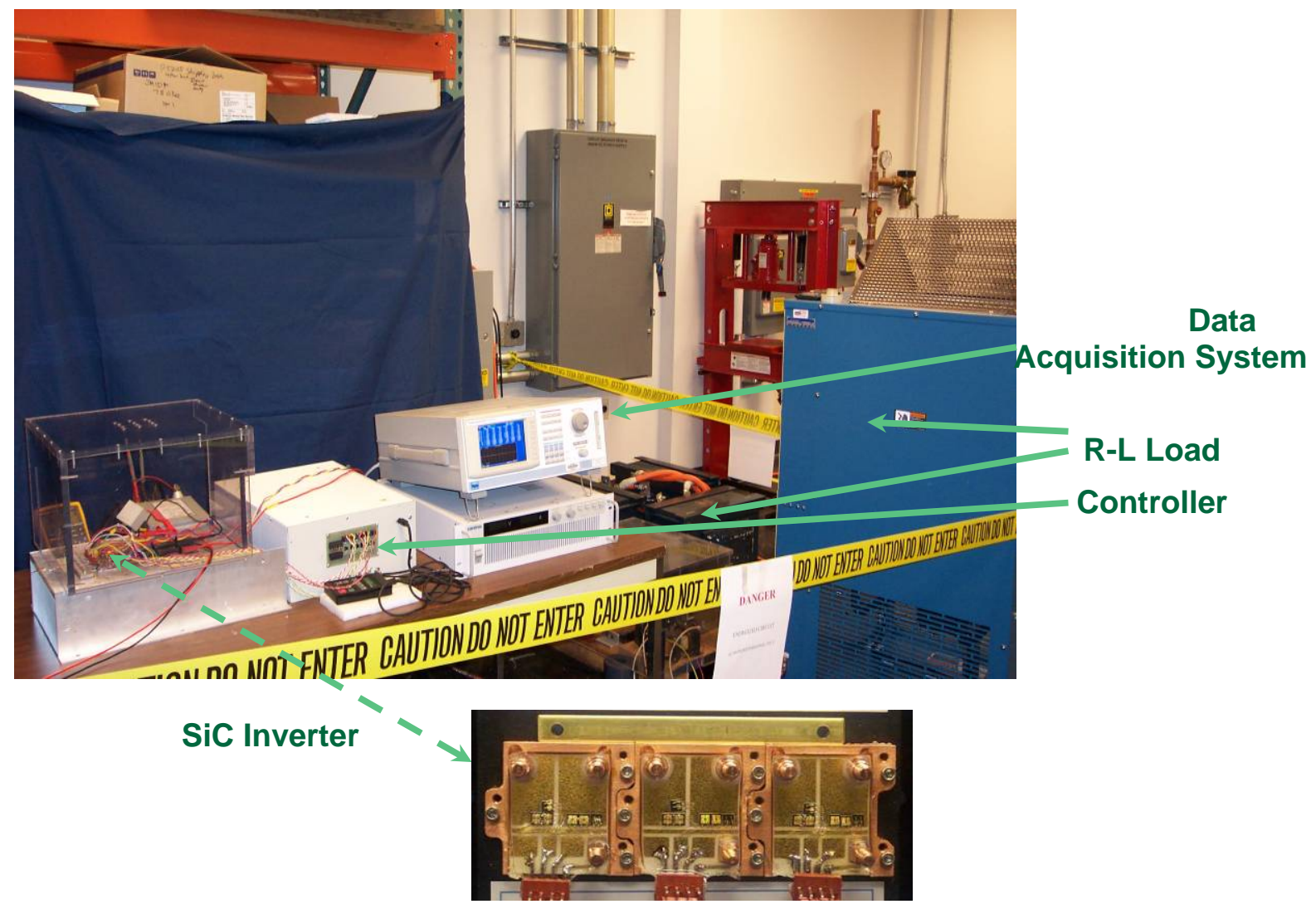

Fig. 4.23. Test setup for R-L load test.

\subsubsection{Operation}

The gate signals to the inverter modules were checked with no load on the inverter. The inverters were connected to a three-phase R-L load. The operating current was controlled by varying the load resistance. The dc-link voltage was varied from 0 to a maximum bus voltage of $400 \mathrm{~V}$. The frequency of operation was fixed, and the load was varied for a particular dc-link voltage. For each setting of the load and frequency, the dc-link voltage, dc-link current, input power, output power, efficiency, output currents, and phase voltages were recorded. The load was increased in steps without exceeding the power rating of the inverter or exceeding the power rating of the load. The procedure was repeated, increasing the output frequency command in steps of $10 \mathrm{~Hz}$ from 10-100 Hz. 


\subsubsection{Results}

The operating waveforms for the SiC inverter at different load settings are shown in Fig. 4.24. The plots of efficiency curves for different operating conditions are shown in Figs. 4.25 and 4.26. It can be seen from the plots that the efficiency of the $\mathrm{Si}$ inverter module is much higher than the $\mathrm{SiC}$ module.

To investigate the reasons for this difference, the inverters were tested with a resistive load only. With a resistive load, only the JFETs and IGBTs conduct, not the diodes. The efficiency plots for different resistive-load settings of the inverters are shown in Figs. 4.27, 4.28, and 4.29. Again, the efficiency of the all-SiC inverter was lower.

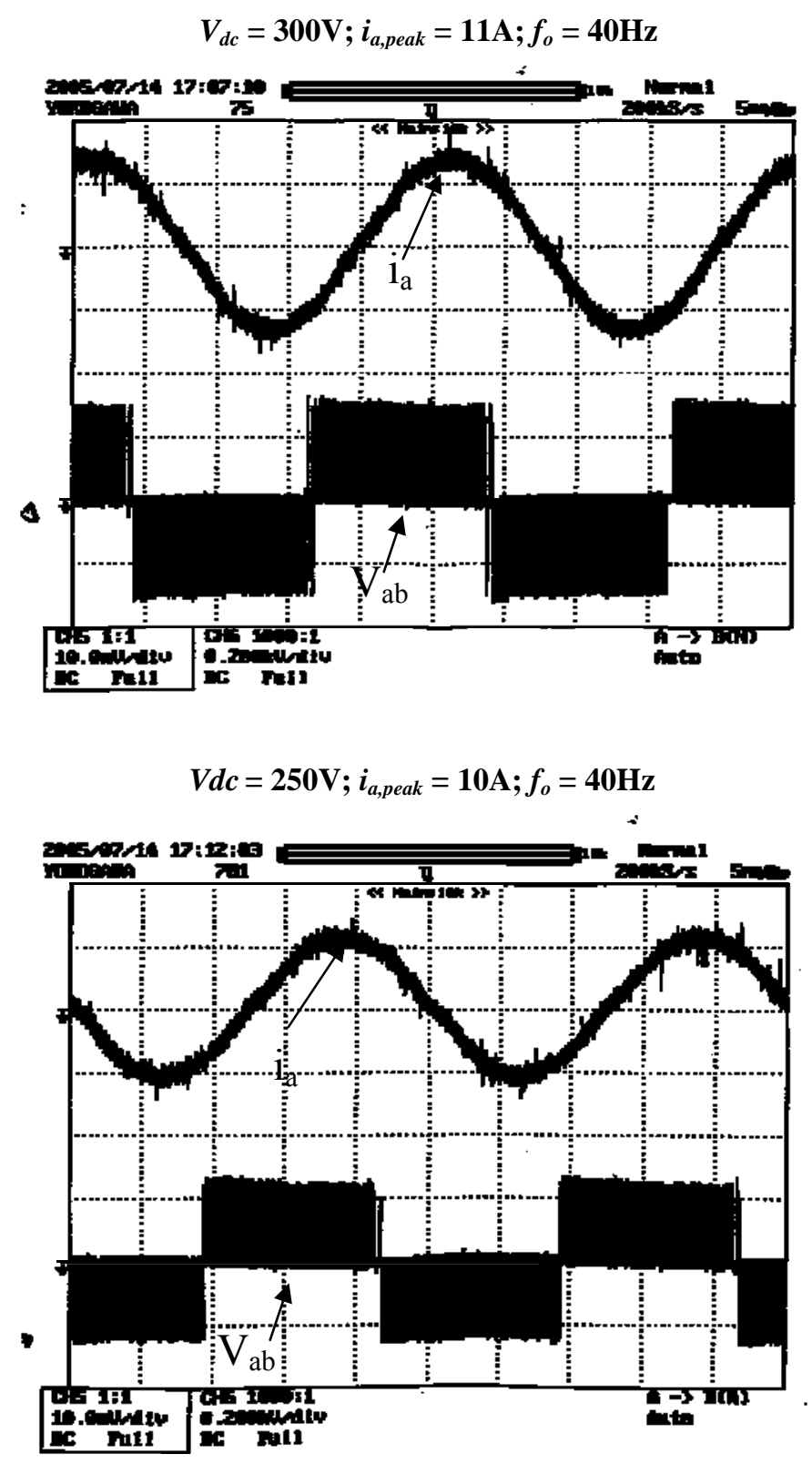

Fig. 4.24. Operating waveforms of SiC module for R-L load test. 


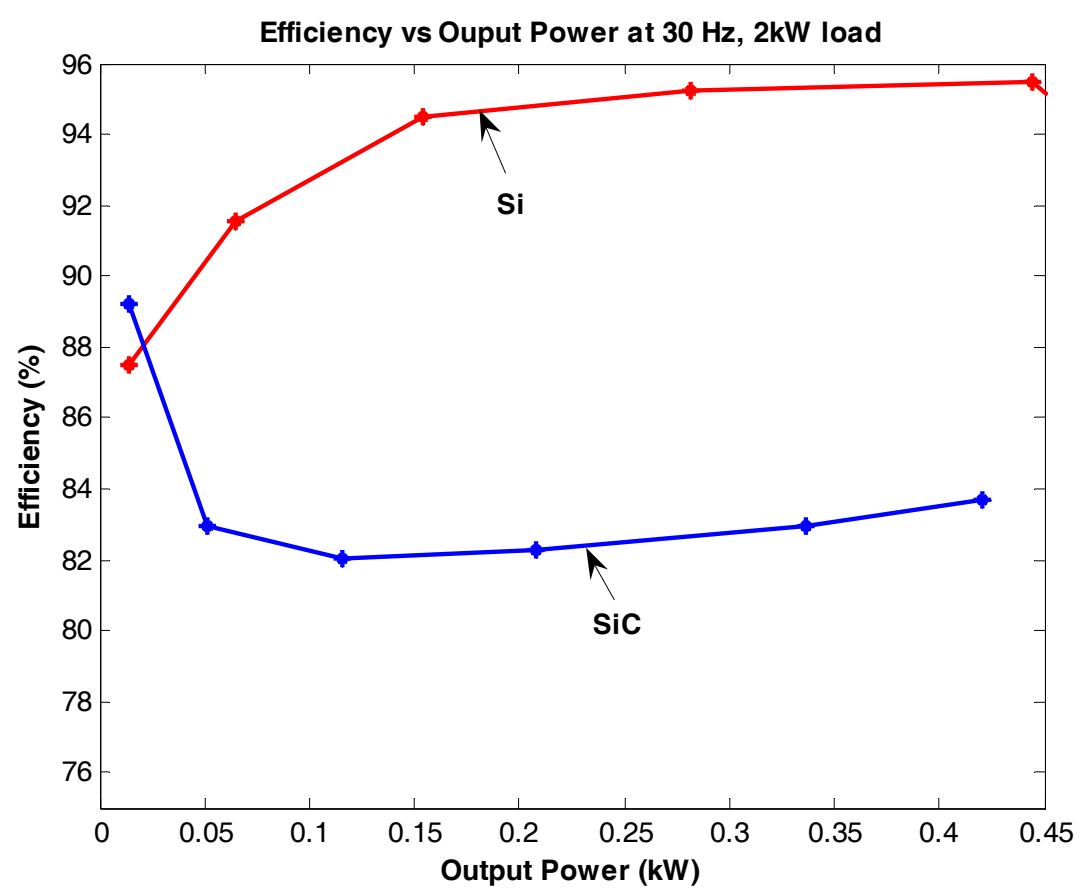

Fig. 4.25. Efficiencies comparison plot at $30-\mathrm{Hz}$ operation for $\mathrm{R}-\mathrm{L}$ load test.

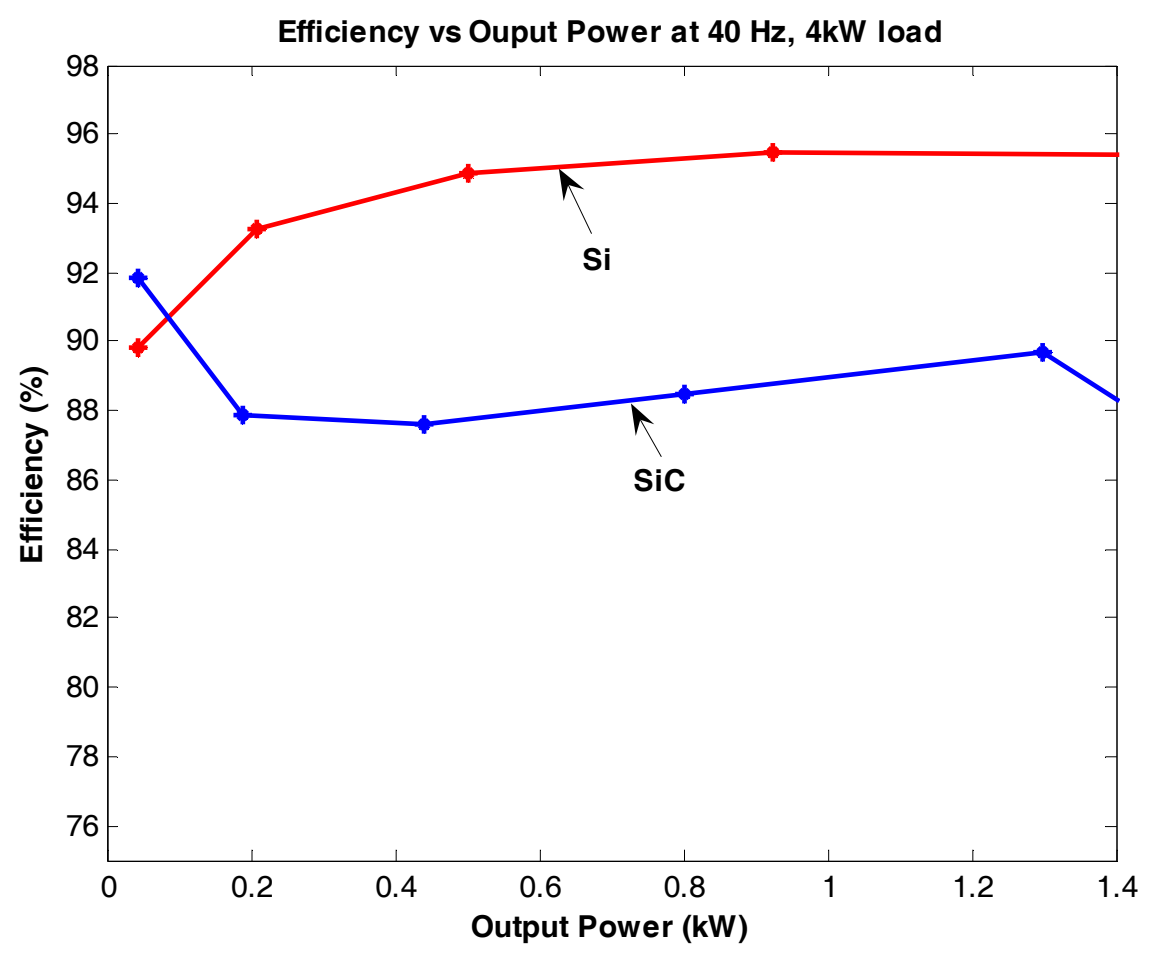

Fig. 4.26. Efficiencies comparison plot at 40-Hz operation for R-L load test. 


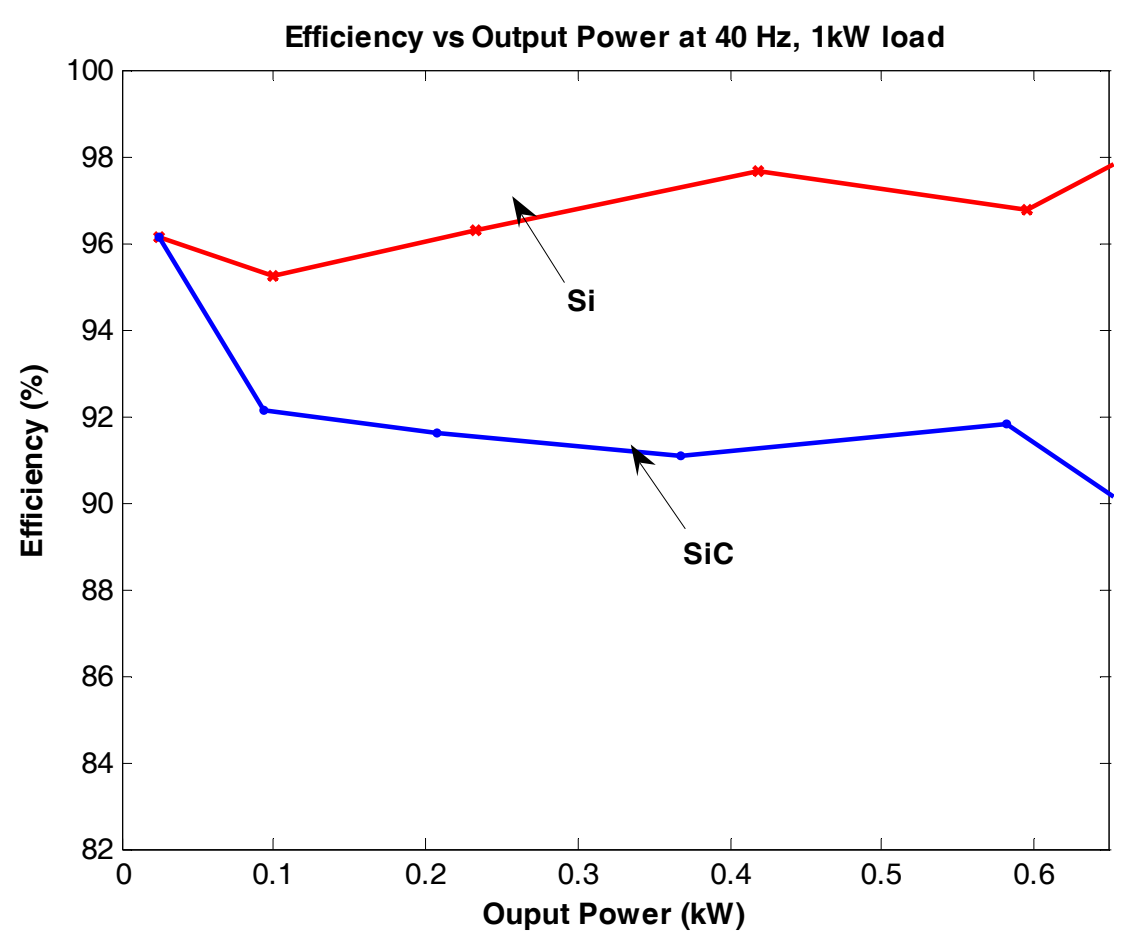

Fig. 4.27. Efficiencies comparison plot at $40-\mathrm{Hz}$ operation for resistive-load test.

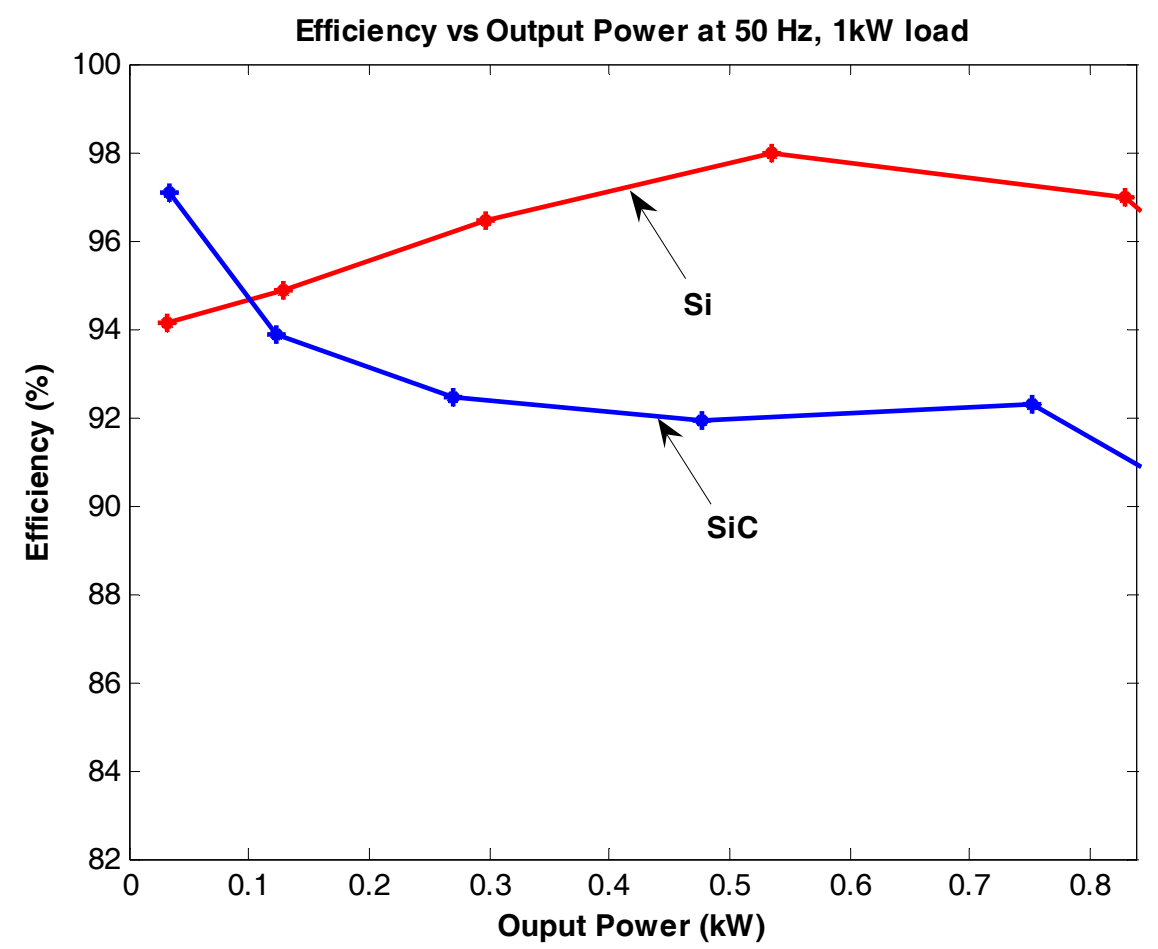

Fig. 4.28. Efficiencies comparison plot at 50-Hz operation for resistive-load test. 


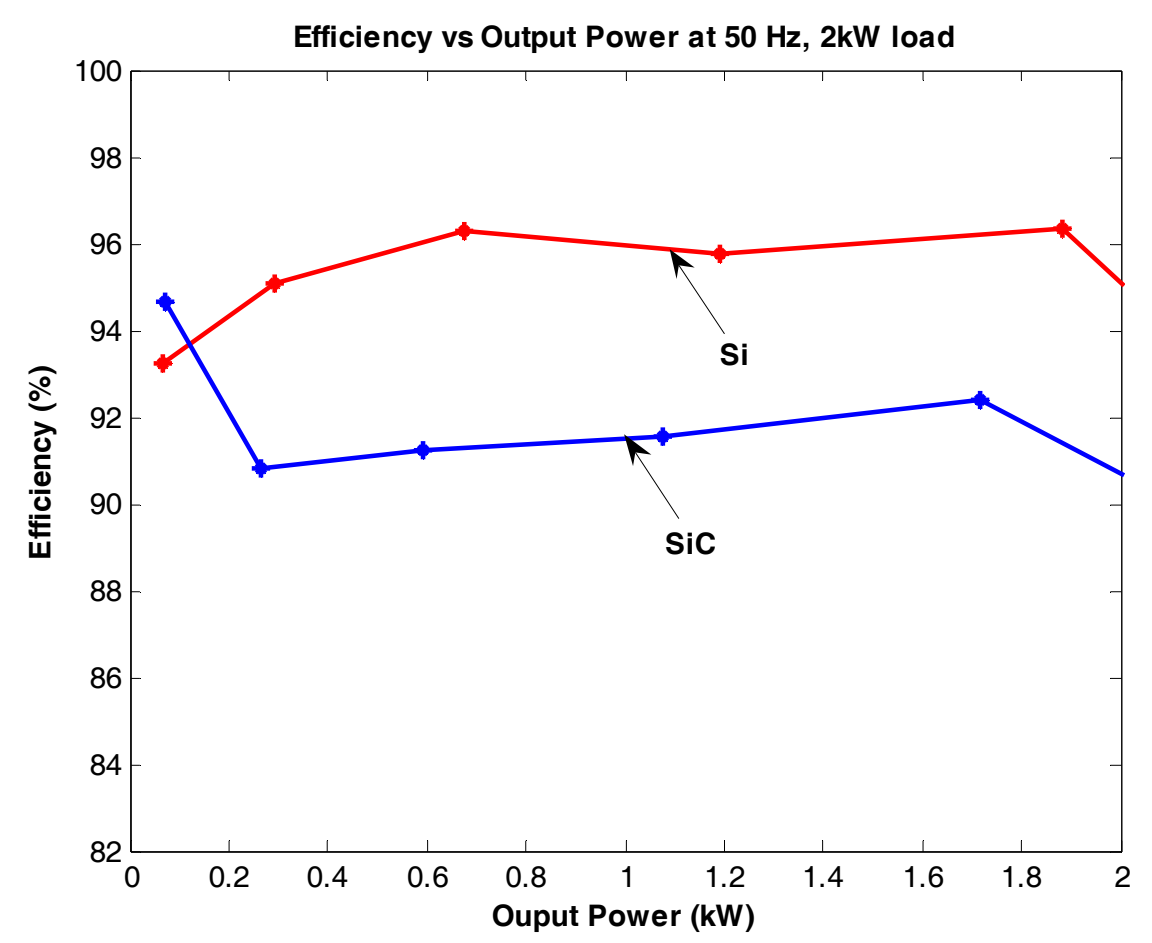

Fig. 4.29. Efficiencies comparison plot at $50-\mathrm{Hz}$ operation for resistive-load test.

To get a better understanding of the reason why the all-SiC inverter efficiency was worse than that of the all-Si inverter, a comparison of the static characteristics of the IGBT, the SiC JFET, and the diodes in the inverter modules are shown in Fig. 4.30 and 4.31.

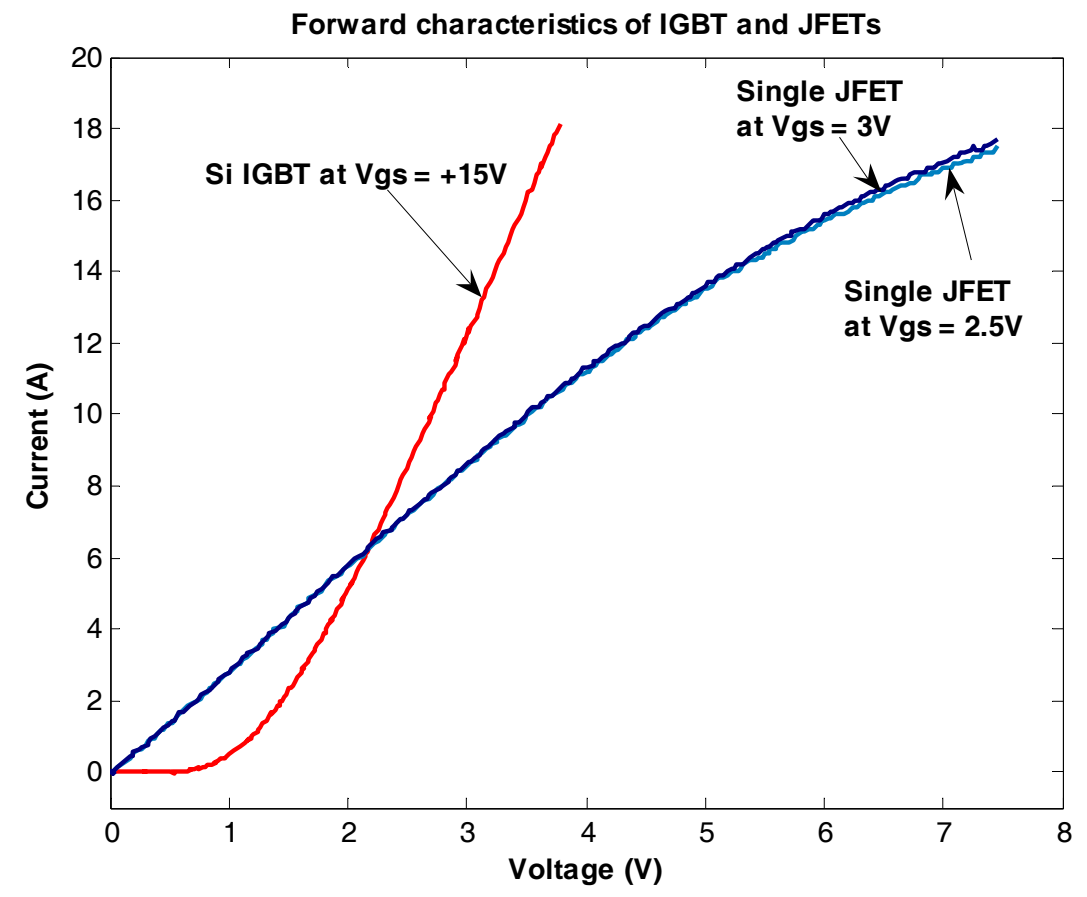

Fig. 4.30. Forward characteristics of IGBT and JFET in the Si and SiC modules. 


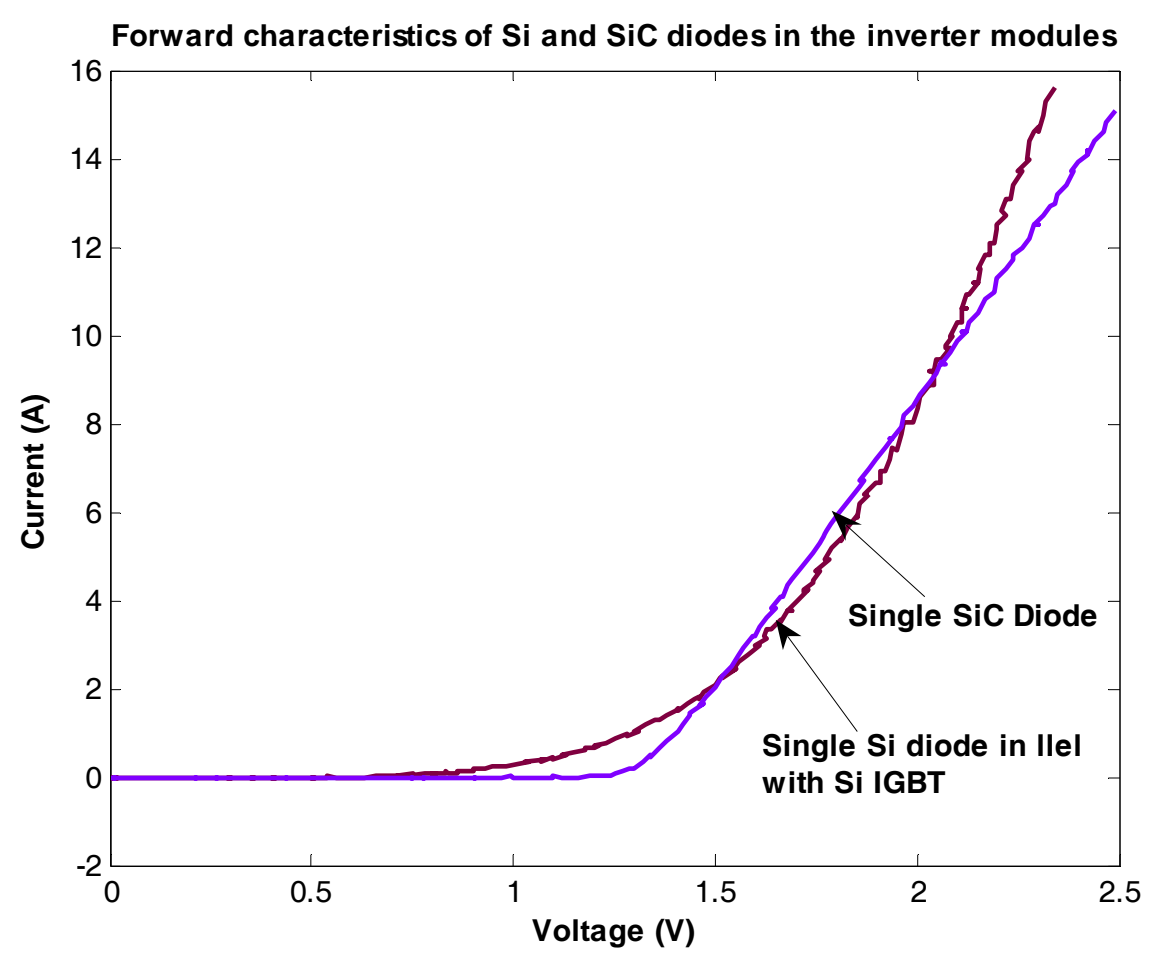

Fig. 4.31. Forward characteristics of diodes in the Si and SiC modules.

The on-state voltage drop of the Si IGBT is much less than that of the SiC JFET at higher-current levels because of the higher on-resistance of the SiC JFET. The high value of this resistance is attributed to the fact that it is a prototype device and there are still some material and processing issues to be resolved. Note that at lower currents, the SiC JFET has a lower on-state voltage drop. Considering that these particular Si pn and SiC Schottky diodes have similar static characteristics, an all-SiC inverter is expected to have higher conduction losses.

The turn-on and turn-off waveforms for the SiC JFET and Si IGBT for 4-kHz operation are shown in Figs. 4.32 and 4.33. These waveforms show that the SiC JFETs in the all-SiC inverter are much slower than the Si IGBTs tested; therefore, they have much higher switching losses.

The analysis of the conduction and switching losses of the devices shows that the devices in the all-SiC inverter are not as efficient as the devices in the off-the-shelf all-Si inverter module. 


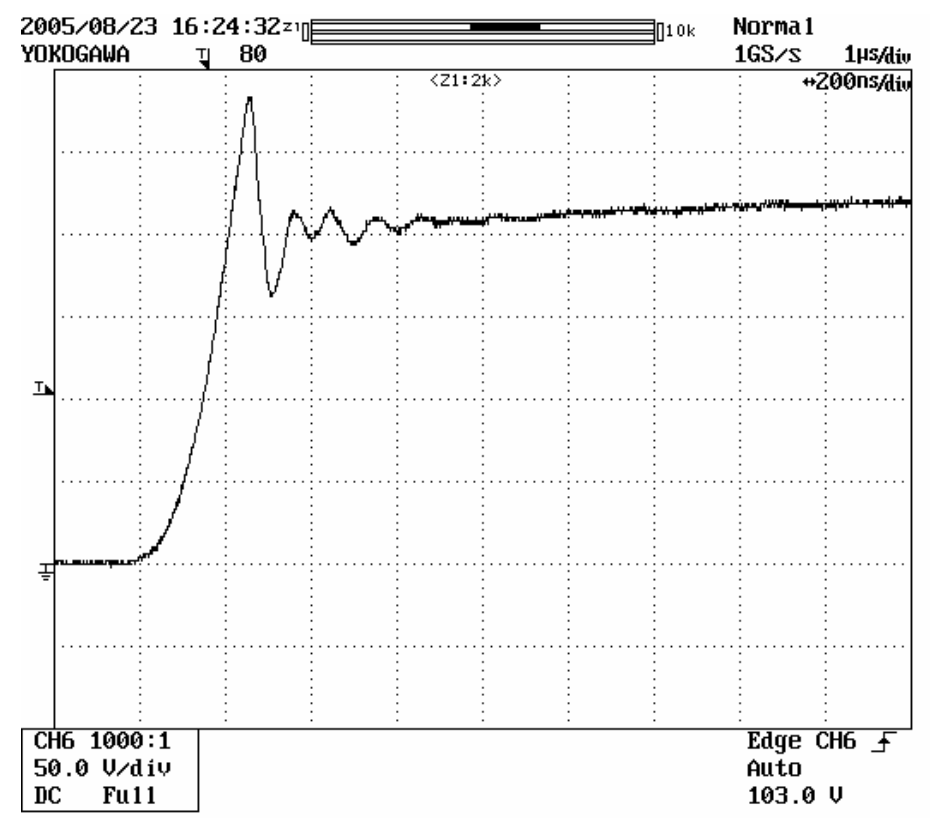

Fig. 4.32(a). Turn-off voltage waveform of SiC JFET.

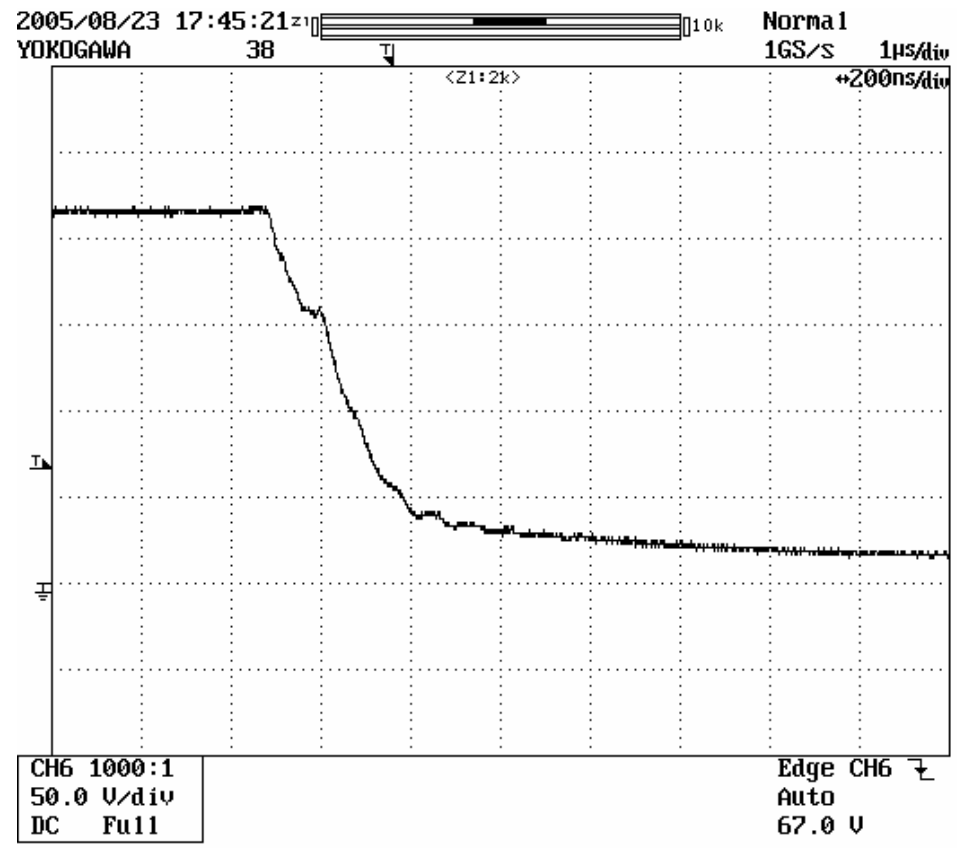

Fig. 4.32(b). Turn-on voltage waveform of SiC JFET. 


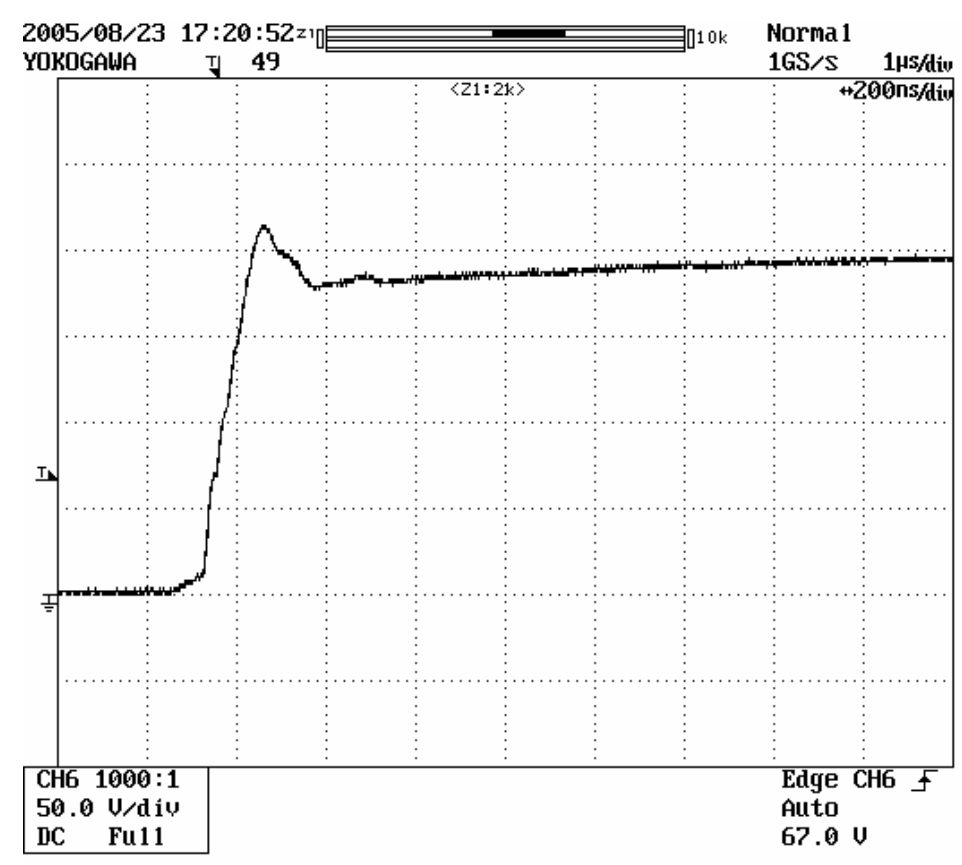

Fig. 4.33(a). Turn-off voltage waveform of Si IGBT.

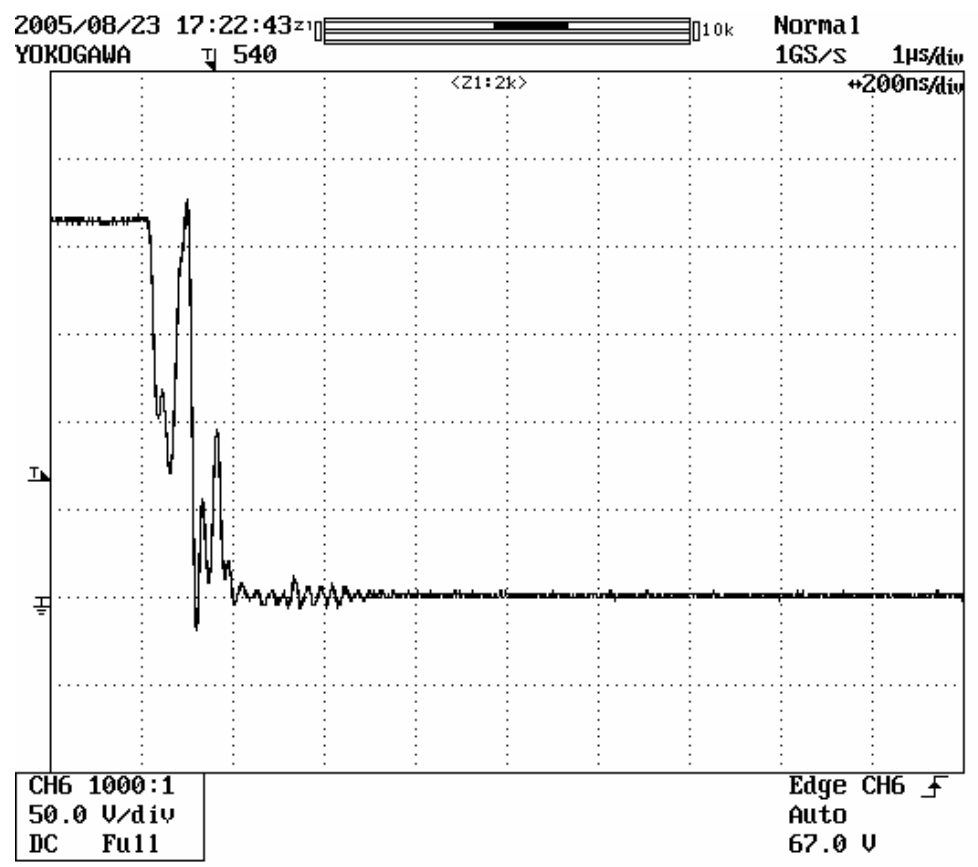

Fig. 4.33(b). Turn-on voltage waveform of Si IGBT.

\subsection{CONCLUSIONS}

The all-Si and all-SiC inverter modules were successfully simulated and tested with various loads. The $\mathrm{SiC}$ JFET and the $\mathrm{SiC}$ diode used in the module were characterized and the parameters were extracted to build their models. These models were used in the simulation of the inverter, and the efficiencies were found to be low. 
The efficiencies of the all-SiC inverter were at least $2-3 \%$ less in the $83-95 \%$ range. The analysis of the conduction and switching losses of the devices showed that the devices in the all-SiC inverter are not as efficient as the devices in the off-the-shelf all-Si inverter module.

It should be noted that the $\mathrm{SiC}$ JFETs used in the all-SiC inverter were experimental samples. They still have room for improvement. The test results in this chapter should not be viewed as discouraging. The next chapter will discuss the performance of some other, more promising SiC JFETs with respect to $\mathrm{Si}$ IGBTs. 


\section{DURATION TESTS}

\subsection{INTRODUCTION}

Reliable operation of power modules exposed to the high-temperature requirements in under the hood conditions is an important automotive requirement. Most common failures in power modules are due to temperature cycling over high-operating temperatures. Several SiC Schottky diodes and SiC power switches were tested at ORNL and their performances evaluated under different operating conditions. Even though it has been claimed that $\mathrm{SiC}$ devices have superior characteristics compared with Si devices, the reliability of the material quality has always been questionable.

To test the reliability of selected SiC power devices, four different buck converters were developed with Si IGBTs, Si pn diodes, SiC JFETs, and SiC Schottky diodes. The devices in the converters were operated at different voltage and current levels and at different frequencies in order to subject them to thermal stress and study their behavior. The results and analysis of the test data will be presented in the following sections.

\section{$5.2 \quad$ TEST SETUP}

The test setup for the duration tests is shown in Fig. 5.1. The four buck converters were enclosed in a box for higher ambient temperature and also as a protective feature. The four different buck converters are shown in Fig. 5.2.

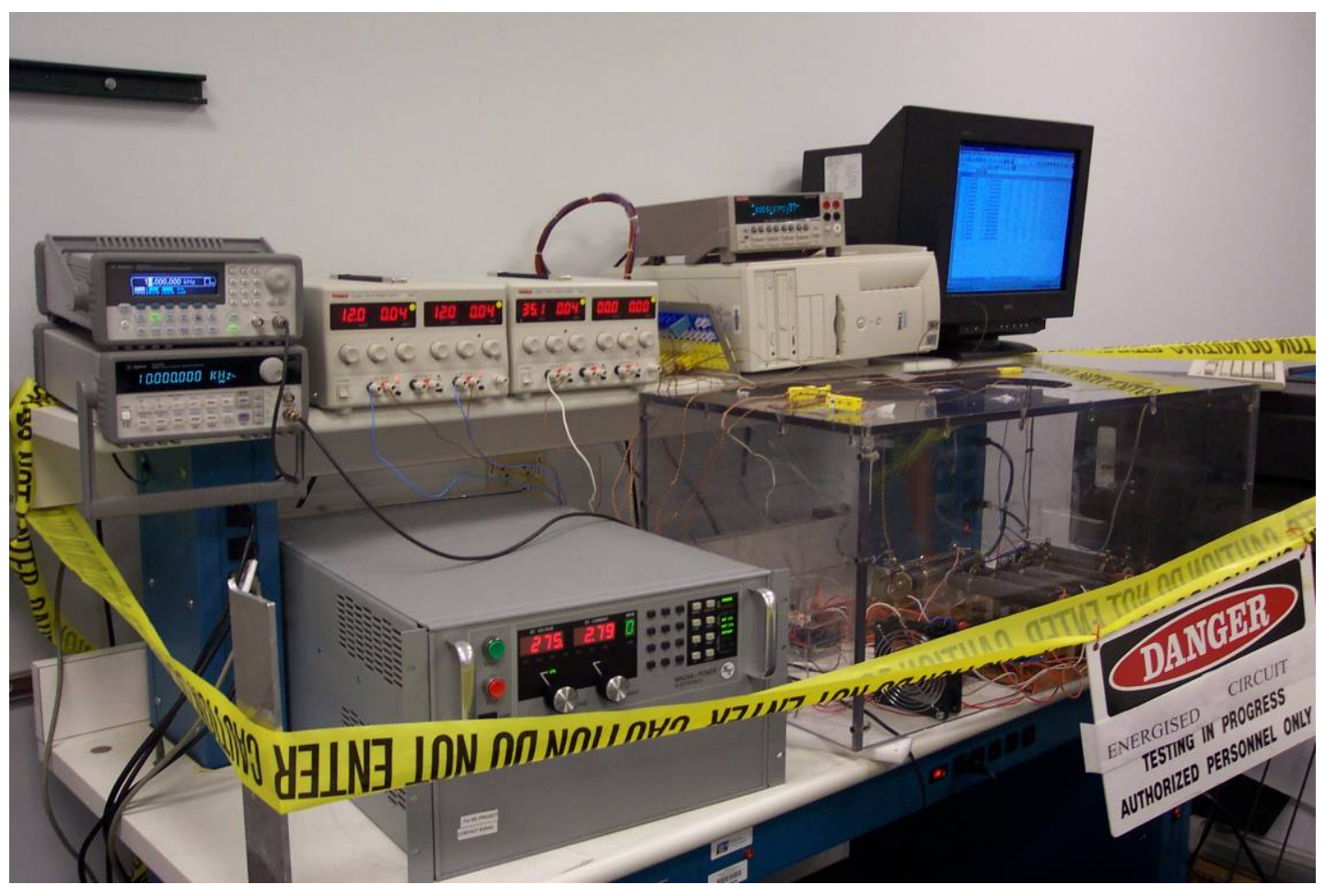

Fig. 5.1. Test setup for duration testing. 


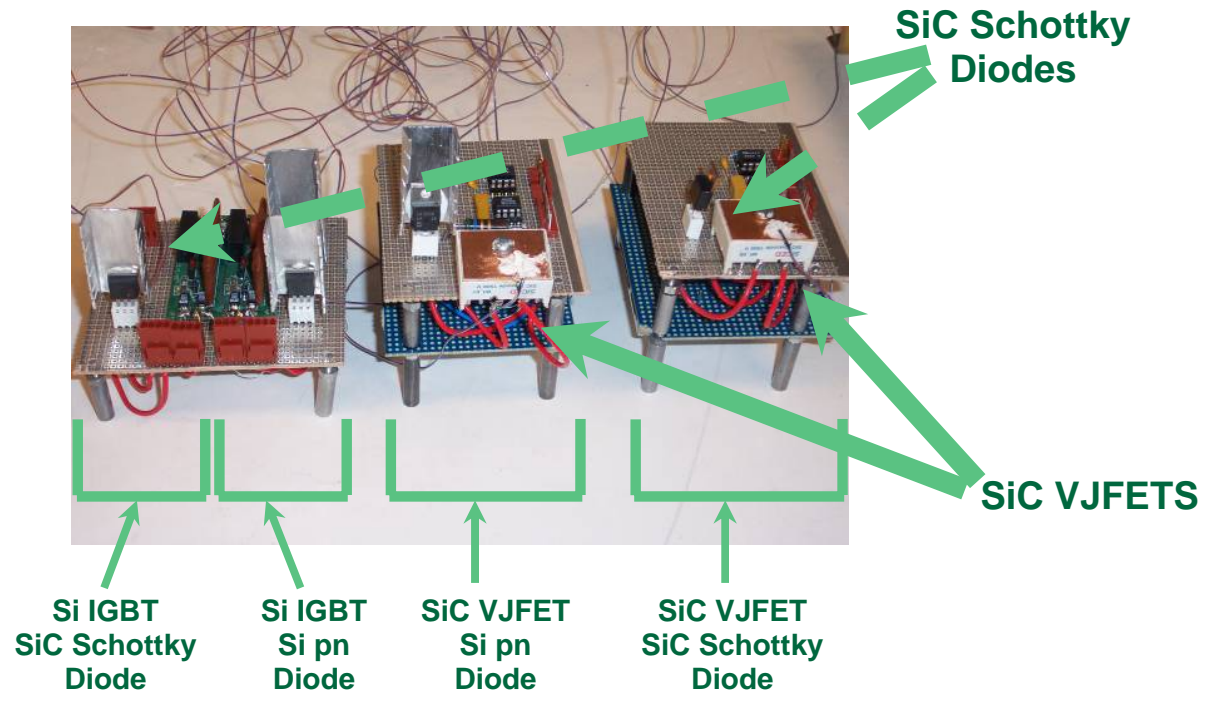

Fig. 5.2. Four different buck converters.

The specifications of the devices and components used in the converters are shown in Table 5.1, and the circuit topology is shown in Fig. 53 . The static, dynamic, and gate characteristics of the $\mathrm{SiC}$ devices used in these converters were presented previously in Chapter 2.

Thermocouples were attached to the cases of these devices to monitor their thermal responses. All the devices except the SiC JFETs were attached to a heat sink.

Table 5.1. Specifications of the devices and components used in the buck converters

\begin{tabular}{|l|l|}
\hline SiC JFET (SiCED) & $1200 \mathrm{~V}, 2 \mathrm{~A}$ \\
\hline SiC Schottky diode (Cree) & $600 \mathrm{~V}, 10 \mathrm{~A}$ \\
\hline Si IGBT (IRF) & $1200 \mathrm{~V}, 11 \mathrm{~A}$ \\
\hline Si pn diode (Harris) & $600 \mathrm{~V}, 10 \mathrm{~A}$ \\
\hline Inductor & $1.2 \mathrm{mH}$ \\
\hline Thermocouple & type T \\
\hline
\end{tabular}

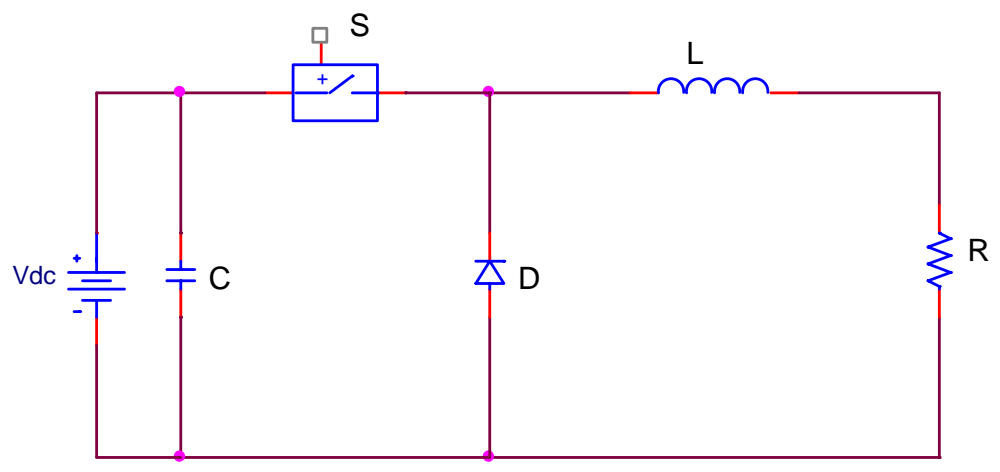

Fig. 5.3. The buck converter topology. 


\subsection{OPERATION}

The buck converters were fed from a single dc supply source, and the load current was varied by changing the input voltage. The operating current was limited to a maximum of $2 \mathrm{~A}$ because of the $\mathrm{SiC}$ JFET current rating. They were operated continuously for 7.5 hours every day for 6 months. During this time, their operation was closely observed and their case temperature data were recorded. The following section will show some of these temperature profiles and will draw conclusions.

Note that the device temperature data obtained from the thermocouples also recorded noise over long periods of operation. The thermocouples are generally very sensitive to the noise around the measuring surface. Typical temperature profiles of switches and diodes obtained during testing are shown in Figs. 5.4 and 5.5. Only the temperature profiles of the devices in the all-SiC converter were clean. Also, the Si IGBT with the $\mathrm{SiC}$ diode is less noisy than the ones with $\mathrm{Si}$ diodes because the $\mathrm{SiC}$ diode has better reverse-recovery characteristics than $\mathrm{Si}$ pn diodes. For improved visualization, a moving average filter was used (Appendix B) to filter the noise from the signals.

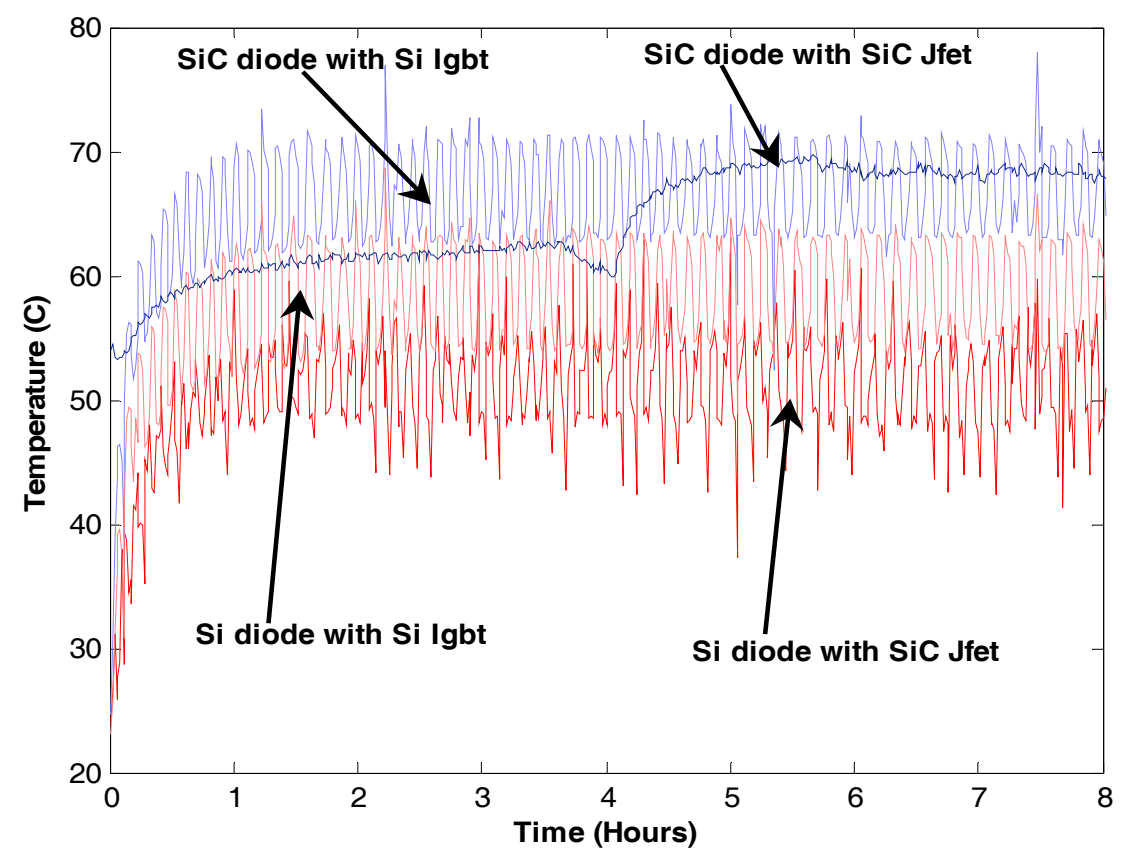

Fig. 5.4. Plot of temperature data for diodes without the filter. 


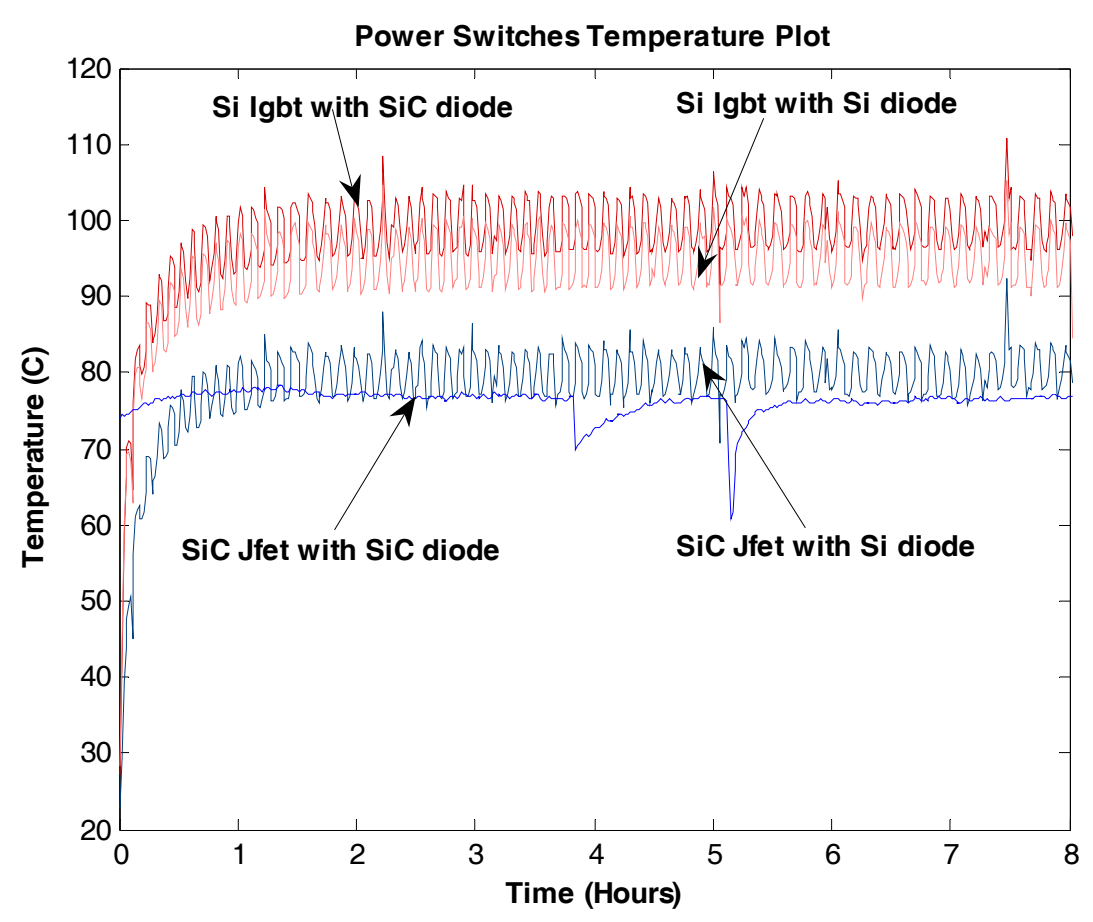

Fig. 5.5. Plot of temperature data for switches without the filter.

\section{Case 1}

The converters were first operated at $250 \mathrm{~V}, 50 \%$ duty cycle, and $10 \mathrm{kHz}$. All the devices, except the SiC JFETs, were mounted on a heat sink. The temperature profiles for the main power switches in all the buck converters are shown in Fig. 5.6. The Si IGBTs operated at $108^{\circ} \mathrm{C}$ and $97^{\circ} \mathrm{C}$, and the SiC JFETs were operating at much lower temperatures-around $60^{\circ} \mathrm{C}$. The SiC JFETs without heat sinks were operating at lower temperatures compared with the Si IGBTs with the heat sinks.

To stress the devices to their maximum continuous operating conditions without exceeding the operating temperature, the power levels were increased in the following cases. 


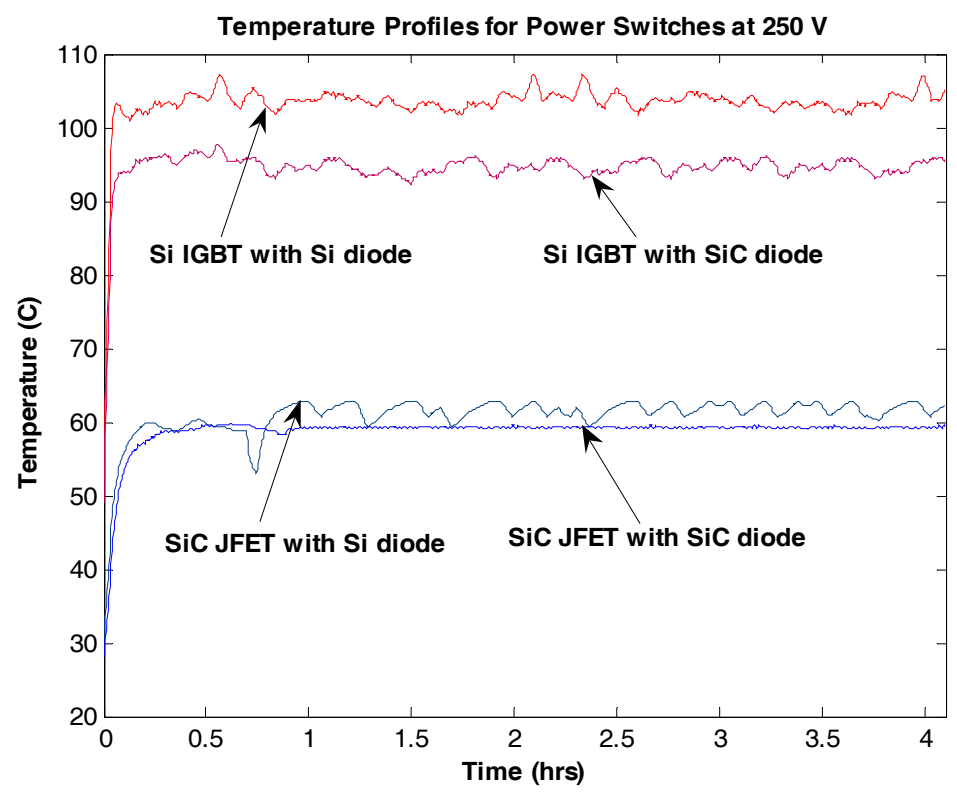

Fig. 5.6. Temperature profile for power switches at $250-\mathrm{V}, 10-\mathrm{kHz}$ operation.

\section{Case 2}

The dc input voltage was increased to $300 \mathrm{~V}$, keeping all other parameters the same. The Si IGBT in the all-Si converter failed at 300-V, 1.5-A; however, the other IGBT and SiC JFETs kept operating. Table 5.2 shows the temperature at which the IGBT failed with a drain-source short because the temperature was beyond the thermal capability of the device. Note that the Si IGBT with the SiC diode did not fail. To find the reason why one IGBT failed and not the other, the turn-on current waveforms of both IGBTs were compared and are shown in Fig. 5.7.

Table 5.2. Temperature data of power devices at $300-\mathrm{V}, 10-\mathrm{kHz}$ operation

\begin{tabular}{|c|c|c|c|c|}
\hline $\begin{array}{c}\text { SiC JFET with } \\
\text { Si diode, C }\end{array}$ & $\begin{array}{c}\text { SiC JFET with } \\
\text { SiC diode, C }\end{array}$ & $\begin{array}{c}\text { Si IGBT with } \\
\text { SiC diode, C }\end{array}$ & $\begin{array}{c}\text { Si IGBT with } \\
\text { Si diode, C }\end{array}$ & $\begin{array}{c}\text { Time } \\
\text { (min) }\end{array}$ \\
\hline & & & & \\
\hline 40.8 & 38 & 68.6 & 69.7 & \\
\hline 64.8 & 60.8 & 116 & 125.1 & 5 \\
\hline 82.6 & 75.6 & 141.1 & 168.9 & 10 \\
\hline 79.6 & 70.6 & 115.7 & 263.3 & 15 \\
\hline 82.7 & 71.1 & 118.5 & 287.2 & 20 \\
\hline 85.3 & 72.4 & 121.5 & 298.9 & 25 \\
\hline 86.1 & 72.9 & 122.3 & 293.1 & 30 \\
\hline
\end{tabular}

As seen in Fig. 5.7, the Si IGBT has a current spike during turn-on because of the effect of the reverserecovery current of the diodes. Note that to stress the devices, no snubbers are used. As expected, the peak value of the current spike is less when a SiC Schottky diode is used instead of a $\mathrm{Si}$ pn diode because the peak reverse-recovery current of the $\mathrm{SiC}$ diode is smaller. Since the reverse recovery of the diode adversely affects switching and consequently the switching losses of the IGBT, a Si pn diode will cause higher losses on the IGBT than the SiC Schottky diode. This is why a Si IGBT will be hotter when used 
with a $\mathrm{Si}$ pn diode as opposed to a SiC Schottky diode. This effect will be more significant at higher switching frequencies because the switching losses are proportional to the switching frequency.

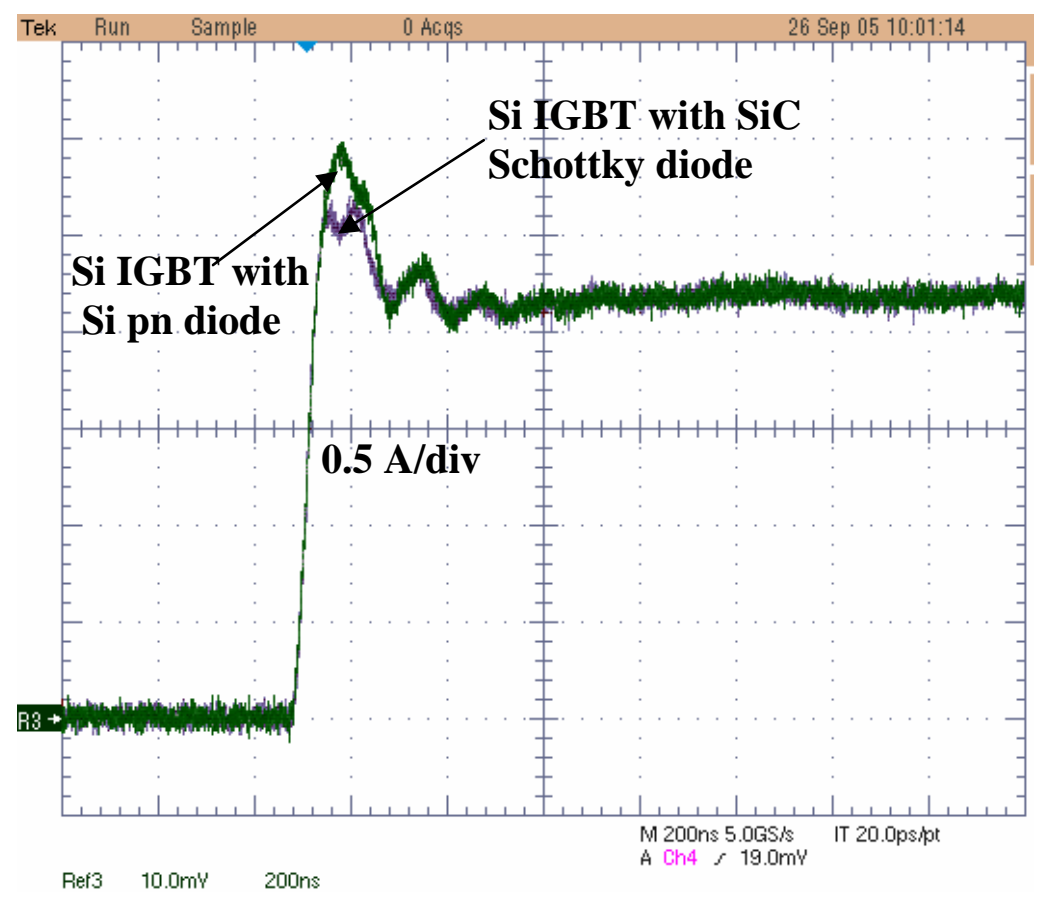

Fig. 5.7. Turn-on current waveforms of Si IGBTs with SiC and Si diodes.

\section{Case 3}

After experimenting with several test conditions, the operating voltage was fixed at $200 \mathrm{~V}$ for safe operation without device failure and the duration tests were continued. The converters were operated at 10 $\mathrm{kHz}, 50 \%$ duty cycle, and $200 \mathrm{~V}$. The temperature profiles were obtained for different frequencies.

The temperature profiles recorded for each device for 7.5 hours are shown in Fig. 5.8. These profiles show that the $\mathrm{SiC}$ diodes were operating at higher temperatures than the $\mathrm{Si}$ diodes. Even though this seems to contradict what was said about SiC Schottky diodes earlier in this report, a previous ORNL simulation study [2] has shown that the conduction losses of SiC Schottky diodes dominate at lower switching frequencies, and they are much higher than those of the Si pn diodes. The static characteristics shown in Fig. 2.14 indicate that the on-state resistances of the SiC diodes are much higher than those of the Si pn diodes, and hence they have higher conduction losses. This confirms the results of the simulation study.

SiC JFETs, without heat sinks, operate at much lower temperatures than Si IGBTs, which indicates that the $\mathrm{SiC}$ devices have lower losses than the Si IGBTs. The comparison of the static characteristics of the $\mathrm{SiC}$ JFET and the Si IGBT is shown in Fig. 5.9. It is interesting to note that the $\mathrm{Si}$ IGBT and the $\mathrm{SiC}$ JFET with the $\mathrm{SiC}$ diodes operate at lower temperatures than the ones with the $\mathrm{Si}$ pn diodes. This is again because of the better reverse-recovery characteristics of the SiC Schottky diodes. 


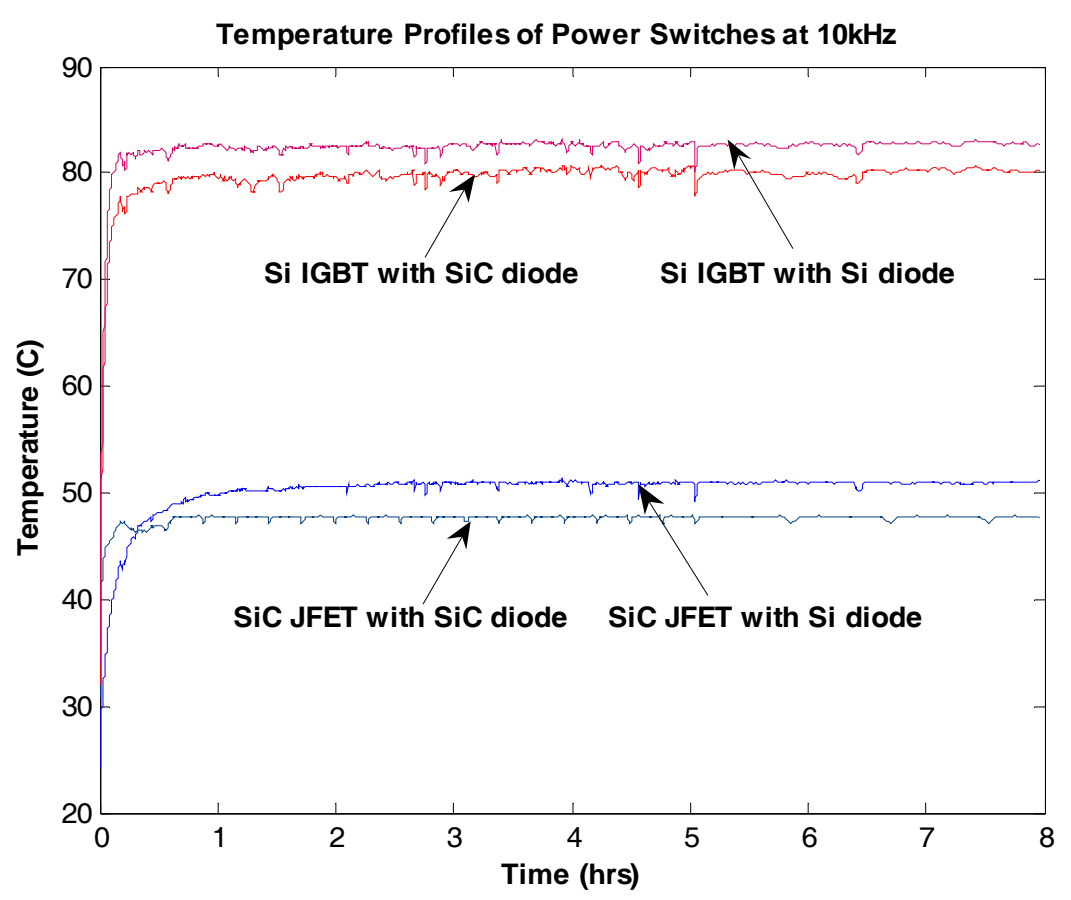

(a) Switches.

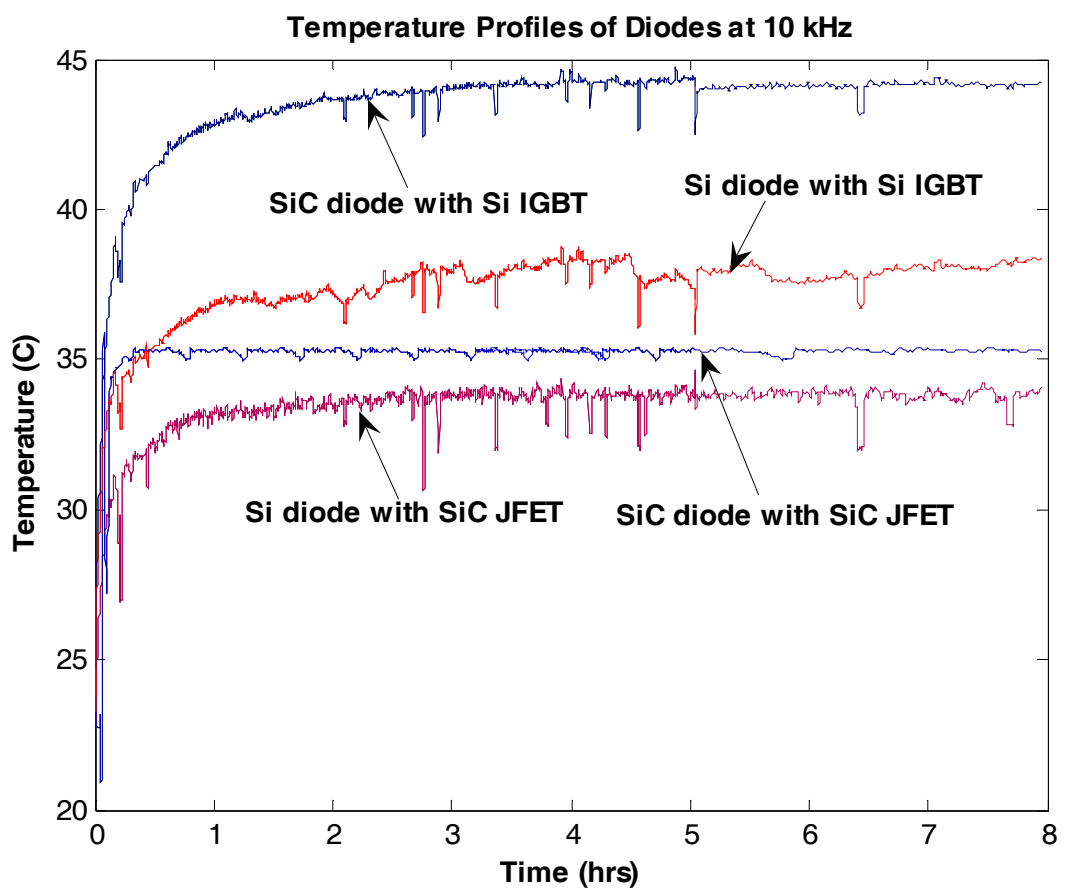

(b) Diodes.

Fig. 5.8. Temperature profile for $10-\mathrm{kHz}$ operation. 


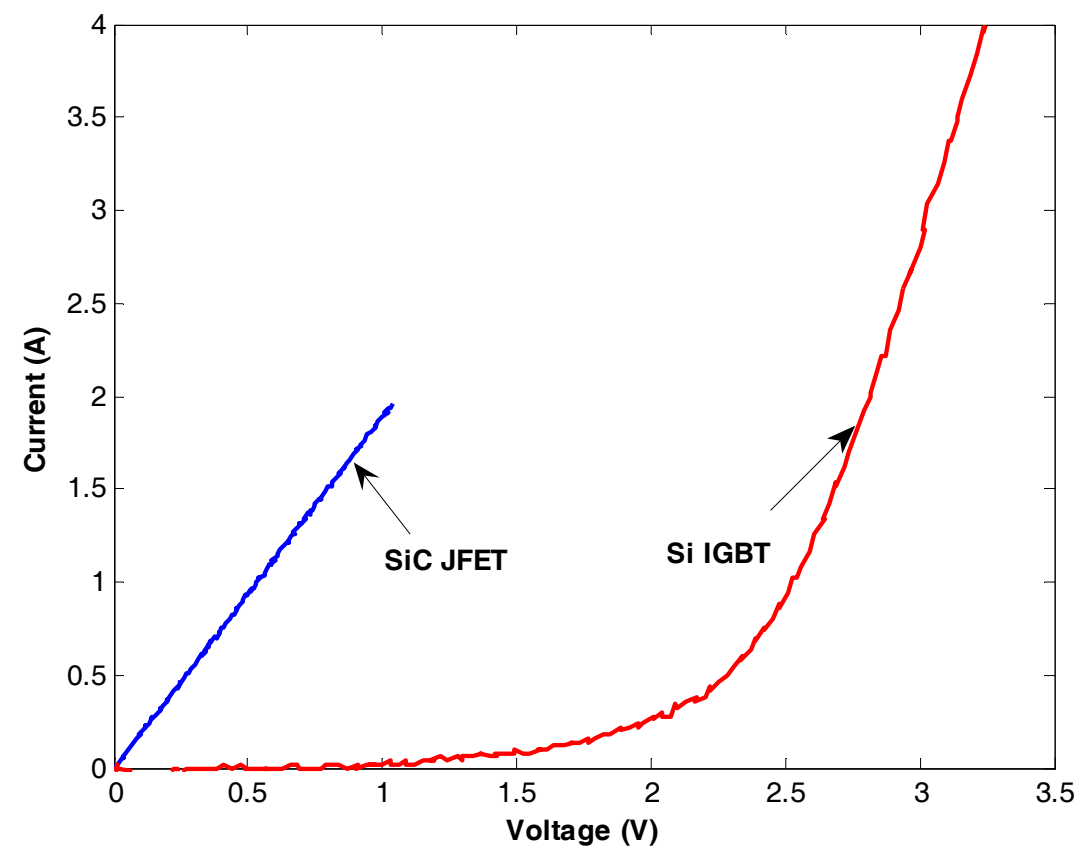

Fig. 5.9. Comparison of static characteristics for Si IGBT and SiC JFET.

Figures 5.10-5.15 show temperature profiles of the switches and diodes for different switching frequencies. Figures 5.16 and 5.17 show all the profiles in Figs. 5.10-5.15 plotted together. This figure shows that the operating temperatures of the $\mathrm{SiC}$ diodes do not change much with an increase in switching frequency because the switching losses of SiC Schottky diodes are significantly lower than those of the Si pn diodes. However, the Si diodes have higher switching losses, and hence their operating temperatures get higher as the frequency increases.

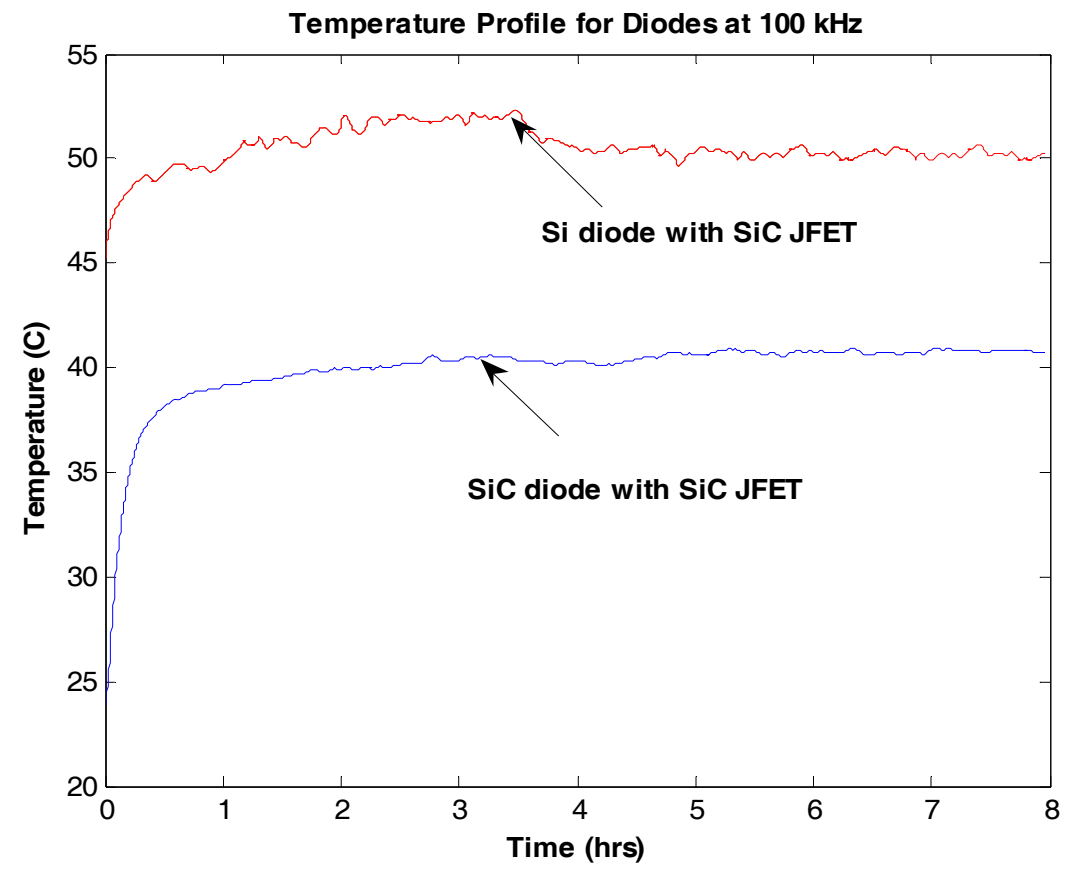

Fig. 5.10. Temperature profile for diodes at 100-kHz operation. 


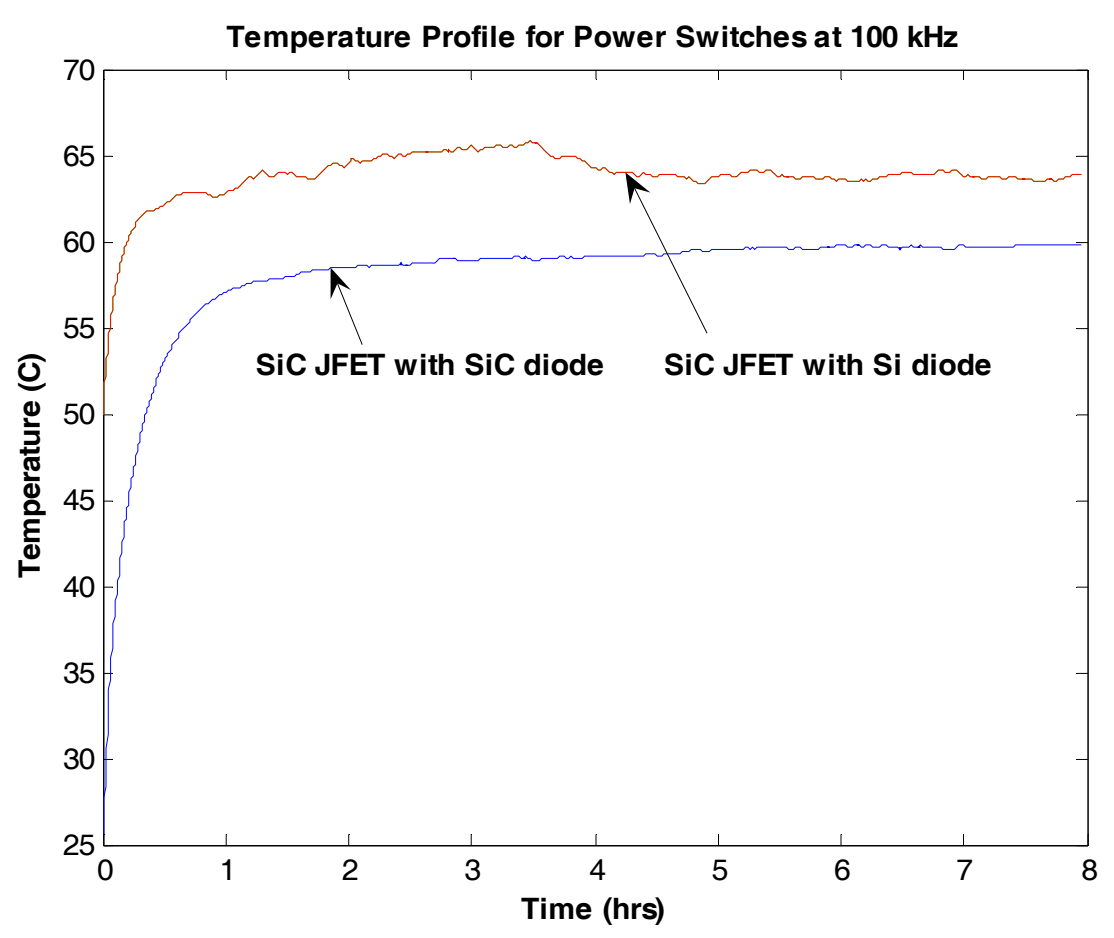

Fig. 5.11. Temperature profile for power switches at $100 \mathrm{kHz}$.

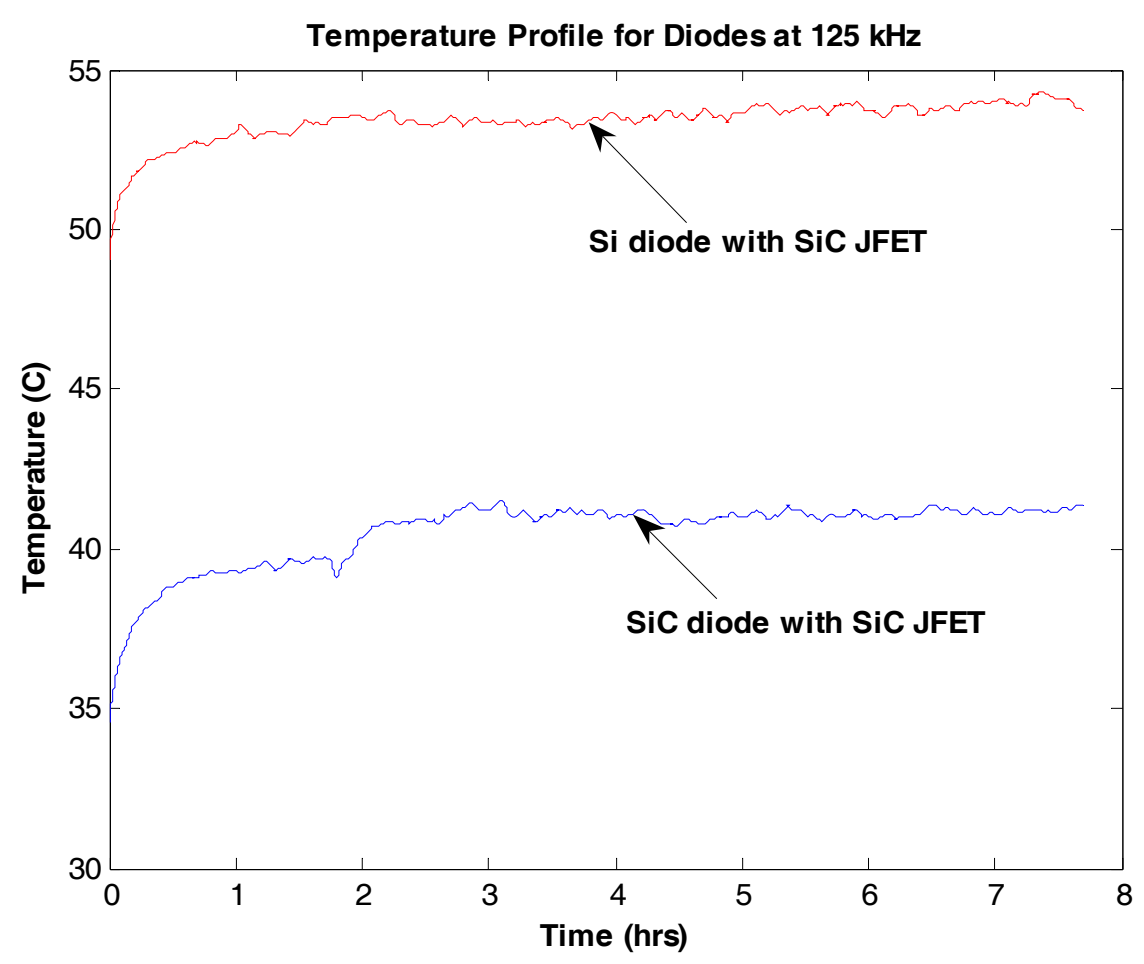

Fig. 5.12. Temperature profile for diodes at $125 \mathrm{kHz}$. 


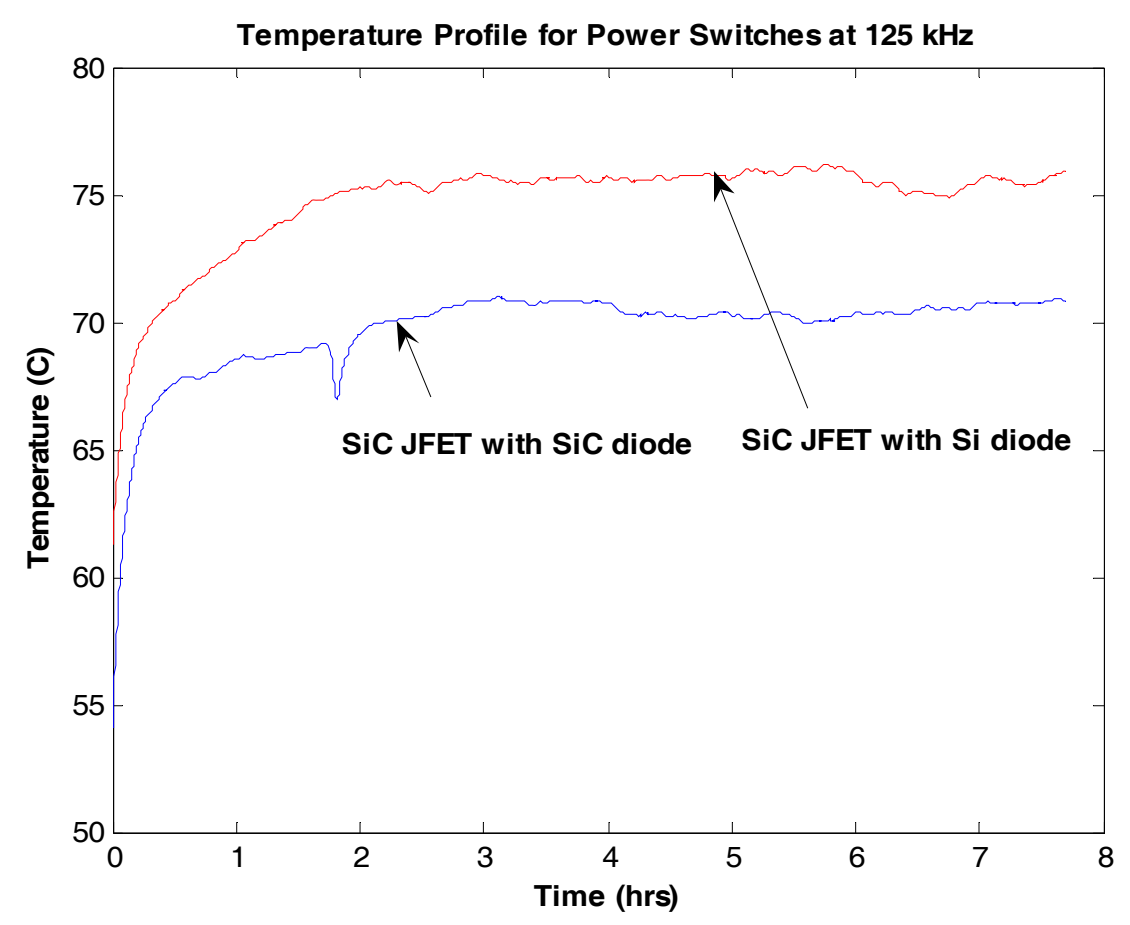

Fig. 5.13. Temperature profile for power switches at $125 \mathrm{kHz}$.

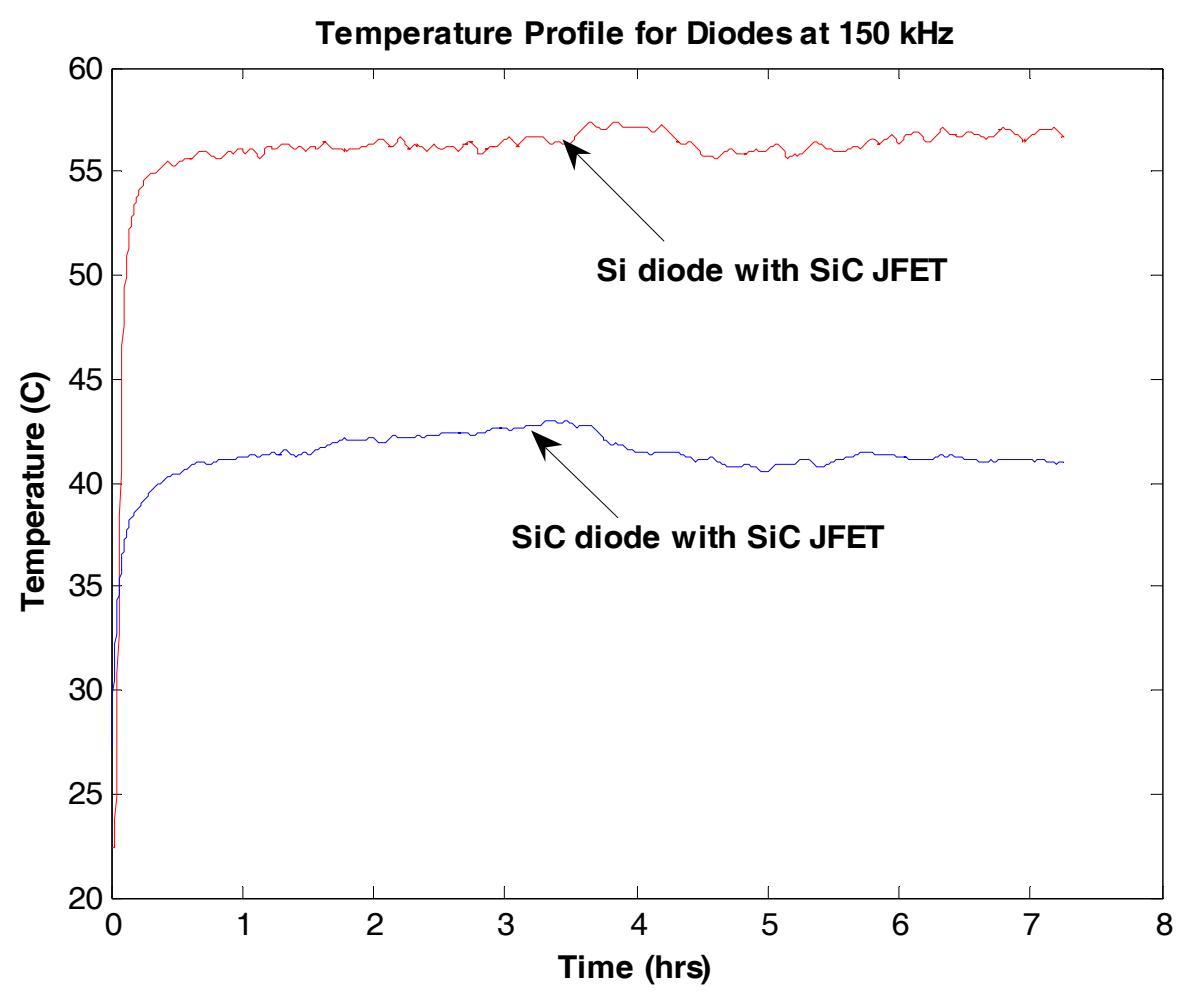

Fig. 5.14. Temperature profile for diodes at $150 \mathrm{kHz}$. 


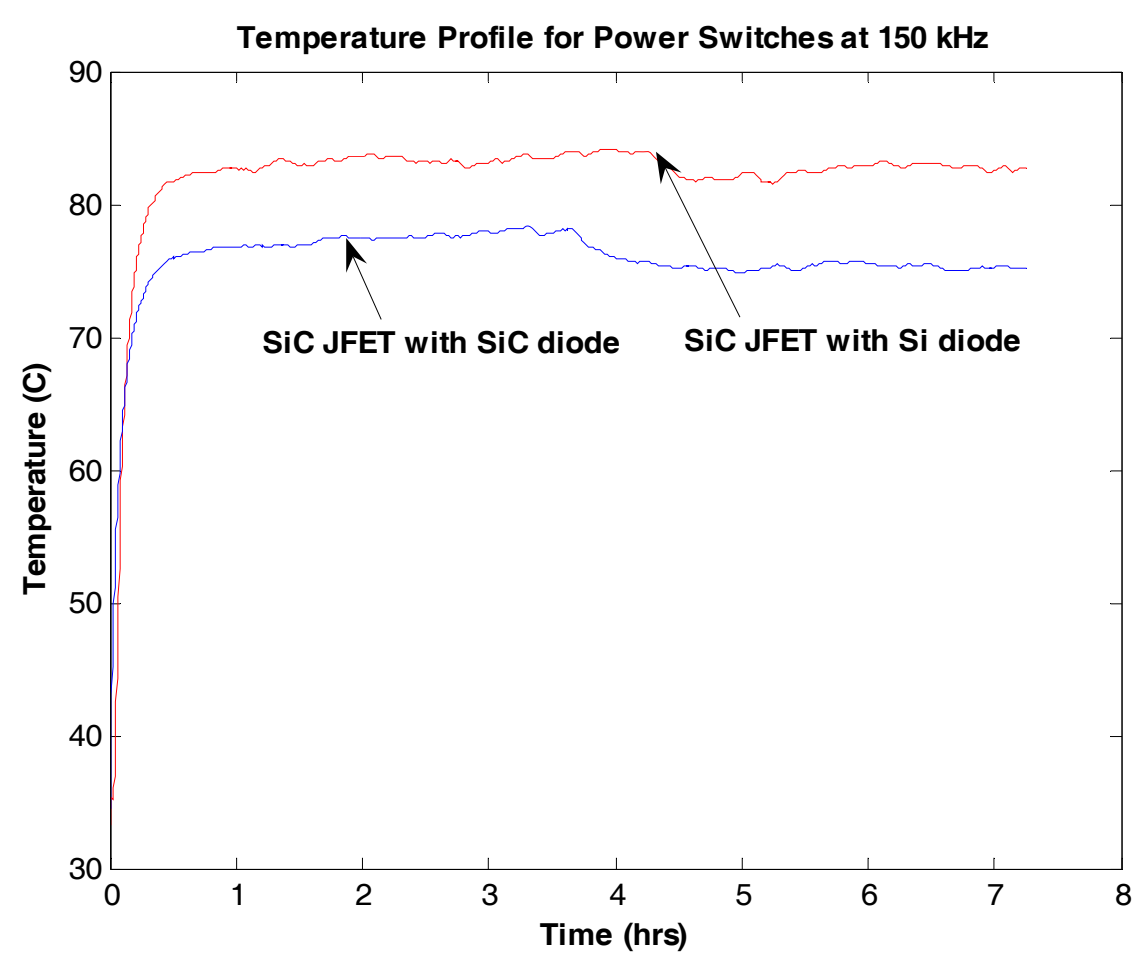

Fig. 5.15. Temperature profile for power switches at $150 \mathrm{kHz}$.

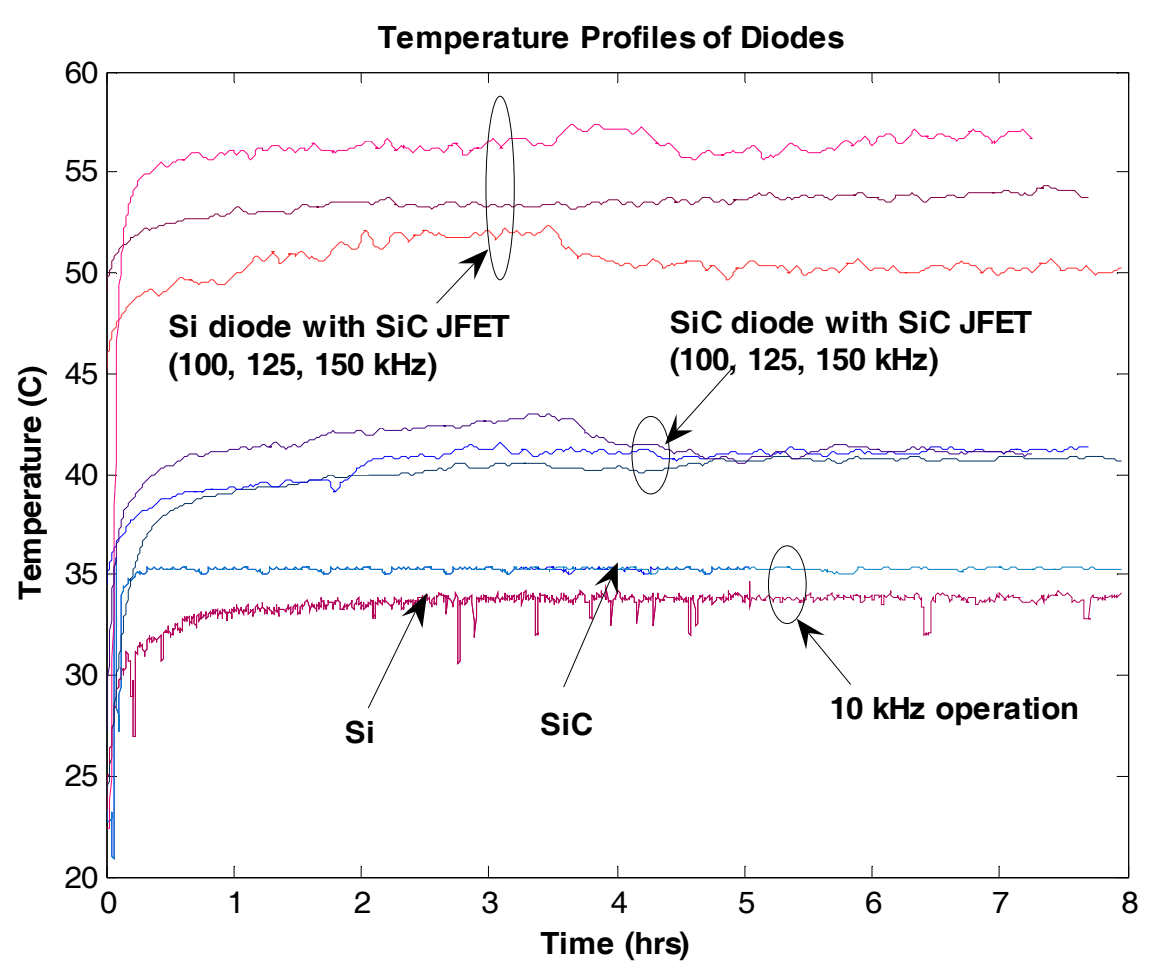

Fig. 5.16. Temperature profile for diodes at different operating frequencies. 


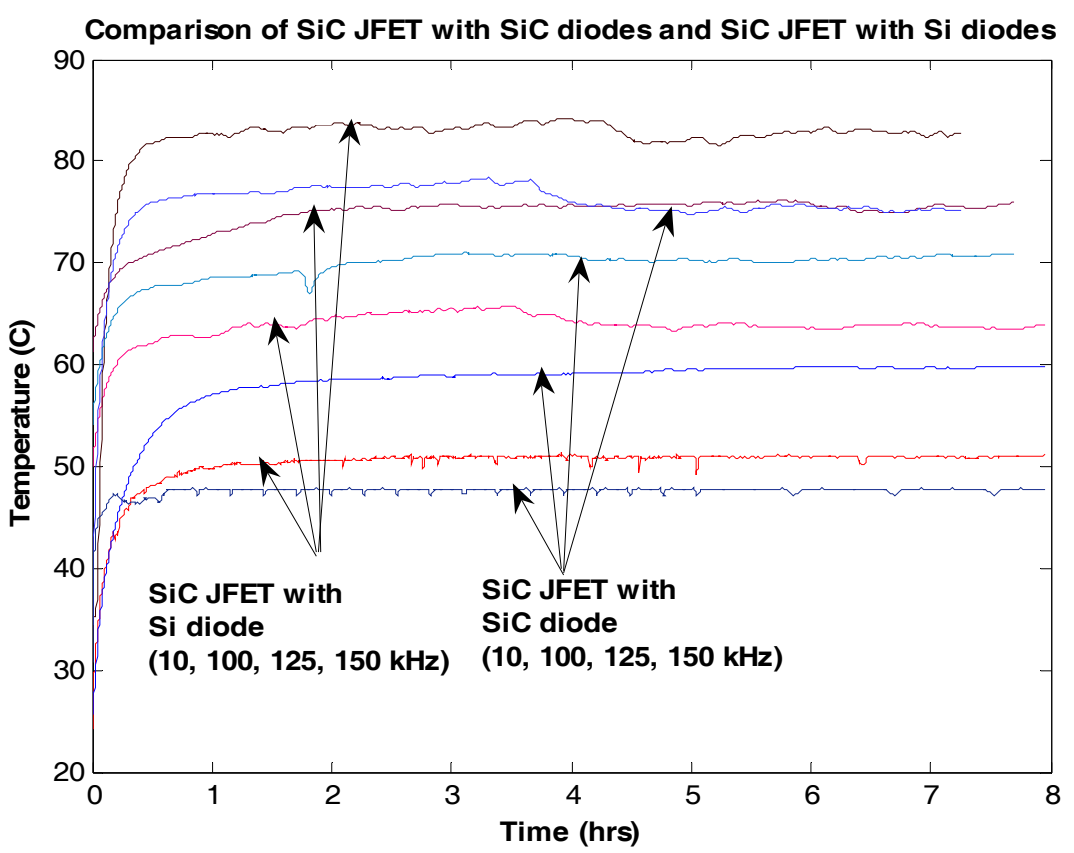

Fig. 5.17. Temperature profile for switches at different operating frequencies.

\section{Case 4}

Since Si IGBTs are limited in their switching frequency, the buck converters with Si IGBTs were tested separately at lower switching frequencies. The temperature profiles of the switches and diodes for $200 \mathrm{~V}$, $50 \%$ duty cycle and in a frequency range of $15-25 \mathrm{kHz}$ are shown in Figs. 5.18-5.23. Figure 5.24 shows that the temperature profile of the Si IGBT with a SiC Schottky diode does not change much with switching frequency. However, the temperature of the IGBT with a Si diode increases with switching frequency. This also shows that the $\mathrm{SiC}$ diodes have less effect on the main power switch because of the negligible reverse-recovery losses. Even though the temperatures of the Si IGBT in the all-Si converter increase as the switching frequency increases, the Si pn diode compared with the SiC Schottky diode still operates at a slightly lower temperature. 


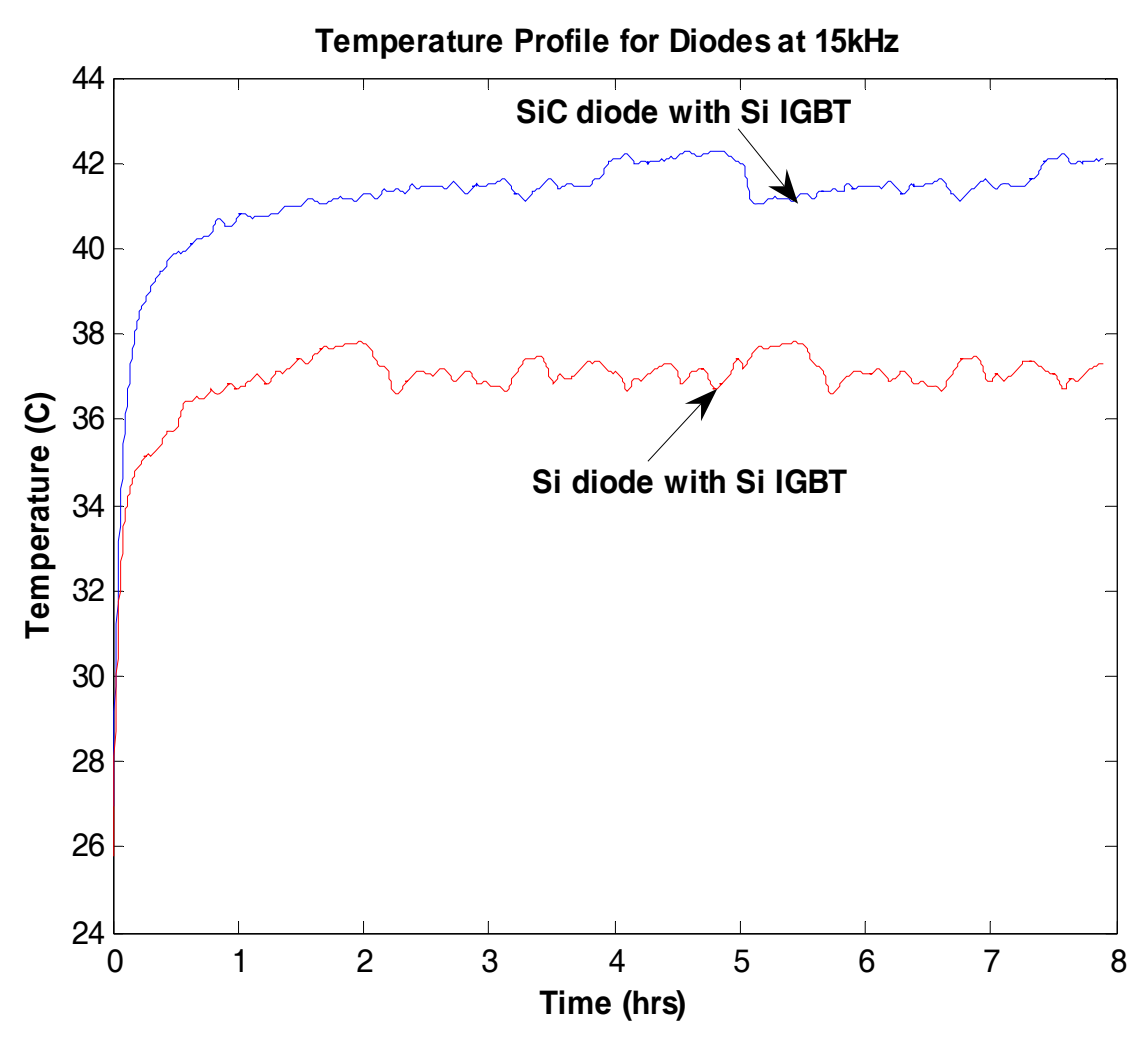

Fig. 5.18. Plot of temperature profile for diodes at $15 \mathrm{kHz}$.

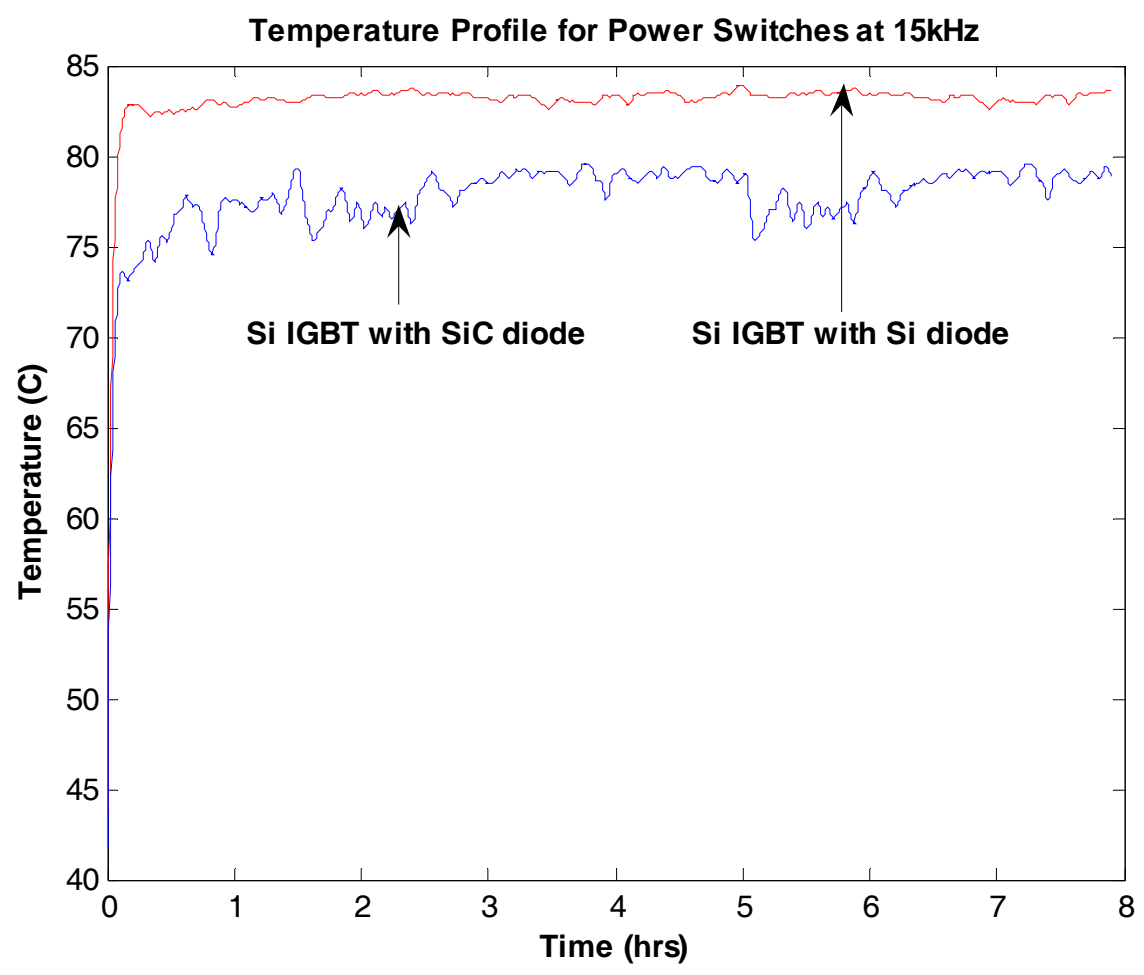

Fig. 5.19. Plot of temperature profile for power switches at $15 \mathrm{kHz}$. 


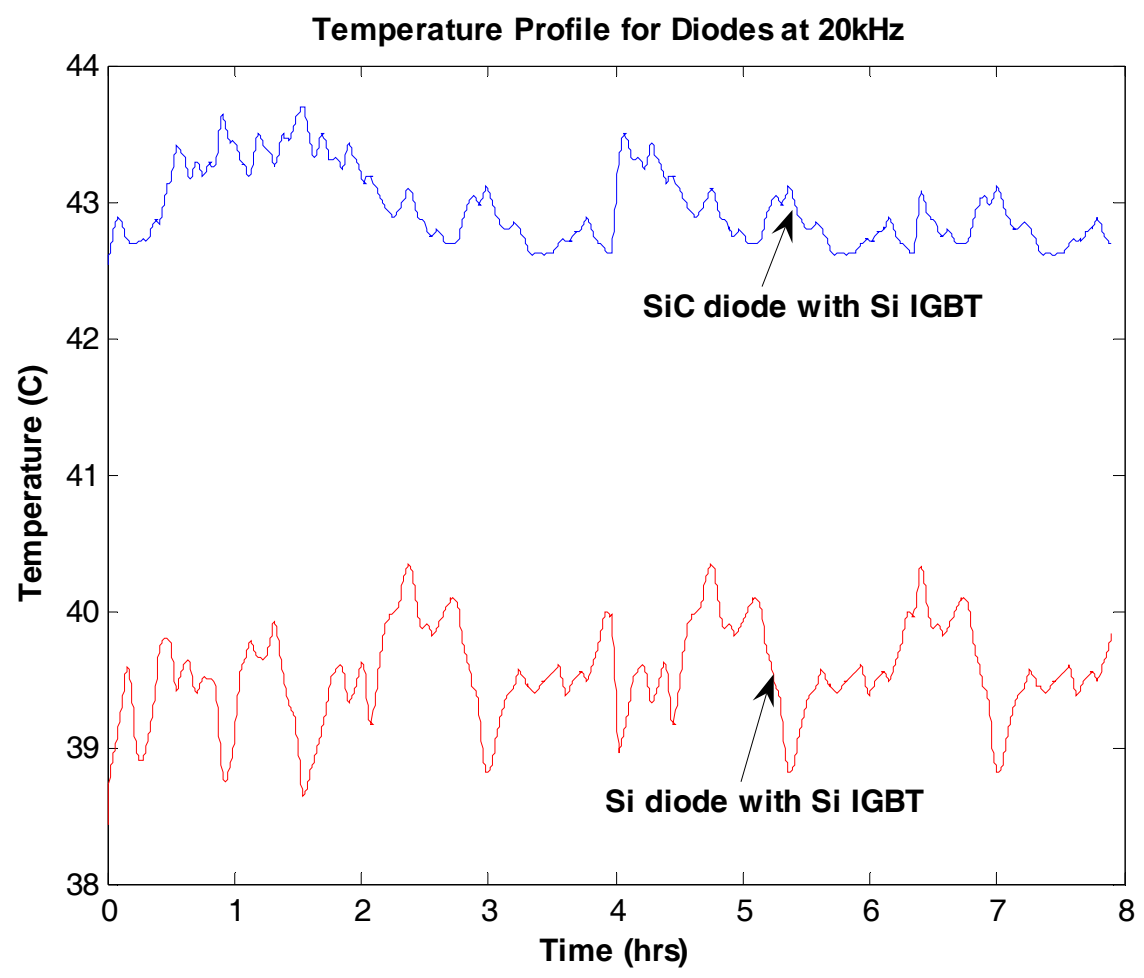

Fig. 5.20. Plot of temperature profile for diodes at $20 \mathrm{kHz}$.

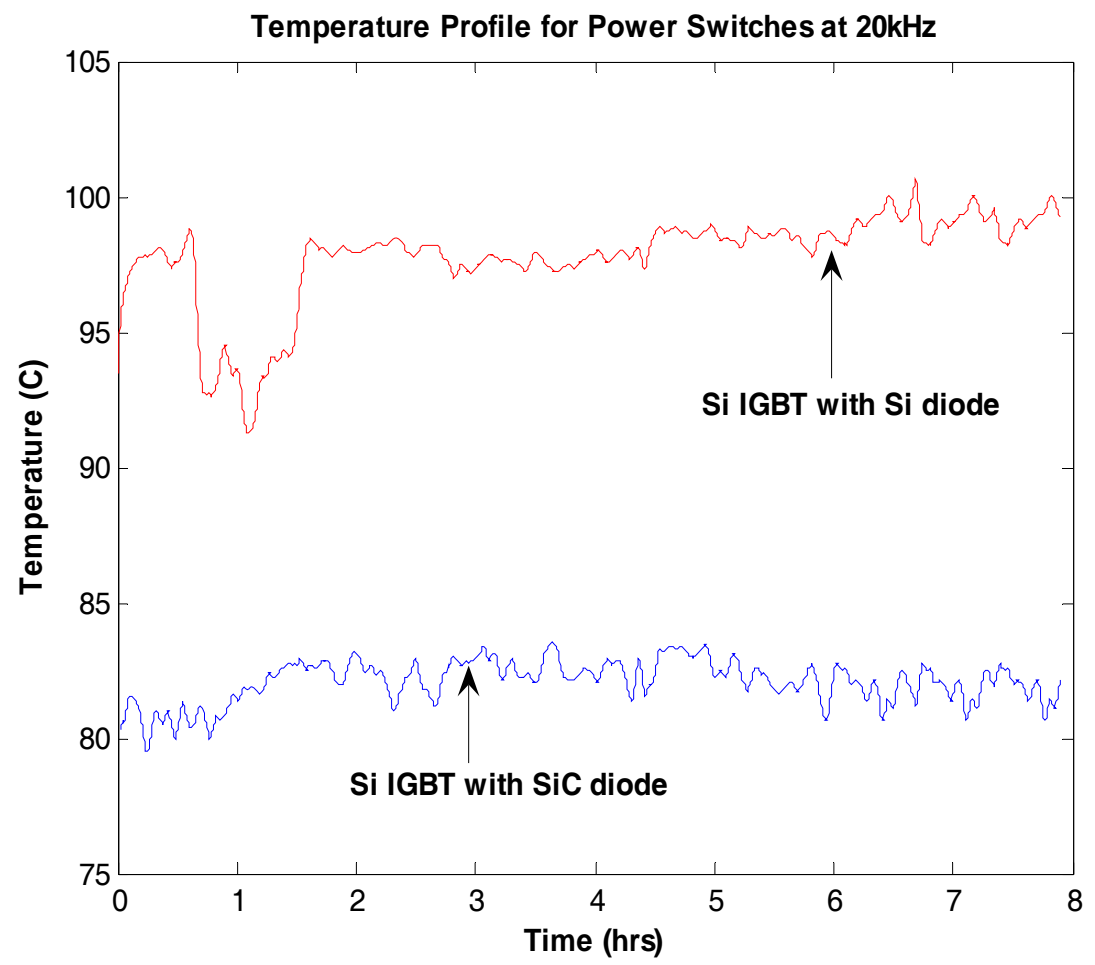

Fig. 5.21. Plot of temperature profile for power switches at $20 \mathrm{kHz}$. 


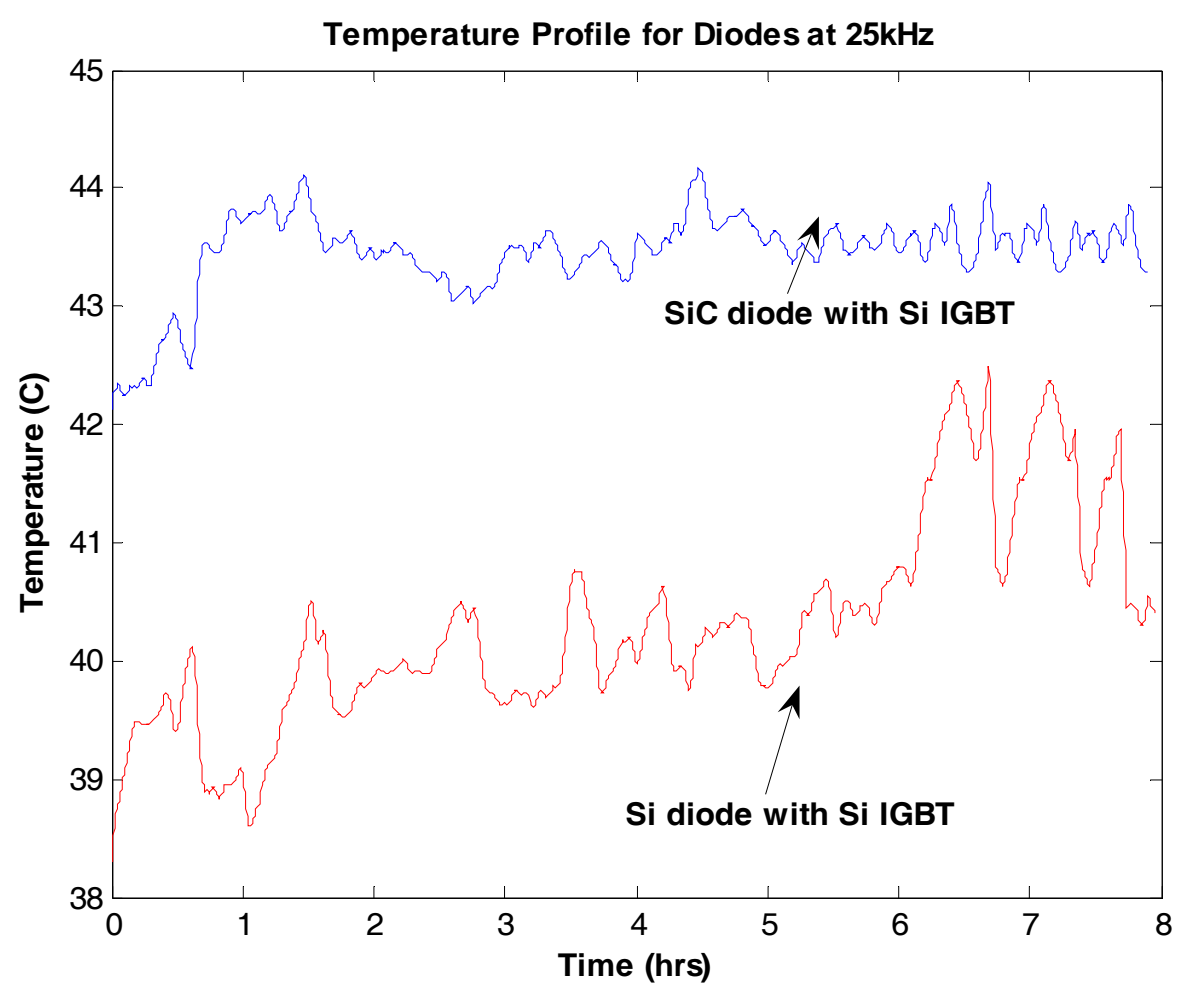

Fig. 5.22. Plot of temperature profile for diodes at $25 \mathrm{kHz}$.

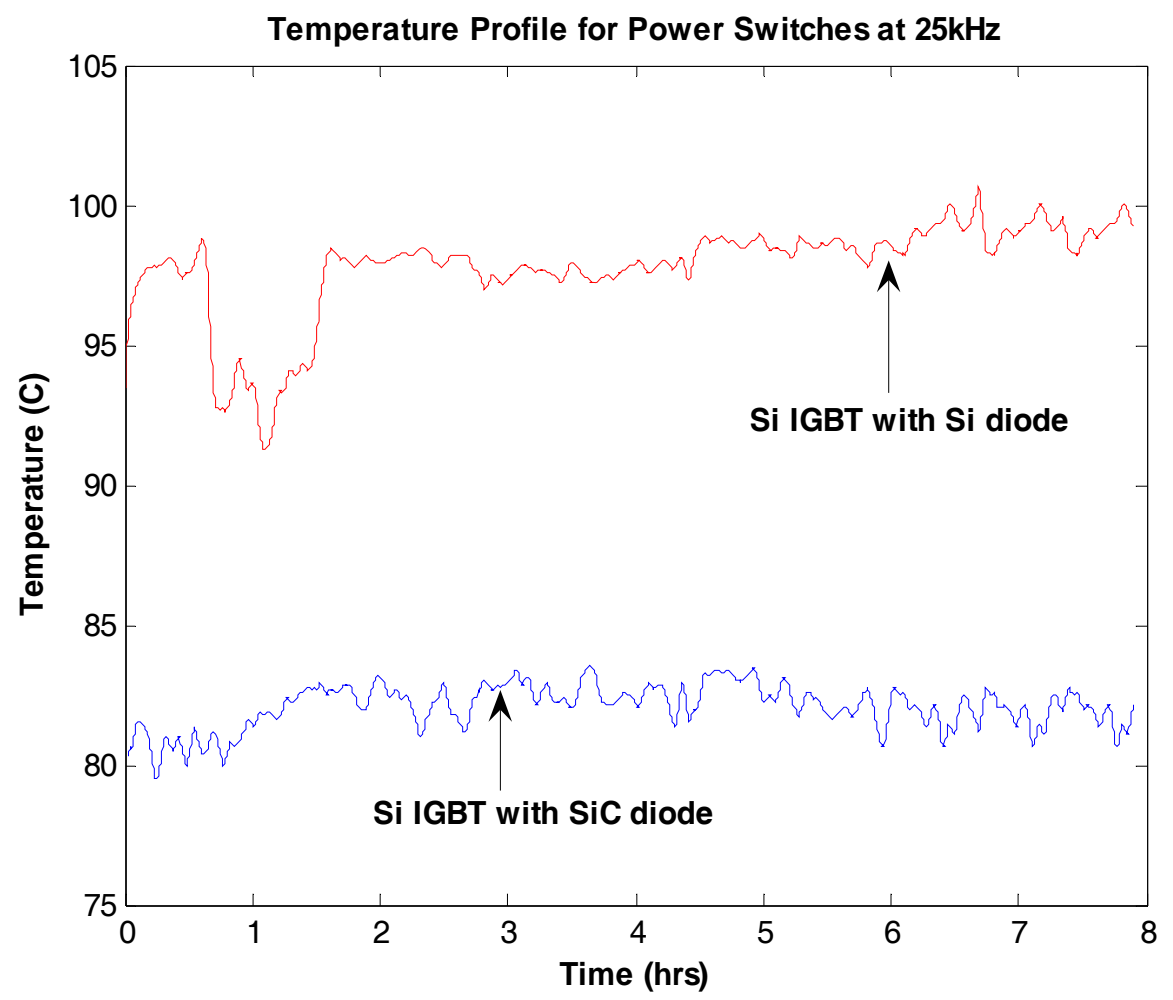

Fig. 5.23. Plot of temperature profile for power switches at $20 \mathrm{kHz}$. 


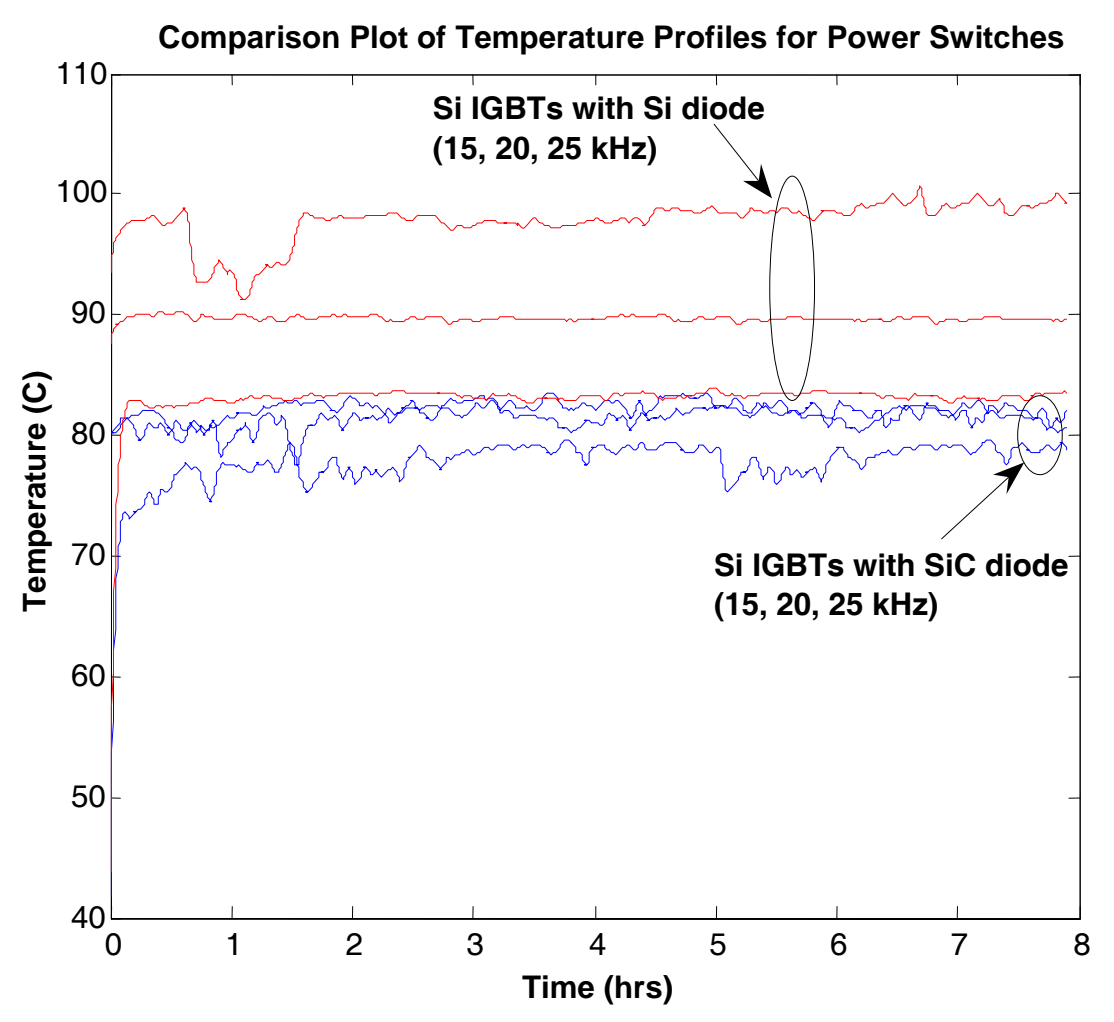

Fig. 5.24. Plot of temperature profile for power switches at different frequencies.

\subsection{DEVICE FAILURE DISCUSSION}

During the tests, several power switches failed at different operating conditions. The diodes never failed over several months of operation.

Si IGBTs failed at certain operating conditions because the thermal limits of the devices were exceeded. Even with heat sinks, they required cooling at higher power levels. It should be noted that only case temperatures were measured and the junction temperatures would be much higher. Note that the devices were operated without any snubber circuits, thus stressing the power switches even more than normal.

SiC JFETS operated at higher voltage levels than the Si IGBTs and without heat sinks. They failed only after several days of operation

SiC JFETs operated without any failures even at higher voltage levels and without heat sinks. However, the JFETs failed repeatedly after several days of operation. An investigation of the devices that failed found that the gate-to-source of some devices was shorted, while some had an open drain-to-source failure. This shows that these experimental samples need more reliability improvement. 


\section{$5.5 \quad$ CONCLUSIONS}

The duration tests were completed successfully and the analysis of the data was presented. The SiC diodes have shown better thermal performance than the Si devices at higher power levels and higher frequencies. However, at lower frequencies and for the same power levels, the Si diodes had lower losses and hence were operating at lower temperatures.

The SiC JFETs were operating at lower temperatures for all the operating conditions than the Si IGBTs, even without heat sinks. The temperatures of the SiC JFETs operating at $150 \mathrm{kHz}$ were comparable to the temperatures of Si IGBTs operating at $10 \mathrm{kHz}$ for the same power levels. This significant difference in operating temperatures will result in reduced heat sink size and volume when SiC devices are used.

Some Si IGBTs failed during operation because of the extreme stresses they were under. Some SiC JFETs also may have failed because these are still experimental samples and they need further improvement. 


\section{CONCLUSIONS}

Several new $\mathrm{SiC}$ devices were acquired, tested, and characterized over a wide temperature range, and the results were presented in Chapter 2 of this report.

The SiC Schottky diode parameters were extracted from test data and models were developed in Saber. The SiC diode models were used in an inverter model, and the simulation studies showed that the efficiencies of the Si IGBT, SiC diode hybrid inverter were higher than an all Si inverter. The 55-kW Si IGBT-SiC Schottky diode hybrid inverter developed in collaboration with Cree and Semikron was tested extensively. The inverters were tested with an inductive load and a dynamometer load. They were operated in motoring and regeneration modes to study the effect of the SiC Schottky diodes on the system. The efficiencies of the hybrid inverter were measured and revealed that they were higher than those of the $\mathrm{Si}$ inverter. The average loss reduction in the hybrid inverter was up to $35 \%$ with an inductive load. The inverters were tested to a maximum power of $47 \mathrm{~kW}$.

The SiC JFET parameters were extracted from the test data and the models were developed in Saber. The models were used to study the inverter performance. The results showed that the efficiencies were low (83-94\%). The all-SiC inverter module developed in collaboration with Rockwell was tested with inductive and pure resistive loads and compared with an IGBT-based Si module. The efficiencies of the $\mathrm{SiC}$ module were less compared with the Si module because of the higher on-state losses of the SiC JFET. It should be noted that the SiC JFETs are still prototype devices, and it appears that the SiC power switches need further improvement to make them comparable to the Si devices.

Duration tests were conducted using buck converters. Four buck converters were built with different combinations of Si IGBTs, SiC JFETs, Si pn, and SiC Schottky diodes. The converters were operated an average of 7.5 hours a day for several months. The experiments revealed that the SiC JFETs had better performance in terms of operating temperatures for the same power levels with the same load. The SiC Schottky diodes had better thermal performance at higher frequencies since they have lower reverserecovery losses compared with the Si diodes.

It was interesting to note that the all-SiC converter and the hybrid converter (Si IGBT-SiC diode) had less noise in the thermal data than the Si-based converters. This indicates that there is a reduction in emitted noise when $\mathrm{SiC}$ devices are used.

The diodes in the duration tests never failed even after several months of operation. The Si IGBTs failed only for some operating conditions. However, the SiC JFETs failed repeatedly after several days of operation. This shows that the SiC JFETs are not yet mature enough to handle long-duration operation.

It can be concluded that the $\mathrm{SiC}$ Schottky diodes perform better than similar $\mathrm{Si}$ pn diodes. The use of $\mathrm{SiC}$ Schottky diodes in traction drives results in much lower losses for the same operating conditions. The reliability of the power switches is a concern, but their performance is promising.

It is important to follow current developments in $\mathrm{SiC}$ power-device technology closely because the pace of improvement has increased considerably. Better, less expensive and more reliable SiC power devices are not far away. 


\section{REFERENCES}

1. B. Ozpineci, L. M. Tolbert, S. K. Islam, and F. Z. Peng, "Testing, Characterization, and Modeling of SiC Diodes for Transportation Applications," pp. 1673-1678 in IEEE Power Electronics Specialists Conference, Cairns, Australia, June 23-27, 2002.

2. L. M. Tolbert, B. Ozpineci, S. K. Islam, and F. Z. Peng, "Impact of SiC Power Electronic Devices for Hybrid Electric Vehicles," pp. 765-771 in SAE 2002 Transactions Journal of Passenger CarsElectronic and Electrical Systems, ISBN 0-7680-1291-0, 2003.

3. B. Ozpineci and L. M. Tolbert, Comparison of Wide Bandgap Semiconductors for Power Electronics Applications, ORNL/TM-2003/257, UT-Battelle, LLC, Oak Ridge National Laboratory, November 2003.

4. S. Hodge, "SiC Schottky Diodes in Power Factor Correction," pp. 14-18 in Power Electronics Technology, August 2004.

5. H. R. Chang, E. Hanna, and A. V. Radun, "Demonstration of Silicon Carbide (SiC)-Based Motor Drive," pp. 1116-1121 in Conference of the IEEE Industrial Electronics Society, November 2-6, 2003.

6. A. M. Abou-Alfotouh, A. V.Radun, H. R. Chang, and C. Winerhalter, "A $1 \mathrm{MHz}$ Hard-Switched Silicon Carbide DC/DC Converter," pp. 132-138 in IEEE Applied Power Electronics Conference, February 9-13, 2003.

7. M. Bhatnagar, P. K. McLarty, and B. J. Baliga, "Silicon Carbide High Voltage (400 V) Schottky Barrier Diodes," pp. 501-503 in IEEE Electron Device Letters, October 1992.

8. M. Chinthavali, B. Ozpineci, and L. M. Tolbert, "High Temperature Characterization of SiC Power Electronic Devices," pp. 43-47 in IEEE Workshop on Power Electronics in Transportation, October 21-22, 2004.

9. A. R. Hefner, R. Singh, J. Lai, D. W. Berning, S. Bouche, and C. Chapuy, "SiC Power Diodes Provide Breakthrough Performance for a Wide Range of Applications," pp. 273-280 in IEEE Transactions on Power Electronics, March 2001.

10. M. L. Heldwein and J. W. Kolar, "A Novel SiC J-FET Gate Drive Circuit for Sparse Matrix Converter Applications," pp. 116-121 in IEEE Applied Power Electronics Conference, February 2226, 2004.

11. B. Allebrand and H. Nee, "On the Possibility to Use SiC JFETs in Power Electronic Circuits," European Conference on Power Electronics and Applications, Austria, 2001.

12. M. Ruff, H. Mitlehner, and R. Helbig, "SiC Devices: Physics and Numerical Simulation," pp. 10401054 in IEEE Transactions on Electron Devices, June 1994.

13. D. Peters, H. Mitlehner, R. Elpelt, R. Schorner, and D. Stephani, "State of the Art Technological Challenges of SiC Power MOSFETs Designed for High Blocking Voltages," European Conference on Power Electronics and Applications, Toulouse, France, September 2-4, 2003. 
14. S. H. Ryu, A. Agarwal, J. Richmond, J. Palmour, N. Saks, and J. Williams, "10 A, 2.4 kV Power DIMOSFETs in 4H-SiC," pp. 321-323 in IEEE Electron Device Letters, June 2002.

15. S. H. Ryu, S. Krishnaswami, M. Das, J. Richmond, A. Agarwal, J. Palmour, and J. Scofield, "4H-SiC DMOSFETs for High Speed Switching Applications," 5th European Conference on Silicon Carbide Related Materials, August 31-September 4, 2004.

16. K. Mino, K. S. Herold, and J. W. Kolar, "A Gate Drive Circuit for Silicon Carbide JFET," pp. 11621166 in Conference of the IEEE Industrial Electronics Society, November 2-6, 2003.

17. M. Chinthavali, B. Ozpineci, and L. M. Tolbert, "Enhancing Power Electronic Devices with Wide Bandgap Semiconductors," Advanced Workshop on Frontiers of Electronics, Aruba, December 1722, 2004.

18. T. R. McNutt, "Modeling and Characterization of Silicon Carbide Power Devices," Ph.D. Dissertation, Department of Electrical Engineering, University of Arkansas, Fayetteville, Arkansas, 2004.

19. D. Zendzian, AIPM 42 V Software Functional Description Manual, SEMIKRON, Inc., March 2002.

20. A. S. Kashyap, "Compact Modeling of Silicon Carbide Junction Field Effect Devices," M.S. Thesis, Department of Electrical Engineering, University of Arkansas, Fayetteville, Arkansas, 2005. 


\section{APPENDIX A: i-v CHARACTERISTICS OF SiC AND Si DIODES}

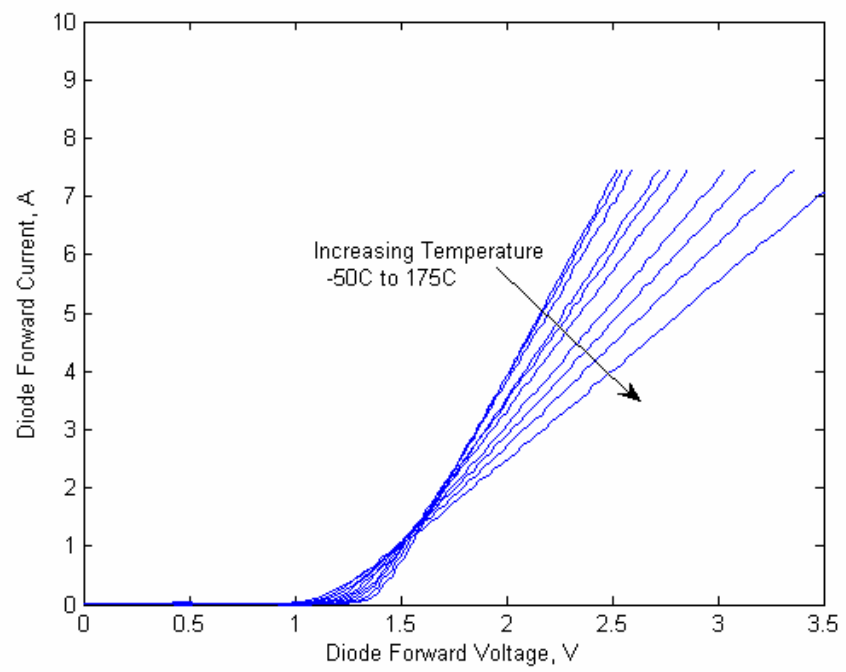

Fig. A.1. i-v characteristics of $S 1(1200 \mathrm{~V}, 7.5 \mathrm{~A})$ at different operating temperatures.

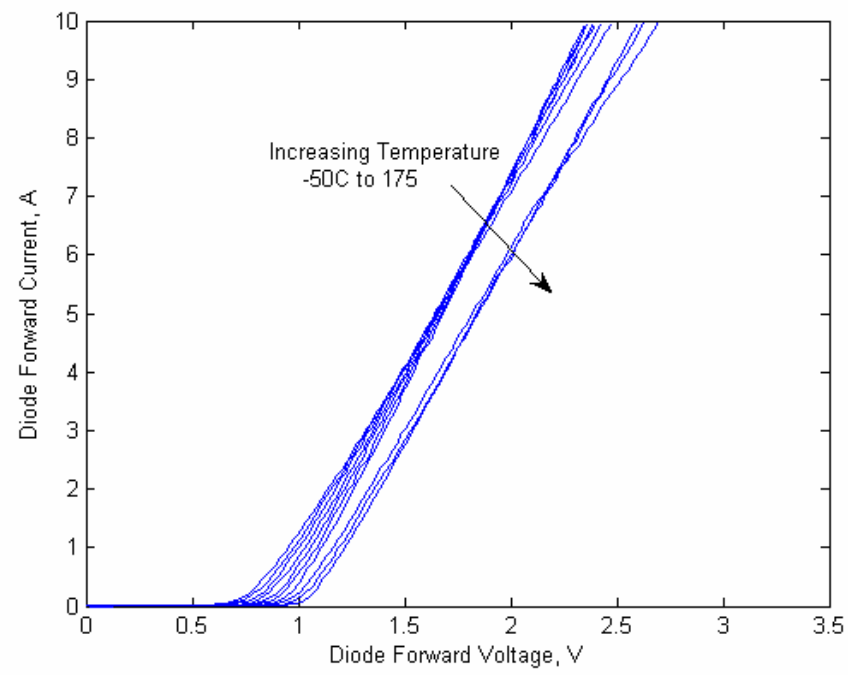

Fig. A.2. i-v characteristics of $S 4(300 \mathrm{~V}, 10 \mathrm{~A})$ at different operating temperatures. 


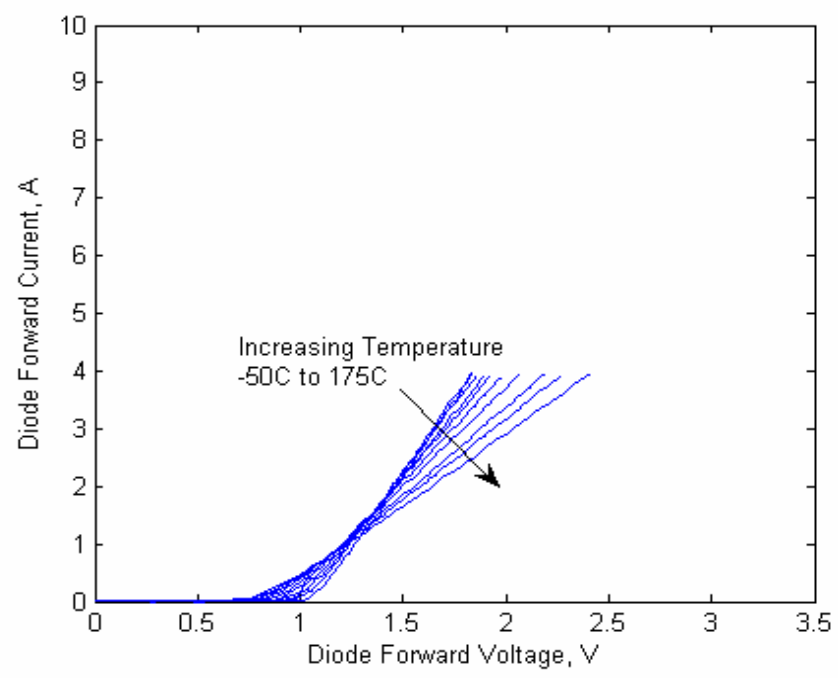

Fig. A.3. i-v characteristics of $S 2(600 \mathrm{~V}, 4 \mathrm{~A})$ at different operating temperatures.

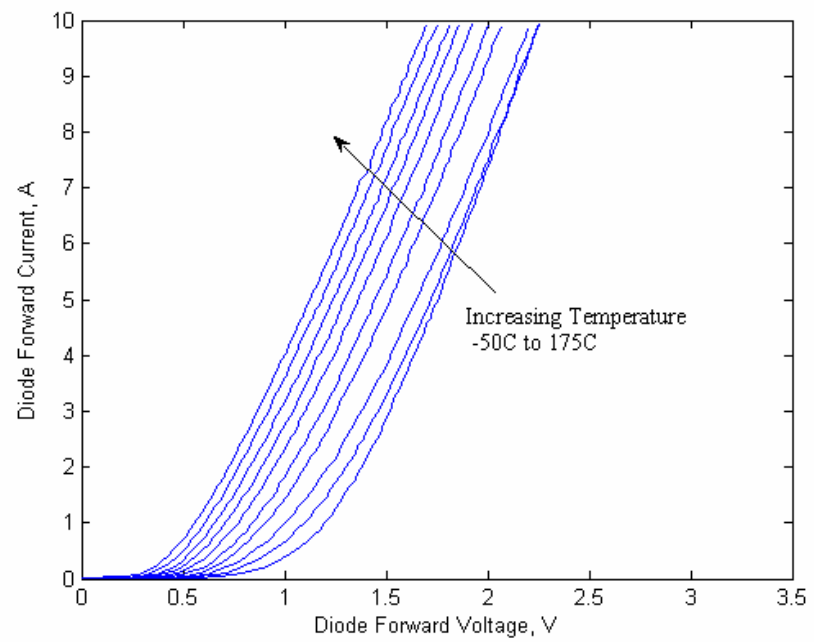

Fig. A.4. $i-v$ characteristics of $\mathrm{Si}$ pn diode $(600 \mathrm{~V}, 10 \mathrm{~A})$ at different operating temperatures. 


\section{APPENDIX B: MOVING AVERAGE FILTER EXPLANATION}

A moving average filter is a low-pass filter generally used to smooth the data and to remove the noise in the sampled data. The moving average filter can be viewed as a window (an array of data points considered at one time); moving along the data and the data points inside the window will be averaged to find a new value. The smoothness of the data depends on the size of the window. A new array of the averaged values of size $N$ will be created where

\section{$N=$ array size/window size}

The window size chosen for all the data plots is 13 .

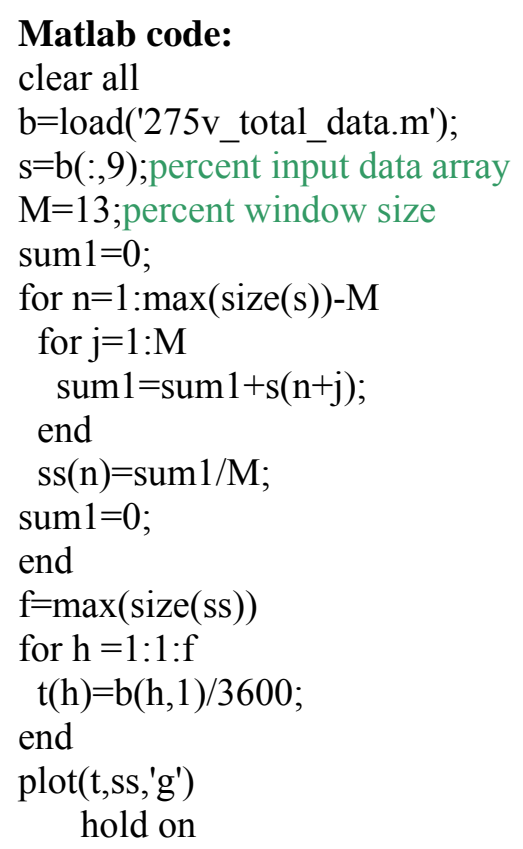




\section{DISTRIBUTION}

\section{Internal}

\author{
1. D. J. Adams \\ 2. E. C. Fox \\ 3. K. P. Gambrell \\ 4. L. D. Marlino
}

\author{
5. M. Olszewski \\ 6. M. Starke \\ 7-8. Laboratory Records
}

\section{External}

9. T. Q. Duong, U.S. Department of Energy, EE-2G/Forrestal Building, 1000 Independence Avenue, S.W., Washington, D.C. 20585.

10. R. R. Fessler, BIZTEK Consulting, Inc., 820 Roslyn Place, Evanston, Illinois 60201-1724.

11. K. Fiegenschuh, Ford Motor Company, Scientific Research Laboratory, 2101 Village Road, MD2247, Dearborn, Michigan 48121.

12. V. Garg, Ford Motor Company, 15050 Commerce Drive, North, Dearborn, Michigan 481201261.

13. E. Jih, Ford Motor Company, Scientific Research Laboratory, 2101 Village Road, MD-1170, Rm. 2331, Dearborn, Michigan 48121.

14. W. C. Johnson, University of Tennessee-Knoxville, ECE Department, 414 Ferris Hall, 1508 Middle Drive, Knoxville, Tennessee 37996.

15. A. Lee, Daimler Chrysler, CIMS 484-08-06, 800 Chrysler Drive, Auburn Hills, Michigan 483262757.

16. F. Liang, Ford Motor Company, Scientific Research Laboratory, 2101 Village Road, MD1170, Rm. 2331/SRL, Dearborn, Michigan 48121.

17. M. W. Lloyd, Energetics, Inc., 7164 Columbia Gateway Drive, Columbia, Maryland 21046.

18. M. Mehall, Ford Motor Company, Scientific Research Laboratory, 2101 Village Road, MD-2247, Rm. 3317, Dearborn, Michigan 48124-2053.

19. N. Olds, USCAR, nolds@uscar.org.

20. J. Rogers, Chemical and Environmental Sciences Laboratory, GM R\&D Center, 30500 Mound Road, Warren, Michigan 48090-9055.

21. S. A. Rogers, U.S. Department of Energy, EE-2G/Forrestal Building, 1000 Independence Avenue, S.W., Washington, D.C. 20585.

22. G. S. Smith, General Motors Advanced Technology Center, 3050 Lomita Boulevard, Torrance, California 90505.

23. E. J. Wall, U.S. Department of Energy, EE-2G/Forrestal Building, 1000 Independence Avenue, S.W., Washington, D.C. 20585.

24. B. Welchko, General Motors Advanced Technology Center, 3050 Lomita Boulevard, Torrance, California 90505.

25. P. G. Yoshida, U.S. Department of Energy, EE-2G/Forrestal Building, 1000 Independence Avenue, S.W., Washington, D.C. 20585. 